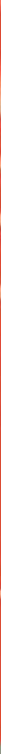

Routledge Advances in Translation and Interpreting Studies

\title{
QUEERING TRANSLATION, \\ TRANSLATING THE QUEER
}

THEORY, PRACTICE, ACTIVISM

Edited by

Brian James Baer and Klaus Kaindl

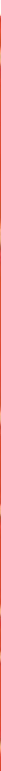




\section{Queering Translation, Translating the Queer}

This groundbreaking work is one of the first book-length publications to critically engage in the emerging field of research on the queer aspects of translation and interpreting studies. The volume presents a variety of theoretical and disciplinary perspectives through fourteen contributions from both established and up-and-coming scholars in the field to demonstrate the interconnectedness between translation and queer aspects of sex, gender, and identity. The book begins with the editors' introduction on the state of the field, providing an overview of both current and developing lines of research, and builds on this foundation to look at this research more closely, grouped around three different sections: Queer Theorizing of Translation, Case Studies of Queer Translations and Translators, and Queer Activism and Translation. This interdisciplinary approach seeks not only to shed light on this promising field of research but also to promote cross-fertilization between these disciplines toward further exploring the intersections between queer studies and translation studies, making this volume key reading for students and scholars interested in translation studies, queer studies, politics, activism, and gender and sexuality studies.

Brian James Baer is Professor of Russian Translation in the Department of Modern and Classical Language Studies at Kent State University.

Klaus Kaindl is Associate Professor at the Centre for Translation Studies at the University of Vienna. 


\section{Routledge Advances in Translation and Interpreting Studies}

For a full list of titles in this series, please visit www.routledge.com

19 Critical Translation Studies

Douglas Robinson

20 Feminist Translation Studies

Local and Transnational Perspectives

Edited by Olga Castro and Emek Ergun

21 Studying Scientific Metaphor in Translation

An Inquiry into Cross-Lingual Translation Practices

Mark Shuttleworth

22 Translating Frantz Fanon Across Continents and Languages

Edited by Kathryn Batchelor and Sue-Ann Harding

23 Translation and Public Policy

Interdisciplinary Perspectives and Case Studies

Edited by Gabriel González Núñez and Reine Meylaerts

24 Translationality

Essays in the Translational-Medical Humanities

Douglas Robinson

25 The Changing Role of the Interpreter

Contextualising Norms, Ethics and Quality Standards

Edited by Marta Biagini, Michael S. Boyd and Claudia Monacelli

26 Translation in Russian Contexts

Culture, Politics, Identity

Edited by Brian James Baer and Susanna Witt

27 Untranslatability Goes Global

Edited by Suzanne Jill Levine and Katie Lateef-Jan

28 Queering Translation, Translating the Queer

Theory, Practice, Activism

Edited by Brian James Baer and Klaus Kaindl 


\section{Queering Translation, Translating the Queer Theory, Practice, Activism}

\section{Edited by Brian James Baer and Klaus Kaindl}

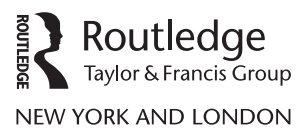


First published 2018

by Routledge

711 Third Avenue, New York, NY 10017

and by Routledge

2 Park Square, Milton Park, Abingdon, Oxon OX14 4RN

Routledge is an imprint of the Taylor \& Francis Group, an informa business

(C) 2018 Taylor \& Francis

The right of the editors to be identified as the authors of the editorial material, and of the authors for their individual chapters, has been asserted in accordance with sections 77 and 78 of the Copyright, Designs and Patents Act 1988.

All rights reserved. No part of this book may be reprinted or reproduced or utilised in any form or by any electronic, mechanical, or other means, now known or hereafter invented, including photocopying and recording, or in any information storage or retrieval system, without permission in writing from the publishers.

Trademark notice: Product or corporate names may be trademarks or registered trademarks, and are used only for identification and explanation without intent to infringe.

Library of Congress Cataloging-in-Publication Data

A catalog record for this book has been requested

ISBN: 978-1-138-20169-9 (hbk)

ISBN: 978-1-315-50597-8 (ebk)

Typeset in Sabon

by Apex CoVantage, LLC 
To Keith Harvey, whose groundbreaking scholarship made this volume possible 
$\because$ Taylor \& Francis

Taylor \& Francis Group

http://taylorandfrancis.com 


\section{Contents}

Introduction: Queer(ing) Translation

BRIAN JAMES BAER AND KLAUS KAINDL

1 Sexuality and Translation as Intimate Partners? Toward a Queer Turn in Rewriting Identities and Desires JOSÉ SANTAEMILIA

2 A Scene of Intimate Entanglements, or, Reckoning with the "Fuck" of Translation

ELENA BASILE

3 Beyond Either/Or: Confronting the Fact of Translation in Global Sexuality Studies

BRIAN JAMES BAER

4 The Future Is a Foreign Country: Translation and Temporal Critique in the Italian It Gets Better Project SERENA BASSI

5 Ethnography and Queer Translation EVREN SAVCI

6 In All His Finery: Frederick Marryat's The Pacha of Many Tales as Drag JAMES ST. ANDRÉ

7 Transgenderism in Japanese Manga as Radical Translation: The Journey to the West Goes to Japan 
viii Contents

8 Speaking Silence and Silencing Speech: The Translations of Grand Duke Konstantin Romanov as Queer Writing SERGEY TYULENEV

9 Translation's Queerness: Giovanni Bianchi and John Cleland Writing Same-Sex Desire in the Eighteenth Century CLORINDA DONATO

10 Literary Censorship and Homosexuality in Kádár-Regime Hungary and Estado Novo Portugal ZSÓFIA GOMBÁR

11 On Three Modes of Translating Queer Literary Texts MARC DÉMONT

12 Queering Lexicography: Balancing Power Relations in Dictionaries

EVA NOSSEM

13 Queer Translation as Performative and Affective Un-doing: Translating Butler's Undoing Gender into Italian

MICHELA BALDO

14 Years Yet Yesterday: Translating Art, Activism, and AIDS across the Visual and the Verbal

MARK ADDISON SMITH

List of Contributors 


\section{Introduction}

\section{Queer(ing) Translation}

\section{Brian James Baer and Klaus Kaindl}

Since de Lauretis introduced queer theory as "another discursive horizon, another way of thinking the sexual" (1991: iv), which moved away from the reification of essentialist identities to focus on desire and performance, this approach has played an important role in the analysis of sex and gender in literary, film, and cultural studies. Despite its claim of interdisciplinarity, however, translation studies have been slow to integrate fully the concepts and theoretical instruments of queer theory. To the extent that queer theory problematizes the representation of otherness, and translation studies highlights the otherness inherent in representation, bringing together queer theory and translation studies should productively destabilize not only traditional models of representation, understood as mimesis, reflection, and copying, but also the authorial voices and subjectivities they project.

For reasons not entirely clear, translation and interpreting studies scholars have reacted to queer theory with some delay, and research focusing on queer aspects of translation and interpreting have, until only recently, been rare, rather uncoordinated, and often marred by conceptual confusion-so that not all works dealing with issues of sexuality and specifically homosexuality can be considered queer. ${ }^{1}$ For many years, Keith Harvey's groundbreaking work (2003a, 2003b) was like a voice in the desert. But scholars in the field appear now to be making up for lost time: ${ }^{2}$ Following the publication of a special issue of the journal In Other Words (2010) dedicated to issues of translation and sexuality, edited by B.J. Epstein, and Christopher Larkosh's edited volume Re-engendering Translation (2011), which includes three chapters dealing with the translation of sexuality across languages and cultures, there have appeared in rapid succession a special issue of the journal Comparative Literature Studies (2014), edited by William J. Spurlin; the collected volume Sexology and Translation (2015), edited by Heike Bauer; a special issue of the Transgender Studies Quarterly titled Translating Transgender (2016), edited by David Gramling and Aniruddha Dutta; and Queer in Translation, edited by B.J. Epstein and Robert Gillette (2017). ${ }^{3}$

While all these works contribute to the ongoing project of establishing a relationship between queer theory and translation studies, Bauer's volume and Gramling and Aniruddha's special issue stand apart for their theoretical 


\section{Brian James Baer and Klaus Kaindl}

sophistication and their focus on the relationship between queer theory and translation studies as mutually productive and mutually interrogating. As Bauer states,

While translation thus serves as a framework for analysing how sexuality travelled across linguistic boundaries, and the politics of this process, it can also help to conceptualize the construction of sexual desires and bodies. Many of the studies included here explore specifically how observations of the body and its desire were translated into new knowledge formations and disciplinary practices.

While Bauer's collection is focused primarily on demonstrating the role of translation in transnationalizing the science of sexology, and Gramling and Aniruddha's special issue, on demonstrating the role of translation in transnationalizing the concept of transgender-with most of the authors in these collections working outside of translation studies-our focus will be primarily on the ways in which queer theory can support an interrogation of the dominant models of the theory and practice of translation, with most of the authors in the volume working as practicing translators, teachers of translation, and translation scholars. In other words, if confronting the fact of translation can help to transnationalize sexuality studies, then what can an engagement with queer theory do for translation studies? Let us begin to answer that question by defining what is meant by queering translation.

Commenting on the term transnational, Inderpal Grewal and Caren Kaplan remark, "[translational] has already becomes ubiquitous in cultural, literary and racial studies that much of its political valence seems to have been evacuated" (2001: 663). The same could be said of the profligate use of queer; and so in order to recover the political valence of the concept, which informs all the contributions to this volume, let us begin by tracing its mixed origins. In the spirit of queer theory, however, the goal here is not to disentangle those strands to create independent genealogies but rather to map the complex conceptual overlapping and entangling-the term's "mobility" (Jagose 1996: 2)-that allows queer to connect the theoretical, the political, and the experiential. First, it should be noted that queer in common parlance is often used as a synonym for 'gay' and 'lesbian' but may also denote any nonnormative experience or expression of sexual desire. As the revaluation of a derogatory term, queer also circulated during the AIDS crisis to index an unapologetic, in-your-face activism, as evident in the activist organization Queer Nation and in the organization's slogan "We're here and we're queer!" At the same time queer indexes a theoretical model or positioning, one that rejects the organization of sexuality on the basis of the binary opposition of homosexual/heterosexual, which Eve Kosofsky Sedgwick describes as a minoritarian model, in favor of a more fluid conception of sexual desire, described by Sedgwick as universalist (Sedgwick 1990). As 
Annmarie Jagose describes it, "Queer theory's debunking of stables sexes, genders and sexualities develops out of a specifically lesbian and gay reworking of the post-structuralist figuring of identity as a constellation of multiple and unstable positions" (Jagose 1996: 3). And so, when queer is included as part of the acronym LGBTQ or LGBTQI, it appears as one in a list of identificatory labels while eschewing or questioning identificatory labels; when read queerly then, the Q in LGBTQ would render the other terms suspect, under erasure, to use the Derridean term. As a critical positioning, queer theory challenges the status of dominant regimes of knowledge/power as natural and universal by focusing on the constructedness of those models, on their historical contingency, and on the politics of those models (who is empowered by them and who is left out?). Hence the use of queer as a verb to describe this critical work. Moreover, by demanding the interrogation of dominant practices of knowledge formation itself, queer scholarship has developed as a highly reflexive practice.

It is this dual directive-to address queer phenomena, that is, phenomena that are typically ignored, marginalized, or domesticated by the dominant regime(s) of knowledge/power, and to do so queerly-that we attempt to model in this volume in relation to translation studies. In other words, how might the rendering of queer phenomena across languages and cultures challenge our understanding of translation as theory and practice? At the same time, attention to translation can keep queer scholarship honest-that is, true to its anti-hegemonic orientation, by forcing researchers to interrogate deep-seated Western, and, perhaps specifically Anglophone, biases, as elaborated by Jagose:

Whether queer's transcendent disregard for dominant systems of gender fails to consider the material conditions of the west in the late twentieth century; whether queer simply replicates, with a kind of historical amnesia, the stances and demands of an earlier gay liberation [and, we would add, its progressivist teleology]; and whether, because its constituency is almost unlimited, queer includes identificatory categories whose politics are less progressive than [or, we would add, simply different from] those of the lesbian and gay populations with which they are aligned.

(Jagose 1996: 5$)^{4}$

The general editors of Transgender Studies Quarterly, Susan Stryker and Paisley Currah, make this point in their introduction to the special issue Translating Transgender:

How better to put pressure on the anglophone biases of the field of transgender studies than to explicitly explore the languages through which "transgender," as an analytic lens or identitarian label, does and does not reproduce itself, how names and concepts change in the translation 


\section{Brian James Baer and Klaus Kaindl}

from one context to another, or how they remain incommensurable and untranslatable? (Of course, we recognize that this replicates at another level the very anglonormativity we seek to contest.)

Bauer makes a similar point, "that attention to translation-understood in the broadest sense as the dynamic process by which ideas are produced and transmitted-offers compelling new insights into how sexual ideas were formed in different contexts via a complex process of cultural negotiation" (Bauer 2015: 2), and in so doing, lends new, more concrete relevance to the term transnationalism. ${ }^{5}$

With the goal of promoting a mutually productive and mutually interrogating relationship between queer theory and translation studies, this volume offers various points of departure that stand at the queer intersection of translation, sexuality, and gender in transcultural contexts. The subtitle "Theory, Practice, Activism" defines the tension-filled areas covered by the contributions, and while the chapters have been divided according to these three designations, it is done with the understanding that in both queer theory and translation studies, the three are thoroughly entangled, and so the three sections of the book should not be seen as strictly separate as the volume aims not only to bridge the gap between translation studies and queer studies but also to mediate the tensions between theory, practice, and activism by highlighting their interconnections.

The five chapters in section one offer theoretical approaches to an understanding of queer translation. They are based on a questioning of binary structures, such as the contrasting pairs of source and target text, and involve other disciplines in order to develop a queer translational approach and to expand the largely Anglophone discussion of queer issues to other linguistic and cultural contexts. In the first chapter, José Santaemilia discusses the question of how translation and sexuality are connected or potentially interrelated. He identifies two fundamental research perspectives: questioning how (queer) sexualities are translated, on the one hand, and examining the theoretical potential represented by the sexualization of translation. While the first question, which is concerned with the linguistic, ideological, and political implications of the translation of sexuality, has received considerable attention in research since the 1990s, the second perspective remains largely under-researched. It is precisely in this context that a queer approach opens up possibilities for both sides to sharpen their analytical view on identity-formation processes, to unmask essentialist ideas, and to utilize the subversive potential inherent in the fluid concepts of translation and sexuality in order to understand the practices and discourses involved in negotiating identities.

A concrete example of the sexualization of translation is given by Elena Basile. Her starting point is a self-translated text by transgender writer Nathanaël. Through a close reading of this text, Basile develops her own 
conceptualization of the intimate scene of translation, which differs greatly from Spivak's view of translation as the "most intimate act of reading." Basile is not concerned with idealized intimacy, but with violent aspects, which she vividly terms the "fuck" of translation. With the help of queer theorists Lauren Berland and Lee Edelman, Basile demonstrates the analogies between sex and the scene of translation: just as sex bears witness to a "coming undone" of the corporeal self, translation manifests the coming undone of the linguistic body as an independent, sovereign, and territorialized entity.

Brian James Baer offers another approach to the sexualization of translation, employing translation as a mode of queering global sexuality studies and a tool for calling into question the illusion of the universal prerogative of (Western) theories. Based on a critical reading of Jon Binnie's Globalization of Sex, Baer first demonstrates the invisibility of questions of translation in global sexuality studies, which is surprising given the central role of translation in the deployment of sexual symbols and images from the West. He then investigates, through analysis of translations in the Russian gay journal Kvir, how non-Western queers can negotiate identities in translation, which do not conform to the binary concept of "the West and the rest," and how translation in post-Soviet Russia is used to "provincialize" the Western minoritarian model of homosexuality is provincialized. Translation thus becomes a space in which identities are negotiated, where the local critically engages with the global.

Serena Bassi also looks beyond English to other languages to examine how Western discourses about sexual subjectivities are shaped. On the basis of the Italian localization of the American online campaign It Gets Better, which vows to combat transphobic and homophobic bullying, the author tries to capture the translational elements of contemporary sexual transnational formations. Her aim is to provide building blocks for the development of a queer epistemology, capable of engaging sexuality as a modern discursive formation alongside other modes of difference such as race, gender, and nationality. For this purpose, she employs attempts in queer studies to study sexuality as a modern secular discursive formation and argues that the multiple refractions of metaphysical and religious discourse may have intervened in the Italian localization of the It Gets Better project.

While Baer's and Bassi's research is strongly embedded in the context of cultural studies, Evren Savci proposes ethnographic research methods for the translation of the queer. Both translation studies and ethnology assume that meaning-whether it be textual or social—is not a fixed variable to which recipients have direct access. In both disciplines norms, which are either reproduced or challenged amid asymmetrical power relations between languages and cultures, play a central role. Savci demonstrates how an ethnographic viewpoint can capture the many different processes involved in the translation of nonnormative genders and sexualities into the context of present-day Turkey. By embedding the investigation in an ethnographic 
context, it becomes clear that the local is also heterogeneous. Moreover, understanding these complex ethnographic connections also enables us to undo binaries such as "Muslim versus secular."

In section one, the theoretical reflections are often based on real-life examples and, similarly, the five chapters in section two, which includes primarily case studies, also link practical application to theoretical questions. James St. André examines Frederick Marryat's Pacha of Many Tales as a queer translation, in which various textual modes such as pseudo-translations, real translations, and imitations co-exist. In order to analyze the interaction of these textual modes St. André introduces the metaphor of cross-identity performance, which offers a non-essentialist understanding of translation. This umbrella metaphor covers various techniques that St. André refers to as masquerade, blackface, passing, slumming, and drag. St. André reveals the possibilities offered by these queer metaphors for the understanding and interpretation of translations by examining a translation identified as drag appropriation, which Marryat produced based on an existing translation.

Leo Tak-Hung Chan investigates the representation of transgenderism in Japanese manga translations of a Chinese classic by employing the concept of radical translation. He links this concept of a parodistic appropriation of the original, developed by Reuben Brower and Andrew Riemer, to queer theories, thereby opening up investigative avenues similar to those of St. Andrés concept of cross-identity performance. This contribution also explores translatorial boundaries by examining the multimodal translation of a classic Chinese short novel into the visual language of manga, where the main character, a monk, is queered and graphically represented as a woman. The chapter discusses how to understand gender-bending in the Japanese translation and how to interpret China's fierce reaction to the queer adaptation of this Chinese classic.

Sergey Tyulenev explores translation as a site of expression of homosexual desire in the works of Grand Duke Konstantin Konstantinovich Romanov. Using the theories of sexuality proposed by Eve Sedgwick and Lee Edelman, which see same-sex desire as an affective force that interacts with modes of writing, Tyulenev analyzes the complex combinations of speech and silence in K.R.'s translations, which, in line with Edelman, are described as a special mode of homographesis (writing of homosexual identity). For this purpose, the translations are juxtaposed with other writings of K.R, specifically his diaries and his original poetry. Through a comparative analysis of these three modes of writing, Tyulenev describes K.R.'s homographesis in terms of speaking silence and silencing speech.

Clorinda Donato examines a case in which the English translation attempts to control and contain the queerness of the Italian original. Giovanni Bianchi's novella Breve storia della vita die Catterina Vizzani presents a transgender life story as a quasi-scientific case study, in which gender markers are used flexibly, depending on whether the protagonist appears as Catterina or as Giovanni. Taking into account the scholarly, literary, and socio-cultural 
context in which the narrative was conceived, the strategies and motifs of the translator of the English version, the writer Henry Fielding, are analyzed. Fielding replaces the natural queerness and shifting gender constructions of the original with a discourse that brands the transgender figure as morally dubious and aberrant.

While Donato offers an example of self-censorship on the part of the translator, Zsófia Gombár discusses government censorship of translated queer literature in Portugal and Hungary. Portugal under Salazar and Hungary under Kádár were both authoritarian regimes where discussion of homosexuality was considered taboo. According to Gombár, however, the ideological differences between the two regimes were a decisive factor in determining the nature of censorship regulation. Taking into account agents in politics and publishing, Gombar presents a detailed picture of the works translated, illustrating the subtle differences in dealing with homosexual themes between the two countries.

The four contributions in section three discuss issues of activism and the possibilities of a queer translation practice. In this context, activism is seen as a special form of practical application, which combines the theoretical insights of queer theory and post-structuralist translation theory with the aim of imagining a future for queer writing. Marc Démont provides an example of what such a future might look like by distinguishing among three strategies for handling queer desire in translated texts. According to Démont's typology, a misrecognizing translation takes a hegemonic standpoint vis-àvis the original and seeks to un-queer the text or to conceal its queerness. In contrast, a minoritizing translation attempts to freeze the fluidity of gender roles and sexual desires in the form of equivalents, thus domesticating the multilayered nature of queerness. A queering translation, which Démont underpins theoretically with Appiah's concept of "thick translation," transfers the disruptive force inherent in queer representations into the target language, opening up new interpretive possibilities for the reader.

Eva Nossem calls for the development of a queer approach in the area of lexicography. She begins by challenging the popular notion of an objective, purely descriptive lexicography, and discusses the social norms and values underpinning lexicographical work. In line with Foucault, she assigns a discursive function to lexicographers, through which they play an active role in the production of knowledge. In bilingual dictionaries, the heteronormative ideas conveyed are further exacerbated by requirements of equivalence. Nossem advocates for an anti-normative approach and seeks to lay the foundations for a queer lexicography that establishes the very conditions of possibility for a queer translation practice.

Michela Baldo demonstrates how closely the circulation of theory is tied to activism by discussing queer translation as a performative and affective undoing. Based on her analysis of the Italian retranslation of Judith Butler's Undoing Gender, Baldo explores the possibilities that concepts such as performativity and affectivity offer for translation. While the former refers to 


\section{Brian James Baer and Klaus Kaindl}

translation as situated between creativity and productivity, the latter points to relationality and corporeality, which makes translation into a precarious space. The controversy surrounding the translation of Undoing Gender shows how issues related to translation can also serve as a call for rethinking welfare and social justice in the actual political climate of neoliberal austerity.

The political dimension of queer translation is also evident in Mark Addison Smith's contribution. Smith describes his process of queering-translating?a speech by AIDS-activist Larry Kramer into a handwritten visual-art abecedary of 24 grayscale eye charts, drawing a link between theoretical insights on translation and artistic activism (which also refutes the romantic presumption that theory is anti-creative). Not only does the contribution fit into the current debate of translation as (queer) activism, by transposing text into a work of art, it also questions current categories-such as Jakobson's famous distinction between intralingual, interlingual, and intersemiotic translation-and challenges queer translation studies to examine more closely the queer potential of non-verbal semiotic resources, such as the visuals of Smith's drawings, and to understand artistic processes as part of an activist queer translation practice.

\section{Notes}

1 The lack of attention to queer sexuality in translation is also surprising given the sexuality of James Holmes, one of the founding figures of the field of Translation Studies. As Larkosh notes, "Perhaps precisely because he was an out, gay-identified man active in the burgeoning leather scene of Amsterdam of the mid-20th century, a foundational figure in a second academic discipline, known in Dutch as 'homostudies', and a co-founder of the Amsterdam gay and lesbian bookstore Vrolijk (Keilson-Lauritz 2001), Holmes was hardly someone who needed to be 'outed' by his fellow scholars in more explicit terms. This may shed some light on what now appears as a somewhat disquieting silence about his sexual orientation by translation studies scholars who have written on his contribution to the field" (Larkosh 2011: 2). Holmes himself, however, rarely addressed his sexuality or sexuality in general in his translation studies scholarship, while in his translation practice, he often translated queer texts and authors, such as Catullus, and wrote sexually explicit verse under the pseudonym Jacob Lowland. For a discussion by Holmes of his translations of queer poetry, see the published extracts of a talk given at the Iowa Translation Workshop in January 1984 (Holmes 1989).

2 For a fairly comprehensive list of publications on the subject of translation and queer sexuality, see (Baer and Kaindl 2015).

3 One should also mention here the collected volume Import-ExportTransport: Queer Theory, Queer Critique and Activism in Motion (2012), edited by Sushila Mesquita, Maria Katharina Wiedlack and Katrin Lasthofer. The volume is a theoretically sophisticated treatment of transcultural exchange as it relates to queer theory with a few chapters dedicated specifically to issues of translation. See, for example, the chapters by Kulpa et al. (2012) and Möser (2012).

4 Incidentally, Translation Studies has been accused of similar Western biases. See for example van Doorslaer and Flynn (2011) on the eurocentrism of translation studies. 
5 The urgency of such an interrogation of queer is underscored by Bauer's decision to eschew the term queer in her study of sexology and translation (see Bauer 2015: 6).

\section{References}

Baer, Brian James and Klaus Kaindl. 2015. “A Non Exhaustive Bibliography.” Available online at https:/queertranslation.univie.ac.at/bibliography/ (last accessed February 27, 2017).

Bauer, Heike (ed.). 2015. Sexology and Translation: Cultural and Scientific Encounters Across the Modern World. Philadelphia, PA, Rome and Tokyo: Temple University Press.

de Lauretis, Teresa. 1991. "Queer Theory: Lesbian and Gay Sexualities.” Differences: A Journal of Feminist Cultural Studies 3(2): iii-xviii.

Epstein, B.J. (ed.). 2010. Special Issue: In Other Words 36.

Epstein, B.J. and Robert Gillette. 2017. Queer in Translation. London and New York: Routledge.

Gramling, David and Aniruddha Dutta (eds.). 2016. Translating Transgender. Special Issue: Transgender Studies Quarterly 3(3-4).

Grewal, Inderpal and Caren Kaplan. 2001. "Global Identities: Theorizing Transnational Studies of Sexuality." GLQ: A Journal of Lesbian and Gay Studies 7(4): 663 .

Harvey, Keith. 2003a. “'Events' and 'Horizons': Reading Ideology in the 'Bindings' of Translations. In Apropos of Ideology: Translation Studies on Ideology-Ideologies in Translation Studies, edited by Maria Calzada Pérez, 43-70. Manchester: St. Jerome.

Harvey, Keith. 2003b. Intercultural Movements: American Gay in French Translation. Manchester and Northampton, MA: St. Jerome.

Holmes, James. 1989. "Translating Martial and Vergil: Jacob Lowland Among the Classics." In Translating Poetry: The Double Labyrinth, edited by David Weissbrot, $57-72$.

Jagose, Annmarie. 1996. Queer Theory: An Introduction. New York: New York University Press.

Keilson-Lauritz, Marita. 2001. “James S. Holmes.” In Who's Who in Contemporary Gay and Lesbian History: From World War II to the Present Day, edited by Robert Aldrich and Garry Wotherspoon, 194. London and New York: Routledge.

Kulpa, Robert, Joanna Mizielinska and Agata Stasinska. 2012. “(Un)translatable Queer? or What Is Lost and Can Be Found in Translation." In Import-ExportTransport: Queer Theory, Queer Critique and Activism in Motion, edited by Sushila Mesquita, Maria Katharina Wiedlack and Katrin Lasthofer, 115-146. Vienna: Zaglossus.

Larkosh, Christopher. 2011. Re-Engendering Translation: Transcultural Practice, Gender/Sexuality and the Politics of Alterity. Manchester: St. Jerome.

Mesquita, Sushila, Maria Katharina Wiedlack and Katrin Lasthofer (eds.). 2012. Import-Export-Transport: Queer Theory, Queer Critique, and Activism in Motion. Vienna: Zaglossus.

Möser, Cornelia. 2012. “Translating Queer Theory to France and Germany: Tickets and Boundaries for a Traveling Theory." In Import-Export-Transport: Queer 


\section{Brian James Baer and Klaus Kaindl}

Theory, Queer Critique and Activism in Motion, edited by Sushila Mesquita, Maria Katharina Wiedlack and Katrin Lasthofer, 147-162. Vienna: Zaglossus.

Sedgwick, Eve Kosofsky. 1990. The Epistemology of the Closet. Berkeley, CA: University of California Press.

Spurlin, William J. (ed.). 2014. The Gender and Queer Politics of Translation: Literary, Historical, and Cultural Approaches [Special Issue]. Comparative Literature Studies 51(2).

Stryker, Susan and Paisley Currah. 2016. "General Editors' Introduction." Transgender Studies Quarterly 3(3-4): 331-332.

van Doorslaer, Luc and Peter Flynn (eds.). 2011. Eurocentrism in Translation Studies [Special Issue]. Translation and Interpreting Studies 6(2). 


\title{
1 Sexuality and Translation as Intimate Partners? Toward a Queer Turn in Rewriting Identities and Desires
}

\author{
José Santaemilia
}

\section{Sexuality and Translation: Questions for a Common Exploration}

In this chapter I tentatively explore the research potential of combining two disciplines-sexuality and translation - that seem to have been progressively coming together over the last few years. A number of questions have already begun to be addressed-What happens when sexuality is translated? Why is Simone de Beauvoir's The Second Sex more polite, "less descriptive, more scholarly and detached" (Flotow 2000: 22) than Le deuxième sex? How can we describe Bridget Jones, Helen Fielding's archetypal chick-lit character, as assertive and skeptical (in English) but as a prude (in French)? Why does the dubbing into Spanish of Alfred Hitchcock's Rebecca suppress any reference to the (possible) lesbian relationship between the first Mrs. de Winter and her housekeeper, Mrs. Danvers? What is the role of translation in mediating (the construction of) sexuality? Why are references to sexuality, male or female, (mis)understood, under- or over-represented, in a variety of languages? How do sexual-related terms (gay, lesbian, queer) travel across languages and cultures—or, to put in Masiello's (2004: 2) terms, “[c]an sexuality be translated and represented, with terms that move from nation to nation?" Do the terms for gender/sexual identities have "equivalents" in other languages and cultures, and to what extent are Anglophone borrowings never equivalent? How does translation contribute to confirming or challenging sexual ambivalence? Does our biology (male vs. female), sexuality (heterosexual, homosexual, bisexual, etc.) or gender lead us to translate differently? What is the role of translation in the processes of identity formation in foreign sexual minority cultures? How do feminist writers and activists (e.g., Carmen de Burgos) approach the translation of a misogynistic piece of writing, such as Möbius's Über den physiologischen Schwachsinn des Weibes [On the Physiological Mental Deficiency of Woman] (1900)? Can translation and sexuality become "a space of discursive conflict and negotiation between different ideological positions” (Sánchez 2011: 326)? Why is a piece of erotica more or less daring depending on the language/ culture into which it is translated? Are there ethical issues involved in the 


\section{2}

translation of explicit (or euphemistic) sexual scenes? Does censorship or self-censorship affect the translation of sex? Are four-letter words (im)possible to translate? Is an erotics of translation the only way to recover the voice and the body present in any text, as suggested by Loffredo (2003)? Have the metaphors for the process of translation been "highly sexed, and indeed, heterosexed" (Livia 2003: 154); or, in Chamberlain's (1988) famous formulation, is there a gendered (or sexual) metaphorics at play that renders both translations and women as subordinate while original texts and men are considered superior? And, finally, are queer theorizations likely to inform translation practice and, in so doing, transform translation into a queer-or a queer-conscious-praxis?

\section{The Translation of Sexuality versus the Sex/ualization of Translation}

As can be seen from this list of topics (and from others that will surely be raised in the future), two complementary perspectives can be considered-the translation of sexuality and the sex/ualization of translation. Both are well worth exploring as they address key aspects of cross-disciplinary and cross-cultural research, ranging (in very general terms) from the translators' main challenges in rewriting human sexual experience to the consideration of translation as a sex- or gender-related activity. These two perspectives, which define a rather large and complex area for reflection and research, are likely to be explored from either practical or theoretical perspectives, with both running the risk of generating essentialist positions. And so, while an interest in either sex or translation has been evident since the beginning of time, an interest in both sexuality and translation is much more recent and demands greater documentation and evaluation in order to avoid biased or essentialist analyses.

When we revise any type of research to combine sexuality and translation, we discover that the most common perspective is that translation projects itself onto sexuality (the translation of sexuality), rather than the opposite (the sex/ualization of translation). In fact, translation studies has been incorporating sexuality as an analytical category since the 1990s, with sexuality understood as "a field that is notoriously difficult to translate for reasons of cultural and generational differences-a cas limite that in some ways serves as a test of translation" (Flotow 2000: 16). Its importance is obvious: first, sex/uality—as manifested in acts, desires, identities, and, especially, discourses-is everywhere in our daily lives, in our texts, in our symbolic projections; and, second, when translating sexuality, there is necessarily a translation effect (Flotow 2000) having unpredictable consequences. Translating the language of sex or pleasure, therefore, is not a neutral affair but a political act, with important rhetorical and ideological implications, registering the translator's attitude toward existing conceptualizations of gender/sexual identities, human sexual behavior(s) and moral norms. In this 
sense, translation and sexuality can together form a powerful interdiscipline uniquely capable of unveiling the most intimate textualizations of our identities and desires for queering translation; in particular, it demands "critical attention to the transgressive, anti-normative spaces where contradictory or deferred meanings may emerge" (Spurlin 2014a: 300), bringing to the forefront "the heuristic power of translation to navigate and linger in the ambiguities and gaps woven into the asymmetrical relations between languages and cultures" (Spurlin 2014b: 213), between sexual performances and identifications. Queer theory has adopted Michel Foucault's post-structuralist notion that "sexuality is not an essentially personal attribute but an available cultural category" (Jagose 1996: 78).

Across history, sexuality has generated a wealth of discourses (e.g., erotic or pornographic writings, and swearwords), moral phenomena (e.g., obscenities and taboos), and pragmatic reactions (e.g., censorship and self-censorship) that are amplified or silenced, confirmed or perverted, in translation. Whether applied to language or translation, queer theory has been especially effective in "calling into question conventional understandings of sexual identity by deconstructing the categories, oppositions and equations that sustain them" (Hennessy 1994: 94), revealing them in their various textualizations to be fictitious, incoherent, contingent, and ultimately performative (Butler 1990).

\section{Sexuality and Translation: Toward a Queer Turn}

Perhaps the first step in bringing together insights from both disciplinary fields is to make sense of the current research combining sexuality and translation studies. One of the first realizations in doing so is that many of these studies fail to interrogate basic sex-related (or translation-related) categories or the conceptual bases of these categories, but simply take sex/uality and translation as unproblematic givens. Progressively, however, and as a consequence of what we may call a queer turn in translation studies and in the humanities in general, both categories have come to be treated more critically, illuminating the textualization of our identities and desires while offering analytical tools and approaches for understanding those specific textualizations. For reasons of space, I will focus in this section on two recognizable strands of this research: the translation of erotic literature; and the analysis of censorship and self-censorship of sexual content in translation. In the following section, we will focus on specifically gay/lesbian and queer translation.

Erotic literature, defined as "works in which sexuality and/or sexual desire has a dominant presence" (Brulotte and Phillips 2006: x), represents perhaps the most ancient and sustained manifestation of sexuality in language. Classic works of erotic literature have been repeatedly printed and reprinted since their initial publication. Works by Sappho, Catullus, Boccaccio, Aretino, Delicado, Casanova, Cleland, de Sade, Sacher-Masoch, and many 
others, have been (and will continue to be) translated into innumerable languages, forming part of a world canon of erotic literature. Printings and reprintings, legal or clandestine, pirated or expurgated editions, are part and parcel of this age-old tradition of erotic writing. The monumental Encyclopedia of Erotic Literature (2006), edited by Gaëtan Brulotte and John Phillips, deals extensively with the literary representation of sexuality and desire, but treats translation as invisible, with only brief references to the first translations into major European languages (German, French, and English) of the works analyzed. While erotic literature has turned sexuality into a powerful social discourse, scholars have largely ignored questions related to the translation of erotic literature.

New research, however, is emerging that shows an explicit orientation and a more integrated approach to both sex/uality and translation (Boulanger 2008; Louar 2008; Santaemilia 2005, 2009, 2011; Rao and Klimkiewicz 2012; Henry-Tierney 2013). These publications deal almost exclusively with contemporary (especially French language) authors of erotic (or pornographic) literature, such as Canadian author Nelly Arcan; French authors Virginie Despentes, Catherine Millet, Georges Pailler "Esparbec," Mohamed Leftah and Anais Nin; British authors Ian McEwan and Nipper Godwin; and Spanish writer Almudena Grandes.

For example, Louar (2008) analyzes several versions of Virginie Despentes's erotic novel Baise-moi (1996), including the English translation by Bruce Benderson (1999) and the French-language film adaptation (2000), thus leading to a reconsideration of translation (or adaptation) in terms of alterity and identity. A careful analysis of its different texts and paratexts shows that Baise-moi serves, in French and in English, two different moral projects: the vulgarization of the literary text carried out in the English version, and the rendering of the French film version into a more pornographic and violent text. In Santaemilia $(2009,2011)$, we see how translation serves the purpose of sanitizing sexually explicit language in the works of "canonical" authors. The book Las edades de Lulú (1989), by Spanish writer Almudena Grandes, for example, a marginal, bold and explicitly erotic ${ }^{1}$ text, has generated polemical reactions and has become a privileged locus to test the limits of Spanish contemporary literature and society in terms of its sexual mores. Its publication initiated a boom in erotic literature in Spain. Young Spanish novelists like Lucía Etxebarria, Mercedes Abad or María Jaén have chosen to follow Grandes's example by describing in graphic detail the desires and sexual practices of their female protagonists in order to "implicitly dismantle the inherited models both of eroticism and of literature" (Ríos-Font 1998: 362). An analysis of The Ages of Lulu, the 1992 English-language translation of Grandes's novel by Sonia Soto, reveals the intricate processes and the contradictions involved in the translation of explicit sexuality. The example that follows can be illustrative: 


\section{Example 1}

"Estaba caliente, cachonda en el sentido clásico del término." (1989: 54)

[I was hot, horny/randy in the classical sense of the term]

"I was hot, turned on in the true sense of the word" (1992: 36)

As in many other passages, the English renderings are reasonable, though milder, options for the sexually explicit Spanish terms. When trying to relay the sexual vulgarity present in the Spanish original, the English version proves less physical, less colloquial. The Ages of Lulu deletes crude references to body parts, sexual acts, and to the frenzy Grandes's women experience in wild sexual activity. As these and other examples show, it could be said that the English translation has transformed a bold text about the limits of women's desire into a somewhat desexualized and sanitized one.

Although Las Edades de Lulú is a daring, frenzied book that crudely depicts-among other things-woman's sexual agency, it also resorts to the traditional misogyny and homophobia still pervading the Spanish language.

\section{Example 2}

"Estaba encoñado con Marcelo por lo visto, ...” (1989: 138)

[Apparently he was pussywhipped with Marcelo ... .]

"Seemed he was quite taken with Marcelo ..." (1992: 99)

Example 2 is an instance of those sexualized terms or turns of phrase that are highly idiomatic, and require an explanation in order to inscribe them within the context of Spanish cultural prejudices or taboos. In this instance, in prison, "the Portuguese guy," a transvestite who acts as a sort of girlfriend to all the prisoners in a period of political unrest, "was quite taken with Marcelo" [Sp. encoñado], Lulú's brother. Encoñarse or encoñado are terms that are extremely sensitive and thus problematic when it comes to translation, for a variety of reasons. In the first place, they are derived from the female pudenda (coño, Eng. 'cunt'), possibly the strongest taboo word in the Spanish language. Second, they point to a traditional, unconscious association of a woman's sexual organ with a passing, capricious infatuation. And third, they refer to a (gay) man. These examples seem to reaffirm women's bodies and sexualities as the main sources of verbal hostility and abuse in Spanish. All this, however, is markedly lost in Sonia Soto's translation. Sexually explicit language is, undoubtedly, a privileged space for understanding cultures we translate into insofar as it is a site where "issues of cultural sensitivity are encumbered by issues of gender stereotyping and cliché" (von Flotow 2000: 31), where each culture establishes its moral and ethical limits, where we encounter its taboos. A queer approach would lead us to focus on "mismatches between sex, gender and desire" (Jagose 1996: 3) 
present in both cultures, which might justify the provisional, contingent, strategic constructions of sexuality in the original and translated texts.

Another popular topic is the study of censorship and self-censorship in translation. Defined as "the suppression or prohibition of speech or writing that is condemned as subversive of the common good" (Allan and Burridge 2006: 13), censorship is understood as an external constraint on what we can publish or (re)write. By contrast, self-censorship is an individual moral/ethical struggle between the individual and society. In all historical circumstances, translators tend to censor themselves-either voluntarily or involuntarily-in order to produce rewritings that are 'acceptable' from both a social and a personal perspective. (See Gombár's chapter in this volume for a comparative study of censorship and self-censorship.)

Particularly well researched is censorship in twentieth-century European dictatorships (Italy or Spain under fascist dictators Mussolini and Franco, or Nazi Germany under Hitler), which imposed tight censorship measures, such as pre-publication or editorial censorship, and favored the systematic exercise of self-censorship. Sexual morality, political orthodoxy, religion and racism are among the most popular issues (Merkle 2002; Vega 2004; Gallego 2004; Billiani 2007; Seruya and Moniz 2008; Chuillenanáin et al. 2009). Linder (2004) exposes the complexities, and interrelations, between translation (and particularly, the translation of homosexual slang) and censorship in his study of the censored material in the Spanish versions of Raymond Chandler's The Big Sleep (1939) during the Franco dictatorship in Spain (1939-1975), while Schmitz (1998) studies the suppression of references to sex and bodily functions in the Portuguese translations of J.D. Salinger's The Catcher in the Rye (1951). Ziman (2008) has shown how foreign novels dealing with sexuality are typically sanitized in Chinese translation through archaism, generalization or omission/deletion, while Baer (2015: 142-153) has documented how such works are made publishable in post-Soviet Russia through the strategies of erasure, aestheticization, and Russification.

An especially fertile ground for research into issues related to translation and sexuality has been censorship in audiovisual translation. Lung (1998), for example, shows how sexual references in English-Chinese subtitling on Hong Kong television are routinely mistranslated or omitted. Scandura (2004) carries out a general survey of audience awareness of censorship in subtitling, though just a few examples focus on sexuality. More recently, works by Marcella de Marco (2006, 2009) offer a promising avenue for the study of audiovisual works from a gender perspective, which also involves issues of sexuality. De Marco's Audiovisual Translation through a Gender Lens (2012) is a most valuable contribution. In this respect it is well worth mentioning the work of Delia Chiaro (2007), who has embarked on a study of the Italian translations of references to sex and sexuality that are found in imported English-language TV series such as Sex and the City. Her main thesis is that despite the fact that Italians are seen as liberally using sex-related 
language and Italian TV channels (both public and private, RAI and Mediaset) are famous for exhibiting women as sexual objects, the sexual language present in foreign (mostly American) TV series is severely mitigated, or even omitted, thus challenging the idea that Italian television is as liberated as it seems. Issues of prudery or a specific positioning toward sexuality could be raised here, but that would require a more detailed analysis of the agents and factors involved in the translation process. For example, references to the male sexual organ (from "penis" to "dick" and even "cock") are usually toned down to the childlike term uccello ["bird"], whereas terms for the female sexual organ ("pussy" or "cunt") are again mitigated into patatina ["little potato"] or fica ["fig"]. Similarly, "fuck," in the sense of sexual intercourse, is rendered as either scopare ["screw"] or farlo ["do it"], or it is simply deleted.

The analysis of (self)censorship in the translation of sexuality has much to offer in terms of documenting unspoken personal or social beliefs, values, and prejudices related to gender/sexuality identity construction and the representation of pleasure and desire. Increasingly, though, a queer perspective is called for in order to provide a greater awareness of the limitations of identity categories and of the culture-specific contingency in the representation of accepted public sexualities.

\section{Gay/Lesbian and Queer Sexualities in/through Translation}

But it is certainly the fields of gay/lesbian and queer studies that have most deeply engaged in complex analyses of both the translation of sexuality and the sexualization of translation. Drawing on strong-and sometimes conflicting-theorizations about a field that has been variously called language and sexuality (Bucholtz and Hall 2004) or language and desire (Kulick 2003), in which gay/queer researchers have played a crucial role, both identity- and desire-related aspects are coming to the fore. Key works by Leap (1995, 1996), Livia and Hall (1997), Harvey and Shalom (1997), Cameron and Kulick (2003) and, more recently, Sauntson and Kyratzis (2007) have paved the way for the field to go beyond heterosexuality as the default object of study with resistance (in theory and in practice) to heteronormativity as the main critical position (see Motschenbacher 2010) and a resistance to be slotted into stable sexual identity categories.

A number of studies concerning gay/lesbian in translation have appeared (Keenaghan 1998; Mira 1999; Harvey 1998, 2000, 2003), with a common denominator: making gay/lesbian identity and characters visible in/through translation and through the analyses of translations. At the core of this research is the discursive construction, and performative nature, of gay/lesbian identity, as well as the existence (and reinforcement) of a shared sense of community. Particularly noteworthy are the works by Keith Harvey, still a key source of inspiration for the field, as they contain powerful insights into the translation of sexuality across languages and cultures. Specifically, 
Harvey explores the shifts that occur when homosexual camp talk, associated with the minoritarian model of homosexuality as institutionalized in the United States, is translated into French, a culture that is critical of such minoritarianism as undermining the French notion of universal citizenship. Translations, for Harvey (2003: 10), "par excellence belong multifariously and constitute spaces in which cultural differences intersect and overlap."

More recent, queer-identified research on translation and sexuality, though still revolving around gay/lesbian issues, goes beyond gay/lesbian translation to encompass other "culturally marginal sexual self-identifications" (Jagose 1996: 1). This research is noteworthy for its increasingly critical interrogation of sexuality, and for its holistic approach to gender, sexuality, class, and race matters. Unlike much research on the translation of sexuality in erotic texts and in regard to censorship, queer-identified researchers tend to emphasize a discursive approach to sexuality-related language, focusing on both sexuality and translation as discursive processes that affect our understanding and experience of our bodies, our desires, and our pleasures.

Queer researchers of translation and sexuality have problematized the notions of both sexuality and translation. A wealth of publications in the last decade or so (Bauer 2003; Larkosh 2006, 2007; Kinloch 2007; Valdeón 2010; Baer 2011; Asimakoulas 2012) have shown time and again that translational choices in a number of cultural products-the novels by Argentinian writer Manuel Puig, the American sitcom Will and Grace (1998-2006) or the Greek film Strella (2009), among others-have the potential to unsettle stable social hierarchies, particularly images of masculinities, femininities, gays/lesbians and of a range of other sexual identifications. Such queer research in translation and sexuality evinces a two-way process: on the one hand, the projection of translation onto queer texts-i.e., the critical exploration of alternative or subversive identities and sexualities; and on the other hand, translation as a queer practice. Translation is, therefore, used with a double purpose: (i) to problematize sexual identities; and (ii) to develop a queer politics through translation.

As to the second perspective outlined earlier-the sex/ualization of translation-it is a much less traveled road, though it is a recognizable and powerful avenue of exploration for queer studies. Though still under-explored, a well-known antecedent needs to be mentioned here. Lori Chamberlain (1988) wrote about a gender(ed) metaphorics in translation theories, a sort of metaphorical trap that subverts all gender-related or sex-related identities and condemns women to sexual/textual subordination. The historical paradigm is the famous belles infidèles, which described the dominant approach to translation in seventeenth-century France, holding that translations, like women, could be either beautiful or faithful, but not both. This projects widely held traditional beliefs and stereotypes about fidelity in marriage onto translation.

More recently, Boulanger (2005) has embarked on a philosophical reflection on the erotics of the act of translating, emphasizing the connection 
between sex and text, between body and translation. Rao (2005) suggests the existence of a subversive power in the erotics of translation, a sort of translation caress that involves a revaluation of the corporal dimensions of both text and translator's body. For West (2010: 5), an erotics of translation "investigates the various and desirous negotiations of translator and author in the process of translating and being translated." Larkosh (2011: 4) clearly advocates for a queering of translation when he declares,

In re-engendering the study of translation, it may be possible to uncover the ways that translation has always already been gendered in multiple ways, and how all gender and sexual identifications, whenever they are represented in the translation process, are poised for an extended discussion which points toward their relevance across the limits of a single gender or sexual identity.

Finally, Lacayo (2014) compares translation to the thickness of bodies, to the somatic processes they undergo, to corporeal encounters signaling both distance and proximity. Without a doubt, it is queer perspectives (translating the queer and the queering of translation) that have offered to date the best testing ground for a complex problematization of both sexuality and translation. Their increasing intersection offers a promising panorama for the future. "By refusing to crystallise in any specific form," claims Jagose (1996: 99), "queer maintains a relation of resistance to whatever constitutes the normal." Therefore, a queer praxis becomes a site of resistance to the accepted conventions, traditions, forms of identification, forms of analysis, and forms of translation. Queer postulates are, for Koller (2009: 254), "radically anti-essentialist," thus advocating a social constructionist approach in order to overcome one of the alleged shortcomings of gay/lesbian theory, i.e., the naturalization of gay/lesbian identities into monolithic, ahistorical, stable gender/sexual positions. Burton (2010) proposes a queer translation project which is "antihomophobic in motivation and practice, and destabilising and historicising of gender, sex, and sexuality norms," which is "conscious of intersectionality" (2010: 55) with other forms of subjectivity, and whose main aim is to "destabilize and denaturalise gender and sex norms, historicising them" (2010: 57).

\section{Conclusion}

This chapter has offered an overview of research that might come under the label of "sexuality and translation." For Luise von Flotow (2009: 123), sexuality is "a currently developing analytical category in translation studies," making a specific reference to Larkosh (1996). Christopher Larkosh, however, underlines the "still-unexamined intersections in translation studies, gender and sexualities" (Larkosh 2011: 4). Though apparently contradictory, both statements may be right. We have identified two directions of research (the translation of sexuality and the sex/ualization 
of translation) that seem to be unequally developed. As for the former, it is evident that translation studies at large has incorporated gender (and sexuality) among its current concerns (Flotow 2009; Godayol 2013; Baer and Massardier-Kenney 2016). The latter, however, shows that translation studies has not fully entered the field of language and sexuality, making it susceptible to essentialist positions. I believe, however, that there is a progressive coming together of sexuality and translation. Earlier, I provided only an overview of two well-recognized discourses and phenomena-i.e., the translation of erotic/pornographic literature and censorship or self-censorship in translation-as well as a few ideas about the sexualization/eroticization of translation. In fact, in recent research we can perceive a progressive queering of translation and sexuality studies. Therefore, the last section provides a glimpse at the work carried out by gay/lesbian and, fundamentally, queer researchers into translation and sexuality. Although Flotow, in a recent article, makes the challenging remark that " 'queer" has not (yet) been a particularly fruitful theory in translation" (Flotow 2012: 132), I believe that it is queer translation research that has been offering the most articulate analyses, problematizing both sexuality and translation. It is certainly an area of study in the making, with a degree of terminological instability but open to many approaches and interpretations, still with an enormous potential for evolution.

In the conclusion, let me turn to the question posed in the title of this chapter: are translation and sexuality intimate partners, or are they perhaps strange bedfellows? Both are disciplines heavily rooted in history and society, with rapidly expanding conceptual boundaries and revolutionary potential; and both offer a privileged view into our own inner selves and our intimacies. In fact, through translation practices and discourses of/on sexuality, society attempts to impose moral and ethical boundaries on the self, thus establishing what is 'decent,' 'appropriate,' 'acceptable,' 'moral,' 'proper,' 'perverse,' and so on. Both sexuality and translation represent textualizations of our identities and desires, which regulate and shape the way we understand, speak about, negotiate, accept, and refuse different projections of our selves (identities, desires, pleasures, prejudices). Both are political acts and areas of personal and ideological struggle. An intimate interplay between sexuality and translation may offer critical insights into the subversive potential of the construction of (accepted or alternative) identities and desires across languages and cultures, as "analyses of gender and sexual difference(s) in translation work will provoke new sites of knowledge production, as well as stimulate significant shifts in social identities and categories" (Spurlin 2014a: 205).

A holistic exploration of the (re)writing of desire and identities across languages and cultures-that brings translation into contact not only with issues of gender and sexuality but also with issues related to social class, race, ethnicity, and other factors linked to power asymmetries or ideology-is bound not only to interrogate and challenge received ideas and conceptualizations 
of the self, but also to suggest new ones. For Larkosh (2011: 5), “[n]one of us is exempt from the ways in which acts of translation, whether in a literal or in a more figurative cultural sense, continually reshape understandings of 'our' identities." Gay, homosexual, or dyke; bisexual or transgendered; marriage or civil partnership; cunt or vagina; fuck or make love are not self-evident categories but provisional labels (referring to sexual identities, desires or pleasures) that emerge in local discursive practices, very often through harsh, culture-specific negotiations between conflicting ideological and ethical/moral positions. In the configuration of these extremely powerful labels, a queer understanding of both sexuality and translation is likely to play a fundamental role.

\section{Note}

1 Later on, in 2004, in a process of canonical assimilation by the publishing industry, Las edades de Lulú was published in a new, author-revised edition in the prestigious Andanzas series, which usually features best-selling authors such as John Connolly, Marguerite Duras, John Updike, and many others. All the sexual passages, however, have been left untouched. (For more details, see Santaemilia 2011).

\section{References}

\section{Primary Sources}

Grandes, Almudena. 1989. Las edades de Lulú. Barcelona: Círculo de Lectores.

Grandes, Almudena. 1992. The Ages of Lulu. Translated by Sonia Soto. London: Abacus.

Möbius, Paul Julius. 1900. Ueber den physiologischen Schwachsinn des Weibes. Halle: Carl Marhold.

\section{Secondary Sources}

Allan, Keith and Kate Burridge. 2006. Forbidden Words: Taboo and the Censoring of Language. Cambridge: Cambridge University Press.

Asimakoulas, Dimitris. 2012. "Dude (Looks Like a Lady): Hijacking Transsexual Identity in the Subtitled Version of Strella by Panos Koutras." The Translator 18(1): 47-75.

Baer, Brian James. 2011. “Translating Queer Texts in Soviet Russia.” Translation Studies 4(1): 21-40.

Baer, Brian James. 2015. Translation and the Making of Modern Russian Literature. New York and London: Bloomsbury.

Baer, Brian James and Françoise Massardier-Kenney. 2016. "Gender and Sexuality." In Researching Translation and Interpreting, edited by Claudia V. Angelelli and Brian James Baer, 83-96. New York: Routledge.

Bauer, Heike. 2003. “ 'Not a Translation But a Mutilation': The Limits of Translation and the Discipline of Sexology." The Yale Journal of Criticism 16(2): 381-405. 


\section{José Santaemilia}

Billiani, Francesca (ed.). 2007. Modes of Censorship and Translation: National Contexts and Diverse Media. Manchester/Kinderhook, NY: St. Jerome Publishing.

Boulanger, Pier-Pascale. 2005. "L'érotique du traduire." Meta 50(4). Available online at www.erudit.org/revue/meta/2005/v50/n4/019831ar.pdf (last accessed November 30, 2016).

Boulanger, Pier-Pascale. 2008. "Sa langue se glissa dans sa bouche: De la traduction des adjectifs possessifs his/her dans le récit érotique." Palimpsestes 21: 109-119.

Brulotte, Gaëtan and John Phillips. 2006. "Introduction." In An Encyclopedia of Erotic Literature, edited by Gaëtan Brulotte and John Phillips, ix-xiii. London: Routledge.

Bucholtz, Mary and Kira Hall. 2004. "Theorizing Identity in Language and Sexuality Research.” Language in Society 33: 469-515.

Burton, William M. 2010. "Inverting the Text: A Proposed Queer Translation Praxis." In Other Words 36: 54-68.

Butler, Judith. 1990. Gender Trouble: Feminism and the Subversion of Identity. New York: Routledge.

Cameron, Deborah and Don Kulick. 2003. Language and Sexuality. Cambridge: Cambridge University Press.

Chamberlain, Lori. 1988. "Gender and the Metaphorics of Translation." Signs: Journal of Women in Culture and Society 13(3): 454-472.

Chiaro, Delia. 2007. "Not in Front of the Children? An Analysis of Sex on Screen in Italy." Special Issue on Audiovisual Translation: A Tool for Social Integration. Linguistica Antverpiensa 6: 255-276.

Chuillenanáin, Eiléan Ní, Cormac Ó Cuilleanáin and David Parris (eds.). 2009. Translation and Censorship: Patterns of Communication and Interference. Dublin: Four Courts Press.

Crisafulli, Edoardo. 2001. “Dante's 'Shameless Whore': Sexual Imagery in Anglo-American Translations of the Comedy." TTR-Traduction, Terminologie, Rédaction 14(1): 11-38.

De Marco, Marcella. 2006. "Audiovisual Translation from a Gender Perspective." The Journal of Specialised Translation 6, July. Available online at www.jostrans. org/issue06/art_demarco.php (last accessed November 30, 2016).

De Marco, Marcella. 2009. "Gender Portrayal in Dubbed and Subtitled Comedies." In New Trends in Audiovisual Translation, edited by Jorge Díaz-Cintas, 180-200. Clevedon: Multilingual Matters.

De Marco, Marcella. 2012. Audiovisual Translation Through a Gender Lens. Amsterdam and New York: Rodopi.

Flotow, Luise von. 2000. "Translation Effects: How Beauvoir Talks Sex in English." In Contingent Loves: Simone de Beauvoir and Sexuality, edited by Melanie Hawthorne, 13-33. Richmond: University Press Virginia.

Flotow, Luise von. 2009. "Gender and Sexuality." In Routledge Encyclopedia of Translation Studies, 2nd edition, edited by Mona Baker and Gabriela Saldanha, 122-126. London: Routledge.

Flotow, Luise von. 2012. "Translating women: From recent histories and re-translations to 'queerying' translation, and metamorphosis." Quaderns. Revista de Traducció 19: 127-139.

Gallego Roca, Miguel. 2004. "De las vanguardias a la Guerra Civil.” In Historia de la traducción en España, edited by Francisco Lafarga and Luis Pegenaute, 479-526. Salamanca: Editorial Ambos Mundos. 
Godayol, Pilar. 2013. "Gender and Translation.” In The Routledge Handbook of Translation Studies, edited by Carmen Millán and Francesca Bartrina, 173-185. London and New York: Routledge.

Harvey, Keith. 1998. “Translating Camp Talk: Gay Identities and Cultural Transfer." The Translator 4(2): 295-320.

Harvey, Keith. 2000. "Gay Community, Gay Identity and the Translated Text." TTR 13(1): 137-165.

Harvey, Keith. 2003. Intercultural Movements: American 'Gay' in French Translation. Manchester: St Jerome Publishing.

Harvey, Keith and Celia Shalom (eds.). 1997. Language and Desire: Encoding Sex, Romance and Intimacy. London and New York: Routledge.

Hennessy, Rosemary. 1994. "Queer Theory, Left Polities." Rethinking Marxism 7(3): 85-111.

Henry-Tierney, Pauline. 2013. “Transgressive Textualities: Translating References to Gender, Sexuality and Corporeality in Nelly Arcan's Putain and Paradis, clef en main." Canada and Beyond 3(1-2): 161-179.

Jagose, Annamarie. 1996. Queer Theory: An Introduction. New York: New York University Press.

Karjalainen, Markus. 2002. "Where Have All the Swearwords Gone? An Analysis of the Loss of Swearwords in Two Swedish Translations of J.D. Salinger's Catcher in the Rye." Pro Gradu Thesis-Faculty of Arts, Department of English, University of Helsinki, October.

Keenaghan, Eric. 1998. “Jack Spicer's Pricks and Cocksuckers: Translating Homosexuality into Visibility.” The Translator 4(2): 273-294.

Kinloch, David. 2007. "Lilies or Skelfs: Translating Queer Melodrama.” The Translator 13(1): 83-103.

Koller, Veronika. 2009. "Butch Camp: On the Discursive Construction of a Queer Identity Position." Gender and Language 3(2): 249-274.

Kulick, Don. 2003. "Language and Desire." In The Handbook of Language and Gender, edited by Janet Holmes and Miriam Meyerhoff, 119-141. Oxford: Blackwell.

Lacayo, Aarón. 2014. "A Queer and Embodied Translation: Ethics of Difference and Erotics of Distance." Comparative Literature Studies 51(2): 215-230.

Larkosh, Christopher. 1996. "The Limits of the Translatable Foreign: Fictions of Translation, Migration and Sexuality in 20th Century Argentine Literature." Unpublished Ph.D. dissertation, University of California, Berkeley.

Larkosh, Christopher. 2006. “'Writing in the Foreign': Migrant Sexuality and Translation of the Self in Manuel Puig's Later Work." The Translator 12(2): 279-299.

Larkosh, Christopher. 2007. “The Translator's Closet: Editing Sexualities in Argentine Literary Culture." TTR-Traduction, Terminologie, Rédaction 20(2): 63-88.

Larkosh, Christopher (ed.). 2011. Re-Engendering Translation: Transcultural Practice, Gender/Sexuality and the Politics of Alterity. Amsterdam and Philadelphia, PA: John Benjamins.

Leap, William (ed.). 1995. Beyond the Lavender Lexicon: Authenticity, Imagination, and Appropriation in Lesbian and Gay Languages. London: Gordon \& Breach.

Leap, William. 1996. Word's Out: Gay Men's English. Minneapolis, MN: University of Minnesota Press. 


\section{José Santaemilia}

Linder, Daniel. 2004. "The Censorship of Sex: A Study of Raymond Chandler's the Big Sleep in Franco's Spain.” TTR-Traduction, Terminologie, Rédaction 17(1): 155-182.

Livia, Anna. 2003. “ ‘One Man in Two Is a Woman’: Linguistic Approaches to Gender in Literary Texts." In The Handbook of Language and Gender, edited by Janet Holmes and Miriam Meyerhoff, 142-158. Oxford: Blackwell.

Livia, Anna and Kira Hall (eds.). 1997. Queerly Phrased: Language, Gender, and Sexuality. New York and Oxford: Oxford University Press.

Loffredo, Eugenia. 2003. "The Diseased Body of Language: Translating the Female Body in Jeanne Hyvrard's Mère la Mort." In Género, lenguaje y traducción, edited by José Santaemilia, 485-499. Valencia: Universitat de València/Dirección General de la Mujer.

Louar, Nadia. 2008. "Version femmes plurielles: relire Baise-moi de Virginie Despentes.” Palimpsestes 22 (Traduire le genre: femmes en traduction): 83-98.

Lung, Rachel. 1998. "On Mis-Translating Sexually Suggestive Elements in EnglishChinese Screen Subtitling.” Babel 44(2): 97-109.

Masiello, Francine. 2004. "Joyce in Buenos Aires (Talking Sexuality Through Translation)." Diacritics 34(3): 55-72.

Merkle, Denise (ed.). 2002. Traduction et censure dans le monde occidental [Special Issue]. TTR-Traduction, Terminologie, Rédaction 15(2).

Mira, Alberto. 1999. "Pushing the Limits of Faithfulness: A Case for Gay Translation." In The Practices of Literary Translation: Constraints and Creativity, edited by Jean Boase-Beier and Michael Holman, 109-123. Manchester: St. Jerome.

Motschenbacher, Heiko. 2010. Language, Gender and Sexual Identity: Poststructuralist Perspectives. Amsterdam and Philadelphia, PA: John Benjamins.

Rao, Sathya. 2005. "Peut-on envisager l'avenir de la traduction sans plaisir? Vers une érotique du traduire." Meta 50(4). Available online at www.erudit.org/livre/ meta/2005/000222co.pdf (last accessed November 30, 2016)

Rao, Sathya and Aurelia Klimkiewicz. 2012. "Les défis de la traduction de La vie sexuelle de Catherine M. en anglais et en polonais." Neohelicon 39(1): 235-254.

Ríos-Font, Wadda. 1998. "To Hold and Behold: Eroticism and Canonicity at the Spanish Fines de Siglo." Anales de la Literatura Española Contemporánea 23(1): 355-378.

Sánchez, Dolores. 2007. "The Truth About Sexual Difference: Scientific Discouse and Cultural Transfer." The Translator 13(2): 171-194.

Sánchez, Dolores. 2011. "Translating Science: Contexts and Contests. On the Translation of a Misogynist Scientific Treatise in Early Twentieth-Century Spain.” The Translator 17(2): 325-348.

Santaemilia, José (ed.). 2005. Gender, Sex and Translation: The Manipulation of Identities. Manchester: St. Jerome.

Santaemilia, José. 2009. “La vie sexuelle de Catherine M.: A Journey through 'Woman,' 'Sexual Language' and 'Translation.'” Sendebar 20: 123-141.

Santaemilia, José. 2011. "The Translation of Sexually Explicit Language: Almudena Grandes' Las edades de Lulú (1989) in English.” In Translation and Opposition, edited by Dimitris Asimakoulas and Margaret Rogers, 265-282. Bristol: Multilingual Matters.

Sauntson, Helen and Sakis Kyratzis (eds.). 2007. Language, Sexualities and Desires: Cross-Cultural Perspectives. Basingstoke: Palgrave Macmillan.

Scandura, Gabriella. 2004. "Sex, Lies and TV: Censorship and Subtitling." Meta 49(1): 125-134. 
Schmitz, John. 1998. "Suppression of References to Sex and Body Functions in the Brazilian and Portuguese Translations of J.D. Salinger's The Catcher in the Rye." Meta 43(2): 242-253.

Seruya, Teresa and Maria Lin Moniz (eds.). 2008. Translation and Censorship in Different Times and Landscapes. Newcastle: Cambridge Scholars Publishing.

Spurlin, William J. 2014a. "Queering Translation.” In A Companion to Translation Studies, edited by Sandra Bermann and Catherine Porter, 298-309. Oxford: Wiley-Blackwell.

Spurlin, William J. 2014b. "Introduction: The Gender and Queer Politics of Translation: New Approaches." Comparative Literature Studies 51(2): 201-214.

Valdeón, Roberto. 2010. "Schemata, Scripts and the Gay Issue in Contemporary Dubbed Sitcoms." Target 22(1): 71-93.

Vega, Miguel Ángel. 2004. "De la Guerra Civil al pasado inmediato.” In Historia de la traducción en España, edited by Francisco Lafarga and Luis Pegenaute, 527-578. Salamanca: Editorial Ambos Mundos.

West, Kevin. 2010. "Translating the Body: Towards an Erotics of Translation." Translation and Literature 19(1): 1-25.

Wildeman, Marlene. 1989. "Daring Deeds: Translation as Lesbian Feminist Language Act." Tessera 5: 31-40.

Ziman, Han. 2008. "Sex Taboo in Literary Translation in China: A Study of the Two Chinese Versions of the Color Purple." Babel 54(1): 69-85. 


\title{
2 A Scene of Intimate Entanglements, or, Reckoning with the "Fuck" of Translation
}

\author{
Elena Basile
}

Relents

Qui veut Nathanaël ? I do I do.

Seulement il n'existe pas. Il ne t'embrasse pas. Il ne laisse aucun pli sur ton matelas. Il ne te trahit pas. Le plancher carrelé est froid tu es pieds nus. Nathanaël est déjà loin il n'a jamais été ici pas une seule fois. C'est un garçon queer un garçon aimable maybe even a fuckable boy et on bande et on mouille en tournant les pages en imaginant son souffle. Tu ne peu même pas faire le deuil de Nathanaël car il n'est pas mort. Il n'est pas mort parce qu'il ne vit pas. Personne ne sait qui est Nathanaël au juste. L'as-tu vu ? Je l'ai seulement vu de dos et c'était dans un tableau, un tableau médiocre de surcroît. J'ai entendu dire qu'il aime courir sous la pluie et dormir les yeux ouverts.

(Stephens 2003: 51 bold type added)
A fuckable text

What is a fuckable text and is it only fuckable in English? Is there such thing as a literary hard-on? Who wants Nathanaël? I do I do. Only he doesn't exist. He is not kissing you. He leaves no fold on your mattress. He doesn't break your heart. The tiled floor is cold and your feet are bare. Nathanaël is long gone he was never here not even once. He is a queer boy a loveable boy maybe even a fuckable boy and we are all wet or hard turning pages imagining his breath. You cannot even mourn him because he is not dead. He is not dead because he is not alive. Nobody knows who Nathanaël is. Have you seen him? I have only seen him from behind in a painting and not a very good one at that. I hear he likes to run in the rain and sleep with his eyes open.

(Stephens 2006: 49 bold type added)

I will begin with the question of fucking. What better place, after all, from where to start writing an essay that explores the relation between translation and queerness- that is, between writing and corporeal practices that invariably cross over leaky boundaries, animate thresholds, eschew containment, 
and hold out unexpected textual and fleshy pleasures? If translation, as many theorists contend, holds out dangerous pleasures of cultural transgression and leakage even in its most domesticating and conservative manifestations, and if queerness connotes ways of living that refuse the normative containment of socio-sexual regimes of power, the terrain between them might indeed be a very intimate one, a potentially "fuckable" one-possibly lending itself to unexpectedly pleasurable and fertile couplings. Or might it?

Let's start again. The epigraph to this chapter compels me to ask the question of fucking in translation, because the question itself suddenly emerges from in between the French and English versions of a self-translated text written between 2003 and 2006 by a writer who in 2009 will officially take as their authorial name the "je" of the text's own title, Nathanaël. One is tempted to comment quietly "this is so fucked ..." Notwithstanding the violent phobic assumptions transpiring from it, I am interested in drawing attention to what 'fucked' might indicate in this comment: the perception of an entanglement of sorts, a situation comprised of so many knots and twists, so many tangled threads of language(s) and body(ies) that normal (normative) parameters for mapping, orientation, and recognition no longer apply. There is something untranslatable about this (as in, caught up in its own singular idiom), and yet something that imperiously keeps demanding translation (as in, a loosening of sorts that might enable a potential for expanded communication across recognizable languages and cultural scripts).

So, is there a "fuckable text?" What kind of entangled scene are we made to witness in the French and English versions of this section of Je, Nathanaël? And what kind of scene might I, the writer of this chapter, be projecting upon the white space marking the boundary between the two juxtaposed texts? Are the two scenes (the scene described by the texts and the scene virtually projected between them) commensurable? How might the scene represented in English and in French disturb or illuminate the invisible scene fantasized as taking place between the two languages?

When I first conceived of this chapter, I started out from the assumption that the potential for queering translation theory rests upon the fairly pervasive heterosexist analogy drawn between translation and sexuality, which traverses Western translation theory at least since France's eighteenth-century "belles infidèles." ${ }^{1} \mathrm{My}$ initial project was to draw out the queer potential implicit in such an analogy by means of reframing both sexuality and translation as scenes of intimate and vulnerable encounter between corporeal/ linguistic skins/surfaces, in which the fiction of the firmly gendered, fully territorialized and self-contained sovereign subject/language is exposed and undone. In line with a strong negative trend in North-American queer theory that insists on figuring the political import of the sovereign subject's undoing in sexuality (Berlant and Edelman 2014; Bersani and Phillips 2008; Edelman 2004), I proposed that we extend such a claim toward a queering of translation theory. In short, I was interested in exploring how paying attention to the scene of translation - that is, the scene of linguistic encounter, 


\section{Elena Basile}

of languages touching each other-can acquire political import insofar as it exposes the fiction of self-contained language-systems (historically sedimented as national and colonial), undoes them and repurposes them as constitutively interdependent, vulnerable, constantly interpenetrated. The plan was to back up the methodological centering of my analysis of the scene of translation as a scene of intimacy by making reference to postcolonial critic Gayatri Spivak's famous adagio, that "translation is the most intimate act of reading" (1993: 183). I have to admit, however, that the fantasy accompanying such an act was fairly pastoral-that is, pleasant, pacified, and most of all unhindered by the potential for violent non-relationality and mis-reading at the heart of intimacy itself (something both Spivak and queer theorists such as Berlant and Edelman recursively alert us to). In other words, I imagined Spivak's reader/translator 'making love to,' rather than 'fucking' the text. Obviously, I had not read Je Nathanaël carefully enough-yet. Nor had I taken into account that I could not metaphorize the scene of translation as a scene of linguistic skins touching without taking full stock of the consequences attending to the pornographic construction of the scene itself. ${ }^{2}$

\section{The Scene of Translation}

Let me return to the scene of the fuckable text described in the epigraph mentioned earlier. The French text begins with a question that immediately triggers desire for the absolute singularity of the proper name: "Qui veut Nathanaël? I do I do." Perversely mimicking marriage vows in the direction of potential orgiastic enjoyment (the $I$ being multiplied in repetition), both question and answer draw us readers into the fold of a scene in which the protagonist keeps receding — and whose absence suddenly leaves us exposed to the text's headlights—caught on stage with our pants down so to speak: "et on bande et on mouille en tournant les pages en imaginant son souffle"/ "we are all wet or hard turning pages imagining his breath." Is this the text's fuckability? Its queerness residing far less obviously in the text's object of desire, the "queer amiable boy" that Nathanaël seems to be (invariably so in English across both versions of the text), than in its ruthless exposure of the reader's own pornographic gaze?

Clearly, it didn't take much to shatter the pastoral fantasy that I had appended to the scene of translation. If anything, the text's 'fuckability' violently displaces any idealized notion of intimacy, revealing through such displacement what the pastoral fantasy veils. It reveals, that is, the pornographic construction of the scene itself, where the object of desire is given to see to the desiring subject on condition that the desiring subject be condensed to their disembodied gaze, their body remaining off-scene, unseen. The fuckable text turns $o n^{3}$ such fiction of privileged privacy (a fiction that conveniently scaffolds the sovereign subject's notion of self-sufficiency) exposing the pornographic gaze as body—a disheveled and wanting body at 
that. How else to explain our "hardness or wetness" (the French impersonal "on" in "et on bande et on mouille" powerfully stressing the pure carnality of the text's effects)? And of course, in turning on to us, readers, the text also turns away from the object at the center of the scene of its desire: Nathanaël is nowhere to be found. The "queer boy" is gone and here we are, onlookers, pants down, caught in the text's sudden glare. Queered by it, beyond ourselves.

The scene of sex in the text, in other words, resists being constituted within the classic pornographic paradigm of subject-desiring-object both by means of refusing the discrete spatial divide that affords the (aroused) reader the privacy of being off-scene, and by insisting on placing the object of desire irreducibly beyond the reader's reach. If this is so, what happens then to the idealized scene of intimacy in translation? If we stand by the analogies being drawn out here, such a scene presupposes the disembodied reader/critic peering over the shoulders of a translator at her desk, entirely, intimately absorbed in the process of her task.

This after all, is the fantasy I projected onto the white space between the French and English texts visually juxtaposed in the epigraph. By putting the texts side by side and drawing attention to the space between them, I offered a seductive image of such intimacy. Parting the curtain on it, so to speak, I offered the fantasy of a translator 'making love' to her languages, and put my own reader's gaze at a comfortable and yet titillating distance from the scene itself. The thing is, as we just saw, we did not find intimacy, we found the " $f u c k "$ - with all its attendant vulgarity and violence. And we found the "fuck" as a profoundly disorienting experience of bodily arousal drawn into a zone of indefinite proximity to the object of desire, always somewhere else, just beyond our reach. It is both tempting and satisfying to imagine the juxtaposed languages pleasantly lubricating one another in such intimate encounter, facilitating an indefinite approximation to Nathanaël, as if the name on its own held out the promise of orgasmic delivery from the grip of desire. But French and English here can just as well be seen grating against one another, hurting, and wounding each other, maddened by the limits of their own signifying constraints, only imperfectly supplemented by the other, and forgetful that there ever was a Nathanaël to desire in the first place. The thing is, the difference between pleasurable lubrication and painful friction cannot always be told in advance. Neither can the effects.

\section{Coming Undone}

The very question asked in English about the existence of a "fuckable text" offers us a glimpse into the affective vacillation triggered by such impossibility of knowing in advance what the scene of translative intimacy might deliver ... or where it might take us. Indeed, that interrogative supplement at the beginning of the English text manifests an affective frustration at 
work, whereas the French seems to get away by just permeating the scene with the "stench" of desire inscribed in its title: "Relents."

The olfactory sensorium evoked in the French scene becomes purified of its "stench" in English, leaving a "fucking" question in its wake. The English scene, then, highlights its own production of desire as sensory withdrawal, all along invoking a queer boy, whose egregious English inscription as "maybe even fuckable" across both texts emphasizes more than ever the represented body's stubborn refusal of translation. We need to note, once again, that the queer boy's body is actually absent from the scene of both texts. The description of the body's corporeality is given over to the absence of marks of its passage through the scene. What remains is a ghostly body that traverses both texts and draws attention to the impossibility of any idealized intimacy between discrete languages, while all along gesturing to what could be called here the disruptive intimacy of the foreign.

Indeed, however one wants to read the intrusion of an almost full English sentence in the French version (either as the pervasive imperial association of the signifier "queer" with Anglo-sex culture; or more prosaically as banal authorial code-switching), it is hard not to notice how the "maybe even fuckable boy" presented in the French version migrates into a questionable "fuckable text" in the English one. "Questionable": as in, both "begging the question" (of translation) and "being morally reproachable" (for choices made). So, if the French text's own linguistic sovereignty is disturbed by the presence of English in its midst, can we safely assume that the English text is fully self-contained in its own linguistic universe when its opening question begs the problem of an untranslatable fuckability? The English text, that is, while seemingly not punctured by the presence of a foreign language in its midst, retains a pathetic (as in, full of pathos) awareness of its own signifying limits as language in the adverb "only," which limits the scope of the question: is the text fuckable "only" in English?

The question is obviously rhetorical, but that is not the point. ${ }^{4}$ The point here is that the movement of translation, when attentively pursued as movement, puts pressure on the very frame of linguistic enclosure upon which the purported representational stability of source and target texts is predicated. Languages come undone in translation just like subjects come undone in sex. This is more than a simple analogy (if there ever is such a thing as a simple analogy). Languages and subjects "come undone" in the sexual and in the translative encounter when the materiality of their intermingling passes a threshold of perception, such that they can no longer be governed by the ideational rule of transparent self-identity. To word it somewhat differently: Both in the case of translation and in the case of sex the unruly material entanglement of signifiers and of bodies, which the expression "coming undone" gestures toward, reveals how a language or a subjectivity's ideational existence as discrete and separate entities is a provisional fiction that requires a constant, and always retroactive, policing of boundaries 
to be kept in place. What Nathanaël draws attention to, then, is the unaccounted costs of such policing: that is, the disintegration and ghosting out of the embodied dimension of the translative/sexual encounter itself.

We are faced here with a truly intractable problem. Any rigorous reckoning with the intensity of the linguistic-corporeal entanglements at work in the scene of translation (aka, the fuck) will require something other than an approach based on analytic parsing, wherein one is methodologically compelled to sever such entanglements in order to rebuild retroactively two well-bounded and self-sufficient objects of textual analysis (aren't we always cleaning up after the fuck, pretending we can go back to our undisheveled selves?). The problem is that, on some level, the reader always arrives on the scene of translation after its event: that is, after the linguistic bodies have apparently entered and exited their own material entanglements (i.e., the bed is empty ....). This makes it easy to attribute a methodological primacy to the disembodied gaze in the analytical reconstruction of the scene, while conveniently forgetting that such a gaze sustains a fantasy of mastery and representational normativity that is not only at odds with the dynamic intermingling of the textual bodies themselves, but also belies a profound anxiety about such intermingling's ungovernable effects. "Our (human) fixation on limits, borders, boundaries, confines, must surely be embedded in a profound anxiety as to the impossibility of such," writes Nathanaël in The Middle Notebooks (2015b: 345). No kidding. Anxiety, queer theorist Eve Sedgwick tells us (by way of Melanie Klein), might be the least educable and governable of affects, hence its frequent subjection to repression and splitting (2003: 123-152).

There might, however, be another way to go about the scene of translation, one that does not privilege the (invisibly anxious) pornographic paradigm of the disembodied gaze, the limitations of which I already exposed earlier. Lauren Berlant-possibly the one queer theorist who most effectively deploys the notion of scene as a privileged methodological locus for staking out the sexual as affective intensification on the edge of corporeal becoming-defines scene as a "setting for action, a discontinuous space that appears navigable for moving around awkwardly, ambivalently, and incoherently, while making heuristic sense of what's becoming event" (2014: 99-100). Notice Berlant's emphasis on the scene as a "navigable" space, that is, less as a stage to be visually apprehended as a whole from its outside than as a space to be traversed. This is not a scene governed exclusively by the sense of sight, its sensorium being far more diffused. The salient features of Berlant's scene are neither photographic (the scene does not capture a suspended moment of action) nor theatrical (the scene is not a stage). What characterizes Berlant's description is an emphasis on the scene's spatial discontinuity and on the tentativeness of the body "moving around" within it. Furthermore, the scene's operational features are always already becoming, they are at work within the scene. The moving body is part and parcel of the 


\section{Elena Basile}

scene's composition, and as such it is constantly pushing at the boundaries and frames that reveal it as a "setting for actions" on the brink of "becoming event."

So what if instead of constructing the scene of translation retroactively and at a remove, the reader-critic acknowledges the ongoing effects of her fumbling into it? What if, returning to Spivak's suggestion that translation may be "the most intimate act of reading," we accept the challenge of entering such a scene without knowing the whole of it, the challenge being to become part of its doing, knowing that we'll be caught with our pants down sooner or later? If we are to pant hard enough after a scene, we might want to acknowledge that the scene is neither stable nor given once and for all: foreground, background, what is visible of it, what is not, its protagonists-all of this keeps shifting. If we want to pay rigorous attention to such shifting (without jumping onto facile conclusions of universal sexual fluidity or infinite textual creativity in translation), we might want to practice attunement to the modulations of expanded sensorium (perceptive, affective, cognitive) activated by the textual encounter, rather than anxiously go about retroactively (re)constructing exact boundaries and orientations for the textual objects under scrutiny.

My suggestion that we engage in practices of expanded sensory attunement in translation partially converges with Sathya Rao's proposal of an "erotics of translating" ("une érotique du traduire") that will "take into account the diversity of relational positions (touch, caress), which translation is capable of," and "deploy the translative body in the plurality of its perceptual dimensions (carnal, sensual, intellectual, intuititve, etc." (2005: n.p.). ${ }^{5}$ It departs from Rao, however, insofar as it warns against delimiting in advance the range of such relational positions, and asks that we exercise patient vigilance toward the unexpected reverberations of their entangling effects. The quasi-synonymity of Rao's very short list-touch and caress-, while significantly highlighting an idealized ethical orientation toward non-appropriative otherness, also tellingly leaves out the non-relational paroxysms which inevitably pulse through the sexual/linguistic encounter. ${ }^{6}$

If the scene of translation, once entered, has this powerful ability to turn (back) on us, exposing - if we want to be Lacanian about it-the constitutive lack shaping our desiring selves, what it does is also to puncture the fantasy of mastery that informs whatever methodological claim we have to its analysis. If there is something that queer theory's sustained attention to the vagaries of affect and desire can contribute to current tensions around the disciplinary delimitations of translation studies, ${ }^{7}$ it is the constant and nagging reminder not only of the inevitable partiality of any critical endeavor but also of the way in which that partiality assembles into analytical statements by way of disavowed attachments always on the brink of being exposed.

What I am suggesting here is that there may be another way to go at the problem of the scene of translation without falling back into tired dichotomies of source-target texts that too closely mimic subject-object dichotomies 
(these latter closely associated in turn with fairly exhausted gender binaries). I am suggesting that the "coming undone" of the scene of translation gestures toward ongoing entanglements of corporeal and linguistic materialities that require a kind of attention that proceeds more by way of attunement than (anxious) analytic parsing. By attunement I mean an approach that pays attention to how the movement of texts and their scenes-in the sense articulated by Berlant-modulates the reader's affective sensorium so as to tease out what Spivak calls "the risky ... frayages or facilitations," which take place in translation when the "selvedges of the language-textile give way" (1993: 180). The cost of forcibly cutting through any living entanglement of languages and bodies is a ghosting out of the emerging form that such entanglement was producing in the first place. As I mentioned earlier, however, it may be next to impossible not to produce a ghosting out of some sort when analysis is at stake. Nathanaël's oeuvre has a lot to contribute toward figuring this problem, insofar as it offers a sustained exploration of the aporetic bindings one confronts when the intensity of linguistic-corporeal entanglements is fully attended to. Time to return then to the ghostly queer boy we've been panting after all along.

\section{A Name, On Hold}

A few years after the publication of Je Nathanaël, in 2009 to be precise, the name of the amiable queer boy became the name of the auteure herself. ${ }^{8}$ The shift to a proper name of masculine gender (crucially unaccompanied by patronym) might constitute at first sight the most obvious signal of the author's practice of a poetics in which a concern for trans-lation goes hand in hand with the corporeal question of trans-embodiment. We should be very wary, however, of conceiving such trans-embodiment in any linear temporal fashion, as a migration from one cohesive bodily form to another. Interestingly, the gender shift in authorial name has not been accompanied by a shift in the auteure's use of pronominal gender, de facto intensifying an ongoing inscription of gender indeterminacy, which has consistently characterized the auteure's work from their very first publications. ${ }^{9}$ Indeed, for many years Stephens described her poetics as a mode of "writing the entre-genre" in both English and French. ${ }^{10}$ The semantic condensation of both genre and gender available in the French noun "genre" gestures to a mode of writing that addresses itself to the interstitial moment where language-form (genre) and body-form (gender) enter a space of indeterminate reciprocal delimitation ... and disintegration. It is the maddening difficulty of fixing the boundaries of such delimiting movement without at the same time entering a state of necessary disintegration that has consistently formed the crux of Nathanaël's thinking for over 20 years. Her rigorous exploration of the "entre," or "in-between," of being (among languages, bodies, geographies) recursively engages the ontological slippages into not-being that necessarily take hold when one attempts to stay there: 


\section{Elena Basile}

"between as it occurs, and eludes me in my own work, entre-genre and entre-langues-between genders, genres, between languages-is a fluid, fluctuant, indeterminate place, a place in movement, always, and as such unlocatable, but relational" (Stephens 2008: 27). Nathanaël's careful tracing of such relationality through a close engagement with a philosophical and literary corpus primarily (though not exclusively) wrought from twentieth-century European thought preoccupied with alterity, dissemination and writing the body ${ }^{11}$ has increasingly lead her to think through the ontological uncertainties attendant to the intense entanglements that traverse the (moving) scene of translation. Her thinking keeps traveling across multiple disciplinary (architectural, visual, literary, philosophical, mathematical) and linguistic (French, English, German primarily, but also Spanish) terrains, excavating the impossible "ethics of touch" attendant to the translative gesture (Stephens 2008), ${ }^{12}$ and more recently engaging with the stilled temporalities of catastrophe theory, which eschew the linearities of before and after, and configure the problem of "failure" in translation as the problem of the seismic "fault" or "faille," in which translation manifests as "manifold dismantlings, disintegrations," which are rarely, if ever, "spoken or fretted over" (Nathanaël 2012: 27).

I want to highlight here how Nathanaël's emphasis on dismantlings and disintegrations makes visible the other side of the corporeal-linguistic entanglements I have focused on throughout this chapter. This other side is the constant possibility of unraveling that lurks behind the intimate "fuck" of translation and its seductive promise of absolute presence and reciprocity (otherwise fetishized as equivalence). In the crossing, dismantling, and reworking of boundaries that animates the scene of translation, we are insistently reminded that the passage "always threatens to dissolve what passes" (Stephens 2008: 19), be that a language, a body, an I. In closing, it may be timely to remind the reader that the "threat of dissolution" carried by the movement of translation is never far removed from the threat of the "dissolute," and the moralized sexual excess it implies. We should notice, in other words, the profound solidarity of the attributes of spectrality and queerness that animate Nathanaël (both the authorial persona and the phantasmatic object of textual desire), and lend the proper name a quality of untranslatable singularity without which a practice of attunement to the expanded sensory modulations of the translative encounter may be impossible to conceive:

The name . . . is what remains of us: remains. And in the body's emergence from itself, the spill of what is otherwise contained, in the viscous pore (pour) of language, languages, we translate. We re-form ... ulate the body's own plural text; we submit to (its) disintegration, we want the thing that is unavailable to us, the thing that language does not hold; the part that is body, in and outside of text that multiplies, enfolds.

(Stephens 2008: 30) 


\section{Acknowledgments}

I would like to thank Heather Milne, Chiara Montini, and Trish Salah for their insightful comments on earlier versions of this chapter, and this volume's editors, Klaus Kaindl and Brian James Baer, for their patience and careful editorial work. I am particularly grateful to Nathanaël for their generosity in answering my frequent queries, and for engaging in a sustained email conversation with me about their evolving poetics-focused, among other things, on sidestepping the politics of languaged (dis)embodiment, which translation inevitably veils while at the same time brings to the fore.

\section{Notes}

1 The most authoritative critical account of the history of sexual metaphors in translation theory remains Lori Chamberlain's widely anthologized "Gender and the Metaphorics of Translation" (1988). Although Chamberlain centers gender rather than sexuality in her historical analysis, the great majority of her quotations (from the Earl of Roscommon to Franklin, to Steiner, to Derrida) involve some degree of analogizing between the act of translation and heterosexual intercourse.

2 I mean pornographic here insofar as the scene (whether described or imagined) is first and foremost given to us to see, so it can act "directly on the senses," which, Deleuze argues, is the goal of pornography (1991: 17), otherwise widely understood as a "body genre" (Williams 1991, 2008).

3 English here symptomatically allows my argument to hover between the aggressive and the sexual connotations of "turning on," as in both "turning against" (something) and "triggering sexual excitement."

4 A text can of course become "fuckable" in any one language, provided one attends to the specific denotative/connotative trajectories of the specific language one is working toward. In Asclepias: The Milkweeds-a recently published collection of talks-Nathanaël highlights her acute awareness of such a possibility in her extended footnote on the difficulties of rendering the full denotative and connotative valences of the French "enculer" ("to fuck in the ass") (2015a: 62). Indeed, vulgar and sexualized expressions encounter in translation the same problems as any other idiomatic expression, problems that attend to the denotative and connotative shifts that accompany their passage into an altogether different network of signs. This observation, however, does not impinge on what I am trying to highlight here, which is the value of thinking about the embodied dynamics of the translative encounter through the insights queer theory has to offer into the dynamics of the sexual encounter.

5 "Il s'agirait d'envisager la diversité des positions relationelles (toucher, caresse) dont est capable la traduction .... . [et de] déployer [le] corps traductif dans la pluralité de ses dimensions sensibles (charnelle, sensuelle, intellectuelle, intuitive, etc.)." (French in original, my translation).

6 It is the negative work of these paroxysms that some recent queer theory asks us to pay attention to and remain patiently vigilant about. Lee Edelman and Lauren Berlant's entangled dialogue in Sex or the Unbearable is perhaps the most moving performance of such vigilance-their stubborn mis-readings of one another being as frequently underscored as the heightened reciprocity of the text's dialogic form. 


\section{Elena Basile}

7 Among the many instances of current intra-disciplinary tensions within a field, the 'trans-disciplinarity' of which cannot be fully embraced without risking the dispersal of a tenuously earned institutional legitimacy, is the strong polemic engaged in by Anthony Pym with what he identifies as the "anti-empiricism" of theorists as diverse as Mona Baker and Lawrence Venuti (Pym 2015).

8 "Auteure" is the French feminist neologism for "auteur," which takes advantage of the mute " $\mathrm{e}$ " to inscribe gender difference in authoriality. "Aut(eu)re" is how Nathanaël self-describes in her current website and blog Polysemique (http:// polysemique.blogspot.ca/p/auteure.html). Of note is the clever absenting of 'eu' in "aut(eu)re," which draws attention to the "autre" (other) in "auteure." I refer to the aut(eu)re as "she" in the rest of this chapter, keeping to the same gender pronouns used in the English version of the website.

9 Nathanaël is very clear about the political reductionisms that tend to take place when one gets embroiled in the language specifics of gender indeterminacy. In a recent email, in answer to my request for guidance regarding their pronoun preference, Nathanaël wrote: "I choose elle in French because it represents a grammatical (and other) disagreement with the masculine of the prénom . . . [However,] sometimes I find the excessive attention given to this problem [of gender pronouns] in English hides other problems which cannot easily be resolved at the level of syntax or otherwise ... I am not convinced the pronoun alone will resolve the discomfiture of bodies, in or out of desire" (Nathanaël, personal email communication, October 25, 2016).

10 This description can be found in almost all of the short bio-notes at the end of Stephens's early books (see for example Paper City, 2003, and Touch to Affliction, 2006) and is discussed at length in an interview with Elisabeth A. Tutschek (2010).

11 Walter Benjamin, Maurice Blanchot, Martin Buber, Jacques Derrida, Édouard Glissant, Ingeborg Bachmann and André Gide are some of the philosophers and writers Nathanaël constantly returns to and draws upon in her writing, weaving frequently in and out of different translations of their oeuvres (sometimes triangulating between French, English and German) without ever privileging any one "original" version. A whole set of parallel considerations would apply to Nathanaël's equally strong engagement with European twentieth-century visual art, photography and architectural thought (Claude Cahun and Paul Virilio being among the most prominent authors she deals with). I hope, eventually, to be able to write an essay specifically dedicated to this particular aspect of their work.

12 Impossible insofar as the gesture itself is always wrought of a desire "indistinguishable from the loss from which it arises" (Stephens 2008: 23).

\section{References}

\section{Primary Sources}

Stephens, Nathalie. 2003. Je Nathanaël. Montréal: L'Hexagone. Stephens, Nathalie. 2006. Je Nathanaël. Toronto: Book Thug.

\section{Secondary Sources}

Berlant, Lauren and Lee Edelman. 2014. Sex, or the Unbearable. Durham, NC and London: Duke University Press. 
Bersani, Leo and Adam Phillips. 2008. Intimacies. Chicago and London: University of Chicago Press.

Chamberlain, Lori. 1988. "Gender and the Metaphorics of Translation." Signs 13(3): 454-472.

Deleuze, Gilles. 1991. “Coldness and Cruelty.” In Masochism, 9-138. New York: Zone Books.

Edelman, Lee. 2004. No Future: Queer Theory and the Death Drive. Durham, NC and London: Duke University Press.

Nathanaël. 2012. Sisyphus Outdone: Theatres of the Catastrophal. New York: Nightboat Books.

Nathanaël. 2015a. Asclepias: The Milkweeds. New York: Nightboat Books.

Nathanaël. 2015b. The Middle Notebooks. New York: Nightboat Books.

Nathanaël. "Polysémique: We Walk But These Are Scarcely Surfaces. On marche, mais à peine sur des surfaces.” Available online at http://polysemique.blogspot.ca/ (last accessed January 15, 2017)

Pym, Anthony. 2015. “A Spirited Defense of a Certain Empiricism in Translation Studies (and in Anything Else Concerning the Study of Cultures)." Version 4.1, April 15, 2015. Available online at http://usuaris.tinet.cat/apym/on-line/research_ methods/2015_empiricism.pdf (last accessed October 19, 2016).

Rao, Sathya. 2005. "Peut-on envisager l'avenir de la traduction sans plaisir? Pour une érotique du traduire." Meta 50(4): n.p. Available online at http://id.erudit.org/ iderudit/019855ar (last accessed October 30, 2016).

Sedgwick, Eve Kosofsky. 2003. Touching Feeling: Affect, Pedagogy, Performativity. Durham, NC and London: Duke University Press.

Spivak, Gayatri Chakravorty. 1993. Outside in the Teaching Machine. New York and London: Routledge.

Stephens, Nathalie. 2003. Je Nathanaël. Montréal: Éditions de l'Héxagone.

Stephens, Nathalie. 2006. Je Nathanaël. Toronto: BookThug.

Stephens, Nathalie. 2008. At Alberta. Toronto: BookThug.

Tutschek, Elisabeth A. 2010. "Canadian Literature of the New Millennium: An Interview with entre-genre Writer Nathalie Stephens." Zeitschrift für Kanada-Studien 30(1): 140-145.

Williams, Linda. 1991. "Film Bodies: Gender, Genre and Excess.” Film Quarterly 44(4): 2-13.

Williams, Linda. 2008. Screening Sex. Durham, NC and London: Duke University Press. 


\title{
3 Beyond Either/Or \\ Confronting the Fact of Translation in Global Sexuality Studies
}

\author{
Brian James Baer
}

No human society is a tabula rasa. The universal concepts of political modernity encounter pre-existing concepts, categories, institutions, and practices through which they get translated and configured differently.

(Chakrabarty 2007: xii)

In his book the Globalization of Sex, Jon Binnie levels some very pointed criticism at Dennis Altman's The Global Gay, arguing that Altman presents the adoption of the dominant Western model of homosexuality in other parts of the world as a kind of "false consciousness," casting those non-Western peoples as passive victims of US cultural and economic imperialism. This reflects a broad tendency in postcolonial studies, Binnie asserts, whereby "subalternity tends to get translated into passivity and victimhood" (2004: 71). Binnie calls for an approach to global sexuality studies that acknowledges the "allure" of that lifestyle for many queer individuals across the globe while also crediting those individuals with agency and subjectivity in "deploying and re-working symbols and images associated with the global gay to help fight their own struggles for self-determination, rights and resistance to violence and the production of spaces and territories" (2004: 68), producing not a copy of an original but a thoroughly "glocalized gay subject" (2004: 60).

Although Binnie repeatedly invokes the metaphor of translation, as evident in the aforementioned citations, he makes only three brief mentions in the book of the fact that the subjects of much of the research in global sexuality studies may not speak English or may not speak English fluently, something that must be taken into account in any discussion of the agency of subaltern subjects. The first rather cursory mention occurs in Chapter 3 in a section entitled "Globalization and Queer Communities," where Binnie seeks to qualify the celebration of "the utopian possibilities of queer cyberspaces" (2004: 46) by raising the question of language. As Binnie notes, "There is linguistic hegemony within cyberspace and queer online communities clearly reflect this. The ability to speak English is a precursor or given within many online communities and thus renders these spaces exclusive" 
(2004: 46), a nod not only to all those left out of queer cyberspaces but also to those forced to navigate those spaces in a non-native language. The second mention of language occurs in a section on AIDS and queer diaspora, in a heart-wrenching quotation from P. Well's The Duration of a Kiss (1995), where Wells attempts to describe the experience of illness for an immigrant with limited English:

To be ill in a foreign country was simply to experience in advance the reality of all illness, which is to be homeless. It was to be in a permanent foreign land-one where the language used is barely comprehensible, or at least where words seem to match, only clumsily, what they represent.

(qtd. in Binnie 2004: 112)

The third mention of language mediation occurs in Chapter 6 "On Queer Mobility and the Politics of Migration and Tourism" in reference to a study of lesbian migrants to the United States by Oliva Espin, entitled Women Crossing Boundaries: A Psychology of Immigration and Transformations of Sexuality (1999). Paraphrasing Espin, Binnie writes,

Significantly some respondents felt more comfortable discussing transformations in sexuality in English rather than Spanish, Dutch or German. [. . .] Espin observed that while the women she interviewed said they were more comfortable discussing their new sexual identity in English, they often resorted to their first language in sexual scenes.

(2004: 94; italics added)

While Espin—and Binnie-acknowledge these language preferences as "significant," they seem at a loss to explain what they mean or how they might influence data collection, suggesting only that "it may be easier to come out or explore one's sexuality in a foreign language, noting that the 'exclusive preference of one language over another may compartmentalize the contradictions inherent in being an immigrant' " (qtd. in Binnie 2004: 94). In her interpretation of code-switching as an act of compartmentalization, Espin invokes a traditional discourse on bilingualism that sees it as a defect, in this case, a symptom of trauma, rather than as a set of linguistic resources enabling the creative expression of agency and identity (and, perhaps, too, an implicit act of resistance against the monopolization of sexual discourse by English).

Binnie's lack of attention to language and specifically to the fact of translation is all the more surprising as such attention would have supported his critique of Michael Warner's (1993) assertion that queers have no homeland, a view described by Bob Cant who states, "Lesbians and gay men differ from other groups of migrants in that there is no homeland that can validate our group identity" (1997: 1). Such claims are based on 
the assumption that discrimination leads queer individuals to disassociate themselves entirely from their country of birth. This position has not gone unchallenged. Seidfeld, for example, rejects this argument categorially, noting,

For lesbians and gay men the diasporic sense of separation and loss, so far from affording a principle of coherence for our subcultures, may actually attach to aspects of the (heterosexual) culture of our childhood, where we are no longer "at home." Instead of dispersing, we assemble.

(qtd. in Binnie 2004: 82)

Cruz-Malavé and Manalansan make a similar point, arguing that the position

occupied by queer sexualities and cultures in our globalized world as a mediating figure between nation and diaspora, home and the state, the local and the global [...] has not only been a site of dispossession, it has also been a creative site for queer agency and empowerment.

(Cruz-Malavé and Manalansan 2002: 1-2)

Nevertheless, language as perhaps the most powerful and enduring source of attachment to the culture of one's childhood and translation as a highly "creative site for queer agency and empowerment" remain largely ignored by researchers in the social sciences.

An exception is Richard Mole's recent ethnographic study of Russian-speaking queer migrants in Berlin, which shows that one's native language is in fact an enduring attachment and plays a significant role in the process of "assembling"-for many immigrants, it is "home." ${ }^{1}$ Whether for the sake of expediency or for a wider readership or because an instrumentalist view of translation has been institutionalized in the social sciences, ${ }^{2}$ inattention on the part of Anglophone scholars to questions of language and languaging remains the norm, lending tacit support to the assumption that today "everyone speaks English" and that one's affective connection to a native language and culture is simply lost or discarded in diaspora. For example, when James Allen makes the claim, "I often feel closer to a gay foreigner I've known for five minutes than to heterosexual relations I've known all my life," (qtd. in Binnie 2004: 37), it probably only holds true when this gay foreigner speaks English and speaks it well! And does that gay foreigner struggling to express himself in a foreign language feel the same closeness? One has to wonder.

Moreover, the fact of translation is material proof of the allure underscored by Binnie and testifies to the mutual interdependence of the local and the global. Indeed, perhaps nowhere is the deployment and reworking of symbols and images from the West more evident than in translations, especially when we insist on seeing translation not as a mere reflection of 
the original but rather "as part of a dynamic process of negotiating foreign and local values" and, as such, a "creative and authentic activity" (Cho 2016: ix). In this way, attention to language and to translation in particular can perform an important role in qualifying and questioning the diffusion of global (Western) models, a point made by Dipesh Chakrabarty in the preface to the 2007 edition of his Provincializing Europe:

Nothing concrete and particular could ever be the universal itself, for intertwined with the sound-value or a word like "right" or "democracy" were concept-images that, while (roughly) translatable from one place to another, also contained elements that defied translation. Such defiance of translation was, of course part of the everyday process of translation.

(2007: xiii-xiv)

In what follows, Chakrabarty, "demonstrates with historical examples how modernity was a historical process that involved not just transformation of institutions but categorical and practical translation as well" (2007: xv).

Binnie is not unaware of this problem, however, and suggests at least one reason for this inattention to language, which involves, among other things, rendering acts of translation invisible: the demands of Anglophone publishers:

In the invitation I received to submit the proposal for this book, the two major concerns of Robert Rojek, my commissioning editor at Sage, were that it "must be written for an interdisciplinary market," and that it must appeal to an English-speaking global audience-that is, the book "must mean something to people in Milwaukee, Manchester, Melbourne and all points in between." Obviously the English language is itself a key factor in globalization, and this book reproduces this linguistic hegemony.

Caught between the pressure to appeal to the widest possible Englishspeaking audience, which promotes readable or invisible translations, on the one hand, and the continued disdain for translation emanating from academic departments of foreign languages, which promotes untranslatability (see Lennon 2010: 5), on the other, the fact of translation remains largely ignored in fields across the humanities and social sciences. Empirical evidence of this phenomenon in the field of ethnography was provided by the US-based sociologists Erynne de Casanova and Tamara Moss in a recently published study of 47 ethnographies, which found that, despite the popularity of the metaphor of anthropology as cultural translation, "most ethnographic writing makes actual inter-linguistic translation-the focus of 


\section{Brian James Baer}

this article-invisible" (2017: 2). This lack of linguistic reflexivity is especially troubling in the social sciences where "linguistic difference is seen as a meaningful basis for people's status, and is associated with socioeconomic, religious, ethnic, and national group membership" (de Casanova and Moss 2017: 2).

In what follows, using post-Soviet Russia as a case study, I will argue for greater attention to language and specifically to the fact of translation in the study of sexuality across cultures in order to provide some much-needed nuance to our discussions of sexuality, especially in regard to cultures outside the West/Global North, and to prevent academe's participation or collusion in the homogenization of cultures by glossing over linguistic difference. Specifically, I will examine Russians' engagement with the Western concepts of gay and queer, borrowed into Russian as gei and kvir, revealing translation to be not a site of passive appropriation or of unresolvable contradictions (see Schluter 2002) but rather as a site of complex negotiation, deployment, and reworking of Western symbols and images to suit the needs of a target readership. ${ }^{3}$ By focusing not only on what is lost but also on "what is brought to life through cultural permeability, exchange, influence or simple coexistence" (Kulpa et al. 2012: 116), translation can be seen as an expression of linguistic and political agency rather than an act of submission to the dominating Anglophone culture.

Although the usage of these terms varies in the Anglophone world, I will treat gay as indexing what Eve Kosofsky Sedgwick (1990) describes as the Western minoritarian model of homosexuality, according to which a certain discrete portion of the population identifies as homosexual and pursues rights and protections accordingly as a minority group, generating in the process a discrete and commodified subculture. I will treat queer as a Western post-structuralist critique of the minoritarian model along any number of vectors, as exclusionary, ahistorical, classist, etc. I will examine the deployment of these terms in two important media venues appealing to members of Russia's sexual minorities, the website gay.ru and the journal Kvir.

\section{The Discursive Landscape of Post-Soviet Russia}

Post-Soviet Russia offers an especially fruitful object for such a case study in that Soviet Russia maintained an almost total ban on any references to homosexuality. So with the collapse of communism and the subsequent loosening of censorship restrictions, the Russian book market was suddenly flooded with sexually explicit material both in Russian and in translation. Authors and translators of sexually explicit fiction faced a similar problem: the lack of a vocabulary suitable for public discussion of sex and sexuality, one that was perceived as neither moralizing nor obscene. As the author Elena Koliadina, whose novel Tsvetochnyi krest [A Cross of Flowers] became a success-de-scandale in post-Soviet Russia, due in part to its graphic sexual language, explains, "Contemporary Russian is, of course, lacking in terms of 'decent' conversation 'about that'-for historical reasons 
our sexual lexicon is truly crude, vulgar, or medical” (Koliadina 2011: 27).

The role of translation in the formation of a new public language of sex in Russia, therefore, cannot be underestimated. With the sudden lifting of censorship restrictions in late perestroika and early post-Soviet Russia, works on homosexuality, mostly translated from Western European languages, began to appear. These works, from various historical periods and cultural contexts, now appeared side by side, producing a kind of false synchrony. As Natalia Avtonomovna commented in regard to the "second coming" of Freud, which occurred in post-Soviet Russia after a hiatus of over 50 years, "Freud's second arrival on Russian cultural soil [. . .] corresponded with the opening of all previously closed floodgates, when Western culture of the past half century rained down on the Russian reader without any logic or chronology" (2000: 16; italics added). Moreover, the reliance on foreign borrowings made this new Russian language of sex especially vulnerable to the charge that it was alien, un-Russian. As Georgii Gachev explains,

In the Russian understanding of this word [sex], which was, incidentally, borrowed, unlike other borrowed words, of which there are many in the language, is very recent as it is not present in Dal's dictionary, which captured the state of the Russian language in the mid-nineteenth century. Evidently, the word sex only entered common parlance in the twentieth century-and only in educated circles. This explains why the word sex in Russian parlance has a host of valences and meanings that are different from those in the Romance languages, where sex is a household word, or even in the German-speaking countries, where it entered common parlance earlier and where the range of associations connected with it is wider thanks to the work of Sigmund Freud, who quickly acquired broad popularity and entered into the daily life and lexicon of even the lowest classes of Western society.

The perception of this new sexual discourse as a hostile invasion from the West, reinforced by association with the AIDS crisis, grew increasingly strident as Russia's "transition" to Western-style capitalist democracy went south in the late nineteen nineties, leading to a return to authoritarianism under Putin and Medvedev, and lending an unavoidable political resonance to many translation choices.

\section{The Rise of Gei}

The crucial role played by translation in the acquisition of new terms and concepts is perhaps nowhere more evident than in the spread of the English borrowing "gei," which by the mid-1990s had already crowded out native Russian terms, such as "goluboi." That it was used to index a minoritarian model of homosexuality is supported by the proliferation 
of terms related to an institutionalized gay subculture, such as гей-драма, гей-ковбой, гей-брак, гей-пара, гей-отель, гей-свадьба, гей-клуб, гей-спорт, гей-парад, гей-собор, and гей-бар [gay drama, gay cowboy, gay marriage, gay couple, gay hotel, gay wedding, gay club, gay sports, gay parade, gay gathering, and gay bar].

But while the ascendancy of "gei" attests to the undeniable influence of Anglophone culture in contemporary Russia, and of the minoritarian model of gay identity, in particular, the meaning of this phenomenon is highly ambivalent as evidenced by the fact that the term gei can now be seen not only in gay-friendly publications but also in anti-gay publications, such as the many works of popular psychology, which are almost invariably aimed at a non-gay audience (see Baer 2015). Consider this passage from the introduction of a work entitled Gei i lesbianki [Gays and Lesbians] by one of Russia's leading pop psychologists Dilia Enikeeva, where the use of gei has a distinctly negative, if not threatening, ring to it:

This book is for parents. If you don't want your son to become gay [gei] (or your daughter to become a lesbian), you must read it.

This book is for young women. If you don't want to cry bitter tears when you hear your beloved's confession, "My dear, I'm gay [gei]," then you need to be armed [vo vseoruzhii].

This book is for young men and adolescent boys so that they know the means used by gays [gei] and lesbians to seduce straights.

This book is for journalists (including those who unwittingly or no propagandize same-sex relations, never thinking of the possible consequences).

This book is for anyone who is alarmed at the ever growing number of adherents of same-sex relations because they are entering the ranks of our youth.

This book is for gays [gei] and lesbians, so that they make the corresponding conclusions from reading it.

Enikeeva also includes a chapter in the book entitled "Gei-ubitsy," or gay murderers.

This negative use of gei underscores the argument made by Jarrod Hayes (2000) that the Western minoritarian model of homosexuality is imported along with attendant forms of homophobia. This is something alluded to by Lena, a Russian lesbian interviewed by the American journalist David Tuller in late Soviet Russia, who said,

I don't want to fight for the rights of lesbians-they never repressed lesbians here because no one ever knew that they existed .... No, the problems for lesbians only start when they fight for their rights. Because no the Russian public knows the work. They know that lesbians exist. 
Moreover, the minoritarian model of homosexuality may inspire especially virulent forms of homophobia in more collectivist cultures, such as Russia, or in cultures with a more universalist conception of citizenship, such as France (see Fassin 2001), than in its place of origin, the Anglophone West, where a minoritarian, civil rights model is mainstream and so is less likely to be seen as an assault on the body politic. Moreover, its association with the Anglophone West, and the United States in particular, makes it an easy target of anti-American sentiment. Therefore, it is important to resist the temptation to assign the fact of translation a simple meaning; its meaning must be situated in the shifting discursive landscape of the receiving culture, shaped as it is by the dynamic relationship between source and target cultures. Moreover, as Altman, to his credit, points out, the use of terminology to describe (homo)sexuality in different cultures is not consistent, much of it is borrowed from the West and is often used "to describe a rather different reality" (1997: 419). Close attention to acts of translation, therefore, complicates the simple internationalization of lesbian and gay studies that "would reinforce the collusion of a mainstream Western-oriented lesbian/gay studies with the dominance of a US/Western style of sexual politics" (Puri 2002: 439).

Russia's culture-specific engagement with the Western minoritarian model of homosexuality, as designated by the term gei, is also evident on the site gay.ru, which describes itself as Russia's "national server." Indeed, the title of the site itself, gay.ru, suggests that it reflects the triumph of the Western borrowing gei in Russia's evolving discourse on sex and sexuality. Moreover, of the 658 works of poetry and prose, including biographies, for sale on the site in December of 2015,386 , or $59 \%$, were translations, and of those 386 translations, 232, or $60 \%$, were from English. ${ }^{4}$ It was difficult to make an exact comparison with a US vendor, as the inventory is too enormous to analyze. For example, a search under "gay and lesbian" on the Barnesandnoble.com produced over 21,000 hits. Nevertheless, an examination of the first 100 titles revealed not a single translated work. While at first glance, these figures might confirm Casanova's (2004) distinction between dominated and dominating languages and Russia's dependence on the Anglophone West, delving deeper into the fact of translation suggests that Russia is by no means a passive consumer of global gay culture.

While English was, not surprisingly, the most popular source language on gay.ru, there were translations from ten other languages, as well, from across Europe. The breakdown by language is provided below with the ranking indicated in square brackets:

- Czech: 5 [7]

- Dutch: 12 [4]

- English: 232 [1]

- French: 70 [2]

- German: 14 [3] 
- Hebrew: 1 [8]

- Hungarian: 1 [8]

- Japanese: 8 [5]

- Latin: $1[8]$

- Spanish: 8 [5]

- Swedish: 6 [6]

While the title of the website appears to acknowledge the minoritarian model of homosexuality, a closer examination of the book titles reveals a very loose definition of "gay" literature. The inclusion of works that are in no way gay-themed, such as Henry Miller's Sexus and Plexus, or Phillip Roth's Portnoy's Complaint, suggests the website's purpose goes far beyond a minoritarian agenda, seeking instead to promote open depictions of sexuality and sexual freedom that would "float all boats," so to speak.

Moreover, these statistics may also be interpreted in such a way as to challenge the traditional association of speakers of a "dominated language" with a lack of agency, presenting them as passive victims of Western cultural imperialism. Doesn't the fact that Russian readers have access to works from eleven different languages suggest a certain cosmopolitanism, just as the absence of translations, hence, of non-Anglo perspectives, available to English readers might suggest the opposite, a cultural insularity or provincialism? As Chad W. Post, director of the Three Percent website, notes,

Horace Engdahl, the secretary of the Swedish Academy (responsible for awarding the Nobel Prize in Literature), [. . . ] stated that the U.S. was "too insular and ignorant to challenge Europe as the center of the literary world," and due in part to the paucity of translated works available, doesn't really "participate in the big dialogue of literature."

When analyzed in terms of prose and poetry, the results from gay.ru are even more surprising. The percentage of translated works among the prose offerings is $62 \%$, while of the 55 works of poetry available for purchase on the gay.ru site, only eight, or $15 \%$ are translations; 47 , or $85 \%$, are original Russian works. The ranking of the source languages also shifts in the corpus of poetry translations: French is the most popular source language (4), followed by English (2), and then Dutch (1) and Latin (1). This would appear to confirm the enduring preference for poetry in Russian erotic culture, dating back to the eighteenth century (see Baer 2006), as well as the converse-the primacy of prose, and specifically of the coming-out narrative, in the dominant Anglophone model of homosexuality, which enfolds within it a Western triumphalist reading of history. As Binnie writes, "Narrative around the centrality of coming out and the closet are based on the idea that gay liberation is the highest form of modernity and progress" 
(2004: 80). Moreover, that narrative form, Binnie notes, dependent as it is on the Western concept of the closet, "may not be the most relevant theoretical framework for examining dissident sexualities" in other parts of the world (2004: 79). In fact, this culture-specific narrative, a subgenre of the Bildungsroman, is largely rejected by contemporary Russian queer writers, as Zhenia Bershtein explains,

Rooted in the rationalist Enlightenment tradition, the Bildungsroman follows the individual's search for a place in a community. It is within the community that the stasis is reached. The opposite is true of the fragment, for which the isolation from the surrounding world is a crucial characteristic.

Russian queer writers, Bershtein argues, prefer the latter, which jibes with Russians' marked preference for erotic poetry.

Unpacking the fact of translation, then, is important in challenging the association of translation with cultural imperialism, an association that invariably casts translation as a symptom of passivity and victimhood.

\section{Resisting Gay Culture in Kvir}

The provocatively named Russian journal Kvir was founded in 2005. I say provocatively, because kvir was not a widely used term in Russia at the time of the journal's founding, largely eclipsed by the other English borrowing gei..$^{5}$ In fact, the journal often describes itself as "edinstvennyi gei-zhurnal v Rossii," or "the only gay journal in Russia" (P'er i Zhil' 2007: 16; italics added). The general reluctance of Russians to adopt the term kvir as a way to organize their rather culture-specific critique of "gay" culture led to the 2010 volume Is "Queer" Possible in Russian [Vozmozhen li "kvir" po-russki?], edited by D. Sozaev and self-published by the LGBT organization Vykhod (Out) in a circulation of 2000. In the introduction, Sozaev notes Russia's ambivalence toward this Western borrowing: "To what extent can queer methodologies be applied to Russian reality? Isn't it just another trendy epistemological import? Is queer possible in Russian? These are complex and multivalent questions that do not presuppose simple and straightforward answers" (Sozaev 2010: 6).

The ambivalence in the Russian reception of queer theory is perhaps nowhere more evident that in the Russian journal that bears the title Kvir, for despite the title, the word kvir is rarely used on its pages. Almost all mentions of kvir reference the journal itself. Gei is by far the most popular term used in reference to homosexuality. And the glossy photos of scantily clad or entirely naked male models, which are the journal's trademark, clearly index the kind of gay consumer culture described by Altman in Global Sex. 
A closer look at the translations published in the journal, however, reveals a more complex picture. But before I discuss those translations, let me say a few words about methodology. Because the journal is a hybrid amalgam of local and global cultural references, it is often difficult to ascertain whether something is a translation or not. As is typical with translation in the news media, stories in the target language are often composed of several source language texts, so that there is not a single original. Moreover, many of the authors in this journal assume pen names, some written in Cyrillic letters, such as Lilia Marlen [Lili Marleen], Roma mednyi vek [Roma Bronze Age] and Nespiashchii v Seule [Sleepless in Seoul], and others in Latin letters, such as Notlover, zasa_da, Ake Gaviar, KILLERBEAR, Denza M, and Damir K. In addition, some foreign names are rendered in Cyrillic letters, while other contributors mix Cyrillic and Latin scripts, such as Даниил Goodwin, all of which reflects, perhaps, a desire to blur, or queer, the boundaries between the foreign and the domestic, the local, and the global. In any case, I will examine only those texts marked either overtly or covertly as translations. By covertly, I am referring mostly to interviews with foreign cultural figures who do not know Russian. Although not marked as translations, these interviews were undoubtedly conducted in the foreign language and subsequently translated into Russian, most probably by the journalist who conducted them. This is clearly the case with the interviews with the French writers Pierre Guyotat and Éric Jourdan conducted by Marusia Klimova, a Russian writer with a degree in French language and literature who has published translations of French literary works. Moreover, because only the translations of these interviews have been published, I was unable to compare the source and target texts to determine what shifts were made by the translator, so I will refer to these texts as the creation of the author/translator. Articles taken from German (Stern and M-Männer) British (Guardian) and US (The Guide) newspapers and journals were also clearly translated, for while they were not always indicated as such, the source publication was listed. All of the other translations that were analyzed were overtly marked as translations, with the name of the translator provided, typically at the end of the piece.

The three text types translated in the journal—foreign literary works, articles from the foreign press, and interviews with foreign cultural figures-suggest a complex relationship to minoritarian gay culture. For example, of the translated literary works published in Kvir, all of which were overtly marked as translations, fewer than half were written by openly gay authors (Gerard Reve, Stephen Fry, and David Sedaris). The other authors included the Italian writer Pasquale Ferro, the American writer James Purdy, and two anonymously authored Chinese texts.

The articles translated from the foreign press basically fall into two categories-those celebrating gay minoritarian lifestyle, such as the extract from the memoir of the first openly gay mayor of Berlin, Klaus Wowereit (Voverait 2007: 20-21), and those highlighting gay-related social problems outside of Russia, such as the article about the rape of children by priests in 
Africa (Vize 2010: 20-21), from the German journal Stern. ${ }^{6}$ Other articles capture both sides of the story, such as the article about an Israeli gay youth who was beaten to death because of his sexual orientation. The empathy of the larger Israeli community to the murder so moved the Russian translator, she appended a note to her translation:

I completed the translation of the article an hour before we headed to the meeting with the LGBT community on Rabin Square. 70 thousand (!) people attended. The President of Israel, Shimon Perez, spoke as well as the minister of education, Gideon Saar, the mayor of Tel Aviv, and famous singers ... But the moving part was the speech of the hero of this article, Hena Langer, the instructor of the group Barnoar. He simply couldn't speak through his tears. This was very difficult to watch.

(Kost-Bar 2009: 23)

And so, while the article attests to the fact that homophobia exists everywhere, one can still make a distinction between societies that are more tolerant and supportive and those that are less so.

It is, however, in the interviews with foreigners, unmarked as translations, that the most complex negotiation of global and local identities is evident. Moreover, interviews are the most common type of translated text in the journal. In the time period under investigation, I located 20 interviews with foreign actors, photographers, writers, academics, and others, which reflect positions all across the spectrum between a solidly "gay" position, that is, one supporting a minoritarian, civil rights model of homosexuality, and a "queer" one-that is, critiquing the minoritarian model. Those interviewees who discuss homosexuality through a minoritarian, or gay, lens-all of whom are Anglophone-routinely invoke a developmental model that equates homosexual rights, achieved through political activism, with modernity, and promotes the "normalization" of same-sex desire.

Consider, for example, excerpts from the interviews with British author and actor Stephen Fry: "I would tell him that today in many countries same-sex love is considered normal. Although there remain, of course, still many places where the struggle for equal rights continues" (Frai 2009: 18). Elsewhere Fry notes that, "today in many countries same-sex love is considered normal" (Frai 2009: 18). The Brazilian-American fashion photographer Wander Aguiar also associates development with gay rights and visibility when he speaks positively of a gay subculture that is emerging in Brazil's large cities and mentions that the gay parade in Sao Paolo attracts thousands of people from across the continent (Agiar 2009: 33). The Chilean-born Swedish transsexual Amanda Lepore and the English photographer Anthony Gayton also draw a connection between development and the normalization of same-sex desire. Lepore notes, "In Chile where I was born and raised, society is still not as developed as it is here" (Lapor 2011: 36), while Gayton comments, "In many developed countries same sex relationships serve as a model of stability, love and caring" (Geiton 2011: 90-91). 
Similarly, British actor Mark Gatiss, in a letter to his younger self, assuages the fears and anxieties of that younger self with the assurance that things only get better, that England will develop out of what he call the Dark Ages of Thatcherism:

Dear I . . Y You're gay and you always knew it ... and if you can avoid a single day spent trying to deny the obvious, you'll feel great for having done it .... You don't know it but you're living in the Dark Ages. Everything will change for the better, and radically. One day all the members of your family will attend your wedding to your husband and will then say that it was one of the best days of their lives.

(Getiss 2011: 35)

British actor Rupert Graves also assumes a minoritarian model of homosexuality when, in recounting his own sexual past, he refers to gay and straight as exclusive sexual categories:

I've had same sex relations. I realized that I wasn't gay because the only way I could enjoy myself was to close my eyes and imagine I was with a woman. But I had to figure that out, to test it in practice. I was a closeted straight guy. I probably wanted to be gay because it is refined and interesting. And moreover, I was extremely shy with women.

(Greivz 2011: 35)

That being said, some of the Anglophone interviewees do express a certain ambivalence toward the minoritarian model and/or to the exporting of that model to other cultures. The openly gay filmmaker Tom Kalin, for example, chafes at being labeled a "gay filmmaker": "I don't consider myself a gay director. In Savage Grace there's a lot more heterosexuality than there is homosexuality, although people call it a gay film. I don't think so; for me it's a film about sexuality and power" (Kalin 2007: 37). And British filmmaker Ronald Peck, while acknowledging the importance of positive images of homosexuals in influencing public opinion and leading to greater tolerance, challenges the universal pretensions of the minoritarian model: "I had the impression that gay life in Moscow was taking its own course. That it was somewhere in the background. And that this was exactly where many people-including the gays themselves—wanted it to stay" (Pek 2010: 29).

Compare this to the comments of continental Europeans, whose deep ambivalence toward minoritarian "gay" culture and activist politics could be described as a total rejection. As the French-Algerian writer Pierre Guyotat states to Marusia Klimova,

I do not associate myself in any way with representatives of homosexual culture. Among the characters in my novel A Tomb for 500 Thousand Soldiers, there are a lot of women ... But even when I describe sexual relations between men-it a meaning completely different from purely 
homosexual relations. [...] So, I think that in my texts I am simply trying to get rid of the distinction between the sexes, to destroy the concept of the sexes as such.

(Giiota 2006: 25)

The French author Éric Jourdan, adopted son of the writer Julien Green, rejects the existence of a gay culture altogether:

I don't think anything about gay culture as I feel there is no such thing as gay culture; there's only culture. If you want to write something about gays, you have the right to do so, but the sexual orientation of a writer means absolutely nothing to me.

(Zhurden 2011: 17)

Michel Foucault's partner, sociologist Daniel Defert, expressed Foucault's resistance to the concept of gay on philosophical grounds:

Michel never even called himself a homosexual. He didn't like the word. He felt that it was wrong to assume identities that had been created on the basis of others' views and conjectures. The gay press often reproached him for this. But Foucault always answered: "If fishermen don't advertise on their bait exactly how they catch fish, then why should we constantly talk about how we screw?"

(Defer 2006: 17)

Foucault's position reflects a fundamental post-structuralist insight, namely that social identities both constitute the individual as subject while subjecting him or her to social strictures-which constructs "coming out" not as the liberation of an autonomous liberal subject but also as its subjection, or, to use Althusser's terms, interpolation. Like Foucault, the Belgian fashion designers Tom Notte and Bart Vandebosch, founders of the label Les Hommes, resist labeling themselves: "Our collections are the best answer to any question. In interviews we prefer to talk about our work and not about our private life" (Notte and Vandebos 2009: 19).

The insight that gay identity involves exclusions as well as inclusions is implied by Swedish transsexual Amanda Lapor in an interview entitled "The Labyrinth of Sexuality," where she points out that the gay subculture is not all-inclusive:

As far as I can remember, I was always a part of the gay subculture (gei-subkul'tura). But in fact, even though I was a part of it, I rarely felt I belonged. I mean that I didn't feel myself to be a gay man, do you understand? My perception of the gay scene was from the point of view of a girl. Gay guys didn't attract me at all in a sexual way. I felt I was a girl, who was attracted to straight guys. 


\section{Brian James Baer}

Others recognize the existence of a gay subculture but view it not as a positive sign of development. The German photographer Ulay, the pseudonym of Frank Uve Laysiepen, for example, sees the existence of a gay subculture as a symptom of Western plutocratic social formations: "In the US there is in general a strong tendency toward marginalization, and this is generally true in any westernized society with it plutocratic pressure" (2008: 68). ${ }^{7}$ The openly gay photographers Gilles and Pierre go further, hailing the birth of the "metrosexual" as the end of an exclusive gay subculture:

And there's a curious phenomenon in contemporary culturemetrosexuals. In France today there are a lot of metrosexuals who are not restricted by taboos. They take care of themselves, dress well, and are pretty open to homosexuality. They even want to try it, although at the same time they're a little afraid of it. This is the liberalism achieved after '68-it's an important and significant achievement.

(P'er i Zhil' 2007: 17)

So, in their view, the political activism of ' 68 liberated everyone from the strictures of exclusive gay and straight identities, allowing men to experience their sexuality in a more fluid way. In other words, the goal of liberation politics should be the end of gay, not its institutionalization as a tolerated minority.

In fact, several of the interviewees speak out against gay activism. As Gilles and Pierre note,

We don't need it [gay marriage]. We're good as we are. Among gays the hatred is often stronger than between gays and homophobes. And we were never revolutionaries, crusaders for gay rights—our works speak about homosexuality louder than any demonstrations could.

(P'er i Zhil' 2007: 17)

Michel Defert assumes a similar position when he condemns gay parades, stating,

I don't think that gay parades are such a good idea. Those who participate in them often behave precisely the way society expects them to behave. In short shorts with a rainbow flag and all the rest. In the end gay parades only strengthen these stereotypes in the minds of the general public.

(Defer 2006: 17)

The Italian writer Pasquale Ferro offers a more subtle rejection of collective activism by suggesting that everyone is responsible for oneself: "In Napoli, they say, 'The Lord helps those who help themselves.' [. . . ] Guys, I hope that you are not embittered by the wickedness that surrounds you" (Ferro 2009: 17). The solution here, Ferro suggests, is personal, not political. 
While the critique of minoritarian gay culture leveled by these Europeans could certainly be considered queer, the interviewees-and/or their translators-avoid the term, which might itself be considered a queer gesture-the refusal to label and in so doing to restrict, to exclude, to subject. And so it is interesting that the only interviewee to use the term "queer" is the American Yony Leyser, who made a documentary film about William Burroughs. In the course of the interview, Leyser makes a clear contrast between gay and queer cultures, coming down unequivocally on the side of queer:

Speaking about Burroughs, you have to remember that he wasn't gay. I don't know whether that makes sense to a Russian ear. In San Francisco, there are "mainstream" gays, but there is also an underground queer-movement: transvestites and so on. Queer means other, that is, people who come out against the dominant culture. I hate gay culture and I love queer culture. So people from the gay world have mixed feelings about Burroughs; they can't entirely understand him. [. . .] He doesn't fit into their culture. [. . .] I don't think he was ever considered a gay writer, he was never focused on that, and he didn't identify as a homosexual; he had a wife and child. [...]

(Leizer 2011: 16-17).

\section{Conclusion: What's in a Name?}

One might argue that the global appropriation of the English terms gay and queer represents the monopolization of sexual discourse by the Anglophone West. In other words, not only is the concept of a minoritarian identity indexed as Western, but so too is the critique of that identity, which compels us to pose the question "Can the queer subaltern speak?" What the preceding discussion suggests is that translation can be an important site from which non-Western queers can express themselves, a space "where subject positions may be tried out, contested, and in all kinds of other ways, negotiated" (Blackledge and Creese 2010: 4).

One of the effects of the translations appearing in the journal Kvir is, one could argue, to pluralize the West, complicating the universalist claims of the minoritarian model, essentially provincializing it, as Chakrabarty uses the term, and in so doing making it more difficult to situate Russia on the wrong side of the exclusive, hierarchical binary of "the West and the rest" (Hall 1992). In other words, it deconstructs the myth of a single, unified West, as well as the mutually defining opposition of Russia and the West, as the English filmmaker Ronald Peck suggests at the end of his visit to Moscow, "I have the impression that 'Western' and 'Russian' cultures are not so very different" (2010: 28). By using translations to essentially liberate the discursive field of this restrictive (Cold War?) opposition, Russian queers 


\section{Brian James Baer}

are able to construct new discursive positions from which they can express their ambivalence over the minoritarian model of homosexuality without being labeled either queer or "under-developed" while still entertaining the hope for greater tolerance of same-sex desire, and all the while expanding and refining their public language of sex. As such, the translation of foreign gay/queer texts appears not as a simple act of borrowing or appropriation from a dominating language by a dominated one but rather as a complex act of cultural negotiation, resistance, and world-making.

\section{Notes}

1 Taken from a lecture delivered by Mole at Kingston University on 6 February 2016 titled "Identity, Belonging and Solidarity among Russian-speaking Queer Migrants in Berlin."

2 Lawrence Venuti describes the instrumental model of translation as one in which "translation is seen as the reproduction or transfer of an invariant that is contained in or caused by the source text, whether its form, its meaning, or its effect. Hence either translation can be easily done or it can never be done: these versions are inversions of one another" (Venuti 2017: 6). Both versions of the instrumental model support the invisibility of translation in academic research: it is either so simple and straightforward as to be undeserving of attention or it is impossible and so should be ignored entirely in favor of the source text. The latter position continues to be that of many departments of foreign languages and literatures.

3 US anthropologist Daniel Schluter did fieldwork among Russian gays and lesbians in the 1990s, noting that, while Western reports on homosexuality in Russia in the early nineties "generally seem to support the notion that gay community institutions are forming, read closely and objectively, actually they show a very mixed record of results" (2002: 163). Schluter then concludes, "That contradiction in these reports is what is most accurate about them" (2002: 240). Those contradictions, Schluter implies, were caused by Western observers' tendency to see Russia through the lens of Western models and conceptions of homosexuality.

4 I eliminated the approximately 12 anthologies and collections from my corpus as it was often unclear whether they contained translations or not.

5 One of the rare exceptions can be found in the title of a 2011 article on the economist John Maynard Keynes: "Dzhon Keins: Kvir kak elita" [Queer as the Elite] (Karelin 2011/94: 26).

6 The spellings of names in the in-text citations to sources in the Russian journal Kvir may differ from the accepted spelling of those names in Roman script as the in-text citations represent the Library of Congress transliteration of the names as they appeared in Russian (Cyrillic).

7 The negative valence of the word marginalization is similarly reflected in the use of gay ghetto in the journal, despite the fact that there are no gay neighborhoods in Russian cities.

\section{References}

\section{Primary Sources}

Agiar, Uender [Wander Aguiar]. 2009. "Sneg, mekh i butylka vodka." Interview conducted by Sergei Pavlov. Kvir 74: 32-33. 
Defer, Daniel' [Daniel Defert]. 2006. “Frantsuzskii dedushka.” Interview conducted with Igor' Sadreev. Kvir 40: 16-17.

Enikeeva, Dilia. 2003. Gei i lesbianki [Gays and Lesbians]. Moscow: Astrel' and ACT.

Ferro, Paskuale [Pasquale Ferro]. 2009. "Pomogi sebe sam i Bog tebe pomozhet." Interview conducted by Vladimir Kursanov. Kvir 77: 16-17.

Frai, Stiven [Stephen Fry]. 2009. "I potriasaiushche provel vremia v Peterburge." Interview conducted by Viktoriia Degtiareva, Anna Smirnova (trans.). Kvir 75: 16-19.

Geiton, Entoni [Anthony Gayton]. 2011. "Entoni Geiton: Sviatoi greshnik.” Kvir 90-91: 22-23.

Getiss, Mark [Mark Gatiss]. 2011. “Mark Getiss: 'Eto mebe za Oskara Uail'da.'” Interview conducted by Viktoriia Detiareva. Kvir 93: 32-35.

Giiota, P'er [Pierre Guyotat]. 2006. “P'er Giiota.” Interview conducted by Marusia Klimova. Kvir 35: 24-25.

Greivz, Rupert [Rupert Graves]. 2011. "Pupert Greivz. I byl naturalom v chulane." Interview conducted by Viktoriia Degtiareva. Kvir 90-91: 32-35.

Kalin, Tom [Tom Kalin]. 2007. "Prestuplenie dolzhno byt' krasivym." Interview conducted with Dmitrii Volchek. Kvir 50: 36-39.

Karelin, Vladislav. 2011. "Dzhon Keins: Kvir kak elita" [Queer as the Elite]. Kvir 94: 26-29.

Koliadina, Elena. 2011. Interview. Kvir 95: 27.

Kost-Bar, Khen. 2009. "Byt' presleduemym.” Gai Gomel' (trans.). Kvir 74: 20-23.

Lapor, Amanda [Amanda Lepore]. 2011. "Labirinty seksual'nosti.” Interview conducted by Danila Beliaev. Kvir 94: 36-37.

Leizer, Ioni [Yony Leyser]. 2011. "Ia nenavizhu gei-kul'turu.” Interview conducted by Mikhail Agafonov. Kvir 95: 16-17.

Notte, Tom and Bart Vandebos [Tom Notte and Bart Vandebosch]. 2009. "Les Hommes. Nevinnaia krasota." Interview conducted by Kai Karenin. Kvir 71: 18-21.

Pek, Ron [Ron Peck]. 2010. "Polunochniki." Kvir 80: 26-29.

P'er i Zhil' [Pierre et Gilles]. 2007. "Nestareiushchie moriachki.” Interview conducted by Konstantin Andreev. Kvir 45: 16-17.

Ulay (pseudonym of Frank Uve Laysiepen). 2008. "Snimki shli po rukam." Interview conducted by Margarita Meklina. Kvir 62: 66-69.

Vize, Zenke. 2010. “Iznasilovania detei v tserkvi.” Kvir 80: 20-21.

Voverait, Klaus [Klaus Wowereit]. 2007. “. . . I eto tozhe khorosho,” Konstantin Kropotkin (trans.). Kvir 51: 20-21.

Zhurden, Erik [Eric Jourdan]. 2011. “Liubimye angely Erika Zhurdena.” Interview conducted with Marusia Klimova. Kvir 94: 16-19.

\section{Secondary Sources}

Altman, Dennis. 1997. “Global Gaze/Global Gays.” GLQ 3: 417-436.

Altman, Dennis. 2001. Global Sex. Chicago: University of Chicago Press.

Avtonomovna, Natalia. 2000. "Freid v Evrope i Rossii: paradoksy 'vtorogo prishstviia” [Freud in Europe and Russia: The Paradoxes of His 'Second Coming']. Voprosy Filosofii 9: 16. 


\section{Brian James Baer}

Baer, Brian James. 2006. "Russia." In Encyclopedia of Erotic Literature, edited by Gaetan Brulotte and John Phillips, 1141-1145. New York: Routledge.

Baer, Brian James. 2015. "Let's Talk About Sex: Mapping (Homo)Sexual Discourse in Post-Soviet Russia." In New Approaches to Gender and Queer Research in Slavonic Studies, edited by Dennis Scheller-Boltz, 173-184. Wiesbaden: Harrassowitz Verlag.

Baer, Brian James. 2016. Translation and the Making of Modern Russian Literature. New York and London: Bloomsbury Press.

Bershtein, Evgenii. 2011. "An Englishman in the Russian Bathhouse: Mikhail Kuzmin's Wings and the Russian Tradition of Homoerotic Writing." In The Many Facets of Mikhail Kuzmin: A Miscellany, edited by Lada Panova and Sarah Pratt, 75-87. Bloomington, IN: Slavica.

Binnie, Jon. 2004. The Globalization of Sex. London: Sage Publications.

Blackledge, Adrian and Angela Creese. 2010. Multilingualism. London and New York: Continuum.

Cant, Bob. 1997. Invented Identities? Lesbians and Gays Talk About Migration. London: Cassell.

Casanova, Erynne de and Tamara Moss. 2017. "Translation in Ethnography: Representing Latin American Studies in English." Translation and Intepreting Studies 12(1): 1-23.

Casanova, Pascale. 2004. The World Republic of Letters. Translated by M.B. DeBevoise. Cambridge, MA: Harvard University Press.

Chakrabarty, Dipesh. 2007. Provincializing Europe: Postcolonial Thought and Historical Difference. Princeton, NJ: Princeton University Press.

Cho, Heekyoung. 2016. Translation's Forgotten History: Russian Literature, Japanese Mediation, and the Formation of Modern Korean Literature. Cambridge, MA: Harvard University Press.

Cruz-Malavé, Arnaldo and Martin F. Manalansan IV (eds.). 2002. Queer Globalizations: Citizenship and the Afterlife of Colonialism. New York: New York University Press.

Espin, Oliva. 1999. Women Crossing Boundaries: A Psychology of Immigration and Transformations of Sexuality. London: Routledge.

Fassin, Eric. 2001. "Same Sex, Different Politics.” Public Culture 13(2): 215-232.

Gachev, Georgii. 1994. Russkii eros [Russian Eros]. Moscow: Interprint.

Hall, Stuart. 1992. "The West and the Rest: Discourse and Power." In Formations of Modernity, edited by Stuart Hall and Bram Gieben, 275-331. Cambridge: Polity Press and Open University.

Hayes, Jarrod. 2000. Queer Nations: Marginal Sexualities in the Maghreb. Chicago: University of Chicago Press.

Kulpa, Robert, Joanna Mizielinska and Agata Stasinska. 2012. "(Un)translatable Queer? or What Is Lost and Can Be Found in Translation ..." In Import_Export_ Transport: Queer Theory, Queer Critique and Activism in Motion, edited by Seushila Mesquita, Maria Katharina Wiedlack and Katrin Lasthofer, 115-146. Vienna: Zaglossus.

Lennon, Brian. 2010. In Babel's Shadow: Multilingual Literatures, Monolingual States. Minneapolis, MN: Minnesota University Press.

Post, Chad W. 2014. "The Myth of the 'Three Percent Problem.'" In The Art of Empathy: Celebrating Literature in Translation, edited by Don Ball, 38-41. Washington, DC: National Endowment for the Arts. 
Puri, Jyoti. 2002. "Nationalism Has a Lot to Do with It! Unraveling Questions of Nationalism and Transnationalism in Lesbian/Gay Studies." In The Handbook of Lesbian and Gay Studies, edited by Diane Richarson and Steven Seidman, 427-442. London: Sage.

Schluter, Daniel P. 2002. Gay Life in the Former USSR: Fraternity Without Community. New York: Routledge.

Sedgwick, Eve Kosofsky. 1990. Epistemology of the Closet. Berkeley, CA: University of California Press.

Sozaev, Valerii (ed). 2010. Vozmozhen li “kvir" po-russki? LGBT Issledovaniia. Mezhistsiplinarnyi sbornik (Is Queer Possible in Russian? LGBT Research. Interdisciplinary Collection). Saint Petersburg: LGBT organizatsiia Vykhod.

Venuti, Lawrence. 2017. "Introduction: Translation, Interpretation, and the Humanities.” In Teaching Translation: Programs, Courses, Pedagogies, edited by Lawrence Venutie, 1-14. London and New York: Routledge.

Warner, Michael. 1993. "Introduction.” In Fear of a Queer Planet: Queer Politics and Social Theory, edited by Michael Warner, vii-xxxi. Minneapolis, MN: University of Minnesota Press.

Wells, Peter. 1995. The Duration of a Kiss. London: Minerva. 


\title{
4 The Future Is a Foreign Country Translation and Temporal Critique in the Italian It Gets Better Project
}

\author{
Serena Bassi
}

It Gets Better is a popular awareness-raising campaign vowing to spread the following message internationally: no matter how much suffering and damage homophobia and transphobia may cause in the present, a better future awaits lesbian, gay, bisexual, and transgender people, who should therefore remain hopeful and push past the pain. To respond to rising suicide rates among youth bullied because of their sexual orientation or non-conforming gender identity, the slogan "It Gets Better" draws from the "doctrine of the improved tomorrow" (Freeman 2007: 165) typical of Western progressive political movements. The campaign invites LGBT-identified individuals to upload a personal video on the social networking website YouTube; the videos typically juxtapose past experiences of suffering with stories of happy and fulfilling adult lives. Since the project mission is to deliver its message "to lesbian, gay, bisexual and transgender youth around the world" and "effect change in local communities" (aitgetsbetter.org), It Gets Better raises important questions about translatability and power: can we craft a universal message out of time-bound and context-specific notions of "identity," "change" and "future?" What is at stake in rendering socially marginal subject-positions intelligible and knowable across languages? Who really benefits from "finding equivalence" in the translation of injured subjectivities?

Although the project was originally devised to intervene into American public discourse, ${ }^{1}$ fifteen foreign versions (in seven different languages) ${ }^{2}$ of the It Gets Better project were produced through an atypical process of translation by the users of the online platform themselves. It Gets Better is unique vis-à-vis the instances of non-professional translation on the Web $2.0^{3}$ that have been the focus of empirical studies (O'Hagan 2009; Olohan 2014). What makes the conditions under which the translations were produced different is that the translators themselves were not aware of translating, since the very discourse on how the project spreads its message around the world renders the processes of translation invisible. While the project founders are conscious that "to effect change in local communities," the theme needs to be reformulated "in ways that are tailored to local language, culture and need," the internationalization of the awareness-raising 
campaign is driven by a desire to "demonstrate the unifying theme that it gets better" (aitgetsbetter.org). In line with both this objective and the concern with respecting cultural specificities, the It Gets Better project solicits the making of new videos from international project participants (who are invited to upload them onto one of the eleven "international affiliates" channels) that replicate the format of the US-American campaign. In this way, the international channels can be accessed as if they were originals, because they have "the look and feel of locally made products" (Fry quoted in Pym 2004: 46) and show no trace of their derivative nature. ${ }^{4}$ The "translation modality" (Hurtado 2001) through which international versions were produced out of the US-American project is a process of linguistic and cultural adaptation resulting in "complete localization," in which "all content and examples are from the new locale" (Brooks quoted in Pym 2004: 9).

This chapter analyzes the Italian version of the It Gets Better project to make a case for extending our definitions of localization (Pym 2004; Jimenez-Crespo 2013) to phenomena that, strictly speaking, do not form part of the GILT (Globalization, Internationalization, Localization, Translation) industry. My rationale for opening up definitions in this way is to alert translation scholars to the presence of instances of web-based translation work in which one's own subjectivity is fundamentally entrenched in and indistinguishable from the process of transfer. Crucially, the tailoring of the It Gets Better message to "local culture and need" and its reassembling into "local languages" was outsourced to former victims of homophobic violence living in one of the fifteen affiliate countries. Scholarship on volunteer and activist translation (O'Hagan 2009) shows that translating and subtitling jobs on the web are frequently outsourced "to an undefined, generally large group of people in the form of an open call" (Howe quoted in Jimenez-Crespo 2013: 62). Similarly, It Gets Better outsourced the localization of the project to anyone who feels he or she has a story to tell about surviving homophobic or transphobic violence in one of the languages available.

However, the open call encouraging international users to contribute to the internationalization of the project (see ${ }^{b}$ itgetsbetter.org) does not address them as localizers or translators, nor does it explicitly ask users to produce a version of an existing text. The emphasis of the campaign is instead on a sort of confessional practice through which survivors of homophobic and transphobic violence narrate their story to LGBT youth in their personal videos. This is because for the message of the campaign to ring true and genuinely international, it is crucial that the first-person testimonies that make up the project are perceived as authentic, unique, and emerging from a wish to share personal and intimate memories. As I have previously argued (Bassi 2017), the format of the campaign and the slogan "It Gets Better" invite project participants to make sense of their own journey from a painful past to a joyful present as part of a larger, ongoing LGBT civil rights 
struggle and an even larger master narrative of Human Progress. Inevitably, responding to such an invitation involves formulating a story of the Self in explicitly temporal terms and discussing concepts of time, growth, and history. This chapter investigates the ontological categories of "change" and "time" employed in some of the videos of the Italian-language version of the It Gets Better project. Through this analysis, I begin to "queer" localization by approaching it as a kind of "unmarked" translation work that can elicit alternative models of subjectivity.

The Italian affiliate YouTube channel is entitled Le Cose Cambiano (Things Change); in reframing the project in the foreign language, the certainty of an improved tomorrow for marginalized sexual subjectivities (unequivocally conveyed in English through the slogan It Gets Better) falters. Instead of utilizing the idea of "improvement" and "linear development" to group together the videos uploaded by users, the Italian It Gets Better project substitutes a progressive and teleological idea of time and history with a notion of "change" that is open to interpretation and re-signification. Queer studies scholars (Manalansan 1997; Puar 2013) have suggested that "gay" and "transgender" are identity categories produced by Western secular modernity, which would thus inscribe sexual and gender dissidents into a vision for "a better tomorrow" as self-regulating and self-entrepreneurial agents of change. By contrast, I show that, when we de-center Anglophone sexualities in the study of contemporary Western LGBT politics, ontological categories that defy positivistic and modernist paradigms may play a far more important part in the construction of messages of sexual liberation and social emancipation than scholarship in queer studies has accounted for up until now.

\section{Self-Knowledge, Localization, and Capitalism's Pursuit of Equivalence}

A polysemous political sign, "queer" does not refer to a particular sexual orientation, gender identity, or emancipatory project. In the humanities and the social sciences specifically, "queer" does not describe an object of study, but an epistemology—a way of knowing the modern nation-state, empire, and capitalism that foregrounds bodies, desires, and intimacies. Queer critique programmatically engages sexuality as a modern discursive formation alongside other modes of difference such as race, class, gender, and nationality. Regrettably, a power-laden formation missing from the list is language, in spite of growing evidence that linguistic hierarchies and monolingualism are "woven into modernity's most minute and sophisticated political structures" (Gramling 2016: 3). In this volume, Brian James Baer notes the lack of attention to language and the consequent erasure of the fact of translation that characterize global sexuality studies (see Chapter Three in this volume). This critical blind spot is, of course, partially produced by the hegemony of the English language in the field. Since queer activists and cultural producers 
"have often been prototypes of transnational and translingual border crossing," the fact that queer studies is now "more Anglophone, more monolingual and less translated" than ever (Gramling and Dutta 2016) is certainly problematic. However, I suggest that the most insidious problem caused by the Anglo-centric monolingualism of queer studies is not one of erasure or exclusion, but an epistemological one. To what extent does the privileging of English-language sites and sources determine not only the conclusions we come to but also our very approach to knowledge production? In particular, what may a queer translational approach to sexuality and capitalism look like?

If, as Anthony Pym argues in his important study of localization The Moving Text, localization is "the showcase market strategy of international capitalism" (2004: 47), it remains unclear how the collusion between localization as a widespread contemporary translation modality and capitalism plays out for Web 2.0 users, since the variety of forms that localization takes online remain understudied. To participate in one of the fifteen non-English language versions of the anti-bullying project and produce a video to upload, the users of It Gets Better project need to possess a particular form of literacy that combines the ability to speak about one's inner world with intercultural skills. First, both Anglophone and non-Anglophone users need to possess enough self-knowledge and proficiency in using international terms such as "coming out," "homophobia," "transphobia" and "hate crime" to be able to tell a coherent story in which they present themselves as survivors of a specific kind of hate-motivated violence. In fact, the project expects all users to turn an injury and a set of painful memories into resources for other users of the channel, who are at present targeted by bullies and may be looking for tips and strategies for their life to "get better." Moreover, non-Anglophone users of the online platform have to combine their ability to make sense of their experiences of exclusion and pain with the skill to interpret a foreign message, so that they can tell their own story in such a way as to fit the campaign format and therefore demonstrate the unifying theme of the project.

The emphasis in the discourse of the It Gets Better project on a "unifying theme" binding the international channels together-that is, the unfaltering certainty that the lives of LGBT people are designed to improve globally-is reminiscent of the metaphor that figures translation as a form of "bridge building"; a trope that has come under increasing scrutiny by translation scholars (Baker 2006: 41). The will to bridge, which presumes cultural differences and facilitates dialogue between national communities (which is typical of modern Western discourse about translation), is substituted in the vision of the It Gets Better project for an equally problematic desire to render experiences of oppression "equivalent," as well as generate "equivalent" tools to combat social injustice and initiate a homogenous process of sexual liberation across the world. In order for the international videos to reiterate the English-language message that it gets better, the knowledge 
about oneself has to appear "equivalent" to the stories told on the main US-American website. Indeed, the contemporary GILT industry, of which these internationalized YouTube channels are part, is animated by the goal of "making everything perfectly equivalent to everything else"; an objective that Vicente Rafael describes as a segment of a larger capitalist project to measure, control, and produce value out of all human activities. In this sense, translation is implicated in the struggle "to control the production and circulation of difference" through "the attempt to tame language" and the processes of transfer of meaning (2016: 190). Such a goal is seemingly achievable with the help of technologies such as automated translation tools, but also through online platforms where users can upload user-generated content, share skills, and resources.

The project under examination here is a unique example of web-based volunteer translation for a number of related reasons. First, as I have argued in the introduction, the act of localizing coincides with that of telling an "original" story about oneself. The two acts are, in fact, indistinguishable from one another. Second, instead of "crowdsourcing" a particular translation or subtitling task, It Gets Better can be said to crowdsource the production of "equivalent" injured subjectivities and "equivalent" marginal subject positions. In this sense, localization emerges as a particular kind of cognitive and affective work. Third, this localization functions as a site to extract "queer value" (Wesling 2012) from forms of intercultural knowledge production that have been rendered invisible, as well as a tool to exercise control over linguistic plurality. However, the very strategy of "complete localization" affords users considerable space to resist the pursuit of equivalence and the attendant attempt to control linguistic plurality. Most videos begin with localizers repeating the campaign slogan, so that the phrase "it gets better' and its supposedly equivalent translations hold the multiple localized version of the anti-bullying project together. This structure allows localizers to embed the campaign title into their own story and offer their own interpretation of it in the light of the events they report. Thus "Things change" is no longer a stand-alone sentence but is deployed as a "structure of anticipation" (Baker 2006: 106), which prefigures what comes next.

\section{In Nature Things Change: Subjectivity and Temporal Critique}

Since the publication of a number of interdisciplinary interventions on "the temporal regimes embedded in sexuality as a field of knowledge" (Freeman 2007: 160), "queer" has undergone a sustained critical redefinition as "a set of possibilities produced out of temporal and historical difference" (Freeman 2007: 159). The It Gets Better project invites localizers to articulate their own stories with the expectation that these may produce multiple "equivalences" with respect to injured subjectivities, marginal subject positions and of ideas of a "better tomorrow" for queer people. Instead, as 
I will argue, the "completely localized" videos of the Italian It Gets Better project show a series of ruptures in the global flow of linguistic meaning. In the case of the Italian version of the It Gets Better project, queer critiques of chrononormativity (Freeman 2007) are helpful in highlighting the limits of localization's late capitalist dream of total control over linguistic plurality. The asymmetry and lack of semantic correspondence in linguistic systems means that dreams and designs of semantic equivalence can never come true, as I will attempt to show through three examples taken from the videos making up the Italian version of the It Gets Better project. Drawing attention to the ruptures in meaning that translation as a diffused social practice engenders is of crucial importance in the context of contemporary debates in queer studies, because, as I have pointed out earlier, such debates are often grounded on monolingual analyses and do not interrogate the (simultaneously) transnational and translingual circulation of meaning. In referring to her own experiences as a transgender person, one of the localizers, Sharlot, rearranges, complicates and "mistranslates" the "original" message:

Ciao, mi chiamo Sharlot, sono una fotografa, sono italiana e sono qui per dare la mia testimonianza sul fatto che le cose cambiano. Vi faccio un esempio? Io sono una persona trans, transessuale e questo già vi fa capire che le cose cambiano, in natura le cose cambiano. Prima avevo dei tratti maschili, ora con la transizione, ho dei tratti più femminili. È cambiata la mia pelle, son cambiati i miei capelli. È cambiato anche il mio carattere, sono diventata più dolce. Quindi le cose cambiano, le cose cambiano in natura. Tutti i giorni le cose non sono mai uguali, anche se apparentemente sembrano uguali. Le opinioni cambiano, le idee cambiano, la gente cambia.

(Eris 2014: 0.08-1.15)

[Hi, my name is Sharlot, I am a photographer, I am Italian and I am here to give my account of the fact that things change. Shall I give you an example? I am a trans person, transsexual, and this already tells you that things change, in nature things change. I used to have male features and now, with transition, I have more feminine traits. My skin changed, my hair changed. My personality changed too, I am sweeter now. Therefore things change, they change in nature. Everyday things are never the same, even if they seem the same. Opinions change, ideas change, people change.]

The basic assumption of the vast body of scholarship on "queer time" 5 - that ideas of time produce bodies and subjects-is evident in Sharlot's self-presentation. She calls upon her experience of medical transition from male to female to argue that change undercuts all experience in the social and in the natural world. In other words, she employs her minority position as a transgender individual to make a universalist claim about 
the very meaning of the idea of "change." By doing so, she articulates her transgender identity in a way that runs quite contrary to existing dominant discourses on transgender identity in a number of ways. First, Sharlot breaks radically with a distinctly Western history of imagining the transgender subject as located not in "nature" but in the history of science and technological progress. In one of the foundational scholarly discussions of transgender identity, Susan Stryker (1994) discusses the political potential of transgender subjects and presents transgender claims to existence as waging a war on nature. Stryker compares trans subjects to the literary monster Frankenstein to argue that they are simultaneously born out of modern scientific paradigms and haunting these, when formulating claims for agency and autonomy. By contrast, Sharlot's localization of the It Gets Better project refuses the idea that a discrete historical moment or a social institution has produced "transgender" as an identity category. Instead, she presents transgender existence as unmarked and indistinguishable from constant and all-encompassing transience and transformation that is the marker of existence. In fashioning transgender subjectivity as paradigmatic of the workings of nature, Sharlot interestingly presents being transgender as an existential rather than a historically specific and socially determined condition.

Scholarship in queer studies has long discussed movements for LGBT liberation as bolstering a Western, modern, and self-sufficient idea of the subject which is predicated on a linear, developmental temporal construction (see Manalansan 1997; Puar 2013). According to queer critics Lisa Duggan (2003) and Jasbir Puar (2013), late-modern, large-scale shifts have displaced heterosexuality and heteronormativity as the only norms disciplining sexual behavior, resulting in the emergence of a "new homonormativity." Homonormativity refers to "a politics that does not contest dominant heteronormative assumption and institution, but upholds and sustains them, while promising the possibility of a demobilized gay constituency and a privatized, depoliticized gay culture anchored in domesticity and consumption" (Duggan 2003: 179). The new "homonormativity" makes room for queer identities in mainstream society on the condition that they begin to inhabit a set of conservative institutions and conform to the dominant narratives that these uphold. Following on from Duggan (2003), queer scholars have analyzed gay progress narratives like the one espoused by the It Gets Better project as part of the historical emergence of autonomous choosing and self-regulating subjectivities associated with forms of neoliberal governance (Ferguson 2005). Even though Sharlot's story forms part of an international project held together by what can be described as a "homonormative" message, her ideas of time and subjectivity evoke a remarkably different imagery. Her story of oppression and emancipation is not "equivalent" to those imagined by the campaign format.

The It Gets Better project invites participants to share their journey from a painful past to a joyful present, and to structure such a story around the following events: coming out, falling in love, finding a romantic partner, 
and starting a family. By contrast, Sharlot presents time as an ever changing whole and thus refuses to volunteer a set of hierarchically organized sequences-that is, the story of her coming out and her subsequent moving on to a happy life-to demonstrate that things indeed change. Thus her suggestions for surviving as a transgender person do not involve an investment in a better future. Instead, in her account "past" and "present" collapse into one ongoing temporal dimension. As a consequence of the temporal regime she constructs, her idea of medically transitioning and, with it, her approach to transgender identity do not foreground ideas of agency or choice. Sharlot indeed adopts ideas of time, as It Gets Better invites her to do, to give voice to an emancipatory message, but the notion of liberation underpinning her story exceeds the social world and draws rather from metaphysical approaches to subjectivity. While she can be said to resist neoliberal regimes of self-regulating subjectivities, she does so not by providing an alternative political vision. Rather, Sharlot can be said to reframe the conversation on "change" and "future" by adopting different ontological categories of time.

In the example discussed earlier, "progress" as the central idea of the It gets better project has been resemanticized. The modern, secular, and autonomous subject of LGBT politics, which queer studies literature sees as problematically turning sexual politics into a conservative enterprise, has been displaced and substituted by a different metaphysically inflected subjectivity. Similarly, the following localizers interpret the slogan "Things change" as a reference to the transience and ephemerality of human existence:

C'è un'evoluzione continua. Qualcuno diceva che non ti puoi immergere due volte nelle acque dello stesso fiume . . . c'avevo 4, bimbe a scuola, era una cosa drammatica . . . ma certi concetti arrivano. Cioè il cambiamento è insito.

(Benvenuti 2013: 2.20-2.32)

[Things are in a continuous evolution. Someone used to say that you cannot immerse yourself twice in the water of the same river . . girls, I constantly had fails at school, it was awful . . . but even then some concepts stick. That is to say, change is intrinsic.]

A volte le persone ce l'hanno con noi per motivi a volte inesistenti, per stronzate, perchè non gli andiamo bene per come ci vestiamo, per come siamo, per come la pensiamo, per i nostri gusti sessuali, per i nostri orientamenti di vario genere, per le nostre scelte. Insomma, ci possono essere mille motivi o perchè abbiamo fatto una cosa che improvvisamente viene considerata negativa da tanti, o esecrabile moralmente da altri. Insomma, la gente perde un sacco di tempo e di energie in una serie infinita di stupidaggini e di stronzate senza, senza motivo, senza alcuna finalità reale. Però io son convinto che questo, anche quando ci sembra tutto, anche quando ci sembra totalizzare la nostra giornata, 
questa opinione negativa che hanno gli altri di noi, per una motivazione futile, stupida. E a volte anche proprio concettualmente sbagliata, anche quando ci sembra così totalizzante, in realtà poi passa, clamorosamente dopo un po' quello che oggi sembra tutto, domani viene dimenticato, diventa niente, diventa una cosa grande così. Quindi non vale la pena di prendersela più di tanto. Oggi ti sembra un ostacolo invalicabile, domani rimarrà forse un pezzetto $\mathrm{di}$, così, un pezzetto di un periodo negativo nella nostra memoria, niente di più. Quindi, le cose cambiano. Le cose cambiano, questo volevo dire. Quello che oggi è enorme, domani non è più niente. Le cose cambiano. Ciao.

(Pezzali 2013: 0.06-1.24)

[Sometimes people have a problem with us for non-existent reasons, for stupid shit, because they don't like what we wear, the way we act, what we think, our sexual preferences, our various orientations, our choices. Basically, there can be a thousand reasons, or because we did something that is suddenly considered negative by many, or morally objectionable by others. Basically, people waste lots of time and energy in an infinite series of stupid shit, with no real purpose. But I am convinced that this, even when it seems to us to be everything, even when it seems to take over our day ... this negative opinion that people have of us, for a futile, stupid reason, and sometimes it's even conceptually wrong, even when it seems to take over, in reality it just goes away, remarkably, after a while, that which seemed to matter today, gets forgotten, it becomes nothing tomorrow, it becomes a small thing. Therefore, there is no point taking it too seriously. Today you think it is an unsurmountable obstacle, tomorrow it might become maybe a small piece of a negative period in our life, nothing more than that. So things change. Things change, that's what I wanted to say. What seems enormous today, tomorrow is nothing. Things change. Bye.]

In both of the accounts quoted above, "change" is translated as referring to the transience of existence rather than to history as a narrative of progress. Instead of suggesting that society has embarked on a journey of increasing acceptance and freedoms, the two localizers point out that discrimination against a particular group is ephemeral and transient. In this sense, while the campaign format relies on a progressive temporal regime that imagines time as a linear journey toward a better future, all three localizers employ ideas of timelessness in order not just to describe their own subjectivity, but also to indicate a path of emancipation for LGBT individuals.

Another user of the project also borrows from metaphysical language to describe her suffering following her religious family rejecting her for being a lesbian:

Da lì si è aperto un calvario immenso, che è durato tantissimi anni, perchè i miei genitori hanno cercato di cambiarmi in tutti i modi possibili 
e immaginabili. Mi hanno portata dal prete perchè loro sono molto religiosi, quindi volevano che il prete mi convincesse a cambiare. E non avendo funzionato questa cosa, hanno deciso di portarmi da uno psicologo, psichiatra che ha tentato delle terapie per farmi tornare normale, tra virgolette. Per fortuna io sono scappata da queste situazioni e ho capito che, nonostante per i miei genitori io fossi sbagliata, in realtà io ero così. Per cui non c'era modo di cambiarmi, neanche se avessero voluto.

(n.n. 2014: 1.00-1.49)

[From then on, an immense Calvary opened for me, which lasted many years, because my parents have tried to change me in all possible and imaginable ways. They have brought me to the priest because they are very religious, so they wanted the priest to convince me to change. And because this did not work, they've decided they'd take me to the psychologist, a psychiatrist who has attempted therapies to make me normal again, in inverted commas. Fortunately, I managed to run away from these situations and I understood that, even though I was wrong according to my parents, I was not. There was no way of changing me, even if they would want to.]

This localizer complicates the idea of a secular model of subjectivity emerging uniformly throughout the West as the main mode for articulating LGBT political struggles. Here, as in the examples discussed so far, the concept of 'change' is pivotal to the narrative, but it is associated with a homophobic rhetoric that sees "queerness" as a deviant psychological trait that can and should change, rather than with the protagonist of the narrative. Thus this localizer does not understand change as positive, or as a tool in the fight against homophobia. In the structure of anticipation that the localizer is constructing here, the theme of change evoked by the title is at the center of the story, but it is endowed with the negative association of the constraints placed on queer people by homophobic rhetoric. The localizer does not equate "change" with "progress" or "improvement," and contradicts the message of the Italian campaign that "change" represents an emancipatory political horizon for LGBT people.

\section{Concluding Remarks}

To make a case for further exploring the usefulness of a "translational approach" in the ongoing interdisciplinary effort of developing a queer epistemology in the Humanities and in the Social Sciences, I chose to turn to an atypical translation product. This for two main reasons: first, to capture the translational elements of contemporary sexual transnational formations, it is necessary to move beyond "the binary cognitive structures that translation studies has depended on to describe translations," (Tymoczko 2007: 198 ) such as the source text/target text opposition, and refigure translation 
studies as the study of instances of localization, movements of "material objects" in time and space (Pym 2004: 5). Second, showing that this apparently atypical translation can be read as an instance of "complete localization," allowed me to "queer localization" and argue that the multilingual versions of the It Gets Better project result from both an invisible process of translation and from the extraction of "queer value" in the name of a search for equivalence.

Through this translation work carried out by "invisible" volunteer translators, dominant discourses on sexuality and subjectivity in late capitalism are disassembled and reconstituted in surprising ways. Thus, the stakes in rendering this kind of translation work visible lie in the political possibilities that it opens up for research on both volunteer translation and in queer studies. In fact, it is the affective and cognitive labor of the international users of this online platform that permitted the internationalization of this anti-bullying online campaign. The chapter attempted to open up the definitions of localization that scholars in translation studies are currently working with by highlighting the presence of the Web 2.0 of multilingual products like the It Gets Better project that adopt translation modalities such as "complete localization." I have done so to encourage a more sustained engagement in translation studies with contemporary translation modalities in the GILT industry and beyond that do not conform to conventional ideas of translation activity.

Moreover, by concentrating on the ontological categories of time and change constructed by some of the users of a localized YouTube awareness-raising campaign, this chapter showed how a critical focus on translation as a diffused social practice that is sometimes invisible has the potential to help us reexamine key terms in queer studies such as "time" and "change" and the subjectivities that these terms produce. The videos of the Italian version of the It Gets Better project implicitly discuss ideas of the Human, development, future, and change, but through localization, their meaning is transformed. The result of the changes in meaning I have highlighted in my analysis is the creation of different models of subjectivity, which demand that we reconsider the argument prominent in queer studies that a monolithic, conservative, "homonormative" understanding of sexual subjectivity lies at the core of contemporary mainstream Western LGBT politics. The multiple refractions of metaphysical and religious discourse in Italian modernity may have intervened in the localization of the It Gets Better message and, as a result, different categories of "time" and "change" were evoked in the Italian reiteration of the project.

While "homonormativity" is a political discourse that delegates emancipatory change to conservative social institutions such as the market and the family, what is interesting about the examples analyzed here is that they move away from discussing the social altogether. In fact, none of the contributors cited here understands "change" as a social phenomenon. For example, while Sharlot's message does not conform to a neoliberal and 
assimilationist understanding of transgender politics, its distance from such politics is not ideological; that is, she does not choose a set of left-wing narratives over the dominant conservative ones. The mission of the It Gets Better project is to export an English-language slogan that makes reference to a sort of LGBT-inflected version of the progressivist doctrine of the "improved tomorrow" around the world. The localizations analyzed here present instead strongly metaphysically inflected models of subjectivity, which push back against a recurrent scholarly characterization of Western LGBT politics as predicated on a modernist paradigm of identity and individual agency.

Although it is important to be critical of the disproportionate power that the US exercises in the internationalization of LGBT politics and culture, contemporary sexual identity politics is not "simply a phenomenon North America has foisted egregiously on other cultures" (Lane 1996: 1). LGBT-identified individuals who do not live in the USA and those who do not speak English adopt various translation strategies and modalities to appropriate and reshape discourse about sexual subjectivities. While the localizers whose translation work I have used here as an example formulaically repeat the translation of the campaign slogan in their videos, they structure their stories so as to partially disavow the supposedly unifying project theme. Since translation as a simultaneously interpretative and productive practice engenders "exorbitant gain" (Venuti 2013: 142), the stories of the Self told on the localized YouTube channel can hardly be contained within the bounds of the English terms "gay," "transgender" or "queer." Likewise, the meanings that the stories on the international It Gets Better channels proliferate can hardly be reduced to and subsumed into the paradigm of equivalence.

\section{Notes}

1 As Itgetsbetter.org explains, "in September 2010, syndicated columnist and author Dan Savage created a YouTube video with his partner Terry Miller to inspire hope for young people facing harassment" in response to a number of highly visible news stories about LGBT youth committing suicide after they had been the target of school bullies in the United States.

2 While the project website avoids using the labels "original" and "translations," the hierarchical ordering of English (the language in which the project was devised) as the project's primary language, and Spanish, Moldovan, German, Italian, Swedish, and Portuguese as equally secondary, is exemplified by the interface of the project's YouTube platform (www.youtube.com/user/itgetsbet terproject). On it, the US-American channel dominates the homepage, while the "international affiliates" are listed one after the other on a side column.

3 Web 2.0 describes World Wide Web websites that allow the users to generate their own content.

4 Translation studies scholars have long debated the difference between localization and translation, with some scholars arguing that the two practices are different in a number of important ways (Pym 2004) and others that all translation involves the radical domestication and cultural adaptation of the foreign texts 


\section{Serena Bassi}

that localizers argue is unique to localization (Quirion 2003). Unravelling the dispute goes beyond the scope of my discussion whilst I understand "localization" as a "translation modality" and I will refer to the labor of localizing that I discuss here as "translation work," I choose the term "localization" instead of the more general label "translation" to describe the cultural product under examination. This is because the term "localization" and particularly "complete localization" allows me to highlight the radical erasure of the fact of translation in the production of this online campaign.

5 See, for example, Halberstam (2005), Munoz (2009) and Rohy (2009).

\section{References}

\section{Primary Sources}

Benvenuti Carla. 2013. "Le cose cambiano." Available online at www.youtube.com/ watch?v=jbQbjE6cOXk (last accessed February 7, 2017).

Eris, Sharlot. 2014. "Le cose cambiano." Available online at www.youtube.com/ watch?v=lQJiDErQu-4 (last accessed February 7, 2017).

${ }^{a}$ Itgetsbetter. Available online at www.itgetsbetter.org/pages/about-it-gets-betterproject/ (last accessed February 7, 2017).

bItgetsbetter. Available online at www.itgetsbetter.org/content/international (last accessed February 7, 2017).

n.n. 2014. "Le cose cambiano." Available online at www.youtube.com/watch? v=DP_89xoychY (last accessed February 7, 2017).

Pezzali, Max. 2013. "Le cose cambiano." Available online at www.youtube.com/ watch? $v=\mathrm{nOv}-0 \mathrm{tSMWdU}$ (last accessed February 7, 2017).

\section{Secondary Sources}

Baker, Mona. 2006. Translation and Conflict: A Narrative Account. Manchester: Routledge.

Bassi, Serena. 2017. "Displacing LGBT: Global Englishes, Activism and Translated Sexualities." In Feminist Translation Studies, edited by Olga Castro and Emek Ergun, 235-248. London: Routledge.

Duggan, Lisa. 2003. The Twilight of Equality. Boston, MA: Beacon Press.

Ferguson, Roderick. 2005. "Raceing Homonormativity: Citizenship, Sociology, and Gay Identity." In Black Queer Studies, edited by Patrick Johnson and Mae Henderson, 52-67. Durham, NC: Duke.

Freeman, Elizabeth. 2007. "Introduction." GLQ 13: 2-3.

Gramling, David. 2016. The Invention of Monolingualism. London: Bloomsbury.

Gramling, David and Aniruhdda Dutta. 2016. "Introduction." TSQ 3: 3-4.

Halberstam, Jack. 2005. In a Queer Time and Place: Transgender Bodies, Subcultural Lives. New York: New York University Press.

Hurtado, Amparo. 2001. Traduccíon y traductología. Madrid: Cátedra.

Jiménez-Crespo, Miguel A. 2013. Translation and Web Localisation. London and New York: Routledge.

Lane, Christopher. 1996. "Christopher Lane Responds to Dennis Altman.” Available online at www.australianhumanitiesreview.org/emuse/Globalqueering/lane. html (last accessed February 7, 2017). 
Manalansan IV, Martin. 1997. "In the Shadows of Stonewall: Examining Gay Transnational Politics and the Gay Diasporic Dilemma." In The Politics of Culture in the Shadow of Capital, edited by Lisa Lowe and David Lloyd, 485-505. Durham, NC: Duke University Press.

Munoz, José Esteban. 2009. Cruising Utopia: The Then and There of Queer Futurity. New York: New York University Press.

O'Hagan, Minako. 2009. "Evolution of User-Generated Translation: Fansubs, Translation Hacking and Crowdsourcing." The Journal of Internationalization and Localization 1: 94-121.

Olohan, Maeve. 2014. "Why Do You Translate? Motivation to Volunteer and TED Translation." Perspectives: Studies in Translatology 7: 17-33.

Puar, Jasbir. 2010. "In the Wake of 'It Gets Better." The Guardian.

Puar, Jasbir. 2013. "Homonationalism as Assemblage : Viral Travels, Affective Sexualitites." Jindal Global Law Review 4: 23-43.

Pym, Anthony. 2004. The Moving Text: Localization, Translation and Distribution. Amsterdam: John Benjamins Publishing Company.Quirion, Jean. 2003. La formation en localisation à l'université : pour quoi faire? Meta 48:4, 546-558.

Rafael, Vicente. 2016. Motherless Tongues. Durham, NC: Duke University Press.

Rohy, Valerie. 2009. Anachronism and Its Others: Sexuality, Race, Temporality. New York: State University of New York Press.

Stryker, Susan. 1994. "My Words to Victor Frankenstein About the Village of Chamounix." GLQ 1:3.

Tymoczko, Maria. 2007. Enlarging Translation, Empowering Translators. London: Routledge.

Venuti, Lawrence. 2013. “Translation, Simulacra, Resistance." In Translation Changes Everything, 141-157. London and New York: Routledge.

Wesling, Meg. 2012. “Queer Value.” GLQ 18: 107-125. 


\title{
5 Ethnography and Queer Translation
}

\author{
Evren Savci
}

Translation became a key concept in my research on queer politics in contemporary Turkey despite my training in sociology. I say despite, as it was not immediately clear to me how I would combine my training as a sociologist and an ethnographer, on the one hand, and my interest in language, sexual and political discourses, the power of naming, and regimes of truth inspired by queer theory, on the other. This was regardless of the fact that I considered myself a cultural sociologist, and was familiar with the work of scholars within sociology and cultural anthropology who argued against culture as superstructural and therefore epiphenomenal to the economy or political structures, who stated that culture had its own logic and structure, and that it was oftentimes as material as anything else (Alexander 1990; Geertz 1973; Hays 1994; Sahlins 1976; Sewell 1992; Williams 1977). Cultural sociologists also pointed out that the very thing that sociology is interested in studying, "the social," needed to be understood as deeply intertwined with the cultural, as meaning-making is a key component of the social and cannot be divorced from the cultural. In other words, if the human is a meaning-making creature, and if the social world is created as much through meaning as it is through material production, then meaning and culture are inevitably central to the very thing that we call the social.

Given how much scholarship has been produced within cultural sociology, and how much debate has occurred about the place of culture within the field, it is quite surprising that sociology would pay little attention to language itself. Elsewhere, I have argued that cultural sociology would benefit from a heightened attention to the linguistic component of meaning-making, both because language provides the very context in which meaning, and therefore the social, is produced, and also because it is within given linguistic structures, possibilities and limitations that we as scholars produce our understanding and interpretation of the very social world we observe (Savc1 2017). My own way into making room for the linguistic within the social, and bridging sociology and queer theory became "translation." As my project sought to understand the ways in which particular concepts of nonnormative genders and sexualities, such as cinsiyet kimliğ $i$ (gender identity), cinsel yönelim (sexual orientation), homofobi (homophobia), LGBT hakları 
(LGBT rights), and nefret suçları (hate crimes), traveled to the context of Turkey and entered public political discourses, translation became not only a key concept but also a methodology for my research. I argue that the ways in which such vocabularies enter into public and political discussions shed light onto the logic of the operating political economy and the particularities of its moralizing logics-in this case, a system I refer to as neoliberal Islam. This project also had two unintended outcomes: introducing translation as a methodology to (transnational) sociology in order to provide a way for sociologists to engage with language and the linguistic component of transnationally circulating meanings, and introducing ethnography as a valuable method to translation studies. It is the latter proposal that I take up in this piece. In the following section, I first outline what I find to be the three important commonalities between translation and ethnography. Then I detail what I argue ethnography can contribute to translation studies with examples from my work.

\section{Where Translation and Ethnography Meet}

Most critically and productively, translation and ethnography meet in their refusal of the notion that textual and social meanings are fixed, uncomplicated, and directly accessible to the outside reader/observer. Translation studies, even in its most classic form, is premised on the movement of language and ideas, and thus is deeply interested in how meanings circulate. Yet contemporary translation scholars further complicate the notions of a fixed "source language" and "target language" that the field initially widely employed, and stress that translation does not indicate smooth transitions but ruptures in meaning (Cronin 2009: 218; Mezzadra and Sakai 2014: 11). They argue for the role of various (cultural) translators in meaning-making (Bassi 2017), historicize the very category of "language," which we have come to understand as bounded comparable entities, and reveal such an understanding of language, as well as the notions of "native speaker" and "mother tongue," to be effects of modernity and nation-states (Yildiz 2012: 9; Mezzadra and Sakai 2014: 13). Similarly, while most classical ethnographers might set out to "observe" something they deem an empirical reality, critical ethnography does not treat the world as a text with a fixed meaning that will reveal itself to the ethnographer if she stares at it long enough. In other words, "society is not a text that communicates itself to the skilled reader" (Asad 1993: 187). Ethnography ideally does not treat a segment of "life" as a text to be read, for instance by translating the dynamics of a workplace into a "text" via fieldnotes, but sets out to understand social dynamics and social change through grasping how people interact and make sense of those dynamics, structures, and changes. The act of writing the ethnography is ultimately not an act of freezing a dynamic social field, but capturing some of that dynamism and complexity in our analyses. ${ }^{1}$ This I find marks one of ethnography's key distinctions from other (qualitative) 
sociological methods, such as content analysis (or humanities' methods such as close readings). Of course the ethnographer's narrative is a particular one, and one that gets privileged over other stories that one might be able to tell based on similar observations-in other words, there is never one answer to the question "what is this a case of?" That is not what sets ethnography apart from other qualitative methods-it is not somehow more scientific or objective. What ethnography allows for is an ability to capture narratives in practice, in all their complexity as much as possible, while understanding what these practices mean to subjects who engage in them.

Further, just like translation, which engages with categories and norms, and can either normalize or disturb them (Simon 2009: 210), ethnography deals with social practices and institutions, the meanings and functions of which are very much dependent on categories and norms. Ethnography, too, can either successfully question the categories and norms that inform the social institutions and practices it studies (such as criminality, gender, ethnicity, class, nationality, etc.) or simply reproduce and reify those very categories. ${ }^{2}$ For instance, an ethnography of how "women" and "men" workers interact with subordinates and superordinates in a workplace can be conducted and written in a way that completely reifies the categories of womanhood and manhood, often treating them as "explanatory variables." Or it can be an account of the very bureaucratic structure and culture of the workplace and the interactions that structure devises, encourages or discourages, and how those craft subjects into the binary genders of manhood and womanhood.

Finally, scholarship on power/knowledge and politics of epistemology (Foucault 1980; Haraway 1988; Hill Collins 1990; Said 1979) have inspired translation studies scholars as well as ethnographers to note power asymmetries between languages and cultures, which affect not only what languages or cultures are likely to be "translated" and made intelligible for whom, but also the particular framing such translation will take. For instance, Talal Asad reminds us that "cultural translation" between two cultures happens in a global context, where "because the languages of third world societies ... are seen as weaker in relation to Western languages ... they are more likely to submit to forcible transformation in the translation process than the other way around" (1993: 190). This is especially due to the asymmetrical political-economic relations of "cultures" as well as to the fact that "Western" languages are often the dominant producers and distributors of desirable knowledge worldwide. Mona Baker (2010), on the other hand, notes that the effects of the global political economy on translational outcomes need to be understood beyond "accurate versus inaccurate" translations, and that the narrative framing of an "accurate" translation can nevertheless serve to politicize the translated story at hand in particular ways. For instance, as her analysis of the Middle East Media Research Institute (MEMRI) shows, while most of the translations provided by MEMRI are accurate, their framing of the need to translate Arabic, Farsi, 
Urdu, Pashtu, or Turkish language sources as a result of their commitment to "researching Islamist ideology and Islamist organizations that threaten the West" already provides the framework through which the readers are invited to understand their translations.

It is worth noting here that while these three points are analytically distinct, in practice, they are deeply intertwined. The more successful attempts in emphasizing global power hierarchies are those that do not reify "language" and "culture" as naturally existing, monolithic entities, but those that recognize the historical construction of those very things that we have come to recognize as a particular language or culture. At the same time, attempts not to reify language or culture, or any other concept or category of thought these fields operate with, should not evacuate these discussions of considerations of power. The fact that "the Turkish language" is a historically constructed and changing category does not mean that what is referred to as "Turkish language" is without power over subjects, or that it does not work to impose and solidify an understanding of national unity. Neither does this erase the fact that vis-à-vis what we have come to consider "English," for instance, Turkish has little value or power.

\section{Ethnography's Contribution to Queer Translation}

I maintain that ethnography can contribute to translation studies in multiple ways. For one, ethnography can help further decenter the individual translator as the source of translated meaning by paying attention to multiple ways in which concepts are "translated" as they are used by various subjects. This also means that ethnography can help resist easy and popular narratives both by contextualizing events and by helping us unpack the complexities in people's engagements with particular discourses. For instance, ethnographic sensibilities can help us simultaneously engage with "[c] oncepts such as citizenship, the state, civil society, public sphere, human rights, equality before the law . . . all [all of which] bear the burden of European thought and history" (Chakrabarty 2000: 4) as they are employed in their current globally disseminated state while challenging their assumed universality. In other words, instead of assuming that everyone means the same thing when they say, for instance, "I support LGBT rights," ethnographic methods presume that most people understand and mean different things by this statement. This illuminates the fact that there are many "translators" of "LGBT rights" as the term gains circulation independent of its "original translator," which has the potential to reveal the multiple translations that can often co-exist in contradiction.

In comparison, a content analysis of news media's use of LGBT rights as a frame might tell us about whether or not this use has become more widespread over time. But this tells us nothing about how people use such terminology, why they chose it (or don't), and perhaps most importantly, what exactly they mean by it. For me, this is important not because it advances us 


\section{Evren Savci}

closer toward some "truth" about the social world, but because it is the very operations of power that are revealed by the uses of particular terminology and the ideological worlds that encapsulate them, as well as who has legitimate access to them and who does not. This is why I find interviews, and especially probing for further explanation, to be a central part of ethnography. The statement "I support LGBT rights" begs at least two follow-up questions: what the interviewee means by "LGBT rights," and what they mean by "support."

One of the things I wanted to capture in my research was precisely the emergence of LGBT rights, sexual orientation and gender identity as key pieces/expressions of a particular regime of truth in contemporary Turkey. For instance, as differently disenfranchised groups were making claims for being included in the anti-discrimination clause of the new constitution proposal of the Adalet ve Kalkınma Partisi (AKP) government in Turkey in 2008, we experienced the emergence of what I term "homosexual rights as a litmus test." This was a historical conjunction of various issues. There was the redrafting of the military constitution of Turkey, which divided the leftists and left-leaning liberals into anti-militarists, who wanted to replace the old constitution with a civil one, on the one hand, and secularists, who were suspicious of the motivations of the self-proclaimed "mildly Islamist" government, on the other. ${ }^{3}$ There was an increasingly vocal and visible LGBTI movement and an increasingly vocal and visible headscarf movement. In addition, there were the demands of the European Union accession process, and pressures from the European Council sections to redefine "family" to include "alternative family" formations, gesturing not exclusively but certainly to gay and lesbian families, to which conservative Turkish politicians were forced to respond to.

These politically complex and sensitive dynamics led to a series of demands by different constituencies to be included in the new civil, and what many hoped to be a more democratic, constitution. A petition by self-proclaimed "women with headscarves" demanded the right to wear the headscarf at public universities, but also added that this was simply one of many democratic rights the citizens of the country needed, along with a judiciary that actually delivered justice. The LGBT activists were also excited for a civil constitution and started a petition to demand that cinsel yönelim (sexual orientation) and cinsiyet kimliği (gender identity) be added to the anti-discrimination clause of the new draft.

While the latter demand barely made it into the news, except for a few online news blogs with dissident politics, the possible legalization of headscarf wearing at public universities and offices created quite heated national debates. One reason headscarf-opponents cited for their position was that allowing headscarves at university campuses would create a slippery slope, which would lead to demands to wear headscarves at high schools and eventually at elementary schools. Easily impressionable at a young age, many of the girl children of the nation as a result would find themselves under 
peer pressure (presumably exercised by their friends wearing headscarves). These concerns became so vocal that finally Minister of State Burhan Kuzu decided to make a statement to alleviate such fears during the summer of 2008. "We do not have to respond to every request," he stated, referring to possible future requests for headscarves at elementary schools. "There is a high level of requests from homosexuals for equality and the right to marriage. ${ }^{4}$ Are we going to give it to them simply because they are asking for it? We are obliged to act within the responsibilities of (the party in) power" (Çolak and Karakuş 2008).

This statement simultaneously set up headscarf rights and LGBT rights as comparable, and indicated that there was a "limit" to what was demandable as a democratic right. While it seemed the minister only used the analogy to suggest that democratic rights did not constitute a slippery slope and headscarf wearing at elementary schools was as unthinkable as a "right" as were the demands of "homosexuals," this historical moment marked the beginning of the treatment of one's position on "homosexual rights" as a litmus test. This test was not "administered" to all citizens of the nation, of course, but only to those who were suspected of being disingenuous in their use of human rights frameworks to make a case for the wearing of headscarves at public universities. Over the next couple of years, headscarf activists would be questioned in a number of public forums about their stance on "homosexual rights," even when the topic seemingly had nothing to do with sexual or gender justice. Now understood as a "package deal," democratic rights were presented as only available to those who were able to stand up for any and all of them.

The secularist suspicions of the AKP government's motives behind the redrafting of the constitution and the weakening of the military seemed to echo in the headscarf skepticism of even those who were willing to have the conversation with headscarf activists and who sympathized with women's right to education regardless of their level of piety. While initially some Muslim headscarf activists openly stated that they did not know much about LGBT rights or the conditions of "homosexuals" in the country and shied away from making any statements, ultimately, this conflation seemed to be sanctioned by a number of Muslim human rights NGOs making a collective declaration in 2010 in support of the AKP minister Aliye Kavaf, who in an interview with the Turkish daily Hürriyet stated that homosexuality was an illness and that it needed to be cured (Bildirici 2010). A number of journalists published criticisms of this declaration, stating that Muslim NGOs had failed the litmus test of human rights (Türker 2010; Uğurlu 2010; Yaras 2010). In the aftermath of this declaration, a third Muslim headscarf supporter voice emerged, critiquing those who claimed homosexuality to be an illness. The most prominent voice of this position, Hilal Kaplan, criticized Muslims' embrace of the secular-scientific rhetoric of "illness" and argued that for Muslims homosexuality was not an illness, but a sin. 
I discuss the complex positions various headscarf activists and some other Muslim human rights organization members held vis-à-vis "homosexual rights" elsewhere in more detail (Savci 2016). For the purposes of this piece, however, I want to point out two important lessons for how ethnography and attention to various practices of language can contribute to translation studies. For one, this story illustrates how various reactions that seemed to "not support LGBT rights" in fact are quite different in their positions vis-àvis sexuality, modernity, religion, and liberal rights discourses. Overlooking their differences and the complexities of these political and intellectual positions and lumping them together under the same homophobic "against LGBT rights" rubric only serves to further lock ourselves into binaries of "pro/against," which then easily maps onto "us versus them." I do not find these binaries simply empirically untenable, or intellectually unviable, but also politically dangerous. The "mildly Islamist" AKP government, which increasingly proved to favor authoritarian and autocratic rule, has gained a lot of power from these divisions, as exemplified in the then Prime Minister Erdoğan's infamous framing of his voter base as his " $50 \%$ " and his reference to Gezi Park protestors as drunken looters. Simple "us versus them" divisions all over the world serve ultra-nationalist, fascist, and anti-immigrant sentiments. It is for this reason, if for no other, that it is worth paying attention to how language is practiced and how various subjects might articulate quite different and at times contradictory positions even as they utter the same words.

And second, this story reveals that not everyone has legitimate access to particular languages, and in this case, the language of "human rights." Mere articulation of a discourse does not tell us about how such articulations are received. In other words, I suggest that not only does addressing not guarantee whether the message will arrive at its destination (Sakai 1997), but it also does not tell us anything about how it will arrive. ${ }^{5}$ In this particular case, what was employed in exchanges where women headscarf activists were being questioned regarding their position on LGBT rights was a "perverse" rights-discourse, where "fundamental rights and liberties" were treated as a totality, yet not everyone's relationship to the discourse (and exercise) of fundamental rights and liberties was seen as equally genuine. Therefore, some were required to produce proof of their sincerity while others were not, which would then serve as proof that they deserved the fundamental rights and liberties they were requesting.

The logic of sincerity that framed deserving versus undeserving subjects of human rights was informed by what some secularists suspected Muslim headscarf activists to be as articulated in the phrase kendine Müslüman [Muslims to themselves]. This expression indicates not only self-seeking motives on behalf of those who are claimed to be Muslims to themselves-suggesting they are only after their own rights, liberties, and welfare-but also points out a deep-seated insincerity by underlining Islam's emphasis on justice and welfare for all. To be a true Muslim therefore is to be a Muslim to everyone. 
As such, in this contemporary use against pious Muslim groups in Turkey, the expression kendine Müslüman married religious insincerity with political insincerity, simultaneously dismissing the religiosity and the political motives of Muslim groups, and particularly of women with headscarves. Therefore, the use of "human rights" as a recognizable liberal framework to demand the right to wear the headscarf did not have the same effect as demanding just any other right due both to the political histories of the Republic, as well as to what some perceived to be a particularly tenuous moment in time regarding the redrafting of the constitution.

One final note on the place of ethnography in this particular case study: A lot of these debates occurred, as I recounted earlier, in newspapers or television shows, and unlike the rest of my case studies, the archive for this particular story relies on fewer ethnographic observations or interviews-so how is this any different from classic content analysis? ${ }^{6}$

My ethnographic sensibilities and training in queer theory always push me to look at the unruly and the uncategorizable, and do not allow me to look for a simple "Muslim stance" on the issue of homosexuality. Yet my ethnographic work, too, very much framed my understanding of these debates. At the time, there was a tangible joy and excitement in the country, especially among liberals who were celebrating finally having a government that was attentive to ethnic and religious liberties, and also the fact that that government happened to be an openly "mildly Islamist" party. The staunch and violent secularism of the Republic, a history replete with bloody military coups as well as repression of ethnic minorities in the name of "Turkish national unity," had left many wishful for everything AKP seemed to stand for: that democracy did not need the "protection" of an army, that pious Muslims finally had a chance to show that they, too, knew how to work toward a democratic future, that the nationalistic myths upon which this country was built were crumbling, and that citizens finally had a chance to rebuild those foundations and imagine a coexistence that worked for all those subjected to the nation, and not only an elite few.

Many LGBT activists, along with a large number of "straight" citizens, experienced both the hope and the disillusionment of AKP's politics, and it is in this context that a rethinking of Islamic piety and alliances became possible but then were quickly foreclosed. This was evident both in the individual activists" rhetoric, but also in the approaches to "religion" in two different Pride Week events. In 2008, a panel on LGBT rights in Muslim societies featured activists from Lebanon, Palestine, and South Africa, who were struggling to create a living space for LGBT-identified subjects in their home countries without reproducing Orientalist and Islamophobic tropes. In 2010, however, a forum on LGBT and religion had quite an anti-religion tone, somewhat due to the moderator's seemingly personal position on the issue, and the few objections that iterated religion's importance or simply asked why such an attack on religion was necessary or desirable were dismissed without actual engagement. ${ }^{7}$ Thus, my "reading” of the unfolding of 
these debates is very much informed by my ethnographic observations of the changing political positions of LGBT activists, as well as the larger political debates in the nation.

\section{To Conclude}

If following Raymond Williams (1977) we accept that language is social practice and a historically changing structure, then ethnography gives us access to understanding how exactly language is practiced, and allows us to trace the effects of linguistic change. Combining ethnography as a method and translation as a methodology/approach to knowledge also helps us to further historicize and transnationalize languages, thanks to translation studies' emphasis on the historical constitution and the circulation of what we come to refer to as "languages."

Queering translation via ethnography then enables us to treat language in all its complexity, especially revealing how meaning is made in practice and how changes in language and in practice inform each other. This has particular salience, as political language and political practice are deeply linked, informing what we come to imagine as a politically viable future. This also means that translation studies can become the interdisciplinary field par excellence, combining insights from humanities and social sciences and allowing us to understand the textual, the verbal, and the social in relationship to each other.

Furthermore, ethnography helps expose the heterogeneity of "the local" and thus contributes to the breaking down of the source versus target language binary that translation studies scholars are working against. This move by extension would also put pressure on what constitutes "the center" - not in order to dismiss existing power differentials in languages and so-called cultures but to denaturalize and historicize such asymmetries. I see exposing the heterogeneity of the "local" to be a crucial task of scholars who are invested in exposing global inequalities, given the ease with which critical analyses invested in exposing the effects of, for instance, US cultural imperialism can have the unintended outcome of producing the very third world difference they seek to dismantle (Mohanty 1988). As I argued earlier, exposing that there is no singular "Muslim stance" on the issue of LGBT rights in Turkey is not only a matter of factually accurate scholarship but also a matter of undoing the "Muslim versus secular" binary that has served the authoritarian and autocratic politics of the current Turkish government.

Finally, the complexity with which ethnography allows us to translate "queer" and to queer translation also has potential to contribute to decentering queer studies' English-centeredness. Translation studies already has a wealth of scholarship that historicizes and thus complicates the very thing that we refer to as "language" and puts pressure on the modern regime of translation that privileges homolingual address. In my current book project, I emphasize that queer theoretical arguments about language being 
constitutive of the subject neither properly historicize language nor do they imagine the constitution of subjects in a heterolingual world. If queer theory's interest in questioning sexual epistemologies, and their co-articulations with racialization, colonialism, imperialism, medical, psychiatric and penal institutions, and neoliberal capitalism (Eng et al. 2005: 2) is sincere, then bringing translation studies to bear on queer studies can hopefully have the effect of rendering queer theory finally heterolingual. This would complicate the various co-articulations of sexual epistemologies with colonialism, imperialism, or neoliberal capitalism as they are currently imagined to happen both within and through English-language terminology, as well as homolingually. What ethnography can contribute to the effect translation studies can have on queer theory is to complicate "the local," and thereby prevent simplistic reductions of the cultural to the linguistic. Such reductionist accounts themselves always already rest on assumptions about the unity of national languages and the historical erasures that have followed from them.

\section{Notes}

1 I disagree with Mezzadra and Neilson's (2013) characterization of ethnography as requiring "an ethnographic data set obtained primarily through direct sensory experience" (a description they borrow from Feldman (2011)), which they find to be a shortcoming of ethnography, especially in studying global processes that require attention to movements across borders. I do not have the space for an extended discussion of this issue, but it is worth noting that this approach overlooks ongoing debates within Sociology about the relationship between theory and evidence (for a recent contribution, see Reed's (2011) Interpretation and Social Knowledge), and especially about ethnography's ongoing place as a questionable method for producing "generalizable knowledge." But as many ethnographers know, what we produce knowledge about is not always directly observable "facts"-for instance "habitus" and "field" are not necessarily simple empirical and observable facts, but they became concepts through which Bourdieu orders and makes sense of the things he observes as an intellectual. Further, given that ethnography in its ideal form is not about freezing social fields even when they do not move across borders in the classic sense, it is unclear why we should believe it would be an inadequate way to study global processes that involve mobility and borders. A great example of such ethnography is Anna Tsing's (2005) Friction: An Ethnography of Global Connection, with which Mezzadra and Neilson (2013) also seem to find a great deal of affinity.

2 There are some exceptional cases where an ethnography directly deals with a category. See for instance David Valentine's (2007) Imagining Transgender: An Ethnography of a Category.

3 It is worth noting here that these divisions did not necessarily produce a binary of those who voted yes and those who voted no. A large number of voters vetoed the referendum, as they found the draft to be lacking in critical areas, yet voting no to a civil constitution that would replace a militaristic one did not seem in good conscience.

4 In fact, during my field work I traveled with Lambdaistanbul activists to Ankara to hand in the signatures collected over the last few months for a petition demanding that "sexual orientation" and "gender identity" be included in the 


\section{Evren Savci}

anti-discrimination law of the Constitution. There was no mention of gay marriage as an issue on the LGBT groups' agenda on the petition, and neither during any of the meetings or protests.

5 This point also relates to Asad's (1993) discussion of unequal languages I cited earlier. He emphasizes that the inequality of languages in cultural translation is not simply a matter of translating Dinka, or Kabbashi Arabic into English, but an accommodation "in the sense of a British, middle-class, academic game as opposed to the modes of life of the nomadic, tribal Sudan" (1993: 193). Thus, language is always also affected by class and other axes of inequality. In this case, what determined different users' access to human rights languages was not necessarily directly their class, but where they were imagined to fall vis-à-vis the secular principles of the Republic.

6 I should note here that I did reach out to Hilal Kaplan for an interview, but she never returned my email.

7 One of the speakers on the 2008 panel was the South African gay imam Muhsin Hendricks, who is also extensively featured in Parvez Sharma's 2007 documentary A Jihad for Love.

\section{References}

Alexander, Jeffrey. 1990. “Analytic Debates: Understanding the Relative Autonomy of Culture." In Culture and Society: Contemporary Debates, edited by Jeffrey Alexander and Steven Seidman, 1-27. Cambridge: Cambridge University Press.

Asad, Talal. 1993. Genealogies of Religion: Discipline and Reasons of Power in Christianity and Islam. Baltimore, MD: The Johns Hopkins University Press.

Baker, Mona. 2010. "Narratives of Terrorism and Security: 'Accurate' Translations, Suspicious Frames.” Critical Studies on Terrorism 3(3): 347-364.

Bassi, Serena. 2017. "Translingual Queer Practice: International English and Translated Sexualities." In Feminist Translation Studies, edited by Olga Castro and Emek Ergun. London: Routledge.

Bildirici, Faruk. 2010. Escinsellik Hastalik, Tedavi Edilmeli [Homosexuality Is an Illness; It Should Be Cured], March 7. Available online at http://arama.hurriyet. com.tr/arsivnews.aspx?id=14031207 (last accessed April 17, 2011).

Chakrabarty, Dipesh. 2000. Provincializing Europe: Postcolonial Thought and Historical Difference. Princeton, NJ: Princeton University Press.

Çolak, Saliha and Abdullah Karakuş. 2008. "Eşcinseller de eşitlik istiyor, verecek miyiz? (The Homosexuals Are Also Demanding Equality, Are We Going to Bestow It?)" Milliyet, January 28. Available online at www.milliyet.com.tr/2008/01/28/ siyaset/asiy.html (last accessed April 17, 2011).

Cronin, Micheal. 2009. "Response." Translation Studies 2(2): 216-219.

Eng, David, Judith Halberstam and Jose Munoz. 2005. "What Is Queer About Queer Studies Now?" Social Text 23(3-4): 1-17.

Feldman, Gregory. 2011. "If Ethnography Is More Than Participant-observation, Then Relations Are More than Connections: The Case for Nonlocal Ethnography in a World of Apparatuses." Anthropological Theory 11 (4): 375-395. Foucault, Michel. 1980. Power/Knowledge: Selected Interviews and Other Writings 1972-1977. Edited by Colin Gordon. New York: Pantheon Books.

Geertz, Clifford. 1973. The Interpretation of Cultures. New York: Basic Books.

Haraway, Donna. 1988. "Situated Knowledges: The Science Question in Feminism and the Privilege of Partial Perspective." Feminist Studies 14(3): 575-599. 
Hays, Sharon. 1994. "Structure, Agency, and the Sticky Problem of Culture." Sociological Theory 12: 57-72.

Hill Collins, Patricia. 1990. "Black Feminist Epistemology." Black Feminist Thought, 251-271. New York: Routledge.

Mezzadra, Sandro and Brett Neilson. 2013. Border as Method, or, the Multiplication of Labor. Durham, NC: Duke University Press.

Mezzadra, Sandro and Naoki Sakai. 2014. "Introduction." Translation: A Transdisciplinary Journal 4: 9-27.

Mohanty, Chandra. 1988. "Under Western Eyes: Feminist Scholarship and Colonial Discourses." Feminist Review 30: 60-88.

Reed, Isaac Ariel. 2011. Interpretation and Social Knowledge. Chicago: University of Chicago Press.

Sahlins, Marshall. 1976. Culture and Practical Reason. Chicago: University of Chicago Press.

Said, Edward. 1979. Orientalism. New York: Vintage Books.

Sakai, Naoki. 1997. Translation and Subjectivity: On "Japan" and Cultural Nationalism. Minneapolis, MN: University of Minnesota Press.

Savc1, Evren. 2017. "Language and Social Knowledge.” Ethnography 18(1): 57-67.

Savc1, Evren. 2016. "Subjects of Rights and Subjects of Cruelty: The Production of an Islamic Backlash Against Homosexuality in Turkey." Political Power and Social Theory 30: 159-186.

Sewell, William H., Jr. 1992. “A Theory of Structure: Duality, Agency, and Transformation." American Journal of Sociology 98: 1-29.

Sharma, Parvez. 2007. A Jihad for Love. New York: First Run Features.

Simon, Sherry. 2009. "Response." Translation Studies 2(2): 208-213.

Tsing, Anna. 2005. Friction: An Ethnography of Global Connection. Princeton, NJ: Princeton University Press.

Türker, Yıldırım. 2010. Müslüman'a En Büyük İmtihan [The Biggest Exam for the Muslim]. Radikal, April 12. Available online at www.radikal.com. tr/Radikal.aspx ? a Type $=$ RadikalYazar $\&$ ArticleID $=991007 \&$ Yazar $=$ YIL DIRIM+T\% C3\% 9CRKER \&Date $=12.04 .2010 \&$ CategoryID $=97 \&$ utm_ source $=$ feedburner\&utm_medium $=$ feed $\&$ utm_campaign $=$ Feed $\% 3 \mathrm{~A}+$ Yildirim Turker+\% $28 \mathrm{Y} \% \mathrm{C} 4 \% \mathrm{~B} 1 \mathrm{ld} \% \mathrm{C} 4 \% \mathrm{~B} 1 \mathrm{r} \% \mathrm{C} 4 \% \mathrm{~B} 1 \mathrm{~m}+\mathrm{T} \% \mathrm{C} 3 \%$ BCrker+Radikal+ Yaz \%C4\%B1lar\%C4\%B1\%29 (last accessed April 18, 2011).

Uğurlu, Ozanser. 2010. Hani mazlumun yanındaydınız? [So You Were Supporters of Subjects of Cruelty?] Radikal 2, March 28. Available online at www.radikal. com.tr/Radikal.aspx?aType $=$ RadikalEklerDetayV3\&ArticleID $=988209 \&$ Catego ryID=42 (last accessed May 6, 2011).

Valentine, David. 2007. Imagining Transgender: Am Ethnography of a Category. Durham, NC and London: Duke University Press.

Williams, Raymond. 1977. Marxism and Literature. Oxford: Oxford University Press.

Yaras, Dilek. 2010. “Mazlum-Der'in turnusol kağıdı: Eşcinsellik” [Mazlum-Der's Litmus Paper: Homosexuality]. Internethaber, March 30. Available online at www.internethaber.com/mazlum-derin-turnusol-kagidi-escinsellik-9536y. htm? interstitial=true (last accessed May 6, 2011).

Yildiz, Yasemin. 2012. Beyond the Mother Tongue: The Postmonolingual Condition. Bronx: Fordham University Press. 


\title{
6 In All His Finery \\ Frederick Marryat's The Pacha of Many Tales as Drag
}

\author{
James St. André
}

\section{Introduction}

In 1835, the British popular novelist Frederick Marryat published a pseudotranslation, The Pacha of Many Tales. Like many eighteenth- and nineteenthcentury collections of stories, it imitates the structure of the Arabian Nights. In Marryat's book, the pacha ${ }^{1}$ is bored with life and tries various means to relieve the boredom; none work until a courtier suggests listening to storytellers to provide him entertainment. This loose framework eventually ends with the pacha being deposed and killed by one of the storytellers, who, we learn, is actually a Frenchman disguised as a follower of Islam. The entire collection is shot through with irony, contempt for oriental despotism, and a predilection for tales in which nothing is as it seems, with cross-dressing, spying, and subterfuge figuring prominently in all the tales.

The majority of the tales are told by various foreigners, who promise the exotic to the pacha, just as Marryat offers this exotic collection to the British reader. The tale told by the storyteller who has traveled the greatest distance, a Chinese narrator, turns out to be an adaptation of an authentic translation of a Chinese play, The Sorrows of Han (1829), by John Francis Davis, who worked for the British East India Company and translated many works into English. So, within a large collection of original work by Marryat, one tale is borrowed. Like so much else in the collection, then, the tale is passing as something other than what it is-a sort of reverse authentic fake.

Marryat's version of the tale, somewhat shorter than Davis's translation, can be summarized briefly. ${ }^{2}$ The Chinese emperor Youantée consults his soothsayers regarding the taking of a wife; the results are cryptic and promise heartbreak and sorrow, but he decrees nonetheless that all the country's most beautiful women must have their portraits painted and presented to the throne for consideration as his future wife. His minister, Suchong Pollyhong Ka-te-tow, takes advantage of being in charge of this selection process to accept huge bribes from many people anxious to have their daughter selected. Only Whanghang, the proud father of the country's most beautiful woman, Chaoukeun, refuses to offer him a bribe, and in revenge, the portrait of an ugly woman is substituted for that of his daughter. Enraged 
that such an ugly woman should have had the audacity to enter the competition, the emperor has her locked up in the inner palace, where one night he overhears her singing. Enraptured, he discovers who she is and resolves to punish Ka-te-tow, who flees with her real portrait to the Tartars in the north, persuading their khan to demand her in marriage as the price of peace. The Chinese acquiesce, but, rather than become the khan's wife, Chaoukeun drowns herself in a river on the border between China and Tartary. In most of these plot details, Marryat follows Davis's translation very closely, although there are changes in focalization and some events are reinterpreted, as discussed below.

One way to understand this story would be to perform an orientalist reading of the text. In such a reading, the entire text would become a justification of European superiority over the Orient, with rampant corruption, incessant toadying, and vicious backstabbing displaying all too clearly why the British must take up the "White Man's Burden" in Egypt and beyond.

The problem with such an approach is that it reduces all the texts to a single message and fails to acknowledge the great differences among the various textual practices engaged in the production and reproduction of knowledge about the orient. Why, for example, does Marryat employ certain textual practices, especially (but not limited to) exaggeration, and what might that tell us about his message? How do we account for the differences in approach found when comparing Marryat's adaptation with Davis's original translation?

Elsewhere, I have argued that this embedding of an adapted authentic translation within a larger pseudo-translation (for, of course, the text presents itself as an authentic record of happenings in Egypt, including dialogue, all of which could only have taken place in Arabic) is an excellent example of why the boundaries of what we consider the proper domain of translation history should be "queered" to include both pseudo-translation and adaptation (St. André 2012).

Building on my previous work, I wish to consider The Pacha of Many Tales as drag translation, focusing on the story told by the Chinese narrator and the framing text found before, after, and in certain places within the tale. It is the interaction between these two textual features, and their situation within the larger framework of the Arabian Nights-like structure of the story collection as a whole, that produces this specific drag effect. Before doing that, however, some discussion of the use of metaphors in translation research is in order.

\section{For a Queer Metaphoric Understanding of Translation}

Metaphors have played a crucial role in understanding translation from antiquity down to the present, as discussed in the collection Thinking through Translation with Metaphors (St. André 2010). Depending upon what sort of metaphor(s) we choose to describe translation, we may imagine translation in different ways, or focus on different aspects. Metaphors 
of translation as static objects (the reverse side of a rug, for example) focus our attention on the finished product, and suggest a very tight and local correspondence between parts of the source text and parts of the target text. Metaphors such as les belles infidèles at once personify, gender, and denigrate translation. The metaphor of translation as walking in the footsteps of the source text author shifts attention away from the finished product onto the act of translation, emphasizing the translator's skill as a kind of detective tracking the author's every move. In all of these cases, we can see how different metaphors frame the translation process in radically different ways.

Metaphors for translation can also reveal underlying conceptions of language, communication, and cognition. The metaphor of translation or the translator as conduit has been shown to be undergirded with a particular philosophy of language, that of meaning versus form, where meaning is conceptualized as being independent from its formal expression in any one particular language. Meaning is therefore capable of being moved and/or repackaged through the process of translation, with its "outer appearance" changed while its "inner essence" remains identical (for more detail see Martin de León 2010).

My ongoing project of queering translation adopts a new performative metaphor, as detailed in my upcoming monograph Translating China as Cross-Identity Performance (2017). Cross-identity performance offers a non-essentialist, post-positivist way of understanding translation and captures a variety of practices, including but not limited to passing, slumming, blackface, masquerade, and drag. As I argue in my monograph, the complexity of the metaphor mirrors the complexity of the translation process, although they share in common the (mis)representing of an Other by a performer who is capable of operating in two different cultural spheres. It also shifts emphasis away from the oft-decried image of the translator as copyist to an understanding of translation as transcreation, thus attributing to the translator creative agency. Moreover, that transcreation is based not on the faithful rendering of a particular work, but on the deployment and reworking of generic or typical features of particular text types. If crossing is based on the mimicry of general traits, then we can begin to think of translation not in terms of equivalence or fidelity but in terms of successful or unsuccessful performance, and we can also consider other related types of textual practices, such as pseudo-translation and adaptation, as in the case of Marryat. Since drag, as we will see below, emphasizes the performative nature of translation through exaggeration and parody, which is a general feature of Marryat's work, it allows the Chinese translated tale to be integrated into the wider thematics of the book as a whole. It also foregrounds the importance of ambiguity and the coexistence of multiple layers of meaning. Specifically in Marryat's case, this will, hopefully, offer a more nuanced approach to the complexity of the colonial encounter, allowing us to move beyond a reductive orientalist reading of his work.

Finally, and perhaps most importantly in the particular case of The Pacha of Many Tales, it also allows for new insights into old questions in translation studies, such as the (in)visibility of the translator, by rethinking the 
translator's traditional invisibility not as indicative of a passive victimhood but rather as offering a host of performative possibilities. Queering translation in that sense acknowledges that invisibility or semi-invisibility is a part of the translators' habitus. Thus, rather than seeing invisibility in exclusively negative terms, these queer metaphors allow us to see the creative performative possibilities offered by semi-visibility, insofar as these performances rely on the play between the visible and the invisible. Thus they better capture the unique nature of the translator's task, with invisibility no longer being seen as the translator's curse or burden but rather as opening up unique performative possibilities for the translator to exploit. ${ }^{3}$

\section{Sir John Francis Davis's 1829 Translation}

Since Marryat's drag performance is based on a genuine translation, a few words concerning that text are in order here. First, there are virtually no authentic translations from Chinese into English before the late eighteenth century. However, the vogue for oriental tales, which started with Letters Writ by a Turkish Spy (Marana 1691) and The Arabian Nights Entertainment (Galland 1712) led to a plethora of pseudo-translations purporting to be translations from various oriental languages, including Chinese (see Conant 1908). The late eighteenth and early nineteenth century was a period of reaction against such literary fakes and pseudo-translations. Thus writers sought to establish the "truth" of their translations in opposition to the pseudo-translations (St. André 2006). From "truth" to "true and faithful translation" is a short step, and so plain-Jane translations were the watchword of the day rather than the "belles infidèles." In my taxonomy of cross-identity performance, such a style of translation is akin to "passing," claiming to be that which it is not: an authentically "Chinese" voice in English. ${ }^{4}$

Davis accomplishes this passing by claims of authenticity and absolute fidelity to the original in the paratextual material, along with silent but extensive changes in the translation. This makes the text read as a "simple" and "plain" tale, which Davis in his introduction advances as the reason he translated the piece in the first place: the simple and moving story accurately reflects Chinese culture, society, and family organization, and is therefore a true representation of China. (St. André 2017)

Davis's translation thus functions to tell an "unvarnished" truth about China and the Chinese: that, in comparison to the Tartars to the northwest, they are cowardly and ineffectual when it comes to protecting their borders. Rather than leading his men out to protect the women and children on the battlefield, the emperor is reduced to bartering for peace by offering one of his female subjects, the most beautiful and talented woman in his palace. Her willingness to sacrifice herself for the common good of the country and the safety of the emperor sends a strong condemnatory signal regarding the emasculated state of Chinese men. As Chaoukeun is the only really strong character in the story, her death, and the khan's subsequent decision to respect the sacrifice of her life to protect her chastity, serves as a disturbing 
condemnation of the entire Chinese empire. Davis's "plain” translation only serves to highlight the tragedy of her situation, dignifying it with simple yet eloquent language that passes as an authentic account of how the Chinese really are. Understanding his translation as a form of passing helps to bring into focus the gendered and racial stereotyping in the text.

\section{Marryat's Drag Appropriation}

Marryat's textual practice could not be more different, although I noted earlier that he sticks fairly closely to Davis in terms of the basic plot. On the macro level, Marryat turns Davis's play into a short story and, in the process, also gets rid of all paratextual notes and explanations. These changes can be attributed to the need to fit the material into the existing framework of telling tales in The Pacha of Many Tales.

The prophecy near the beginning foretelling doom in Marryat's version is one significant addition. As the tale unfolds, the Chinese narrator periodically interrupts the flow of the story to comment on how events in the story fulfill the prophecy. These elements are related to a theme that is presented in the frame tale: the role of fate in human actions, part of an ongoing conversation between the pacha and Mustapha. The emphasis on fate in the Chinese tale thus ties it thematically into the collection as a whole. It also relates the tale to a large body of stereotypical representations of "Orientals" as resigned fatalists, as opposed to the British as believers in free will and individual choice. The Turkish term "kismet," which Marryat employs in the collection several times, is one key term in this fatalist discourse, thus inscribing the tale within a broader "oriental" geography. ${ }^{5}$

At the micro level, Marryat manages to preserve quite a bit of the imagery from Davis's translation, sometimes almost word for word. Minor details, such as the musical instrument the heroine plays (a lute; Davis 1829: 7; Marryat 1873: 300), or the use of lanterns held up at night to illuminate the face of the heroine the first time the emperor sees her (Davis 1829: 7; Marryat 1873: 301), are preserved; many other examples can be found in a line-by-line comparison of the two texts.

Even when Marryat follows Davis closely regarding details, however, he consistently exaggerates them, generally for comic effect. An illuminating example is when Marryat turns Davis's "Transmit our pleasure to the officer of the guard to behead Maouyenshow, and report to us his execution" (1829: 8) into: "Hasten, O mandarins, let the scissors of disgrace cut off the two tails of this wretch, and then let the sword of justice sever off his head" (1873: 301). Here several things are happening at once. The use of "hasten" as a command, coupled with the "O" in front of mandarins (both already old-fashioned and formal diction in the nineteenth century) establishes the emperor as someone used to thinking of himself as an absolute authority. The employment of parallel structure, "let the X of Y perform an action," which is potentially lofty diction (think of all the coordinated synonyms in legal terminology such as "terms and conditions" and "cease and desist") is 
set up only to be subtly undermined by the choice of terms and the logic of the actions. "Sword of justice" is a perfectly normal collocation, but when it follows the faintly ridiculous "scissors of disgrace," the whole tone of the passage is thrown into question.

The implication that cutting off someone's hair to disgrace them is thought to be a penalty of equal weight to decapitation is part of a dense network of references to hair in the section relating both to the Chinese storyteller and to other sections of the narrative. These references draw at least partially upon stereotypes circulating in the nineteenth century regarding the Manchu hairstyle, which was mandatory for all adult males in the Qing empire. Failure to adopt the hairstyle was tantamount to treason and could be punished by death. Referred to in English neutrally as a "queue" or derogatively as a "tail" and "pigtail," the queue was one of the most visible signs of Chineseness to the foreign eye, and contributed to the spectacle of Chineseness in a wide variety of formats, including cartoons. ${ }^{6}$ In evoking that stereotype and exaggerating it (cutting someone's hair is tantamount to killing him), along with the overblown rhetoric, the sentence becomes drag.

Moreover, other sections of The Pacha of Many Tales also contain references to hair, queues, tails, and haircutting. One important narrative is told by a barber, and when a British sailor is introduced we are first told by Mustapha that "his hair is hanging behind, down to his waist, in a rolled up mass, as thick as the arm of your slave," and then when he actually appears he is described as having "a tail which hung down behind, below his waist" (1873: 252). The persistent references to barbers, long hair, and "tails" on men throughout the text alerts the reader to the importance of this detail in the Chinese text, and reaches out to biblical descriptions of male hair, specifically the story of Sampson and Delilah, for in that story hair is literally equated with life: once Sampson's hair is shorn, he loses his strength and is doomed to death. When discussing the danger the British sailor risks when he sits down in the presence of the pacha, Marryat says that he was "unmindful how very near he was to one who could cut off his head or his tail by a single movement of his hand" (1873: 251), again equating the preservation of one's hair with preservation of one's life. Finally, the "tails" of various narrators are also homophones of the "tales" of the pacha.

Another, more extreme example of exaggeration in Marryat's adaptation from Davis's translation occurs just before this passage. Hearing the sound of the heroine playing the lute, the emperor in Davis's version says to an attendant, "Discover to what part of our palace that lady pertains; and bid her approach our presence: but beware lest you alarm her" (Davis 1829: 7). Marryat turns this simple action into an elaborate drag scene:

Go, then, and quickly summon all our highest officers of state, to lay their robes upon the ground, that she may pass over them to our presence at the dragon below the terrace.

The Magnificent Youantee, brother of the sun and moon, returned to his former seat, filled with pleasing anticipations, while the eunuch 
hastened to obey the celestial commands. The mandarins of the first class hastened to obey the orders of Youantée; their furred and velvet cloaks, rich in gold and silver ornaments, were spread from the tower to the dragon at the terrace, forming a path rich and beautiful as the milky way in the heavens. The pearl beyond price, the peerless Chaou-keun, like the moon in her splendour, passed over it into the presence of the great Youantée.

(Marryat 1873: 300-301)

Here Marryat accomplishes his drag performance mainly by the addition of modifiers. "Youantée" is modified by both "Magnificent" and "brother of the sun and moon," while "cloaks" are modified by "furred and velvet" and "rich in gold and silver ornaments." The heroine is not merely "Chaoukeun," but "the pearl beyond price" and "peerless," and her progress is "like the moon in her splendour." The richness of this descriptive prose is analogous to the glittering sequins, feather boas, and other over-thetop accoutrements typically favored by drag queens. Indeed, the choice of imagery-the sumptuous clothing thrown down-cries out to be interpreted as drag spectacle, which typically features elaborate costumes.

At the same time, the modifiers are all chosen with a double meaning; on the surface, they are all positive, yet it is clear that the underlying meaning is negative. This double valence is made possible by the attribution of these superlative descriptions to the mindset of the Chinese narrator. In other words, the use of the figure of the Chinese narrator for the story means that, far from representing the views of the author Marryat, they are to be taken by the British reading public as representative of how Chinese people think, and the sum total is that the Chinese appear to be full of themselves.

\section{Drag and Spectacle}

Looking at these two examples and thinking of Marryat's work as drag performance draws attention to the fact that, on many levels, the story itself is centrally about spectacle. Virtually all the characters in the play make a spectacle of themselves. The khan is portrayed as a horse-flesh eating, kvass-drinking man of few words, interested only in war and plunder; the emperor is portrayed as impossibly self-centered and unrealistic in his expectations, at one point throwing a temper tantrum and issuing an edict that everyone in the country should be beheaded because he has not gotten his way. The evil minister is re-christened with a faintly silly name, Suchong Pollyhong Ka-te-tow, and has a penchant for flowery speeches, regaling the khan with a long and rambling speech only to find himself rudely cut off by the khan, who demands that he get to the point. Finally, even the heroine, who is perhaps the most sympathetically portrayed character, is made a spectacle of twice. The first time is when she is ushered into the presence of the emperor, treading on the cloaks that have been thrown down before her feet; the second, after having 
agreed to marry the khan because she thinks he will be more manly than the Chinese emperor, she kills herself in a dramatic gesture when she meets the khan on the border and finds him ugly and uncouth, sighing over her fate and blaming the prophecy. These are all significant departures from the way in which the characters are portrayed in Davis's translation. In that version, the heroine sacrifices herself, not out of disappointment, but for patriotic reasons; moreover, her death brings peace to the realm, the khan being awed by her self-sacrifice and withdrawing his troops without attacking. That ending is omitted in Marryat's version, the story ending instead with a declaration that the prognostication by the ministers at the beginning of the story had been fulfilled, thus again foregrounding the issue of fate as a general "Oriental" characteristic.

The importance of spectacle to drag also explains the centerpiece of Marryat's tale, the wedding procession of Youantée and Chaoukeun. This set piece, which occupies four pages, is something that is completely absent from Davis's translation. All of the techniques noted earlier involving exaggeration and the use of modifiers are employed here, with each line more ridiculous than the last, so that even the pacha, who is elsewhere portrayed as fairly credulous when listening to the tales, doubts its veracity.

The importance of spectacle is not limited to the story itself: the Chinese story is prefaced by a short scene wherein the narrator is ushered into the presence of the pacha. The man's old and wrinkled appearance, symbolic of the belief that China was an ancient civilization, is combined with terminology that emphasizes his craven behavior, including the performance of a kow-tow, in front of the pacha, who is "pleased with the man's humility" (1873: 294).

This description can be contrasted with that of another of the narrators, the British sailor, whose manly demeanor and upright carriage are the antithesis of the Chinese. The sailor, however, can also be profitably read through the lens of drag. Marryat makes him an inveterate drunk, a brawler, and chewer of prodigious wads of tobacco that cause him to look deformed (1873: 250-251). In other words, Marryat has condensed and exaggerated key features of nineteenth-century British sailors, just as he has condensed and exaggerated features of the Chinese narrator, an indication that Marryat's style is not so much oriental as generally satirical.

Both the Chinese and the British narrator are performing a drag spectacle for the pacha, almost like a fashion catwalk. They enter, display themselves, and are judged first on their appearance, second on their comportment and finally on their storytelling ability.

It is not just the various narrators who perform drag in the book, however. More importantly, the interpreting that is performed by the pacha's attendant Mustapha highlights how translation may contribute to a drag effect. Caught between a rude, uneducated British sailor, who when ushered into the presence of the pacha sits without being invited to do so, and the pacha, who expects all people to tremble in awe at his presence, Mustapha manages a creative interpreting "double act," which creates a stereotyped 
image of the Other for each man. When the sailor sits without invitation, Mustapha tells the pacha that the man is so in awe of him that his legs refuse to support him (1873: 251). When the pacha orders the man to tell his life story, Mustapha instead instructs him to tell a pack of lies (1873: 251).

This conscious mis-interpretation back and forth between the pacha and the sailor continues throughout the tale, resulting in the character Mustapha doing exactly what the author Marryat does with the Chinese tale: sticking closely to the plot but embellishing it with details that make it more stereotypically comprehensible to the other. When the sailor describes his wife as "as pretty a craft to look at as you may set your eyes upon; fine round counter-clean run-swelling bows-good figure-head, and hair enough for a mermaid," Mustapha turns this nautical description into one that could have come straight out of the Arabian Nights: "her eyes were bright as those of the gazelle, that her eyebrows were as one, her waist as that of the cypress, her face as the full moon, and that she was fat as the houris that await the true believers" (1873: 255). When the sailor mentions that he married two women and was tried for "biggery," his malapropism reminding the reader that he is uneducated, the pacha is as shocked to hear that one wife is the norm for the British, just as British readers were shocked to hear that Muslims took multiple wives; ${ }^{7}$ but then the pacha is reconciled to this seemingly preposterous cultural difference by deciding that an infidel deserves no more than one wife.

If we read the tale of the Chinese and the British storytellers side by side, then, a picture emerges of cross-cultural storytelling as always having the potential to become drag. The tale of the British sailor, which is full of preposterous lies and exaggerations, signals to us that Marryat himself is doing the same thing with Davis's translation, adapting it to appeal to a local audience while adding details that will resonate with pre-existing expectations.

Indeed, the Pacha of Many Tales may be read as not just demonstrating drag translation but actually celebrating it. In the frame tale, the most successful storytellers are those who perform the most outrageous drag for the pacha, to wit, the British sailor and the French Huckaback. Encouraged by Mustapha who, as we have seen, acts as (mis)interpreter, the British sailor piles one "whopper" on top of another. One section of his story begins,

"I sailed in a brig for the Brazils, and a gale came on, that I never seed the like of. We were obliged to have three men stationed to hold the captain's hair on his head; and a little boy was blown over the moon, and slid down by two or three of her beams, till he caught the mainstay, and never hurt himself."

"Good," said Mustapha, who interpreted.

"By the beard of the Prophet, wonderful!" exclaimed the pacha.

The result is that the pacha is pleased no end and rewards him liberally with gold. 
Recruited early in the collection by Mustapha to entertain the pacha with lies, Huckaback tells more tales than any other narrator in the collection (seven in total, in imitation of Sinbad) and, like the British sailor, finds that the more outrageous the tale, the more it pleases the pacha. His first tale is of his own youth, claiming to have been trained as a barber, and he regales the pacha with an account of how he removed "pounds of flesh" along with hair from customers when shaving them (1873: 86) or cut the throat of an English sailor with his razor while fighting him underwater (1873: 89). Finding the pacha somewhat bored by his first tale, which features a love story, Mustapha urges him to make up something more incredible on subsequent days. Huckaback obliges and spins yarns of ghosts, miracles, and all sorts of impossible events; the result is that the pacha is delighted by this drag performance and rewards him liberally.

Given the importance of references to tails and hair throughout the collection (the sailor whom Huckaback fights is described as having "a pigtail as thick as a cable" (1873: 88), and haircutting and shaving come up frequently), it is only fitting that a man who claims to be trained as a barber is, at the end of the collection, made pacha upon the death of the current pacha and the poisoning of Mustapha. But Huckaback is also the most frequent practitioner of drag throughout the collection, and thus it is that Marryat celebrates drag by crowning his most consummate drag artist.

Here we come to a central difference between an understanding of translation that is orientalist or orientalizing and one that sees it as cross-identity performance. With cross-identity performance, there is always the possibility of reciprocity and of multi-directional performance of various kinds-as underscored in Marryat's tale by the active role of the interpreter as creative mediator who is simultaneously a plain Jane and also a belle infidèle. Rather than insist that these translation techniques of exaggeration and stereotyping can only be used as the tools of a hegemonic colonial power, Marryat's text shows us that they can be used in a wide variety of situations to achieve different ends.

\section{Conclusion}

Marryat's adaptation may thus be profitably understood as drag spectacle, a reading that highlights several facets of the text. First, there is the fact that Marryat is parodying not only the Chinese, but other groups as well, including British sailors, the French, and Egyptians, suggesting a more nuanced perspective than the label orientalism affords.

Second, it allows a careful reading of certain elements in the text that reveal both what the British thought about China, but also how knowledge of China was bound up in more general discourse about the Other (the East) and the self. The use of specific imagery, in particular the "tail" of the Chinese narrator, is part of a dense network of references to hair and power throughout the work that draws upon the biblical image of Samson for its power, and prefigures the downfall of the pacha at the end of the collection, 
to be replaced by his barber. The collective weight of changes to details of the text shifts the emphasis of the story to the workings of fate or "kismet," stressing the similarities of the Chinese with other "Eastern" nations while contrasting the rugged individualism and mastery of one's own destiny supposedly embraced by the British.

Thus, approaching The Pacha of Many Tales through the lens of queer performance, specifically, drag, opens up new possibilities of interpretation and understanding, not just for the story of the Chinese storyteller, or even the entire work The Pacha of Many Tales, but of a wider network of textual practices that together create, maintain, and transform our understanding of other cultures.

\section{Notes}

1 Title of the governor of Egypt appointed by the Ottoman Empire; often spelled pasha.

2 Sixteen pages. All statistics regarding page numbers, length, and quotations from Marryat's book are based on the 1873 edition.

3 Thanks to the editors for pointing out the homologies between this question and the work of Hermans (1996) and Schiavi (1996), who argue that the translator always reveals her/himself in the translation, and that this constitutes one of the unique features of translated texts. My queer metaphors are ways to conceptualize this play with (in)visibility; hence the number of queer translators who see in translation a site at which they can reveal/conceal themselves (the work of Tyulenev (2010) on translation as queer smuggling is also apposite here). The phenomenon of pseudo-translation attests to the fact that authors saw translation as a unique and creative discursive position that played provocatively with (in)visibility.

4 I must note here that "belles infidèles" translations could also qualify as passing rather than drag if they espouse a style that is not foreign to the readers. This is one example where existing dichotomies do not always map neatly onto different categories of cross-identity performance. See St. André (2007) for a discussion of the relationship of this issue to the fleuriste versus anti-fleuriste debates in the late eighteenth and early nineteenth centuries.

5 Indeed, the working of fate is closely associated with the tradition of the oriental tale right from the beginning; see Irwin (2004: 197-200) for a discussion of its role in the Arabian Nights.

6 The distinction between Manchu and Chinese was seldom noted in the popular press, and therefore the queue could and was read simply as "Chinese" at this time in Britain. For just one example of how this hairstyle was depicted in the popular press, see Anonymous (1891).

7 Presumably, the genteel English audience would read "bigamy," although "buggery" is also available as a queer reading.

\section{References}

\section{Primary Sources}

Davis, Sir John Francis. 1829. Han Koong Tsew, or, the Sorrows of Han: A Chinese Tragedy. Translated from the original with notes. London: Printed for the Oriental Translation Fund by A.J. Valpy. 
Galland, Antoine. 1712. Arabian Nights Entertainments: Consisting of One Thousand and One Stories . . . Translated into French from the Arabian MSS, by M. Galland, of the Royal Academy; and now done into English from the last Paris Edition. London: Printed for Andrew Bell.

Marana, Giovanni P. 1691. The First Volume of Letters Writ by a Turkish Spy, Who Lived Five and Forty Years, Undiscovered, at Paris: Giving an Impartial Account to the Divan at Constantinople, of the Most Remarkable Transactions of Europe; and Discovering Several Intrigues and Secretes of the Christian Courts (Especially of that of France) from the Year 1637, to the Year 1682. Written originally in Arabick, first translated into Italian [or rather, written in Italian by G.P. Marana], afterwards into French, and now into English [by William Bradshaw?], 2nd edition. London: Printed for Henry Rhodes, near Bride-Lane, in Fleet-street.

Marryat, Frederick. 1873. The Pacha of Many Tales. London: George Routledge and Sons. [1st edition, London: s.n., 1835.]

\section{Secondary Sources}

Anonymous. 1891. "A Day with an East-End Photographer.” The Strand Magazine 1(5), May: 458-465.

Conant, Martha Pike. 1908. The Oriental Tale in England in the Eighteenth Century. New York: Columbia University Press.

Hermans, Theo. 1996. “The Narrator's Voice in Translated Narrative." Target 8(1): 23-48.

Irwin, Robert. 2004. The Arabian Nights: A Companion. New York: Tauris Parke.

Martin de León, Celia. 2010. "Metaphorical Models of Translation: Transfer vs Imitation and Action.” In Thinking Through Translation with Metaphors, edited by James St. André, 75-108. Manchester: St. Jerome Publishing.

Schiavi, Giuliana. 1996. “There Is Always a Teller in a Tale.” Target 8(1): 1-22.

St. André, James. 2006. "Traveling Toward True Translation: The First Generation of Sino-English Translators." The Translator 12(2): 189-210.

St. André, James. 2007. “The Development of British Sinology and Changes in Translation Practice: The Case of Sir John Francis Davis (1795-1890)." Translation and Interpreting Studies 2(2), Autumn: 3-42.

St. André, James (ed.). 2010. Thinking Through Translation with Metaphors. Manchester: St. Jerome Publishing.

St. André, James. 2012. "Exploring the Role of Pseudo-Translation in the History of Translation: Marryat's Pacha of Many Tales." In China and Its Others: Transforming Knowledge Through Translation: 1829-2010, edited by James St. André and Peng Hsiao-yen, 29-50. Amsterdam: Rodopi.

St. André, James. 2017. Translating China as Cross-Identity Performance. Honolulu, HI: University of Hawai'i Press.

Tyulenev, Sergey. 2010. “Translation as Smuggling.” In Thinking Through Translation with Metaphors, edited by James St. André, 241-274. Manchester: St. Jerome Publishing. 


\title{
7 Transgenderism in Japanese Manga as Radical Translation
}

\author{
The Journey to the West \\ Goes to Japan
}

Leo Tak-Hung Chan

The subversive nature of manga is a fact widely acknowledged. Using "an expressive format that combines stylized and simplistic imagery with a laconic text," it can "lampoon, satirize, romanticize [and] reimagine the world in which people live" (Allison 1996: 56-57). But what if the target of the parody is a text from another culture? A case in point involves the parodic manga versions of the Chinese classic The Journey to the West (Xiyouji; hereafter The Journey), representing a shift from a verbal to a visual medium and from a Chinese to a Japanese context. Not surprisingly, when such manga is translated back into Chinese, readers in China are offended to see their own cherished literary work tampered with, leading in 2007 to a critical attack on Japanese manga versions of a parodic nature (Lin and Zhang 2008: 168); official statements were issued concerning the need to curb the translation of such works in order to protect the health of Chinese culture. Much venom was directed not just at manga derived from The Journey, but on Japanese parodies in general. An article in the national newspaper Huanqiu shibao was subtitled "Why Does Japan Parody the Classics of Other Countries?" Among the commentators (e.g., Zhu 2007; Lin and Zhang 2008), the point was stressed that a culture of egao, or 'malicious meddling,' originated in a Japanese concept that had spread to Mainland China via Taiwan and Hong Kong. There were also strongly worded articles, such as "Malicious Meddling: When Does Cultural Sacrilege End?" and "Why Does Japan Meddle Maliciously with the Classics of Other Countries?"

The most contentious issue appearing in the spate of criticism directed against these versions of The Journey revolves around transgenderism, understood in its broader sense as referring to both gender and sex change, with transgendered individuals understood to include transsexuals, cross-dressers, and those who deviate from accepted social norms for males and females (Phillips 2006: 7-14). The most significant aspect of the Japanese "malicious meddling" is evident in the treatment of the central character Tripitaka (Chinese: Xuanzang; Japanese: Sanzō), who goes to India in search of the Buddhist scriptures: he is turned into a woman in the Japanese versions. Such transgendering has also occurred, though less frequently, with 
the three companions who join the historical-mythical quest for the Buddhist scriptures in India-the trickster Monkey (Chinese: Sun Wukong; Japanese: Son Gokū), the part-human, part-beast Pigsy (Chinese: Zhu Bajie; Japanese: Cho Hakkai), and the water-demon Sandy (Chinese: Sha Wujing; Japanese: Sha Gojō). ${ }^{1}$

In a way, the gender-bending found in Japanese manga based on The Journey is unique because the female or feminized monk does not appear in any East Asian (i.e., Korean) version (see Song 2011). Scholarship on this curious phenomenon has been rather divided and, following a feminist approach, one could highlight the attempt on the part of female manga artists to empower women and subvert traditional patriarchy, attaching much significance to the subversive potential of mass culture. But moving beyond such an approach, queer theory could offer a new perspective, since transgenderism, grounded on the knowledge that gender is mobile and not fixed, works effectively to deconstruct the essentialist male-female binarism itself. In this connection, we will be using the definition of "queer" offered by David M. Halperin in his biography of Michel Foucault, as "whatever is at odds with the normal, the legitimate, the dominant" (1995: 62). Diane Richardson's idea that queer theory is "a fluid, mobile, non-specific zone of enquiry that is resistant to being 'fixed" " (2006: 20) also demarcates it from much of traditional feminist theory.

What is of greatest interest in the manga versions of The Journey is that queerness is dealt with in the parodic mode, evidenced by instances of what both Reuben Brower (1974) and Andrew Riemer (2010: 43) have called "radical translation." Both scholars have sought to theorize the relationship between translation and parody, and what they have said can be appropriately applied to the present case study.

Brower notes that, although parodies work with the style or thought of the original, invariably the act involves playing in a constructive (showing admiration) or destructive (embodying rivalry) manner. Examples are "translations" of the Classics (The Iliad, Ovid, Lucan, and Vigil) by Dryden, Shakespeare, and Chapman. But for him, while both the parodist and the translator can have impure motives, "no translator sets out to parody (in the critical sense) the author he has chosen to translate, in a work publicly offered as a translation" (1974: 5). One strives for freedom; the other strives for fidelity. Parody, in other words, is practically impossible in translation proper. It is often seen, however, in the extremely free forms of translation we are looking at here. (See also St. André's chapter in this volume.) Because of the room allowed for manipulation, amplification, and recreation, the parodic is an available mode, as is obvious in many Japanese radical translations of The Journey. Riemer (2010: 43) also discusses parodic translations, a practice prevalent in the seventeenth and eighteenth centuries and exemplified by the English example of Samuel Johnson's free re-renderings of Greek and Latin originals. While alterations to the original text can be made to conform to cultural assumptions of the target audience, for Riemer, 
there is another possibility: changes can be made where the translator sees certain hidden potentials in the text that can be explored or exploited. The Japanese manga artists, in rewriting The Journey, can be viewed as creative manipulators, or radical translators.

\section{The Female/Feminized Monk and the Three Disciples}

Before exploring the incidents of transgenderism, let me provide a brief synopsis of the sixteenth-century Chinese folk novel. The Journey opens with the stories of the origin of the four main characters: Tripitaka, Monkey, Pigsy, and Sandy. After a description of the past history of the rebellious Monkey, we are told that Tripitaka is approached by the bodhisattva Guanyin, who entrusts him with the mission of retrieving the Buddhist scriptures from India so that the Chinese people may be enlightened. He then recruits the other three pilgrims in the first part of the story, and, as he does so, the reader also learns of the lackluster pasts of the lazy and lascivious Pigsy and the careless and indecisive Sandy. During the journey itself, the four pilgrims encounter a total of 81 "catastrophes" when demons abduct Tripitaka so they can devour his flesh, said to confer immortality on those who partake of it. While Monkey is able to fend off some of the demons, in many cases it is the intervention of Guanyin and other deities (like Red Boy) that saves the day. Their adventures are depicted in some famous episodes like those involving the Ox-Demon King, the Iron-Fan Princess, the White-Bone Spirit, and so on. The sequence of events is somehow presented as having taken place in actual geographical locations in Turkestan, Afghanistan, and Kyrgyzstan, but these are no more than fantasy recreations of places along the Silk Road. At the end, the pilgrims reach their destination, accomplish their mission of obtaining the scriptures, and are welcomed into the Buddha's palace. All these plot elements, themes, and characters are rewritten to varying degrees at the hands of the Japanese manga artists.

The following works are among contemporary manga published since the 1990 s that feature various aspects of transgenderism:

1 Terada Katsuya's The Marvelous Adventures of Monkey King [Saiyükiden daien'ō] (1995/1998-2010). In this story, the female monk is sadistically treated by Monkey, whom she accompanies on the journey west with the goal of killing Gautama Buddha.

2 Kamishiro Yū's Demonic Journey to the West [Yōma Saiyūki] (1994). This is in essence a girls' (shöjo) love story with the plot propelled by the demons fighting over the possession of the precious Magical Ball in the human world, while a love affair develops between the three-eyed superhuman hero and the heroine, Sanzō Noriko, whose name recalls Tripitaka's.

3 Yamamoto Atsuji's The Maiden Team [Saiyū shōjotai] (1989/1995). This is a boys' (shōnen) manga about three girls who help Tripitaka 
secure new Buddhist sutras from India in order to establish a Department of Buddhology at a so-called Tang Culture University.

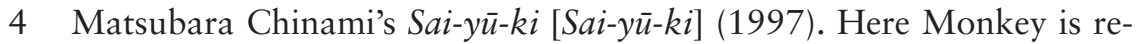
figured as the daring heroine, Kusano Misora, a high-flyer at school who becomes transformed into Monkey whenever she lets down her long hair and removes her spectacles.

5 Tanaka Kanako's Three Beast-Men [Sanjüshi] (2000). In this boys' manga, Tripitaka is a big-bosomed woman whom it is the duty of the three Beast-men to protect. She is repeatedly desired and harassed by the demons she comes across, including once by her disciple Pigsy.

6 Maya Mineo's Patariro Journey to the West [Patariro Saiyüki] (2000). This version is suffused with same-sex romance and fantasy elements. It is not confirmed equivocally at first whether Tripitaka, with his head of wavy, blond hair, is male or female (Figure 7.1), but it is precisely such androgyny that is key to this radically queered text.

Several preliminary observations can be made with respect to these transgendered versions of The Journey. First, transgendering involves Tripitaka in most cases: she turns into a female monk in (1) and (5), and becomes an androgyne in (6). Androgyny, as we shall see, is a much more subversive element than simple male-to-female sex change. Second, manga in various genres-romance, adventure, and science fiction in particular-borrow motifs and characters from the original story, albeit to varying degrees, resulting in a spectrum of works marked by different degrees of fidelity to,
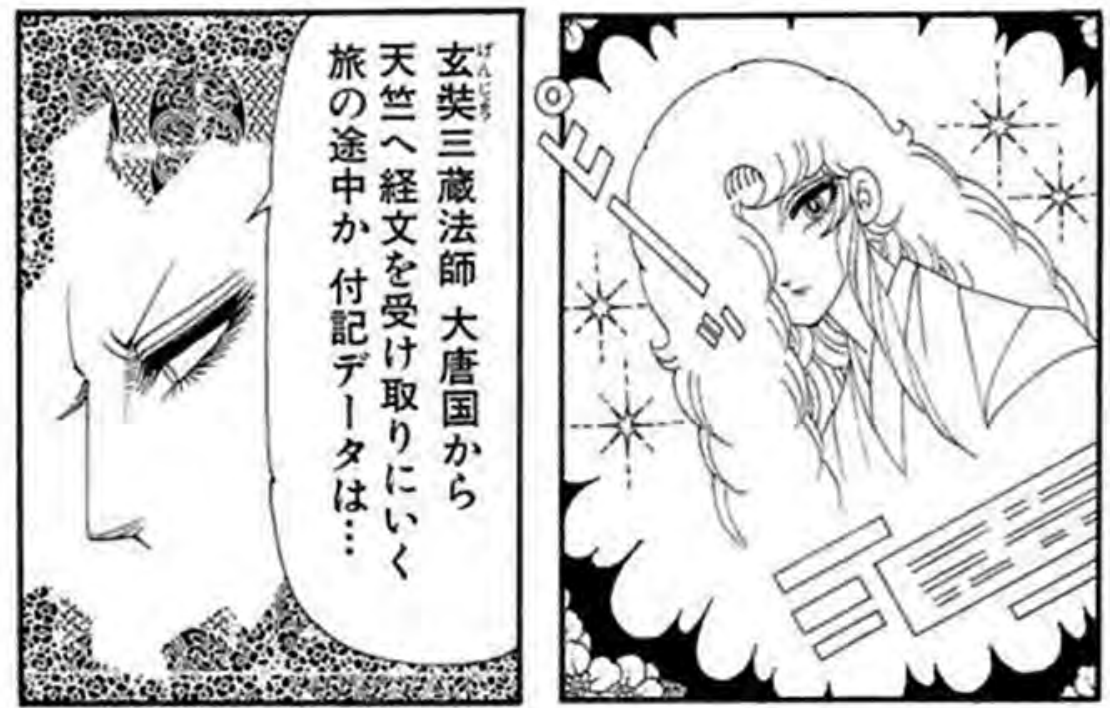

Figure 7.1 Tripitaka and androgyny. 
or deviation from, the original (as all translations are). Third, several examples bear only a tenuous plot connection to The Journey, with the characters simply transposed and given independent lives of their own. An extreme case is the radical transformation in (4): it is a "figuration" in which analogues are built through parallel protagonists, with only personal character traits retained in the re-creative transpositions.

Fourth, boys' and girls' manga have taken divergent paths, with the latter allowing for greater imaginative reworking of the relationship between Tripitaka and Monkey, so that Tripitaka can become the young woman to be pursued, in (1) and (2); the former, however, does not elaborate much on the romantic possibilities. If the huge numbers of Boys' Love manga published are any indication, there is a tendency for homosexuality to be spotlighted in girls' rather than boys' manga. Finally, in case (4), the gender change occurs to Monkey rather than Tripitaka. Given that Monkey is an animal to begin with, the transformation is complex, from male beast to human female. In example (3), too, all three accompanying disciples are female. Here the story derives its energy from a trend in recent manga in which "roles traditionally played by males are replaced by strong and independent female characters" (Shiokawa 1999: 117). Summarily viewed, the radical translations as a whole evince quite rigorous tampering with gender identities. Of special interest, however, is how the transgendering enables the presentation of gay and lesbian themes, in this way queering the Chinese classic.

\section{A History of Sex and Gender Change}

In a historical survey of 126 manga versions of The Journey from 1885 to 2011 (see Appendix to Chin 2012: 97-105), Tereko Chin classifies the Xiyouji-based manga into types: gag manga (like Patariro Journey to the West), erotic manga, re-creative manga, and female reader-directed manga (like The Maiden Team) (2012: 92-95)—although these groups are not mutually exclusive. Summing up the changes in the post-war period, Chin notes the increased inclusion of new stylistic elements (robots, gags, erotics) and new generic types (fantasy, mythology), emphasizing that the radical form of "parody" is most appropriate as a description of recent Japanese manga based on The Journey (2012: 84).

With reference to the detailed statistics compiled by Chin, we can begin to position these manga in the broader cultural milieu. The most prominent fact concerns the degree of alteration carried out, since a spectrum exists ranging from relatively faithful versions (though departures from the original are still obvious) to radically "re-creative" ones, which bear only surface resemblance to the source text. Then there are literal and liberal versions, but sex/gender change is already a "must" in the liberal adaptations. By comparison, the earlier versions did not pursue such a bold strategy: most of them were rewritings for children, featuring lighthearted 
humor (Yomoda 1994:310). As mentioned by a number of scholars who have written on girls' manga (see Li 2012: 264-274) or on the emergence of otaku (fan) rewritings for the dojinshi (fandom) market since the 1970s (see Saito 2011: 176), versions catering to young adults, which are more innovative and experimental, appeared only in the late 1970s. Since then, elements pertaining to gender, resulting in more daring and parodic manipulations of the original, have become standard fare. The injection of sexually explicit, even pornographic, matter parallels the queering of the Chinese text.

Closely allied to the sex/gender change in the characters is plot transformation. Whatever history there was in the eminent Chinese monk Xuanzang's actual trip to India to collect the Buddhist scriptures and later to translate them into Chinese is hardly ever relevant in the Japanese manga versions. All sorts of motivations for the journey have been invented to provide a pre-text for fantasies and science fiction, heterosexual and homosexual romances, and pornography. In a majority of cases, the Buddhist elements have been all but eliminated: the three Beast-men journey to India to obtain a lost treasure, not the religious books. ${ }^{2}$ In Terada's The Marvelous Adventures of Monkey King, the goal of the journey is the reverse of that in the original, namely, to kill the Buddha. Another often invoked reason for why Tripitaka's three helpers join him on his trip to India is that they desire to be transformed into humans. In other cases, motivations cease to matter much: the girls in The Maiden Team undertake the trip only to establish a new department in their university. Much closer to the Chinese narrative is that of the Patariro gang, who set off on their westward journey aiming to recover the Buddhist scriptures. But almost halfway through Volume 1, the story veers off into fantastic accounts of the previous (female) lives of the characters and their recurrent sexual escapades.

Incidentally, The Journey is not an isolated instance of transgendering that happens when a Chinese text crosses the border to Japan. Gender slippage or gender ambiguity also occurs in radical manga translations of another of the four great classical Chinese novels, The Three Kingdoms [Sanguozhi]. In his Japanese version of Three Kingdoms [Sangokushi] (1971), Yokoyama Mitsuteru turns Zhuge Liang, a central character famous for his ingenious deployment of military strategies in China, into a beautiful androgynous boy (bishonen). What is more, a macho warrior and a military advisor in the Chinese story, Zhao Yun and Zhou Yu, are portrayed as having long hair and orb-like eyes, respectively, much like the male beauties in girls' manga; at the same time they become physically Japanized. And while the male characters are feminized, cross-dressing also shows up as a prominent plot element: Zhou $\mathrm{Yu}$ is once dressed as a woman, thus becoming embroiled in a love triangle with two generals (see Ng 2014: 243). There is a sense in which transgendering in the comics derived from The Journey reflects a cultural shift rather than a purely textual one. 


\section{Queer Theory, Parody, and Boys' Love in Patariro Journey to the West}

While Japanese theatrical, literary, and folk traditions show transgendering to be very much a "fact" of Japanese culture, they can be said to have only paved the way for sex and gender reassignment of the major characters in The Journey, especially Tripitaka. One should note that the popularity of transgender versions is a recent phenomenon. Equally notable is the fact that the transformations are all one-directional: from men to women (or to the androgyne), rather than vice versa. Queer theory may help account for the complexities of these radical translations. As one Japanese queer theorist has noted: "Once you are able to feminize the male sex, then one would be able to form a feminization of all men, which breaks down the traditionally clear distinction between the superior male and the inferior female" (Nagoshi et al. 2013: 21). Perhaps it is of special significance that the human monk is made female most of the time, not the monkey, or the swine, or the water spirit. The power of queer theory lies precisely in its ability to deconstruct categories of gender that are dependent on a binarism set up between male and female. Much work has already been done by queer theorists on Boys' Love manga in which the potentialities of text-queering are utilized in conjunction with visual theory and reader response approaches. For instance, James Welker has written perceptively on how Boys' Love manga serves to queer heterosexual practices while exploring issues of marginalized gender and sexual practices, as well as those of identity formation (Welker 2006). Does the genre of Boys' Love manga provide us with a clue to unraveling the meaning of transgenderism in manga versions of The Journey?

The five-volume Patariro Journey to the West follows the original Chinese tale quite closely, beginning with Monkey wreaking havoc in Heaven, then being quelled by the heavenly forces and given the mission of helping Tripitaka to secure the Buddhist scriptures in the West. He is portrayed as money-minded and, along with his companion Pigsy, is responsible for most of the comic gags (most often built on puns and other forms of wordplay) in the manga series. Sandy, depicted as a pragmatic character not unlike his counterpart in the Chinese original, is placed in charge of cooking for the group of four pilgrims. Not long after the journey begins, they meet the charming male bodhisattva Bankō, who, after seducing Tripitaka, tells Monkey that his love for all humans, regardless of gender, is a manifestation of his "Buddhist heart" (2.108). Monkey responds by calling him a "playboy" (using the modern term in katakana), and his master Tripitaka a "playboy in a former life" (2.109). As the story progresses, the pilgrims encounter one demon after another, but at critical moments they are rescued by Bankō, not the goddess Guanyin as in the Chinese source text. The plot is then complicated with the introduction of Bankō's "wife" Nata (Figure 7.2a), the virulent Third Prince in The Journey and a famous figure in Chinese legend, and then of Red Boy (Figure 7.2b), son of the Ox-Demon King. Together with 

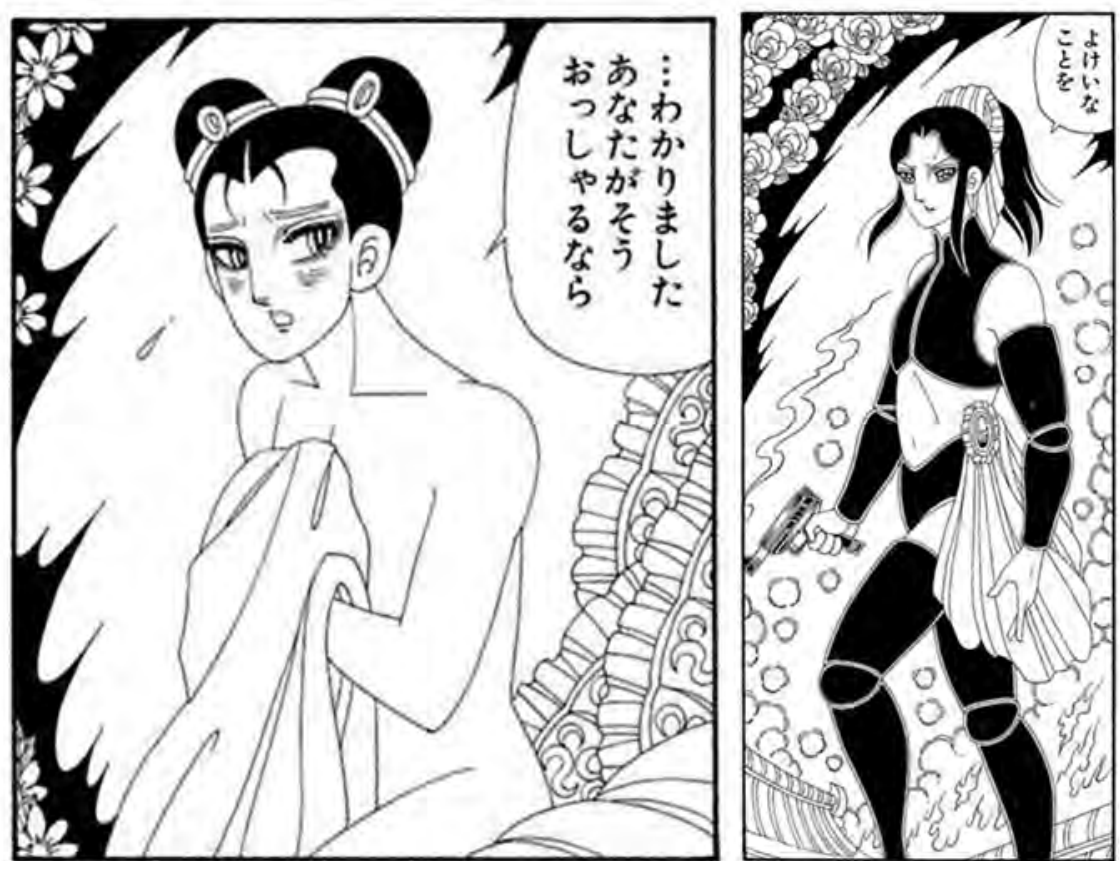

Figure 7.2 (a) Nata and (b) Red Boy.

Tripitaka, these two androgynous "beautiful boys" compete for the affections of Bankō, and it is this love quadrangle that increasingly dominates the plot, allowing gay themes to become central to the story. ${ }^{3}$ Near the end of the story, when the pasts of all four characters are revealed, Tripitaka is said to have been a woman in his previous incarnation as Golden Cicada. With an understanding thus achieved, the pilgrims resolve to move on in their journey west.

A story in the Boys' Love genre, Patariro Journey to the West makes repeated reference to homosexual desire. All four pilgrims are played by "stars" in Maya's system, a practice made popular by Tezuka Osamu (Power 2009: 66): they have already appeared in Maya's chart-topping manga series Patariro but are now given new roles. Tripitaka is "played" by the androgynous Maraihi, the blonde who gets pregnant twice; Monkey, by Patariro, the mischievous 10-year-old child king of the kingdom of Malynera in Patariro; and Bankō, by Bancoran, Maraihi's lover who has blue eyelashes and long hair, famous for his promiscuity and success in seducing young men. As is customary in the genre in question, there are abundant references in the text to the "beautiful boy": a bishonen pageant takes place at one point; a wealthy man wants to marry Monkey disguised as handsome Tripitaka; and so on. Homoerotic scenes involving Tripitaka, Bankō, Nata, 
and Red Boy are not infrequent, but they fall short of being explicit. Nudity is recurrent, but genitalia are never drawn, as they are, albeit obliquely, in some hardcore Boys' Love manga. The gay characters are almost always depicted against flowers in the background, or shown wearing clothes with floral patterns (as with Red Boy). Despite the radical alterations to the plot of The Journey, however, the manga artists have made an effort to show the Chinese landscape (including buildings and temples) and to highlight the Chinese historical background (the Tang dynasty), so that the manga does not come across as completely Japanized.

Undisputedly, Japan produces more queer comics than any other country in the world. Falling within the category of girls' manga, the Boys' Love stories arose out of the "BL revolution" of the 1970s, when groundbreaking manga like Takemiya Keiko's The Song of the Wind and the Tree [Kaze to ki no uta] (1976) showed how a new kind of manga is possible, not only with respect to theme but also in relation to stylistic presentation. As for presentation, in Boys' Love manga the main characters are boys mostly drawn with starry eyes, slender limbs, long hair, and girlish looks-a gesture toward the bishōnen tradition. Written by female authors for a female readership, they have special appeal by presenting the feminized body, from which young girls (not gay readers) derive voyeuristic pleasure and on which they build their romantic fantasies. As for theme, the readers learn about their own sexuality because such manga offers a chance for them to have detached identification with more than one (male) character in the homoerotic relationship. From both perspectives (i.e., materially as well as conceptually), the androgyny of the main characters-the bishonen is neither man nor woman-is therefore a crucial element in reader reception. Of course, on the most simplistic level, such manga has been viewed as erotica about male-male love for a female audience. Sheer pleasure is also emphasized as an element in reading these tales; Rebecca Suter (2013) notes how females can enjoy gay male pornography as much as males enjoy reading about lesbian sex. McLelland has put this very succinctly: "In Japanese society, where gender roles are rigidly fixed, popular culture aimed at women provides a safe space in which the normally non-negotiable regimen of gender can be subverted or overturned" (2000: 74).

Gender-bending — and gender-blending too-also becomes a structural element, not just something done "for fun." Some commentators have observed that, in many of these gay stories, the active and passive roles, analogous to male and female, are clearly identified (see Levi et al. 2010; Shamoon 2012). In Patariro Journey to the West, for instance, Bankō clearly plays the "male" to his "female" sex partners-Tripitaka (Figure 7.3a), Nata (Figure 7.3b), and Red Boy (Figure 7.3c). The result is that girl readers can identify with either of the beautiful boys, whether the one playing the active part or the passive one (Suter 2013: 548-549). It is thus argued that, because there is little interest in queering for a gay readership, as is the case with slash fiction in the West, manga in this category actually reinforces 

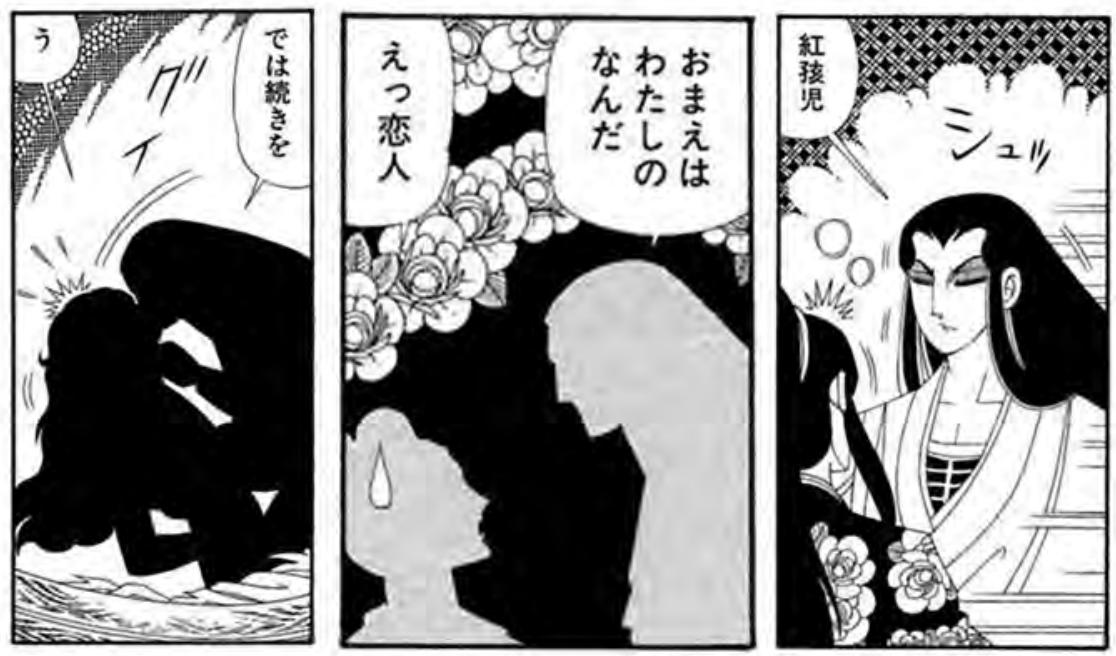

Figure 7.3 Bankō with (a) Tripitaka (b) Nata (c) Red Boy.

rather than undermines heterosexuality. However, that is only partially correct; what the young female reader sees is the difficulty of assigning fixed gender roles to characters on the page. Such uncertainty is displayed on the written page as characters can be seen to be male or female, or both at the same time. ${ }^{4}$ That, perhaps, is the truly revolutionary aspect of Boys' Love manga, a prism through which we can view the significance of the transgendering in the other (non-gay) versions of The Journey, where gender is "queered."

With reference to all six manga versions listed earlier, it can be seen that although there is a gay version-Patariro Journey to the West-the depiction or promotion of same-sex love is not uppermost on the agenda pursued by the manga artists in question. Considered as a whole, they are therefore not as subversive in the way that queer texts in the West allegedly are in their contestation of dominant heterosexual norms in society. What is most special about them is that they highlight gender malleability for readers who can recall that the major characters have lived lives as males in the original Chinese story, or in earlier Japanese manga versions published before the 1990s. Indeed the most subversive element is to be located in the visual representation of the female and feminized monk Tripitaka. It is especially clear in Patariro Journey to the West, the "queerest" of the six adaptations: sporting a head of beautiful hair and long eyelashes, he is not recognized as a "man" until he consummates his love with Bankō halfway through Volume 1, although readers of Maya's extremely popular Patariro series, published earlier, could easily have seen him as linked to Maraihi, an androgyne having the beauty of both sexes. The transfer of the verbal text in The Journey to the visual 
text, leading to a literal "visibility" of the queer, is indeed one of the most exciting aspects of this manga. Such a strategy can be explicated in terms of translational (drag) performance, which St. André has explored in a number of recent articles on queer translation (e.g., St. André 2010).

Mark McLelland has called attention to the early 1990s Gay Boom in Japan (2000: 58), when the destabilization of gender identities proceeded apace: it was seen in many cultural spheres beyond manga, such as film, novels and popular music (McLeod 2013). More than just presenting resistance against patriarchy, these cultural productions represent a camouflaged opposition against gender binaries and heterosexual norms. Without a doubt, the general atmosphere had an impact not only on readers but on the manga adaptors as well. In the case of readers, the racy comics furnish a means whereby they explore taboo problems, not in real life, but in the act of reading. But in the case of adaptors, the manga artists engage in textual play: as parodists, they meddle with gender, rendering it ambivalent or indeterminate.

One should note, in this connection, that the playing with gender in Patariro Journey to the West has extended to the pivotal female deity in the original Chinese novel-the bodhisattva Guanyin. Her role is almost entirely eclipsed by Bankō; she appears only once or twice in the manga, as a female with a beard (Figure 7.4). Given the rigid and structured male-female roles in Japan, parody is a powerful way of breaking the strict constraints in the realm of fantasy. This is much needed in a repressive society where gender-conformity is constantly demanded. The blurring of male-female boundaries, shown in visual form, provides an occasion for poking fun at rigidly exclusive gender identities, as shown by the funny-looking Guanyin in Figure 7.4.

Parody is the ideal mode in which the radical manga translations operate. If Boys' Love manga are, generally speaking, parodies of heterosexual

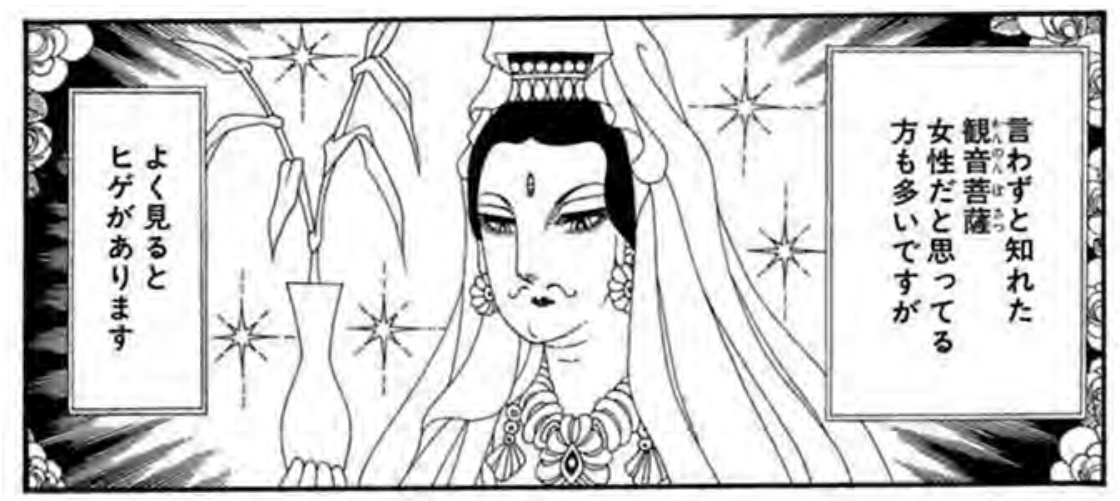

Figure 7.4 The androgynous Guanyin. 
romantic love (Ogi 2009: 246), then the target of the transgendering seen in manga based on The Journey is actually the four male "buddies" in the original Chinese novel, united in their "masculine" quest; but with their advance toward India, they are time and again impeded by a multitude of female demons who desire the monk's flesh. Why should it not be a story of a woman protected yet also preyed upon by men? After all, parody is predicated on the ability to criticize that which is believed to be unacceptable or misguided. By confronting sexual polarities in a playful rather than serious manner, the radical translation in question is a form of queering that exposes the true nature of notions unquestioningly accepted, demonstrating a mode of resistance against strict gender divisions.

Although the parodic mode is stronger in some of the versions than in others, the differences from the original are the cracks through which cynicism, ridicule, and disrespect are inserted. It is in this way that transgendering works in these radical versions. From this perspective, in effect, Tripitaka has undergone sexual reassignment not physically but textually, through translation from Chinese into Japanese. In the final analysis, the most subversive of the manga versions of The Journey, like Patariro Journey to the West, work on the "ground rule" that gender differentiations are absurd and laughable. The parodic and the queer are hence one and the same-inseparable.

\section{Conclusion}

The manga derived from The Journey shows the repertoire of "translation strategies" used to subvert the original: slapstick humor (as in The Maiden Team), adult eroticism (in Three Beast-men), romanticization (in Demonic Journey to the West), and the deployment of star characters (in Patariro Journey to the West). All of these have been deployed in the manga based on the Japanese classic The Tale of Genji, which has been accepted by Japanese readers as a matter of course (see Miyake 2008). The tampering with Chinese cultural elements that occurs in any Japanese text, including artifacts, time, place, clothes, architecture, behavior (like kissing and making love), looks, scenery, rituals, and customs, should therefore not have been unexpected in the manga artists' treatment of the Chinese classics. But while the inclusion of non-Japanese cultural elements (Greek, Egyptian, Russian, etc.) in Japanese manga has never caused a furor in the countries concerned, the reception by Chinese readers is a different thing altogether, if we can judge by reader responses. The question of the Chinese reaction to these manga is fascinating. What does the strong Chinese reaction to the queering of this classic tell us?

To begin with, the diatribes against the radical manga reworkings of The Journey are illuminating in what they reveal about the contest of cultural power between China and Japan. The latter, it has been said, has accumulated much cultural capital at the expense of the former. Issues of cultural 
theft and manipulation are raised from time to time in the history of the two countries' interaction. Zhu Hongbo lists four of the pernicious aspects of the Japanese versions of The Journey: vulgarization of tastes; disruption of the proper order of literary development; destruction of the good will between the two countries; and obstruction of proper cultural transmission (2007: 16-17). He attacks "the spirit of playfulness" in which the Japanese, "eager to pilfer and distort" (2007: 16), have treated revered canonical works from China. Ironically, blatant outrage was also expressed against the parodies of the Chinese classics by Chinese authors themselves. A spate of articles had appeared at around the same time remonstrating the culture of egao in China, focusing on how the culture of consumption and postmodern conceptions of value have given rise to the spoofing or desecration of classics. ${ }^{5}$

But what are the uses of such radical translations in the eyes of the Japanese? How are they perceived by the manga artists and readers? It is obvious that the Japanese manga versions are parodic to their readers in a different way than the Chinese translations of these comics are to the Chinese readership. Theorists of parody describe a wide range of effects achieved by this genre, and they throw light on the concept of radical translation as advanced in the present chapter. Linda Hutcheon (1991), for example, disagrees with the exclusive association of this term with ridicule; Nil Korkut points out that the attitude toward the original "may range from denigration, mockery, and ridicule to respectful admiration" (2009: 21), and M. Carmen Gómez-Galisteo notes that parodies do not "need to have making fun as their main or sole objective" (2011: 62). Such effects are felt by readers responding to the radically altered Chinese text, but it could reasonably be said that the manga versions of The Journey exhibit little of the "maliciousness" that Chinese readers have observed. On the Japanese side, their attitude toward China in the course of the twentieth century has experienced wild fluctuations, with national pride and a sense of their own superiority competing with a feeling of unease toward her giant neighbor and a warm familiarity with things Chinese. For centuries reworkings of Chinese classical novels have been carried out, but the radical translations of the originals as seen in the "queered" versions earlier is a more recent phenomenon.

One may not want to generalize, as Kondo Daisuke did by saying that "China is masculine, Japan is feminine" (because one is continental, the other insular), but perhaps the Japanese manga artists in question do feel the need to define Japan against China in gendered terms when reworking The Journey. The lore of the monk journeying with his three companions has already become a part of the Japanese imaginary, and so it can be infused with cultural specificities running counter to those in the source text, ones that appeal more to Japanese readers. Recent studies of inter-Asian connections have highlighted the way in which cultural materials within East Asia are reworked for consumption by national readerships to such an extent that the concept of ownership needs to be reconceived (Iwabuchi 2010: 207-209). That explains the radical, intensely localized 
Japanese rewritten versions, in manga form, of not just The Journey, but several other ("masculine") fictional classics.

Moreover, audience appreciation of parody is strongly culture specific, as the Chinese reception of the queered manga translations shows all too clearly. In contrast to the Japanese readers, who receive the re-invented Chinese story in a new visual/verbal form, their Chinese counterparts have struck out at the Japanese lack of respect for the original, articulated most blatantly in an amazing variety of gender shifts, transformations, and reconfigurations. And yet, can we dispute the fact that radical translation only carries to an extreme that which all translations point toward? Does not translation operate-as queer theory does-in a "fluid, mobile, non-specific zone of enquiry that resists being fixed" while finding itself "at odds with the normal, the legitimate, the dominant," as Richardson and Halperin have put it?

\section{Acknowledgment}

The author wishes to acknowledge the kind permission given by Hakusensha, Inc. to reprint all the images from Patariro Saiyūki in the present chapter.

\section{Notes}

1 The names of the characters from Arthur Waley's widely read translation of the novel, Monkey (1942), are used in the present chapter for convenience sake.

2 In the voluminous scholarship on the original Chinese novel, much emphasis is laid on a Buddhist interpretation of the text. Anthony Yu (1977-83) did a complete translation in which a conscious effort is made to highlight such an interpretation.

3 The audience's comments on the anime version bear clear witness to their gay readings as well (see URL Bilibili). Judging from web comments in general, young readers are quick in their response to depictions of sexual deviations, and give immediate approval to the gay elements.

4 Another possible reading is that these are, in actuality, lesbian stories because the "boys" the female readers have fallen in love with are "girls."

5 Such spoofing involves works from the Honglou meng [Dream of the Red Chamber], generally hailed as the greatest Chinese novel ever written, to the short stories of modern literary giants like Lu Xun.

\section{References}

\section{Primary Sources}

Kamishiro, Yū. 1994. Yōma Saiyūki [Demonic Journey to the West]. Tokyo: Akita shoten.

Matsubara, Chinami. 1997. Sai-yū-ki [Sai-yū-ki]. Tokyo: Jitsugyō no nihonsha.

Maya, Mineo. 2000. Patariro Saiyüki [Patariro Journey to the West]. Vols. 1-5. Tokyo: Hakusensha. 


\section{Leo Tak-Hung Chan}

Terada, Katsuya. 1998-2010. Saiyūkiden daien'ō [The Marvelous Adventures of Monkey King]. Vols. 1-2. Tokyo: Shūeisha.

Tanaka, Kanako. 2000. Sanjūshi [Three Beast-men]. Vols. 1-2. Tokyo: Shūeisha.

Waley, Arthur. 1942. Monkey. London: Allen \& Unwin.

Yamamoto, Atsuji. 1995. Saiyū shōjotai [The Maiden Team]. Complete version. Tokyo: Kadokawa shoten.

\section{Secondary Sources}

Allison, Anne. 1996. Permitted and Prohibited Desires: Mothers, Comics and Censorship in Japan. Oxford: Westview Press.

Brower, Reuben. 1974. Mirror on Mirror: Translation, Imitation, Parody. Cambridge, MA: Harvard University Press.

Chin, Teroko. 2012. "Nihon ni okeru Saiyūki no saisōsaku gaikyō: Manga bun’ya o chūshin ni" (Re-Creation of The Journey to the West in Japan and China: Focusing on the Field of Comics). Mediagaku 27: 71-96.

Gómez-Galisteo, M. Carmen. 2011. The Wind Is Never Gone: Sequels, Parodies and Rewritings of Gone with the Wind. London: McFarland and Co.

Halperin, David M. 1995. Saint Foucault: Towards a Gay Hagiography. New York: Oxford University Press.

Hutcheon, Linda. 1991. Parody: The Teachings of Twentieth-Century Art Forms. London: Routledge.

Iwabuchi, Koichi. 2010. "Globalization, East Asian Media Cultures and Their Publics.” Asian Journal of Communication 20: 197-212.

Korkut, Nil. 2009. Kinds of Parody from the Medieval to the Postmodern. Frankfurt am Maine: Lang.

Levi, Antonia, Mark McHarry and Dru Pagliassotti. 2010. Boys' Love Manga: Essays on the Sexual Ambiguity and Cross-Cultural Fandom of the Genre. London: McFarland and Co.

Li, Yiyun. 2012. Manhua de wenhua yaniiu: Bianxing, xiangzheng yu fuhaohua de $x i p u$ [The Cultural Study of Manga: Transformation, Symbolism and the Genealogy of Semioticization]. Xinbeishi: Daoxiang chubanshe.

Lin, Tie and Jianyong Zhang. 2008. "Xujia de fankang: Egao wenhua de rengtong bolun" [Fake Resistance: Forced Arguments in Favor of Malicious Meddling]. Chongqing keji xueyuaan yuanbu: Shehui kexue ban 3: 168-170.

McLelland, Mark J. 2000. Male Homosexuality in Modern Japan: Cultural Myths and Social Realities. Richmond: Curzon.

McLeod, Ken. 2013. "Visual Kei: Hybridity and Gender in Japanese Popular Culture." Young 21(4): 309-325.

Miyake, Lynne K. 2008. "Graphically Speaking: Manga Versions of the Tale of Genii." Monumenta Nipponica 63(2): 359-392.

Nagoshi, Julie L., Craig T. Nagoshi and Stephan/ie Brzuzy. 2013. Gender and Sexual Identity: Transcending Feminist and Queer Theory. New York: Springer.

Ng, Benjamin Wai-ming. 2014. “The Adaptation of Chinese History into Japanese Popular Culture: A Study of Japanese Manga, Animated Series and Video Games Based on The Romance of the Three Kingdoms." In Manga and the Representation of Japanese History, edited by Roman Rosenbaum, 234-252. New York and London: Routledge. 
Ogi, Fusami. 2009. "Beyond Shoujo, Blending Gender.” In A Comics Studies Reader, edited by Jeet Heer and Kent Worcester, 244-252. Jackson, MI: University Press of Mississippi.

Phillips, John. 2006. Transgender on Screen. Basingstoke: Palgrave Macmillan.

Power, Natsu Onoda. 2009. God of Comics: Osamu Tezuka and the Creation of Post-World War II Manga. Honolulu, HI: Hawaii Press.

Richardson, Diane. 2006. "Bordering Theory." In Intersections Between Feminist and Queer Theory, edited by Diane Richardson, Janice McLaughlin and Mark E. Casey, 19-37. Basingstoke: Palgrave Macmillan.

Riemer, Andrew. 2010. "Translation, Imitation and Parody." Australian Journal of French Studies 47(1): 36-45.

Saito, Kumiko. 2011. "Desire in Subtext: Gender, Fandom, and Women's Male-Male Homoerotic Parodies in Contemporary Japan.” Mechademia 6: 171-191.

Sasaki, Makato. 2007. Saiyūki azumaasobi-roku: Sabukaruchā ni okeru Chūgoku koten shōsetsu no niji sōsaku ni kanshite [The Journey to the West Goes East: On the Secondary Creation of Chinese Classical Novels in the Subculture]. Ajia yūgaku 105: 186-197.

Shamoon, Deborah. 2012. Passionate Friendship: The Aesthetics of Girls' Culture in Japan. Honolulu, HI: University of Hawaii Press.

Shiokawa, Kanako. 1999. "Cute But Deadly: Women and Violence in Japanese Comics." In Themes and Issues in Asian Cartooning: Cute, Cheap, Mad, and Sexy, edited by John A. Lent, 93-126. Bowling Green: Popular Press.

Song, Zhenhe. 2011. Xiyouji yu Dongya dazhong wenhua: Yi Zhongguo, Hanguo, Riben wei zhongxin [The Journey to the West and East Asian Popular Culture: Focusing on China, Korea and Japan]. Nanjing: Fenghuang chubanshe.

St. André, James. 2010. "Translation as Cross-Identity Performance.” In Thinking Through Translation with Metaphors, edited by James St. André, 275-294. Manchester: St. Jerome Publishing.

Suter, Rebecca. 2013. "Gender Bending and Exoticism in Japanese Girls' Comics." Asian Studies Review 37(4): 546-558.

Welker, James. 2006. “Beautiful, Borrowed, and Bent: 'Boys' Love' as Girls' Love in shôjo manga." Signs: Journal of Women in Culture and Society 31(3): 841-870.

Yomoda, Inuhiko. 1994. Manga genron [Principles of Manga]. Tokyo: Chikuma shobō.

Yu, Anthony C. (trans. and ed.). 1977-83. The Journey to the West, Vols. 1-4. Chicago: The University of Chicago Press.

Zhu, Hongbo. 2007. "Jingdian zai dazhong chuanmei shidai de mingyun: Egaoban Xiyouji zhi wojian" [The Fate of Classics in the Age of the Mass Media: On the Malicious Meddling of The Journey to the West]. Zhongwen zixue zhidao 5: 14-17. 


\title{
8 Speaking Silence and Silencing Speech The Translations of Grand Duke Konstantin Romanov as Queer Writing ${ }^{1}$
}

\author{
Sergey Tyulenev
}

Human sexual desire has been a focus of a plethora of studies across the humanities covering virtually all periods and locales. A surge of studies has not left untouched sexualities in Russia-as they were in the past (Engelstein 1992; Naiman 1997; Karlinsky 1997; Healey 2001, 2006; Moss 2000), or as they are today (Heller 1992; Essig 1999; Baer 2009, 2013). A special object of study has been (homo)sexualities as reflected in works of art (Baer 2009; Moss 2013; Amico 2015) and more specifically, literary art (Karlinsky 1976; Moss 1997; Baer 2011). Translations as sites of expression of (homo) sexual desire have, however, been largely ignored by researchers-which is hardly surprisingly given the traditional invisibility of translation in literary and cultural studies. Some work has been done on this topic from within translation studies (Tyulenev 2010, 2014; Baer 2017), and the present chapter, an examination of the translations of Grand Duke Konstantin Romanov, is intended as a continuation of that effort.

Konstantin Konstantinovich Romanov (1858-1915) was a grandson of Tsar Nicholas I. His was a typical upbringing for a male Romanov. He studied history, military tactics, and foreign languages. He was married to a German Duchess (Elizabeth of Saxe-Altenburg), with whom he had nine children. Less typically, he demonstrated a strong interest in the arts. $\mathrm{He}$ was torn between his military career (first in the navy and then in the Imperial Izmailovskii Guard) and his life-long passion for the arts, especially literature.

This combination of the typical and the a-typical caused considerable incongruities in Konstantin Romanov's life and career. He was a husband, who, judging from his own diaries, was not entirely satisfied within the monogamous heterosexual bounds of his marriage. His literary aspirations were incongruous because they were viewed at the time as inappropriate for a person of his social standing, leading him to adopt the pseudonym "K.R." The pseudonym was not necessarily the most inscrutable and many people knew about his literary pursuits, and yet he had to adopt it to observe the proprieties. ${ }^{2}$ More importantly for the present discussion, K.R. had yet another secret to hide-his queer sexuality. 
Romanov gave expression to these incongruities in writings that include extensive diaries, original literary works (poetry and drama) and translations. In this chapter, I will deal mainly, although not exclusively, with his translations.

\section{Methodology}

Regarding any research into sexuality, Jonathan Katz wrote,

If we open our minds to these tales, we may find ourselves [. . .] within a strange sexual landscape, a mysterious world of affection. We will find mysteries here. So, like detectives, we must look for clues, interpret the rediscovered evidence, and fit together the first, tentative fragments of the puzzle. We must become tracers of missing intimacies, sleuths of sexualities and affections past. We must travel back in time, on the lookout for unfamiliar configurations of lust and love.

(2001b: 12)

To understand how the alternative configuration of "lust and love" characterizing Russian culture of the late nineteenth and early twentieth centuries shaped the verbal representations of the time, we will make use of Sedgwick (1990) and Edelman (1994) who focus on same-sex desire not as a set of historical facts to be uncovered but as an affective force that shapes and is shaped by modes of writing. While making use of Sedgwick's and Edelman's work, I will also extend them, applying them for the first time to translation as a particular mode of queer writing.

As defined by Sedgwick, "closetedness" can be understood as a performative phenomenon "initiated by the speech act of a silence" (Sedgwick 1990: $3)$. In the present chapter, this view is taken a step further: closetedness will be examined as an interaction of speech and silence, as Sedgwick suggested, but also as more complex figurations-as speech functioning qua silence (silencing speech) and silence functioning qua speech (speaking silence). ${ }^{3}$

As a seminal figure in queer theory, Sedgwick calls for overcoming simplistic and exclusive binaries of the present-day discourse on sexuality in general and of the closet in particular. For Sedgwick, the closet concerns not a discrete "gay" minority, but all men, who are on the one hand compelled to create strong homosocial bonds while, on the other hand, they are compelled to police those bonds to prevent the appearance of homosexuality, a double bind that produces the phenomenon of "homosexual panic." The closet, therefore, is of concern to all men. Sedgwick's methodology of attending to performative aspects of texts is, therefore, very useful in avoiding essentialist, minoritarian assumptions.

And so, rather than affixing tags or labels, we will consider K.R.'s case as that of a closet, that is, a complex network of "the known and the unknown, 


\section{Sergey Tyulenev}

the explicit and the inexplicit around homo/heterosexual definition" (Sedgwick 1990: 3). This network is a web of silencing speech and speaking silence and, to take Sedgwick's epistemology of the closet further, a web of intricate interactions of speech called upon by a silence or a silence made conspicuous by a particular type of speech. Silence no longer only conceals but also reveals; speech no longer only reveals but also participates in the act of concealing. Silence and speech thus rebel against their semantically prescribed antonymy that would banish them to polar extremes, developing instead an uncanny oxymoronic affinity, a paradoxical ability to attract and even replace each other.

K.R.'s writings, and primarily his translations, will also be analyzed as a type of "homographesis," as elaborated by Edelman borrowing Marie-Rose Logan's concept of graphesis, defined as "the nodal point of the articulation of a text" that "de-limits the locus where the question of writing is raised" and "de-scribes the action of writing as it actualizes itself in the text independently of the notion of intentionality" (cited in Edelman 1994: 9). Edelman applies it to the formulation of discourse on homosexuality and to the conceptualization, or writing (hence, graphesis, the Greek for writing), of homosexual identity. According to Edelman (1994), like any type of graphesis, homographesis produces a definition of homosexuality originally for the purpose of social stigmatization, but, by the very act of defining homosexuality, it makes it socially visible and generates questions about what alternative sexuality/sexualities there might be, relativizing, one might say, heterosexuality. Homographesis, thus, zeroes social discourse in on homosexuality and opens it up to a repertoire of alternatives; homographesis tries to pin down what homosexuality is and simultaneously promotes performative (re-)enactment of it-one effect of the imposition of homographesis ineluctably calls into existence the other.

Edelman sees homographesis as a lump notion, under which all kinds of writing, whether understood literally or metaphorically, are subsumed, but for our purposes - the focus on translation-it would be useful to view homographesis as a bundle of individualizable modes. With K.R., we find three such modes of homographesis: his diaries, his original literary works, and his translations. In all three, he performed homographesis differently. In what follows, I will discuss all of them, but my primary concern is K.R.'s homographesis as manifested in his translations, a mode of writing or authorship until recently ignored in queer theory.

When theorizing sexuality and its manifestations in literature, neither Sedgwick nor Edelman discuss translation per se. Moreover, while examining manifestations of discourse on sexuality in works of a French-speaking author, Proust, they both took translations, which they generously cited, for granted, well in keeping with the conventions of the social sciences in general and literary studies in particular. In the present chapter, I will concentrate specifically on the role translation may play in the performativity of the closet or in the discourse formation of homosexuality. To the extent 
that translation can be understood as a locus of self-expression or mode of writing that takes place through the assumed creative personality of the author of an original, one might categorize this identification-differentiation as another type of graphesis. Indeed, unlike original writing, translation is a type of writing that is based on somebody else's writing. This creates at least two additional dimensions of the translated text: first, the translator assumes a mask - the creative personality of the original author, while at the same time signaling the reader that s/he wears only a mask (it is a translation, not an original!); and second, one instance of graphesis, whichever it is with whatever agenda(s), is superimposed on another creating a kind of palimpsest. As a result a tension between these layers of graphesis is inevitably produced. Such tension can be found in K.R.'s translations. His case demonstrates that translations can serve as a locus for palpable calibrations of the force of various homo- and other-graphetic rhetorical effects in the concealing/revealing speech-silence dynamics of the closet (cf. Sedgwick 1990: 3).

While the analysis that follows will focus primarily on his translations, each of the three modes of writing practiced by K.R.- diaries, original poetry, and translations-manifests a specific functionality in the dialectics of his closeted homographesis and each manifests different graphetic valences by combining power with other types of graphesis. Our analysis allows us to discursively map K.R.'s speech and silence in regard to manifestations of his sexual desire or, one might say, the distribution of acts of speech and silence among the three different modes of his homographesis.

The homographesis of K.R.'s diaries is characterized by speech proper, which is clearly seen in his diaries. In them, he speaks most sincerely and openly about the complexity of his sexuality. That being said, his diaries had their addressees-although not, as is more usual, across space but across time: the diaries were meant for future generations who would be able to read his diaries only when published posthumously. We can only speculate why K.R. allowed their publication after his death. The historian Sergei Mironenko thought it was K.R.'s attempt to share with future generations his experience of struggling with human passions (Romanov 1903-5). Whether this was so or not, K.R. made a clean breast of it. This is an interesting instance of temporarily silenced speech: silence subdues speech until a point in time when speech is released in the hope of being appreciated by a future reader, who is somehow, in an important way, different from the author's contemporaries. This impulse to confess and converse compelled K.R. to put these things on paper-and even to find outlets in published venues for these coded expressions of homographesis-in the hope that someone out there one day would hear him out and maybe understand him.

Silence resulting from closetedness reigned supreme in K.R.'s literary works. Without his diaries, one might take him for a conventional poet without suspecting that this very conventionality may have been hiding something. Only when K.R.'s poetry is read stereoscopically (cf. Gaddis 


\section{Sergey Tyulenev}

Rose 1997), that is, against his diaries, is its closetedness revealed, constituted by the glaring omission of topics one might have expected from a lyric poet after reading his diaries and by the striking conventionality, or lack of expressive originality, in his numerous bucolics and love poems.

K.R.'s translations, however, are perhaps the most interesting mode in terms of his homographesis. Noteworthy here is not only their coexistence with the diaries (as is the case with his poetry) but also their coexistence with the originals. In translation, K.R. negotiated his course between speech and silence without fully identifying with either of them, while touching on both. On the one hand, one could argue that his translations did not manifest his homographesis as openly as did his diaries. On the other hand, K.R.'s poetry could reveal his secrets either by conspicuously ignoring them or by the selection of certain topics (see more on this later in this chapter): as a poet, K.R. chose his subject matter-while in the case of translations, we can witness not only what topic he chose but also the form he chose to write about it when compared with the translated original. While the scholar of K.R.'s "original" poems might be content with comparing them with the diaries and drawing conclusions based on hints and conjectures, the scholar of K.R.'s translated texts can avail herself of documented textual intersections between the diaries, the source texts, and K.R.'s Russian translations. Thus, in the case of K.R.'s translations, the researcher has two pieces of evidence: the fact of K.R.'s selecting a particular original text and the way he handled the selected text, producing shifts, such as omissions, generalizations, and redistribution of emphases, which, as we shall see next, lend themselves to an informed analysis through the prism of homographesis.

K.R.'s translations represent a complex mode of homographesis that can be seen not only as speech qua silence (as is his poetry). On the one hand, the speech in his translations was selective, and while claiming to speak about "all that enflamed the heart" (K.R.'s translation from a poem by Helene von Engelhardt), it silenced at least a part of what enflamed his heart and what he discussed so passionately and openly in his diaries. On the other hand, K.R.'s translations were a masked speech. K.R. spoke by selecting a particular text and by assuming, or pretending to assume, the translated author's voice. The dynamic is further complicated when one takes into consideration that K.R.'s source texts were not homographetic-but that he made them so. He took perfectly heterographetic texts that, through his rendering via the translational-discursive devices he used, turn out to be homographetically interpretable.

\section{The Diaries}

All his life Konstantin Romanov kept diaries, in which with startling honesty he revealed his anguish but also more positive puzzlement over his same-sex desire. In an 1876 entry, he wrote, "Male beauty seduces me" (Chernyshova-Mel'nik 2008: 38). Diaries of later years contain numerous stories of K.R.'s visits to local bathhouses for sex, such as the following 
entry written in 1904: "I was overwhelmed by sinful thoughts [. . . I I walked up and down twice past the bathhouse doors; the third time, I went in. And so, I have once again sinned in the same way" (Romanov 1903-5). ${ }^{4}$

K.R.'s openness in his diaries makes them, according to our classification, speech about his same-sex desire, yet, strikingly, speech qua silence because this speech was entrusted only to his diaries. Only after his death, speech qua silence was permitted to become speech proper.

From what can be seen in surviving evidence about K.R., the situation of the mid-nineteenth-century USA as described in Katz (2001a: 53) is similar to that of Russia in the second half of the nineteenth century. Like in the USA, in Russia there was no distinction made between a same- and different-sex desire; nor did bisexuality form a third category between homo- and heterosexuality. Dan Healey writes specifically of the context of nineteenth-century Russia:

Masters and servants, coachmen and their passengers, bathhouse patrons and attendants, craftsmen and apprentices, and clergy and their novices exploited the opportunities of their positions to obtain or offer sexual favors. These men and youths should not be mistaken for homosexuals in a modern, European sense; their culture of masculinity included indulgence in same-sex eros, and it did not enforce the necessarily severe penalties associated in a later era with the stigmatized, medicalized condition of homosexuality.

Yet one must be careful not to exaggerate. Surviving documents show that while not being stigmatized as homosexuality, this type of homosexual indulgence could be seen as sinful and, as K.R.'s diaries demonstrate, sometimes by perpetrators of the 'sin' themselves-hence, a complex configuration of silence qua speech and speech qua silence.

\section{K.R.'s Original Poetry}

Along with the diaries, K.R. wrote poetry and plays. In terms of openness about his sexuality, K.R.'s original literary works, when compared to his diaries, are what the negative is to the photograph. What was said openly in the diaries is conspicuously silenced or, at best, only hinted at in poetry. Only one exception is known and that is a juvenile poem "Vizhu l' glaza tvoi":

\footnotetext{
Вижу ль глаза твои, Лазурью глубокие, Душа им навстречу Из груди просится. И как-то весело, И хочется плакать. И так бы на шею Тебе я кинулся.
} 


\section{Sergey Tyulenev}

[When I see your eyes/Of deep azure,/My soul breaks out/To meet them./ And I feel somehow happy/And yet I want to cry;/And I wish I could/ Embrace you.]

Even in this poem, considered homoerotic, there is no homographetic evidence in the text. The evidence is purely biographical. Natalia Chernysheva-Mel'nik claims that this poem reflects K.R.'s homoerotic infatuation with one of the officers among the crew of the military ship on which he served in the late 1870s_-a certain Men'shikov (2008: 37).

This poem is a good example of what can be referred to as an epistemological doubt: to what extent is the homographetic interpretation justified? For instance, the role ascribed to the eyes is significant here. This literary device may be interpreted as the homographetic preference for metonyms allowing the lyric subject to avoid disclosing the gender of the addressee (Baer 2017) and serving as hints at actions; for example, the metonym of eyes may hint at the importance of the gaze in cruising. But eyes are important in heterosexual love poetry, as well. Thus, strictly speaking, the poem can be read as homoerotic based purely on the biographical, rather than textual evidence. In the absence of textual evidence, the homographetic interpretation remains conjectural until there is assurance that the sentiment expressed in a poem was related to a(n allegedly corresponding) biographical fact.

K.R.'s love poetry is considered by literary historians to be a reflection of his intimate experiences: "Love poems by K.R. (as well as poems close to them in their meaning, addressing the people close to the poet) bear an imprint of album lyric poetry (al'bomnaia lirika)" (Muratov in K.R. 1994: 21). Such album lyric poetry is usually associated with rather superficial literary salons of the time and can hardly be considered deep or truly sincere-or even properly lyrical in the sense of expressing the writer's emotions. This is definitely so in regard to K.R.'s same-sex sentiments. His poetry in that sense represented a parallel world having little to do with the K.R. we see in his diaries.

Here, a brief discussion of the reasons why K.R. had to hide behind an intricate tapestry of speech acts and silences is called for. As A. Muratov explains, "When one is to evaluate K.R.'s poetry and the sentiments expressed in it, one needs to take into consideration its author's social status" (1994: 20). Indeed, K.R. lived under constant danger of the disclosure of his sexual leanings and the threat of blackmail. In one of his diary entries, we read the following:

I was upset by a letter from Captain Sosnitskii, who embezzled up to three thousand rubles [. . .] Vindicating himself, he wrote that everybody is sinful; "even you," he continued and mentioned that once on a summer evening in 1903, when he was on duty, I came to the Pavlovsk military school and then went to the Krasnosel'skii bathhouse. "You perhaps recall what happened there," Sosnitskii wrote. On the next day, relieved from duty, he went to the bathhouse and heard from an attendant what we had done together and for what service I had 
paid the attendant 20 rubles. Sosnitskii continued that so far, he had kept the secret, yet if this information were to make into the press, it would be awkward for me to remain in my present position. The case Sosnitskii mentioned was not true: I remember that evening very well: indeed I was in that bathhouse, but I did not give the attendant twenty rubles and there was nothing to pay for. Yet the mentioned situation is wrong only in relation to that particular case. What is frightful [strasbno] is that there had been other cases and they had already become publicly known. I did not receive Sosnitskii and I won't receive him; nor will I take any measures. Be that as it may. Don't I deserve punishment?

(Romanov 1903-1905)

The final 'punishment' indicates a more fundamental issue-the conflict with Christian morals, another reason for K.R.'s hiding. In one of K.R.'s translations, that of a fragment from Shakespeare's Henry IV (see the analysis that follows), we find evidence of how important the theme of guilt was for K.R. (In the translation he could focus on the theme and embark on a kind of study of the phenomenon, because there he spoke under the mask of Shakespeare.)

Yet another reason for K.R.'s closetedness is his socialization. As we saw earlier, in his early years in the navy, K.R. was sexually attracted to his shipmates, but the prevailing discourse on sexuality and masculinity among them made him draw the conclusion that "[an 18-year-old male's] love for another male is unnatural” (cited in Chernyshova-Mel'nik 2008: 38-39). That is why K.R.'s poetry is predominantly a realm of concealing performed by speaking silence; the only instance of revealing speech left behind among his juvenilia is the aforementioned poem "Vizhu l' glaza tvoi" [When I see your eyes. . .]. Since same-sex attraction was viewed as an unnatural feeling, as K.R. learned from his social milieu, there was little expression of it in his publicly accessible literary works.

Additionally, one might suspect that K.R. did not reveal his intimate feelings because of his concerns over his marriage and family status. Being the husband and the father of nine children would no doubt make one cautious even in a relatively indulgent culture, leading one to postpone finding confidantes to a distant future.

Finally, there were perhaps aesthetic reasons. K.R.'s literary output was mostly conventional, although his work is still considered significant in the history of Russian literature. K.R. was never a poet boasting aesthetic breakthroughs. Literary critics and historians saw his literary output at best as a continuation of Pushkin's tradition, his place among nineteenth-century poets being rather modest (e.g., Nikonychev in K.R. 1991a: 19). K.R. never reached the level of daring sincerity in his poetry that other poets of his time achieved; that was left for his diaries.

K.R.'s poetic art is a prime example of building walls of silence and muffled aesthetic conventionalism; it was almost entirely a speaking silence (silence that speaks, manifesting the aesthetics of evasion) or a silencing 


\section{Sergey Tyulenev}

speech (speech that actively silences). The placid sea of homographetic silence can be illustrated by K.R.'s poem with the telling title "Legenda pro mertvoe more" [The Legend of the Dead Sea]. The poem was written in one of the periods when K.R. was trying to overcome his same-sex desire, something considered by him to be a sickness (nedug). Dmitrii Grishin wrote the following about this poem:

If there was any concrete personal motivation behind this poem, the Romantic poetic devices [izyski] hid that motivation as securely as the sea hid the ruins of Sodom and Gomorrah [. . .] There is no trace of the briefly described tragedy, no hint at the warning. There is only the mesmerising mighty beauty of the dead desert. Perhaps the author considered his 'sickness' [nedug] as overcome and buried for ever under the waves of life?

(Grishin 2008: 397)

The poem furnishes a good example of how K.R.'s mechanism of encryption worked. The "sin" or "sickness" (homosexuality) leads to inner struggle and repentance, which is hinted at with the images of Sodom and Gomorrah, which were turned into the Dead Sea; and, finally, it is not a direct portrayal of the author's inner struggle but rather the legend that makes this text into a "publishable" poem.

To appreciate the real significance of this poem, one needs to penetrate the metaphorics of the legend and juxtapose it with K.R.'s personal life (revealed in his diaries). Speech is securely silenced; his own Sodom and Gomorrah are hidden under the sea of that silenced speech. The poem may be considered comparable to the negative of a photographic image of his inner feelings, the photographic image proper being left for the diaries. K.R.'s diaries openly talk about what he himself refers to as "sin" (grekh), "vice" (porok), or "lust" (pokhot' or vozhdelenie), but the poem only alludes to these, concealing them through the biblical imagery (certainly, at the same time, in the complex speech-silence dialectics, revealing them for those few who could, even potentially, decode the allusion).

Referencing the biblical story of Sodom and Gomorrah as symbols of homosexuality is by no means original. Famously, they form the title of the fourth book of Proust's epic À la recherche du temps perdu [In Search of Lost Time]. The title encapsulates the main theme of the volume-the Parisian homosexual demi-world. If Proust's novel is to be considered as an instance of homographesis, as "one of the most explicit representations of [. . .] the gay body as text" (Edelman 1994: 6), then his homographesis is obscured. Like K.R., the narrator, while telling about homosexuality, hides his own homosexuality. ${ }^{6} \mathrm{He}$ objectifies and disowns his subjective experience.

Another degree of distancing or objectification is added in the highly regarded English translation of Proust's book, when the translator C.K. Scott Moncrieff, himself a homosexual, (together with his publisher) decided "that 
the word 'Sodom' should not appear on the cover" and "chose the allusive 'Cities of the Plain'” (Findlay 2014: 249). Moncrieff was reportedly anxious about publishing his translation because of legal considerations and because his family members would be offended (2014: 223, 240-241, 267). He avoided direct indications of homosexuality, "the world in which he himself lived, but had always had to hide," and "in his translation he tried to soften the blow [to his readers] by not being as direct as Proust could be in French, using euphemism and hidden innuendo where he could" (Findlay 2014: 267).

Proust's title and text are a more or less direct suggestion of the theme, while Moncrieff's version is a further step away, more of a hint (although, in the silence-speech dialectics, Moncrieff's veiling translation, for those who knew the French, was revealing, like many acts of censorship, drawing attention to the very thing it would silence). But both, however allusively, use the biblical cities for naming the type of lifestyle and for discussing the forbidden passions as not (yet) punished. In contrast, K.R.'s title and the entire poem emphasizes the punishment of that lifestyle that has already been meted out:

Груды развалин [...]

Словно как трупы недвижные [. . . ]

Это Содом и Гоморра . . . Господь их порочное племя

В оные дни покарал за великие, тяжкие вины. (K.R. 1991а: 97)

[Ruins are like motionless corpses. They are Sodom and Gomorrah. In the olden days the Lord punished them for great, gross faults.]

In K.R.'s case, homographesis goes side by side with his Christian beliefs and writing himself in terms of his faith as a Christian believer-what might be termed as pisteographesis. More such intersections can be seen in his translations.

\section{K.R.'s Translations}

It is important to keep K.R.'s original poetry and translations apart because, in the latter case, the hiatus between what the original poem says and its translation, which may transpose, as we shall see, the source text from hetero- into homographesis, between what the original poem says and what it could say should it be translated in a different way, is put into sharp relief. K.R.'s original poetry still allows an epistemological doubt about interpreting his poems as homographetic, while his translations, based on a stereoscopic triangulation, can be read more convincingly as homographetic. The translations allow for a comparison not only with K.R.'s diaries (where his poetry inevitably stops) but also with their originals, and such comparisons can be quite telling.

K.R. translated throughout his life. From one of his earlier diary entries (1874) we learn that he enjoyed translating: “I am rendering [. . . P Pushkin's 


\section{Sergey Tyulenev}

Boris Godunov [...] into English. [.. .] It is quite amusing [veselo]" (cited in Chernyshova-Mel'nik 2008: 24). Ella Matonina claims that K.R. matured as a playwright thanks to his translations and, with his versions of Schiller's, Goethe's, and Shakespeare's tragedies, he contributed to the evolution of the Russian translation school (in K.R. 1998: 28). K.R. rendered poetry and plays from German, French, Italian, and English.

He saw himself primarily as an aspiring amateur who was willing to learn from experts, notably Fedor Korsh, a philologist, poet, translator, and a member of the Russian Academy, who "worked hard on my translation of The Bride of Messina [Schiller's Die Braut von Messina]; he carefully compared each line in my translation with the original and made many comments" (Romanov 2013: 261, see also on K.R.'s collaboration with Korsh in Romanov 2013: 207, 262-263).

Some of his translations can be contrasted with his diaries in a way comparable to his original poetry. For instance, in his translation of a sonnet by Théodore de Foudras "Sonet. Iz markiza de-Fudra" [Sonnet. From Marquis de Foudras] (1910), we find nothing more than a level-headed and unobtrusive address of a mature narrator to a young sailor: ${ }^{7}$

Ты в моряки идешь; то славное влеченье:

Оно пленяет всех, кто бодр и смел душой [. . . ]

[You are to become a sailor; this is a glorious intention:/It attracts all who are strong and brave in his soul [...]]

Yet this level-headedness cannot but raise a hermeneutic suspicion from a homographetic perspective because in the diaries written in the same period, a very different emotion toward new recruits to the Navy is expressed. In the entry on September 1, 1913, K.R. wrote the following: "I visited the Aleksandrovskii College to see the new recruits. I liked [. . . the very tall, handsome, blond Viktor Liashkevich" (Romanov 2013: 302). On 22 November 1914, he writes of his being attracted to another soldier: "The handsome [krasavets] cornet Levan Melikov was at the breakfast [. . .]" (Romanov 2013: 369). Evidence of the mature K.R.'s attraction to young men, if not necessarily soldiers or sailors, can be found elsewhere in his diaries (Romanov 2013: 222, 229, 296, 375). These entries echo one of the young K.R.'s intimations (made in his diaries at approximately the time he was writing the aforementioned poem "Vizhu l' glaza tvoi"): "The love for a woman does not appeal to me at all. I want strength, freedom, dashing prowess [likhoe molodechestvo], bravery [udal']" (cited in Chernyshova-Mel'nik 2008: 38).

Among the main themes of K.R.'s poetic translations is the high calling to be a poet. In his 1910 translation "Zhizn' pesni” [The Life of a Song] of the poem "Ein Sangesleben" by Helene von Engelhardt, he assumes the identity of the author of the source text and interprets the singer's calling as singing about all of human experience: 
Пой, что прожито тобой [. . .]

Все, чем сердце пламенело,

Спела песнь.

[Sing what you've lived through. [...] The song sang all that enflamed the heart.]

It should be noted here that, as compared to his diaries, which did describe all that enflamed the heart, K.R.'s translations, such as "Sonnet," are as selective as his original poems. While on the surface, their selectiveness can be (and has been) interpreted as conventionalism, it can also be viewed as signposting patches of speaking silence in K.R.'s homographesis.

Some of K.R.'s translations "cooperate" with his diaries by introducing "loudly" speaking silences. Let us consider K.R.'s version of Friedrich Rückert's "Liebst du um Schönheit” [If You Love Beauty]—-Iz Riukkerta” [From Rückert] (1882).

Although love figures prominently in K.R.'s original poetry and translations, there is hardly ever an unambiguous expression of same-sex love/ desire (cf. his diaries). But in his rendering of Rückert's poem, K.R. deploys the type of poetics referred to by Brian James Baer (2017) in his discussion of Aleksei Apukhtin as a poetics of evasion. For instance, K.R. may evade gender markers. Let us see how this poetics works in his translation of Rückert's poem. (In Table 8.1 the keywords in German and their corresponding Russian translations are highlighted in similar fashions.)

K.R. reduces Rückert's original by half: there are four stanzas in the original and only two in the translation. Yet K.R. manages to keep all

Table 8.1 K. R's translation of Rückert's "Liebst du um Schönheit"

\begin{tabular}{|c|c|c|}
\hline Original & Russian & English (from Russian) \\
\hline $\begin{array}{l}\text { Liebst du um SCHÖNHEIT, } \\
\text { O nicht mich liebe! } \\
\text { Liebe die SONNE, } \\
\text { Sie trägt ein gold'nes Haar! } \\
\text { Liebst du um Jugend, } \\
\text { O nicht mich liebe! } \\
\text { Liebe den Frühling, } \\
\text { Der jung ist jedes Jahr! } \\
\text { Liebst du um SCHÄTZE, } \\
\text { O nicht mich liebe! } \\
\text { Liebe die Meerfrau, } \\
\text { Die hat viel PERLEN klar! } \\
\text { Liebst du um Liebe, } \\
\text { O ja, mich liebe! } \\
\text { Liebe mich immer, } \\
\text { Dich lieb' ich immerdar. }\end{array}$ & $\begin{array}{l}\text { О, нет, за КРАСОТУ ты } \\
\text { не люби меня } \\
\text { И не люби за то, что я } \\
\text { живу БОГАТО: } \\
\text { За красоту люби } \\
\text { СИЯНЬЕ ДНЯ, } \\
\text { А за богатство- } \\
\text { СЕРЕБРО И } \\
\text { ЗЛАТО. } \\
\text { И не люби меня за } \\
\text { молодость мою: } \\
\text { Люби весну,-она все } \\
\text { та же бесконечно. } \\
\text { Меня люби за то, что я } \\
\text { люблю, } \\
\text { И что любить тебя я } \\
\text { буду вечно! }\end{array}$ & $\begin{array}{l}\text { [Oh, no, do not love me } \\
\text { for beauty, } \\
\text { And do not love me } \\
\text { because I am rich: } \\
\text { Love the shining of the } \\
\text { day for beauty, } \\
\text { And love silver and gold } \\
\text { for their riches. } \\
\text { And do no love me for } \\
\text { my youth: } \\
\text { Love spring, it is } \\
\text { endlessly the same. } \\
\text { Love me because I love } \\
\text { you, } \\
\text { And I will love you } \\
\text { eternally!] }\end{array}$ \\
\hline
\end{tabular}




\section{Sergey Tyulenev}

the keywords (sometimes slightly modifying them)—Schönheit-krasota [beauty]; Sonne-siian'e dnia [the shining of the day]; Jugend-molodost' [youth]; Früling—vesna [spring]; Schätze und Perlen [literally "riches and pearls"]-bogato [rich], and serebro i zlato [silver and gold] —except for one: there is no corresponding Russian term for Meerfrau, or "mermaid." The image of a mermaid may be considered one of the few indicators of the gender distribution reflected in the original poem: the poem is written on behalf of a female narrator. The speaker advises the addressee to seek beauty with the sun flaunting its golden tresses; youth is better looked for in perennially young spring; and finally, riches can be found with a mermaid in the sea. K.R.'s reduced version evades all clearly "gendered" features: beauty is compared with the shining of the day (although, it should be noted, there is no golden hair associated with the beauty of women's locks and curls), and a mermaid's riches turn into something more reminiscent of the Grand Duke himself: "I ne liubi za to, chto ia zhivu bogato" [And do not love me because I am rich]. Indeed, the translation does not deny that the speaker lives in affluence, unlike the speaker in the original poem, sending the seeker of her love, if he is looking for riches, to a mermaid. Rückert's more gender-specific poem, thus, turns into a generalized declaration of love in K.R.'s Russian translation. Such a poetics of evasion serves as a kind of speaking silence: there is something hidden (silenced) that speaks only when the translation is read stereoscopically against the original and the diaries, opening a queer space that can be inhabited by either male or female.

It is important to note that K.R.'s "elite" readership could perform the kind of stereoscopic reading required to understand K.R.'s translations as homographesis, as evidenced by a collection of his translations (together with his poems) that was published in 1911, that is, when he was still alive (see K.R. 1911). The translations were printed side by side with the originals. This shows that the stereoscopic reading of his translations against their originals is not just a theoretical assumption but it was a quite real practice, which he encouraged.

Although K.R.'s translation technique was not the focus of our analysis, it is worth mentioning that his translations stay fairly close to their originals while retaining rhyme and meter. This, no doubt, further facilitated comparisons of the source and target, making visible not only similarities but also any deviations. Moreover, K.R.'s skillfulness in his translations must have encouraged his readers to see those deviations as intentional, and, therefore, as clues for reading between the lines. The queer reader was thus invited to look beyond what was said explicitly and explore the terrain of implications.

Some of K.R.'s translations weave an intricate fabric of homographesis, which in some instances may be described as pisteographesis. For instance, in the translations "Glaza. Iz Sulli-Prudomma" [The Eyes. From Sully Prudhomme; "Les yeux"] and in "Ne zabyvai. Iz Alfreda de-Musse" [Do not Forget. From Alfred de Musset; "Rappelle-toi"], K.R. is influenced by Christian eschatological visions, specifically, the rather trivial Christian hope that beyond the grave the eternal dawn will shine for many eyes that used to look 
at the dawn and that used to love the beauty of the day ("Glaza" [The Eyes]) or that one's immortal soul will live forever ("Ne zabyvai" [Do Not Forget]). These are translations reflecting K.R.'s religious beliefs, which, as we have seen, profoundly shaped his homographesis. Such evidence provides an interesting addition to Edelman's theory: homographesis can develop in conjunction with other types of graphesis. In these translations, like in the case of K.R.'s "Legend of the Dead Sea," for example, homographesis overlaps with and is sometimes subordinated to pisteographesis.

At other times, however, the combination of homo- and pisteographeses finds a rather controversial and more dynamic expression. To continue the theme of punishment and forgiveness (or the hope of being forgiven), K.R. appears in some translations to accept the inevitability of punishment. For instance, in his "Nadezhda na Boga. Iz Giugo" [Hope in God. From Hugo], a translation of Victor Hugo's "Espoire en dieu," he agrees with the Christian dogma that "[f]or our sin, O my angel, we are to be punished" (cf. "Don't I deserve punishment?" from the diaries) (Romanov 1903-1905). Yet, in this poem, there is also a ray of hope:

Господь, благословив и слезы покаянья И грезы чистоты,-благословит и нас.

[Blessing the tears of repentance and the dreams of purity, the Lord will also bless us.]

This theme of penitence and forgiveness also takes center stage in the scene K.R. selected and translated from Shakespeare's Henry IV (Part II, Act 4, Scene 4). First, in an introduction to his translation, K.R. recounts the events preceding the scene, in which the King, Henry IV, inquires about the eldest of his sons, Henry, the Prince of Wales, and is told about the latter's merrymaking and profligacy. Here K.R. pays special attention to Warwick's defense of the prince who, according to Warwick, is but learning a strange tongue, including even the most immodest words in it, only to avoid such words in the future. Importantly, in his summary, K.R. omits the king's skeptical and rather judgmental reply (that the bee rarely leaves its comb in the carrion).

K.R.'s translation also focuses on the scene when the prince comes to the king and sees him on his deathbed. Thinking that the king is dead, he takes away the crown. The king wakes up and orders the prince back. He rebukes his son for his haste to become the next king. K.R. clearly concentrates on the dynamic of the relationship between the king and his son: the father's reproach, the son's explanation (he took the crown only to upbraid it for having consumed his father's efforts and entire life), and the king's understanding and forgiveness of his son. At this point the translation ends and K.R. leaves the closing lines of the act untranslated. Thus, the most important theme in Shakespeare's tragedy for K.R. is the drama of apparent sinfulness (the prince's debauchery and his seemingly hasty appropriation of the crown) and of the understanding and forgiveness that occurs once the truth is learned and appreciated. 


\section{Sergey Tyulenev}

In his diaries, over many years, K.R. seems to have come to terms with his same-sex desire. He started by referring to it as unnatural love, which he tried to explain away in terms of his appreciation for the perfect human being, one that is strong, free, brave, and with dashing prowess (Chernyshova-Mel'nik 2008: 38-39). As a mature person, in the diary entry made on December 30,1904, K.R. talks about physiology as the reason for his sexuality, rather than licentiousness (raspushchennost') or a lack of willpower (nedostatok voli) (Romanov 1903-5). Here homographesis seems to have parted ways with pisteographesis.

A glimpse of this metamorphosis may be caught in his translation of a poem by Lorenzo Stecchetti Postuma IV, "Quando cadran le foglie e tu verrai" [When the Leaves Fall Down and You See ...]), entitled "Kogda spadut listy" [When the Leaves Have Fallen Down] (1910). The poem describes how on the poet's grave there will blossom flowers of his unsung songs, which are a revelation of his unsaid love (nedoskazannaia liubov'). In the Italian original, Stecchetti talks about the words of love that the narrator failed to say to the addressee (Le parole d'amore che non te dissi [The words of love that I did not tell you]), whereas K.R.'s translation is less specific-or, one might say, evasive. He turns Stecchetti's specific reference to "the love that I did not tell you about" into a homographetic silence that speaks by giving a hint at the love that he himself did not express fully: the grave flowers symbolize a revelation of an unsaid love, or literally "the love that was not expressed fully/to the end" (nedoskazannoi liubvi priznan'e)—a description provocatively close to Wilde's famous words "the love that dare not speak its name" ("Two Loves") published in 1894, which K.R. might have known as these words were used in Wilde's trial and widely circulated. In light of our knowledge of K.R.'s sexual desire from his diaries, this phrase allows a reading of the line as a reference to the love that was not expressed in his poems but that left its clear traces in his translations-same-sex love.

Yet, as usual, K.R. would not allow us to draw definitive conclusions grounded in black-and-white certainties. In a 1911 translation (cf. he wrote about the physiological reasons behind his same-sex desire in 1904), K.R. translated the aforementioned poem "Nadezhda na Boga" [Hope in God] from Hugo in which he returns to the discourse on sinfulness, although of course this did not necessarily refer to his same-sex desire. If this reference to sinfulness does include his same-sex desire, however, then one can speak of his translations as demonstrating a complex dynamic - a genuinely human zigzag trajectory negotiating its way between hetero- and homographesis and these sexual grapheses and pisteographesis, as well as his own and his original authors' grapheses, perhaps among other concerns, aspirations, passions, and obsessions hidden or half-hidden from the world.

\section{Conclusion}

Not only do we see that while K.R. speaks from his closet, he is not completely silent but also that he is speaking (or silent) differentially depending 
on the mode of his homographesis (his diaries, poetry, and translations). In terms of silence and speech, K.R.'s translations are a privileged site of homographesis in his literary œuvre; there his self-expression was not as open and direct as in his diaries (where it was also restricted to readers in a far-off future), but it was more so than in his poetry. K.R. hints at the unsaid love in his translation from Stecchetti; he applies the aesthetics of evasion by removing the female reference in a Rückert poem, and in other translations he emphasizes not only punishment but also understanding and forgiveness, notably in his translation of a fragment from Shakespeare's Henry IV (unlike in his poem "Legenda pro Mertvoe more" [The Legend of the Dead Sea]).

Our analysis of K.R.'s translations viewed as a mode of his homographesis allows us to refine and extend Sedgwick's and Edelman's theorizations of the relationship between homosexuality and writing, or of homosexuality as writing. Most importantly for this study, the phenomena of closeted performativity and homographesis can and should be studied with the help of translation, taking into account the latter's specificity as a mode of expression rather than assuming its transparency or ignoring it as little more than something ancillary.

\section{Notes}

1 I would like to express my heartfelt gratitude to Brian James Baer for his generous help and valuable suggestions.

2 Elsewhere I described a similar situation experienced by women who were representatives of the Russian nobility. They could not publish openly and either used pseudonyms or printed their literary works anonymously, although in their case their gender was an additional 'aggravation' (Tyulenev 2011).

3 Speaking silence in the case of K.R. may remind us of Jonathan Katz's concept of performative silence as identified in the case of John Cage, a leading twentieth-century American composer and a closeted homosexual (2001a). Yet there is a significant difference between the functions of silence in these two cases. As Katz argued, Cage's silence was "a chosen mode of resistance [. . . and a way] to declare his identity within a hostile culture" (2001a: 50). Such a function of silence distinguishes Cage from the majority of closeted people experiencing same-sex desire in a homophobic society "who seek to ape dominant discursive forms, to participate as seamlessly as possible in hegemonic constructions" (2001a: 50). K.R., as we shall see, was not as actively resistant as Cage, yet he was not completely quiescent either.

4 This turning of fascination with male beauty into physical, sexual interaction with it made K.R. different from Leo Tolstoy who wrote in his diary (on 29 November, 1851): "I fell in love with men very often [. . .] I fell in love with men before learning about a possibility of pederasty, but even when I did learn, the idea of having intercourse [soitie] never crossed my mind" (cited in Kon 2001).

5 Other than this, there is another poem "Saint Sebastian, the Martyr" that allows a homographetic interpretation, but one that is foreclosed at the very end by revealing the addressee to be female (Baer 2009: 11).

6 In the words of Chris Power (2007): "[I]n an interesting bit of wish fulfilment, perhaps, [the main character of Proust's book, Marcel, appears as] one of the only heterosexuals in his circle, if not in all of Parisian high society."

7 All texts of K.R.'s translations are from K.R. 1991b. 


\section{Sergey Tyulenev}

\section{References}

\section{Primary Sources}

K.R. 1911. Stikhotvoreniia. Saint-Petersburg: Tipografiia Imperatorskoi Akademii Nauk.

K.R. 1991a. Stikhotvoreniia [Poems]. Moscow: Litfond RSFSR.

K.R. 1991b. “Translations.” Available online at http://lib.ru/RUSSLIT/KR/kr1_3.txt (last accessed May 8, 2016).

K.R. 1994. Vremena goda: Izbrannoe [Seasons of the Year: Selected Poems]. Introduction by A. Muratov. Saint-Petersburg: Severo-Zapad.

K.R. 1998. Dnevniki, vospominaniia, stikhi, pis'ma [Diaries, Memoires, Poems, Letters]. Edited by Ella Matonina. Moscow: Iskusstvo.

\section{Secondary Sources}

Amico, Stephen. 2015. Roll Over, Tchaikovsky! Russian Popular Music and Post-Soviet Homosexuality (New Perspectives on Gender in Music). Urbana, IL, Chicago, and Springfield: University of Illinois Press.

Baer, Brian. 2009. Other Russias: Homosexuality and the Crisis of Post-Soviet Identity. New York: Palgrave Macmillan.

Baer, Brian. 2011. "Translating Queer Texts in Soviet Russia: A Case Study in Productive Censorship." Translation Studies 4(1): 21-40.

Baer, Brian. 2013. "Now You See It: Gay (In)Visibility and the Performance of Post-Soviet Identity." In Queer Visibility in Post-Socialist Cultures, edited by Nárcisz Fejes and Andrea P. Balogh, 35-57. Bristol and Chicago, IL: Intellect.

Baer, Brian. 2017. "A Poetics of Evasion: The Queer Translations of Aleksei Apukhtin.” In Queer in Translation, edited by B.J. Epstein and Robert Gillett, 51-63. London and New York: Routledge.

Chernyshova-Mel'nik, Natalia. 2008. Baloven' sud'by: Istoriia zhizni Konstantina Romanova [A Favorite of Fortune: A Biography of Konstantin Romanov]. Moscow: Enas.

Edelman, Lee. 1994. Homographesis: Essays in Gay Literary and Cultural Theory. New York and London: Routledge.

Engelstein, Laura. 1992. The Keys to Happiness: Sex and the Search for Modernity in Fin-de-siècle Russia. Ithaca, NY: Cornell University Press.

Essig, Laurie. 1999. Queer in Russia: A Story of Sex, Self, and the Other. Durham, NC and London: Duke University Press.

Findlay, Jean. 2014. Chasing Lost Time. The Life of C.K. Scott Moncrieff: Soldier, Spy and Translator. London: Chatto \& Windus.

Gaddis Rose, Marilyn. 1997. Translation and Literary Criticism. Manchester: St. Jerome Publishing.

Grishin, Dmitrii. 2008. Velikii kniaz' Konstantin: Pred vechnoi krasotoi [Grand Duke Konstantin: Before the Eternal Beauty]. Moscow: Veche.

Healey, Dan. 2001. Homosexual Desire in Revolutionary Russia. Chicago and London: The University of Chicago Press.

Healey, Dan. 2006. “Can We 'Queer' Early Modern Russia?” In Queer Masculinities, 1550-1800: Siting Same-Sex Desire in the Early Modern World, edited by Katherine O'Donnell and Michael O'Rourke, 106-124. Basingstoke, New York: Palgrave Macmilian. 
Heller, Leonid (ed.). 1992. Amour et érotisme dans la littérature russe du XXe siècle. Bern: Peter Lang.

Karlinsky, Simon. 1976. The Sexual Labyrinth of Nikolai Gogol. Cambridge, MA and London: Harvard University Press.

Karlinsky, Simon. 1997. "Introduction: Russia's Gay Literature and History." In Out of the Blue: Russia's Hidden Gay Literature. An Anthology, edited by Kevin Moss, 15-26. San Francisco, CA: Gay Sunshine Press.

Katz, Jonathan Ned. 2001a. "John Cage's Queer Silence, or How to Avoid Making Matters Worse.” In Writings Through John Cage's Music, Poetry, and Art, edited by David W. Bernstein and Christopher Hatch, 41-61. Chicago: University of Chicago Press.

Katz, Jonathan Ned. 2001b. Love Stories: Sex Between Men Before Homosexuality. Chicago: The University of Chicago Press.

Kon, Igor. 2001. "Liubov' nebesnogo tsveta" [Love of the Heavenly Color]. Available at http://royallib.com/read/kon_igor/lyubov_nebesnogo_tsveta.html\#0 (last accessed May 7, 2016).

Moss, Kevin (ed.). 1997. Out of the Blue: Russia's Hidden Gay Literature: An Anthology. San Francisco, CA: Gay Sunshine Press.

Moss, Kevin. 2000. "Russia," "Russian Literature.” In Gay Histories and Cultures (Vol. II of The Encyclopedia of Lesbian and Gay Histories and Cultures), edited by George Haggerty, 755-759. New York and London: Garland Publishing, Inc.

Moss, Kevin. 2013. "Straight Eye for the Queer Guy." In Queer Visibility in Post-Socialist Cultures, edited by Nárcisz Fejes and Andrea P. Balogh, 197-220. Bristol and Chicago: Intellect.

Naiman, Eric. 1997. Sex in Public: The Incarnation of Early Soviet Ideology. Princeton, NJ: Princeton University Press.

Power, Chris. 2007. "Going to Sodom and Gomorrah with Proust." The Guardian, December 12.

Romanov, Konstantin. 1903-5. "Konstantin Romanov Dnevniki 1903-1905 gg.” [Diaries of 1903-1905]. Available online at http://az.gay.ru/articles/articles/romanov1. html (last accessed May 2, 2016).

Romanov, Konstantin. 2013. Dnevnik Velikogo Kniaza Konstantina Konstantinovicha (K.R.) [Grand Duke Konstantin Konstantinovich's Diary]. Edited by V.M. Khrustalev. Moscow: PROZAiK.

Sedgwick, Eve Kosofsky. 1990. Epistemology of the Closet. Berkeley, CA: University of California Press.

Tyulenev, Sergey. 2010. “Translation as Smuggling.” In Thinking Through Translation with Metaphors, edited by James St. André, 241-274. Manchester: St. Jerome Publishers.

Tyulenev, Sergey. 2011. "Women-Translators in Russia.” MonTI 3: 75-105.

Tyulenev, Sergey. 2014. "Strategies of Translating Sexualities as Part of the Secularization of Eighteenth- and Early Nineteenth-Century Russia." Comparative Literature Studies 51(2): 253-276. 


\section{Translation's Queerness \\ Giovanni Bianchi and John Cleland Writing Same-Sex Desire in the Eighteenth Century}

\section{Clorinda Donato}

In 1751, John Cleland published his translation of Giovanni Bianchi's 1744 novella Breve istoria della vita di Catterina Vizzani [A Brief History of the Life of Catherina Vizzani] anonymously, under the title The True History and Adventures of Catharine Vizzani. ${ }^{1}$ This short text of some 30 pages recounts the medical, sexual, and social history of its female working class protagonist. Over the past 20 years, Cleland's translation has been one of the primary texts used by scholars of Sapphic literature and female love to analyze and document relationships between women in eighteenth-century England (Dekker and van de Pol 1989: 3). ${ }^{2}$ Cleland's translation is so English in fact, that its purported Italian provenance had been all but forgotten. The Italian source text was never studied, analyzed or even located; indeed, it was easy to surmise that claims of the text's Italian origins had been merely fabricated by Cleland himself as a means of distancing himself from the potential scandal that the contents of the text might cause, especially in light of the consequences he had already suffered as a result of authoring Memoirs of a Woman of Pleasure (Fanny Hill) some three years prior.

The Italian original, however, does indeed exist, and when the source text and Cleland's "translation" are read side by side and compared, a thoroughly divergent presentation of gender emerges, one that is a function of the very different contexts, audiences, professions, and biases that author and translator were addressing. In fact, Bianchi's medically and sociologically motivated narrative of transgendered life and same-sex female relationships prompted a condemnatory rewriting of the text, referred to as a translation, with intent and purpose that ran far afield of Bianchi's. This study explores the issues at stake in the discussion of female sexuality for Cleland, author of Fanny Hill, and Cleland, translator of female desire in The True History and Adventures of Catharine Vizzani.

\section{Gender and Genre in Eighteenth-Century Europe}

Bianchi's novella, published over 250 years ago, strikes us as thoroughly modern in the way that it explores the physiological, psychological, and 
social realities of a transgendered person who lived and presented as both male and female during their lifetime. Indeed, Vizzani, the protaganist of the narration, who was in her fourteenth year, had never felt aroused by any love save for that of other young girls whom she constantly pursued with a burning love, not as a young girl, but as if she were a man" (non d'altro amore si sentì mai accesa che verso le Fanciulle sue pari, alle quali sempre tenea dietro ardentemente amandole non come Fanciulla, ma come uomo stata fosse) (Bianchi 1744: 2).

Bianchi's Breve storia della vita di Catterina Vizzani romana che per ott'anni vestì abito di huom in qualità di Servidore la quale dopo vari casi essendo in fine stata uccisa fu trovata Pulcella nella sezzione del suo Cadavere [Brief history of the Life of Catterina Vizzani, Roman woman, who for eight years wore a male servant's clothing, who after various vicissitudes, was in the end killed and found to be a Virgin during the autopsy of her Cadaver] merges the medical genre of the "consultazione" or medical report with the Boccaccian novella to instruct, to be sure, but also to delight in the telling of a good story whose queer moral, for Bianchi, left the reader with only one possible reaction-every person has the right to live and love. ${ }^{3}$ Bianchi's queer narrative thoroughly questions the purportedly stable relationship between sex, gender, sexual desire, and sexual practice. Bianchi launches a queer textual and narrative challenge to the stability of heterosexuality, by refusing to shore up the correspondence between desires, identities, and practices. Bianchi's choice to celebrate Vizzani/Bordoni's queerness, juxtaposed to Cleland's subsequent attempts to reheterosexualize Vizzani/Bordoni by unqueering the language of the text through rewriting-translation makes for a salient case of reverse queer translation. A brief consideration of the prose genre in the eighteenth century highlights the particular parameters of the Vizzani story in all of its trans states.

In the eighteenth century, new situations, new publics, and new public spheres demanded new genres. Scientific prose and narrative prose met and completed each other, reflecting as well our modern preoccupation with the body and how it works, the mind-body connection, and the right to live and perform gender as one sees fit. The unique narrative pastiche of Bianchi's novella and its resonance can only be fully appreciated when analyzed as a function of its novelty and the social space it breached, both in Italy, where it was written, and in England where it was "translated" (in reality, domesticated to fit English sensibilities) by Cleland, author of Fanny Hill. Vizzani/ Bordoni's polyamourous life is recounted in the Breve storia with elements of the picaresque mixed in, to which Cleland adds a moralizing tone and at times, a thoroughly gratuitous textual addition, as he does in the section "Remarks Upon the Foregoing Dissertation" which he adds at the close of his "translation" of Bianchi's text.

However, in a complete departure from the low life characters of the traditional picaresque, Vizzani/Bordoni is neither entertaining nor morally 


\section{2}

questionable for Bianchi, whereas for Cleland this same transgendered character is both entertaining and morally questionable. ${ }^{4}$

\section{Contextualizing Bianchi's Breve storia and Cleland's True History}

Translations and translation history play a salient role in establishing the view of the other in intercultural relations. For the scholar of British-Italian relations in the eighteenth century, this approach can yield concrete evidence of the interplay of language, culture, and travel, and the perceptions resulting from this intense exchange. It is for this reason that the text to be examined in this chapter, Bianchi's 1744 Breve storia, commands our attention, for it is one of the few examples of narrative prose to have been written in Italian and translated into English in the eighteenth century.

With the advent of queer and gender studies, Cleland's translation has received much scholarly attention as one of only a few texts documenting same-sex relations between women in the eighteenth century, and although we read the text as transgendered, it is important to make reference, as well, to the first iteration of its reception among scholars as a text about same-sex, female relations (Findlen 2009: 243). Due to the paucity of queer scholarship in the Italian academy, no attempts were made to locate Bianchi's source text, let alone investigate the particular conditions in Italy that it was referencing. In England, on the other hand, it is safe to say that Cleland's translation was seen as so representative of lesbian relations in the early modern period that its Italian provenance was all but forgotten. As a text that was extensively rewritten in accordance with eighteenth-century translation practices, Cleland's "translation," I argue, should indeed be retained as part of the English canon. However, in the interest of 1) restoring the author Bianchi's original intent and 2) profiting from an opportunity for the kind of intercultural reading that translations and their source texts can provide, it is important to understand the full range of the national, both English and Italian, and intercultural dynamics at stake when such texts are considered in their own right and in comparative analysis.

What emerges upon comparison of the two versions is a thoroughly divergent presentation of gender as a function of the different audiences the author and translator were addressing. The suspicion that the two texts might differ substantially was raised only in 2006 when Leslie Jensen speculated in her doctoral dissertation (still without access to the Italian source text) that source and translated texts may transmit highly divergent meanings as a function of national perspectives on gender and identity (Jansen 2006: 185-197).5 She speculates correctly about the extent to which England's view of Italy influenced Cleland's translation. To push her analysis a step further, we should consider the two texts together.

When seen from the perspective of the English Cleland, informed by the long-debated topic of Italian sexuality in Britain, England, and Italy are 
connected through a hierarchical relationship in which the ultimate textual authority is assumed by the translated text. These issues will be explored by addressing the belief system and the attendant literary and cultural practices, both single and collective, that prevailed when Cleland took up the pen to rewrite same-sex Italian female sexuality in his "translation" of the Vizzani text.

Cleland's text offers an ideal case for the study of translation as conceptual transformation through rewriting at a number of levels, not the least of which are those of genre and style. What drives these changes is a case of eighteenth-century "gender trouble" (Butler 1990) as described in an Italian source text rendered in English translation. Here Cleland's translation and rewriting of transgender as a British cultural construct transforms and manipulates Bianchi's original concept into a text that speaks to a completely different "interpretive community" than the one Bianchi engaged in his original version. The Bianchi-Cleland texts elucidate perhaps better than any other two texts the theories about cultural translation as they have been presented by Laurence Venuti in his seminal work on literary translation, where he explores questions of cultural translation, fully taking into account Homi Bhabha's theories about the hybridity, heresy, and ambivalence of postcolonial cultural translation, to ask about "the larger questions of why and how the translator should signal the foreignness of the foreign in a translation" (Venuti 2003: 243).

Cleland and Bianchi were both mavericks and literary risk takers, each within his own cultural system. In translating or rewriting Bianchi's text, Cleland confidently leaves out over one-third of the original text, expanding, instead, those areas of the narrative that serve his authorial agenda, not to mention his cultural and sexual politics. Through the crafting of a mock moralistic translation whose stated purpose is that of warning young girls and their families against sexual depravity, Cleland has neatly separated English and Italian customs by projecting a judgment of Italian gender and sexuality onto his text through his additions to the narrative itself, as well as through the adoption of a ribald, swaggering style for a "man-to-man" telling of female sexuality, of which there are clear echoes in his novel Fanny Hill. Cleland establishes a hierarchical power relationship between British and Italian culture, an element that is thoroughly missing from Bianchi's text, with its intended Italian audience. This discrepancy is evident in the following comparison of excerpts from the two texts:

Il presente caso che io ora sono per raccontare fa vedere che anche a di nostri s'è trovata una Fanciulla, che né a Saffo, né all'altre Donzelle di Lesbo nell'amare solamente quelle del medesimo sesso ha ceduto, ma che di gran lunga le ha trapassate, per cui e grandi disastri ha sofferti, e in fine la morte medesima crudelmente ha incontrata.

(Bianchi 1744: 3) 
[The present case that I am about to recount shows that even in our day there exists a girl who neither to Sappho, nor to the other young girls of Lesbos was second in loving those of her same sex, but who far surpassed them, for which she suffered great troubles, finally meeting, cruelly, with death itself.]

The Subject before me is an Instance, that the Wantonness of Fancy, and the Depravity of Nature, are at as great a Height as ever; and that our Times afford a Girl, who, so far from being inferior to Sappho, or any of the Lesbian Nymphs, in an Attachment for those of her own Sex, has greatly surpassed them in Fatigues, Dangers, and Distress, which terminated in a violent Death.

(Bianchi and Cleland 1755: 2; emphasis added)

The text in its two versions offers an important example of cross-cultural transfer and its limitations, while commenting powerfully on relations between the Italian and British peoples in the eighteenth century, when British noblemen and noblewomen traveled to Italy in droves on "the grand tour" to view Roman and Renaissance artifacts. Italy was the site of the sexually ambiguous, the exciting and the transgressive. Clubs formed among the British to celebrate and share memories and exploits accumulated during the grand tour in Italy. One such club, the Society of Dilettanti, founded in 1734, institutionalized the British fascination with Italian erotica and its cross-cultural implications. Living by the motto "Pleasure is a serious business," the Society was particularly fond of the sexually explicit art unearthed at Herculaneum and Pompei, which they collected and displayed in their own private cabinet of obscene curiosities (Redford 2008: 3). ${ }^{6}$ The Society took a holistic approach toward Italy, making its goal that of studying, reminiscing over, and promoting Italian culture, both high and low, going even as far as engaging important painters to memorialize any number of their moments of rapt Italian reflection, albeit with somewhat lascivious undertones, in a series of telling individual and group portraits, recently on display at the J. Paul Getty Museum in Malibu. In London, the interest in Italian life and lifestyles grew exponentially in the two decades following the founding of the Society of Dilettanti. While the Society also financed a number of worthy projects related to the study of ancient Rome and the Italian peninsula, their somewhat dubious reputation is best summed up in Horace Walpole's disparaging remark that "the nominal qualification of membership is having been in Italy, and the real one, being drunk" (Walpole 1743: 318). This was one of the audiences to whom precisely Cleland's "translation" was targeted, but there were others, not the least of which were those audiences, male and female alike, who had made Henry Fielding's 1746 picaresque pamphlet novella, The Female Husband, such a favorite as a cautionary tale of what the growing self-determination for women could lead to, including their literal and figurative wearing of the pants. ${ }^{7}$ 
The chronology of these texts makes entirely plausible that Bianchi's Italian original had landed in Cleland's hands sometime subsequent to its publication in Florence in 1744, brought to England by the ex-patriot community residing in Florence (Findlen 2009: 243).

It is easy to understand why Cleland, author of Fanny Hill, was attracted to the text and immediately saw the potential for giving it a racy, ribald spin. In a recent article, Robert Folkenflik has argued for considering Fanny Hill as a novel in which the pleasure of its pornographic depictions of Fanny cut across class lines in a society in which the rowdy male sexualities of the brothel and tavern variety were common to all; though Fanny's clients at the brothel represent a cross-section of social classes in England, one of the messages of the book is surely their equality when viewed with their pants down (Folkenflik 2009: 105). He also sees the novel as participating in a well-practiced, pornographic discourse that shared common ground with any number of harlots' tales. He critiques Leo Braudy's materialistic interpretation of Fanny Hill to focus on a reading that places Cleland's novel squarely within the tradition of the titillating text. This assessment is extremely useful for our analysis of Cleland's "translation" of Bianchi's text, for it recognizes a tradition of genre, and with it, the particular linguistic codes to which Cleland fully subscribed, i.e., codes for addressing sexual activity in a novel that Cleland automatically adopts when he picks up the pen to translate queerness and reprimand both author, Bianchi, and protagonist, Vizzani/Bordoni. Among these techniques is a circumlocuting, periphrastic style in which specious allusions are made to specific acts or objects by circling around them linguistically, or by defining them with the addition of damning or leading adjectives, such as when he refers to the love between Catterina and Margherita at the beginning of the story as "this whimsical amour" (Bianchi [Cleland] 1755: 34; emphasis added) rather than using Bianchi's words "questo amore (this amour)" or when he refers to Catterina/Giovanni's dildo as "a leathern Contrivance, of a cilindrical Figure, which was fastened below the Abdomen, and had been the chief Instrument of her detestable Imposture,"(Bianchi [Cleland] 1755: 34-35) "quel Piuolo di Cuojo, che cinto di sotto avea,") (Bianchi 1744: 9) [that leather dildo which he had strapped on to himself below] describing them straight on as will be seen next when comparing passages.

The original "story" takes the reader through the vicissitudes of Catterina Vizzani's life as a fourteen-year old girl of low birth from the moment of her sexual awakening through the discovery of her preference for women. Wherever she goes, under the protective disguise of men's clothing and her pseudonym, Giovanni Bordoni, Vizzani/ Bordoni always garners admiration and respect for her/his proficiency as majordomo, providing evidence of the little documented world of the worker, and in the case of Catterina/ Giovanni, the lesbian and transgendered person. For the notorious author of Fanny Hill, the text lent itself to the easy exploitation of a subject he could already lay claim to-the lust and vice of young women. Yet with 


\section{Clorinda Donato}

Fanny, whose appetites are awakened and fulfilled first by Phoebe, rather than a man, love between women is not condemned but rather is presented as merely a prelude to the real thing-love with a man.

Cleland's treatment of a narrative about a woman who desires other women and only women, never men, reorders the priorities of Bianchi's text in which the medical case narrative and the literary narrative blend, occupying an equal role in narrative strategies of the text, constituting a case of "narrative medicine" as the newly emerging field has been defined of late, expressing in a succinct label the inherent dualism of what was formerly known as literature and medicine (Spiegel and Charon 2009: 132). As anatomists became more conscious of the importance of describing lifestyle details when discussing medical cases, literary narrative entered the clinical discussion. Cleland prioritizes Catterina's deviance in an environment in Britain in which the culture of sex was in flux and the conventional trajectory of marriage with the popularizing of sentimental domesticity through the novel, was increasingly threatened by non-procreative sexual practices, which occupied a notable place in public discourse judging from the proliferation of literary and artistic renderings of deviant pleasure, a prime example of which can be found in Fielding's The Female Husband. ${ }^{8}$ As Joanne Bailey has noted, damage to the marriage was always blamed on the women, with adultery always being adjudicated against women, while men's extramarital sexual habits were never an issue (Bailey 2003: 6).

While same-sex female desire had been taken up by the medical profession in England as it had been in Italy, it was deemed to be so deviant that a clitordectomy was recommended so as to prevent women from developing too strong a desire for other women (Parsons 1741). Within this context, the deviant woman is presented within the heterosexual paradigm that Katherine Crawford (2007: 209) has identified in her work on European sexualities. Cleland's Vizzani and Fielding's female husband, Mary Hamilton, are both depicted as deviant sexual predators who pose a threat to British domesticity and more importantly, to male anatomy and performativity, when they reconfigure their gender through the adoption of the dildo. As Jill Campbell (1987: 65) has noted in the case of Fielding's The Female Husband, Mary Hamilton's artificial appendage is every bit as effective as an anatomical one in its ability to confer the benefits associated with being a male, among them marriage and service by a domestic wife in exchange for the virile duties of breadwinner and sexual performance as male. The threat of woman passing as man and usurping male privilege is even more pronounced in the case of Catterina/Giovanni. By the end of the "brief history," Catterina/Giovanni's personal identity has merged with the professional role of breadwinner and therefore potential spouse. Catterina/Giovanni thereby assumes the mantle of power that accompanies that role planning, as she does, to marry her employer's niece (Campbell 1987: 72). 


\section{Comparative Textual Analysis}

In order to illustrate the extent to which Bianchi's and Cleland's texts diverge, we will compare several short passages, presented in the following order: (1) Giovanni Bianchi's source text in Italian, (2) my close English translation in brackets, and (3) Cleland's "translation" with underlined passages to indicate what he has added or altered in Bianchi's text. I will provide commentary where necessary to illustrate the other ways in which Cleland's "translation" has adapted Bianchi's text and domesticated it to facilitate its reception in England.

\section{Example I}

Cleland's recasting of the Vizzani text begins with the title, which in Bianchi's original reads:

Breve Storia Della Vita De Catterina Vizzani, Romana, Che per ott'anni vestì abito da Uomo in qualità di Servidore la quale dopo vari Casi essendo in fine stata uccisa fu trovata Pulcella nella sezzione del suo Cadevero, Di Giovanni Bianchi Professore di Notomia in Siena. [Brief History of the Life of Catterina Vizzani, Roman Woman, Who for eight years wore A Male Servant's Clothing, Who after various Vicissitudes, Was in the end killed And found to be a Virgin during the autopsy of her Cadaver, By Giovanni Bianchi Professor of Anatomy in Siena].

(My translation of the Italian title)

The True History and Adventures of Catherine Vizzani, A YOUNG Gentlewoman a Native of Rome, who for many Years past in the Habit of a Man; was killed for an Amour with a young Lady; and found on Dissection, a true Virgin. With curious Anatomical REMARKS on the Nature and Existence of the HYMEN. By GIOVANNI BIANCHI, Professor of Anatomy at Sienna, the Surgeon who dissected her.

From the title alone, the different orientation of Bianchi's original and Cleland's translation are evident. While Bianchi's title explains without judging, stating that he will narrate the story of a woman who for eight years wore man's clothes, Cleland, on the other hand, immediately alludes to her life as a tribade by adding, "Was killed for an amour with a young lady." There is no social agenda in Bianchi's title, for while the subject's cross-dressing, death, and virginity alluded to in the title piqued the Italian readers' interest; there was no expectation of prurience. Cleland, instead, has made prurience the focus of the title and the promise of the text. By adding the quote "What Odd, Fantastic Things, we Women do!" to the frontispiece, Cleland and his publisher further heighten the sexual interest of the text, while mocking female sexuality, especially in the lesbian and transgendered rendering found in the text. Whereas Bianchi wishes to narrate the story of Catterina's 
life by studying the intersection of the lesbian, transgendered body, and her human life, Cleland promises titillation, prurience, and condemnation for the transgression he perceives.

\section{Example 2}

The story opens with the presentation of the case by the first-person narrator. The passage presented next underscores the ways in which Cleland uses translation to rob Bianchi's Vizzani/Bordoni of their queer agency.

Dico adunque che in Roma fu una Fanciulla di bassa condizione figliuola di un Legnajuolo Catterina Vizzani nomata. Costei essendo d'età d'quattordici anni non d'altro amore si sentì mai accesa che verso le Fanciulle sue pari, alle quali sempre tenea dietro ardentemente amandole non come Fanciulla, ma come uomo stata fosse. Più d'ogn'altra però d'una Fanciulla s'era invaghita, che Malgherita avea nome ... (Bianchi 1744: 4).

[Let me recount, then, that in Rome there lived a young girl of humble origin, daughter of a carpenter, whose name was Catterina Vizzani. At as early of an age as fourteen, she had never felt herself warmed by any other love than that for other young girls, her peers, whom she pursued, loving them ardently, not as a young girl, but as if she were a man. More than any of the others, however, she had become enamoured of one young girl, whose name was Margherita ... .]

\section{Cleland's "Translation"}

Our unfortunate Adventurer's Name was Catherine Vizzani; she was born at Rome, and of ordinary Parentage, her Father being a Carpenter. When she came to her fourteenth Year, the Age of Love in our forward Climate, she was reserved and shy towards young Men, but would be continually romping with her own Sex, and some she caressed with all the Eagerness and Transport of a Male Lover; but, above all, she was passionately enamoured with one Margaret.

(Cleland 1755: 2, bold added)

\section{Example 3}

This example shows Catterina on the job as a man, with the name Giovanni Bordoni. In Bianchi's text, the male pronoun is used throughout as an indication that the author, Bianchi, accepts Catterina as Giovanni. In contrast, Cleland does not. He wants us to know that Giovanni is a she by using the female subject pronoun. This passage is particularly rich with the translator's personal comments about what he calls "the imposture." There is no validation of gender doing in Cleland's text, no attempt to understand the transgendered life; condemnation is the dominant theme for Cleland. 
Buonissimo servigio il Vicario da questo Giovanni ritraeva, perciocchè sapea convenevolmente cucinare, far la barba, pettinare le Parrucche, mescere il Cioccolatte, leggere e scrivere, in somma non era cosa che ad un buon Servidore appartenesse che convenevolmente non facesse, o d'intraprendere non s'argomentasse. Un solo difetto il Vicario che era uomo assai severo in lui riprendeva, che troppo le femmine vagheggiava, e in questo troppo disonesto gli parea; perciocchè Giovanni per essere più grato alle donne in tutto un maschile portamento, e un libero parlare usava. Anzi per parere uomo da vero un bel Piuolo di Cuojo ripieno di Cenci s'ra fatto, che sotto la camiscia teneva ... (Bianchi 1744: 7).

[The Vicar received the best of service from this Giovanni, for he was very proficient at cooking, shaving, styling wigs, mixing chocolate, reading, and writing; in short, there was no task pertaining to a good servant that he would either not perform adequately or that he would object to undertaking. The Vicar, a rather austere man, reproached him for only one flaw-that of desiring women excessively, and in this he appeared exceedingly dishonest. For in order to appeal to women in every respect, Giovanni adopted an overtly masculine demeanor, and spoke with a loose tongue. Indeed, in order to appear to be a real man, he fashioned for himself a nice leather dildo, stuffed with rags, which he kept under his shirt....] (emphasis added).

Never was Gentleman better fitted with a Servant than the Vicar with Giovanni; for, besides Reading, making of Chocolate, and Cookery, she was very dextrous at Pen, Comb, and Razor; in a Word, she was a thorough Proficient in all the Branches of her Employment. The Governor, however, being an austere Man, who made no Allowance for the Impulses of Nature, or the Fervor of Youth, was used not to spare her, for incessantly following the Wenches, and being so barefaced and insatiable in her Amours. She had Recourse to several delusive Impudicities, not only to establish the Certainty, but raise the Reputation of her Manhood. (The Doctor enters into a nauseous Detail of her Impostures, which is the more inexcusable, they not being essential to the main Scope of the Narrative. These, if agreeable to the Italian Goucaratt, would shock the Delicacy of our Nation, with whom I hope the following Lines will ever be in full Force, as the Standard of Criticism:

Immodest Words admit of no Defence; And Want of Decency is Want of Sense.

Though a Veil be drawn over such Ordures, yet as Giovanni's Artifices cannot be one and all concealed, without an Infraction of the Laws of History; and would, besides, occasion too great a Chasm in a Translation. (Cleland 1755: 8-9, bold emphasis added to highlight Cleland's additions; the italics are his) 
The space between textual and cultural in our consideration of the two texts forms the basis of our analysis. The importance of semantic relationships "between items occurring in different parts of the same text," creates a network of co-references that either introduces queer as normal (Bianchi) or queer as depraved (Cleland). Such co-references in the case of Cleland's version include terms such as wantonness, depravity, ordures, hateful, unfortunate, etc. when referring to Catterina/Giovanni and their behavior, none of which are present to the Italian text, which, instead, normalizes transgendered behavior (Schäffner 1991: 116).

\section{Conclusion}

In a 1994 essay, Susan Lanser noticed that "there were significant national and cultural differences in the construction of sapphism in the long eighteenth century, and [that] England was arguably in the vanguard in the project to render Sapphic bodies queer" (Lanser 1994: 42, n. 8). No statement could better describe the divergent intentionality of Bianchi and Cleland in their constructions of Catterina Vizzani: for Cleland, Catterina/ Giovanni is aberrant, queer; for Bianchi, Catterina/Giovanni is normal, one of the many, shifting ways of presenting gender. Indeed, the difference between Bianchi's source text and Cleland's translation lies precisely at the juncture between acceptance, both scientific, cultural and social in Bianchi, and rejection in Cleland's mocking translation, a most jeering form of linguistic outing, that ensures that the queering, becomes a form of permanently negative branding, to be inscribed in the very conjecturing about two women loving each other. And in the case of John Cleland, the queering of Vizzani's body through the mocking translation he made of her persona. As we have seen through our comparison with Henry Fieldings' The Female Husband, and as Lanser has shown with other examples of Sapphic representations in eighteenth century England, Cleland's queering of the Sapphic in his translation of Bianchi's novella, actually serves two purposes: the first, to warn readers of the danger presented by gender-transgressing women, and the second, to denounce Italy as the source of such practices, a clear admonition and provocation to the many grand tourists who flocked to the Italian peninsula in search of antiquities, to be sure, but also sexual pleasure (Daileader 2002).

In the adapted title of Bianchi's text, Cleland informs the reader that "certain needful remarks by the English editor" have been added to Bianchi's text. Placed at the end of the text, these remarks provide the bookend to what has been promised in the adapted title. These remarks definitively establish the British, male gaze on the lesbian/transgendered self, whose sexuality and sexual persona in Bianchi demand consideration as a category that is different from those of wife, mother, prostitute, and nun.

But if Bianchi's Breve storia attempts to expand the conceptual field of female sexuality in early modern Europe, Cleland tries to explain what might drive a woman to a tryst with another woman as a momentary aberration in 
his 1753 Dictionary of Love, where we find the following definition under the headword "Wants":

Women of little experience are apt to mistake the urgency of bodily wants, of the violences of a delicate passion; and sometimes are betrayed into this favourable construction by their own exigencies, which do not suffer them to stand examining motives too nicely. In this case, the appetite is a course feeder, that does not stay to pick its bits, but takes the readiest with a voraciousness that proves more the necessity than the pleasure of the meal. That hunger is all the sauce.

(Cleland 1753: 225-226)

For Cleland, a lesbian/transgendered identity cannot exist. The female sexual appetite is to blame, along with the deformation of the mind the he has presented in his added remarks to the story of Catterina Vizzani. And so, it is time to restore the Italian source culture and the Italian source text to the world of eighteenth-century gender studies through a new translation, one that delineates Bianchi's forays into what we can certainly define as queer theory in the eighteenth century, already practicing queer theory and experimenting with what Teresa de Laurentis would later define as "another discursive horizon, another way of thinking the sexual" (1991: iv). It is hoped that this chapter may allow us to see, appreciate, and celebrate Italian anatomist Giovanni Bianchi's enlightened gender thinking and writing, while understanding the ways in which Cleland attempts to undo Bianchi's queer narration through translation.

\section{Notes}

1 This chapter presents an intriguing aspect of an ongoing research project on Bianchi and Cleland. For the purpose of that project and this study, I have translated Bianchi's story into English, so as to communicate, as closely as possible, Bianchi's original intent. My translations appear throughout this article in square brackets.

2 See Rudolf Dekker and Lotte van de Pol (1989) for one of the first discussions of Catterina Vizzani as a proletarian, lesbian women in early modern Europe; see also review of this same volume by Theo van der Meer.

3 Bianchi greatly admired Boccaccio and had written several Boccaccian novellas in his youth. For a full treatment of Bianchi's Boccaccian turn, see Collina (1957).

4 Bianchi's queer narration can also be traced to earlier writings about same sex love and the debunking of so-called monstrous nature that built to this moment of bold sexual reporting.

5 See the doctoral dissertation by Leslie J. Jansen for a lengthy speculative discussion about the differences in perspective that might exist between the Bianchi's original text and Cleland's translation: "Because this is a translation we do not know exactly what Bianchi said or whether he said it in the tone present in the translation. However, if Bianchi did not present Vizzani in a positive light and it is Cleland, through his translation, who presents Vizzani in this way, then this suggests all the more that Cleland was invested in constructing two very different 
responses to this female husband. Whether Cleland manipulated Bianchi's text or whether Bianchi really did construct Vizzani in a positive light, there is nevertheless a divide between these two texts, which represents the politics of the authors (or at least the politics of Cleland)" (2006: 187).

6 For new perspectives on the grand tour and British social masculinities about which Cleland was clearly writing, see Kelly (2010).

7 See Spencer (2007) for a discussion of Fielding's fluctuating notions of female agency as read through his work, including The Female Husband.

8 A number of works address this topic, see Crawford (2007), Turner (2002), and Trumbach (1998: 90-109).

\section{References}

\section{Primary Sources}

Bianchi, Giovanni. 1744. Breve storia della vita di Catterina Vizzani romana che per ott'anni vestì abito di huom in qualità di Servidore la quale dopo vari casi essendo in fine stata uccisa fu trovata Pulcella nella sezzione del suo Cadavero. Venice [Florence]: Simone Occhi.

Bianchi, Giovanni [and John Cleland]. 1755. The True History and Adventures of Catherine Vizzani, A YOUNG Gentlewoman a Native of Rome, Who for Many Years Past in the Habit of a Man; Was Killed for an Amour with a Young Lady; and Found on Dissection, a True Virgin. With Curious Anatomical REMARKS on the Nature and Existence of the HYMEN. By GIOVANNI BIANCHI, Professor of Anatomy at Sienna, the Surgeon Who Dissected Her. With a Curious FRONTISPIECE. What Odd Fantastic Things, We Women Do! Ep. to CATO. London: Printed for W. Reeve, Fleet-street, and C. Sympson, at the Bible-warehouse, Chancery-lane.

Cleland, John. 1753. The Dictionary of Love: In Which Is Contained, the Explanation of Most of the Terms Used in That Language. London: Printed for R. Griffiths.

\section{Secondary Sources}

Bailey, Joanne. 2003. Unquiet Lives: Marriage and Marriage Breakdown in England, 1660-1800. Cambridge: Cambridge University Press.

Butler, Judith. 1990. Gender Trouble. New York: Routledge.

Campbell, Jill. 1987. “'When Men Women Turn”": Gender Reversals in Fielding's Plays." In The New Eighteenth Century: Theory, Politics, English Literature, edited by Felicity Nussbaum and Laura Brown, 62-83. New York: Methuen.

Collina, Maria D. 1957. Il carteggio letterario di uno scienziato del Settecento. Firenze: Olschki.

Crawford, Katherine. 2007. European Sexualities, 1400-1800. Cambridge: Cambridge University Press.

Daileader, Celia R. 2002. “Back Door Sex: Renaissance Gynosodomy, Aretino, and the Exotic." ELELH 69: 303-334.

Dekker, Rudolf and Lotte van de Pol. 1989. The Tradition of Female Transvestism in Early Modern Europe. New York: St. Martin's Press.

Findlen, Paula. 2009. "Anatomy of a Lesbian: Medicine, Pornography, and Culture in Eighteenth-Century Italy.” In Italy's Eighteenth Century: Gender and Culture 
in the Age of the Grand Tour, edited by Paula Findlen, Wendy W. Roworth and Catherine M. Sama, 216-150. Stanford, CA: Stanford University Press.

Folkenflik, Robert. 2009. "Memoirs of a Woman of Pleasure and the Culture of Pornography." In The Eighteenth-Century Novel, Vols. 6-7, edited by Albert J. Rivero and George Justice, 103-127, August.

Jansen, Leslie J. 2006. "When the Clothes Do Not Make the Man: Female Masculinity and Nationalism in Eighteenth-Century British Literature." Unpublished PhD, University of Maryland, Maryland.

Kelly, Jason M. 2010. The Society of Dilettanti: Archeology and Identity in the British Enlightenment. London: Yale University Press.

Lanser, Susan. 1994. "Queer to Queer: The Sapphic Body as Transgressive Text.” In Lewd \& Notorious: Female Transgression in the Eighteenth Century, edited by Katharine Kittredge, 21-46. Ann Arbor, MI: University of Michigan Press.

Meer, van der Theo. 1990. "Review of The Tradition of Female Transvestism in Early Modern Europe, by Rudolf Dekker and Lotte van de Pol. 1989. New York: St. Martin's Press.” The Journal of Human Sexuality 1(1): 154-158.

Parsons, James. 1741. A Mechanical and Critical Enquiry into the Nature of Hermaphrodites. London.

Redford, Bruce. 2008. Dilettanti: The Antic and the Antique in Eighteenth-Century England. The J. Los Angeles: Paul Getty Museum and the Getty Research Institute.

Schäffner, Christina. 1991. "Semantic Relations in the Lexicon and in the Text: Reflections on Adequate Translation." In Empirical Research in Translation and Intercultural Studies, edited by Sonja Tirkkonen-Condit, 111-120. Tübingen: Narr.

Spencer, Jane. 2007. "Fielding and Female Authority." In The Cambridge Companion to Henry Fielding, edited by Claude Rawson, 122-136. Cambridge: Cambridge University Press.

Spiegel, Maura and Rita Charon. 2009. "Editing and Interdisciplinarity: Literature, Medicine, and Narrative Medicine." Profession 6: 132-137.

Spivak, Gayatri. 1988. "Can the Subaltern Speak?" in Marxism and the Interpretation of Culture, edited by Cary Nelson and Lawrence Grossberg, 271-313. Urbana, IL: University of Illinois Press.

Trumbach, Randolph. 1998. Sex and the Gender Revolution. Chicago: University of Chicago Press.

Turner, James Grantham. 2002. Libertines and Radicals in Early Modern London: Sexuality, Politics, and Literary Culture, 1630-1685. Cambridge: Cambridge University Press.

Venuti, Lawrence. 2003. “Translating Derrida on Translation: Relevance and Disciplinary Resistance." The Yale Journal of Criticism 16(2): 237-262.

Walpole, Horace. 1743. "Letter to Sir Horace Mann, Arlington Street, 14 April 1743." In The Letters of Horace Walpole: 1735-1748. 1842, edited by John Wright, Vol. 1, 318. Philadelphia, PA: Lea and Blanchard. 


\title{
10 Literary Censorship and Homosexuality in Kádár-Regime Hungary and Estado Novo Portugal ${ }^{1}$
}

\author{
Zsófia Gombár
}

The present chapter will explore convergences and/or divergences between the two regimes' attitudes toward homosexuality and sexual minorities through a detailed analysis of selected case studies of Anglophone literary works translated and published, or more exactly, slated to be published, in the two countries. Given the constraints of space, the scope of this study is limited to literature published in book form. Hence, non-literary works, such as medical and psychiatric texts, critical writings, philosophical treatises, and literary translations from English published in periodicals along with unpublished theater translations have been excluded from the analysis.

The research hypothesis of the present study is that in view of the two regimes' different attitudes toward homosexuality in legal terms, translated homosexual-themed literature enjoyed a more favorable reception in Socialist Hungary than in Estado Novo Portugal. This premise might also be strengthened by the fact that in Hungary, literature and, especially high literature was regarded as a tool in the process of building Socialism, and as such was given an exaggerated significance. Occasionally, the Hungarian authorities showed surprising tolerance toward certain nonconformist and even scandalous literary works, if these works were considered to be aesthetically and/ or politically relevant, i.e., as powerful critiques of Western society. In Portugal, however, foreign books discussing delicate issues, including sexuality or homosexuality were normally available only to the educated few, who were generally considered more "strong-willed and less-easily influenced" (Seruya and Moniz 2008: 18).

\section{Historical Background and Context}

Hungary and Portugal are two geographically and culturally distinct countries. Although they share a series of arbitrary characteristics in respect to size, population, religion, and economy, these resemblances alone should not form a basis for comparison in any research project. Indeed, what draws these countries close to each other is the historical fact that both countries lived under dictatorial rule for a significant part of the twentieth century. 
Despite the fact that the right wing and ultraconservative Estado Novo administration and the Hungarian Communist regime were publicly opposed to each other and fascism and communism were considered polar opposites on ideological grounds, the two regimes exhibited some undeniable similarities related to the inner workings of their respective dictatorships. One of those similarities is that both regimes-like almost all dictatorial regimes from Hitler's Germany to the Soviet Union under (and after) Stalin's leadership—show a strong aversion to any deviant conduct that might offend soi-disant public decorum, such as detailed descriptions of sexual acts, any mention of homosexuality and the use of obscene language. The reason behind this prudishness and the fear of sexual directness and deviation might also lie in the belief that a uniform society that suppresses dissident and nonconformist individuals is de facto easier to maintain under political and social control (cf. Gellately and Stoltzfus 2001; Hoffmann and Timm 2009; West and Green 2002).

As far as the legal status of homosexuality is concerned, it should be noted that in Hungary, homosexual activity was decriminalized as early as 1961, while in Portugal, it continued to be punishable by law until 1982, that is, eight years after the end of the dictatorship (Santos 2013: 45). ${ }^{2}$ It is also true, however, that homosexuality, despite being considered a felony in Salazar's Portugal, was tolerated to a certain degree, as long as homosexuality was invisible to the public, or, in other words, remained in the closet. It does not mean of course that detentions, long-term internment, forced hospitalizations, humiliation, especially of those of belonging to the lower social classes or the political opposition did not occur in Portugal (for more information, see Almeida 2010). And it should also be added that in Hungary, decriminalization of homosexuality did not further gay emancipation. ${ }^{3}$ Similarly to Portugal, the topic of homosexuality remained a deep-seated taboo in Hungarian society (see Almeida 2010; Hanzli et al. 2015; Borgos 2011).

The significance and supposed political power attributed to literature and the publishing industry by the two regimes is also very revealing, particularly, considering the divergent censorship practices imposed on books. Unlike theater and cinema, as well as news and press censorship, in Estado Novo Portugal, books were not subject to censorship prior to publication. Basically, this meant that books regarded as posing a threat to the state or public morality could be prohibited and confiscated only after being published. The system was of course far from infallible. A considerable number of potentially subversive books, such as works by Stalin and Lenin or work of erotic fiction, did in fact circulate in the country as they often escaped the censors' attention (Seruya 2010: 138-139).

Unlike in Portugal, in Hungary, the publishing industry-considered as an essential political tool-was under centralized state control. Inconsistencies may also have occurred, but confiscation of books after publication was 
exceptionally rare. Contrary to other Socialist countries of Eastern Europe, Hungary did not have any legally instituted system of censorship. Books were rarely censored by external censorship bodies, as the whole system was shrewdly based on self-censorship practiced by the publishers themselves, whose jobs depended greatly on their sound judgment and political sensitivity (Gombár 2011: 107-108).

Hungarian scholars' relative delay in investigating censorship issues under Socialism might also be attributable to the lack of tangible evidence, since Communist authorities as a general rule avoided written directives and instructions, and relied for the most part on informal and semi-formal oral communication (Gombár 2011: 106). Whereas in Portugal, book censorship reports stored at the National Archive of Torre do Tombo are freely available to researchers, Hungarian scholars are left only with scraps of information and anecdotal evidence. ${ }^{4}$ Hence, the presence of censorship remained largely unconfirmed due to the absence of conclusive evidence.

That changed, however, in 2009, when the research project "EnglishLanguage Literature and Censorship, 1957-1989" was launched. It is currently housed at the University of West Hungary, and involves four other Hungarian universities. The great innovation of the project is that it combines archival research with the oral history method. The research is based on the reader's reports commissioned by the Európa Publishing House between 1957 and 1990 and also on interviews with publishers, readers, and translators. ${ }^{5}$ The present chapter also draws heavily on these reader's reports, which serve as an unparalleled storehouse of information on the day-to-day workings of Kádár-regime censorship.

The current project, however, is also complicated by the scarcity of lesbian and gay historical works in Hungary and Portugal in comparison with other Western countries with long-standing democratic traditions. Nevertheless, despite the unfavorable position of gay historical research in Hungary, large-scale research projects have recently been undertaken (Borgos 2015: 87). A Hungarian research project on the social history of homosexuality coordinated by sociologist Judit Takács was launched in 2013, and in 2009, the documentary film on lesbian life in Kádár-regime Hungary Eltitkolt évek [Secret Years] was released, while the documentary about male homosexuality, Meleg férfiak, hideg diktatúrák [Hot Men, Cold Dictatorship], premiered in 2015, both directed by Mária Takács. The full-length interviews contained in the documentaries were subsequently published in two separate volumes (Borgos 2011; Hanzli et al. 2015). In Portugal, apart from Almeida's and Braga's monographs (2010, 2011), it is almost impossible to find any research conducted on homosexual history in the twentieth century or before, which suggests an indifference and even aversion to the issue on the part of the Portuguese academic community, notwithstanding the contradictory fact that, unlike Hungary, Portugal is considered to be one of the most progressive countries in terms LGBTQ rights expansion in contemporary Europe and other parts of the world. ${ }^{6}$ 
On the subject of translation history and lesbian and gay literature, Keith Harvey in his seminal article on gay identity and gay community urges comparative research to see what gay-themed literary works were translated and published in a given culture and what works were not (2000: 147-148). The present study makes a modest attempt to do this in the Portuguese and Hungarian contexts. Although Harvey also suggests several other pertinent factors to be considered, such as the translator's own sexual identity position, the nature of the publishing house, how the text itself was translated, and how explicit references to gay identity and lifestyle were translated (2000: 148), at this stage, our research was limited to exploring the historical, political, and sociological context of translations of queer literature in Socialist Hungary and Estado Novo Portugal.

\section{Methodology}

At the very beginning of his most ambitious and comprehensive monograph on Hungarian homoerotic and queer poetry, Zoltán Csehy poses the question of whether it is possible to write the history of queer literature or not based only on the available and traceable sources (2014: 15). Csehy's painstaking and arduous research along with an all-embracing corpus leaves little doubt as to the answer and provides a worthy model for other researchers to follow. Inspired by Csehy's working method predominantly based on tracing homothematics and homosociality in literary texts, a vast corpus of Anglophone lesbian- and gay-themed literary works was compiled. The typology devised by Christopher Reed to describe homosexual artistic strategies was likewise adopted in the data collection phase of the study as well as throughout the analysis stages (2011). ${ }^{7}$

The corpus was checked against the bibliographical records on literary translations published between 1949 and 1974 in Hungary and Portugal in order to detect which source texts containing explicit or implicit references to homosexual content were or were not translated in the given period. The initial year of the time period under investigation marks the completion of the Communists' takeover of the Hungarian book industry, while the final year denotes the end of the right-wing dictatorial regime in Portugal. The chosen timeframe, thus, allows us to analyze the published translations when both countries were under dictatorship.

With reference to bibliographical sources, one of the most valuable proved to be the archives of the Hungarian organization the Háttér Society for LGBTQI People in Hungary, which contains an almost complete collection of queer literary works, as well as translations published in Hungary up to this date. ${ }^{8}$ Other bibliographical catalogues were also consulted, such as British Books in Hungary: 1945-1978 and Külföldi szerzök müvei Magyarországon: 1945-1970, 1971-1975 [Foreign Authors in Hungary, 1945-1970, 1971-1975]. In Portugal, due to the absence of all-inclusive bibliographical databases and indices, in addition to PORBASE, the 
Portuguese Union Catalogue online, ${ }^{9}$ and the National Bibliography, the research database of the Lisbon-based project, Intercultural Literature in Portugal, 1930-2000 was meticulously searched for possible matches. ${ }^{10}$

\section{Findings}

Although the list of homosexual-themed literary works in English used in this study is relatively long, exceeding four hundred works, the actual number of literary translations with lesbian and gay content published in Hungary and Portugal in the period under study is significantly lower: 24 in Hungary and 20 in Portugal, which can be interpreted as a natural consequence of state censorship, as well as the general public aversion to homosexuality during that period. On the other hand, even the low number of Portuguese translations reveals that, despite the fact that open discussion of homosexuality in published works was strictly prohibited by law in Salazar's Portugal, lapses on the part of the censors did occur.

It should be added that at this stage of analysis, the degree of self-censorship adopted by the Portuguese and Hungarian translators and publishers has yet to be determined. Indeed, in Portugal as well as in Spain, omission and attenuation of explicit eroticism or homosexual references were a routine procedure undertaken to evade censorship (cf.: Rodrigues 2006; Santos 2008; Linder 2004, 2014). In Hungary, manipulation of the original text also occurred, but on a less frequent basis, which was due to the publishers' high standards of accuracy and faithfulness to the original text, which was systematically checked by proofreaders (Bart 2000: 133-136).

Table 10.1 shows the lesbian and gay-themed translations published in the two countries. Most of the works contain descriptions of explicitly homosexual persons or acts, given by insiders and outsiders. These descriptions are mostly positive or neutral, but negative representations can also be found among them, such as the pedophile Eppes in William Styron's The Confessions of Nat Turner or General Cummings in The Naked and the Dead. The category of "Products of sexual minorities" as postulated by Reed does not apply to the works published in the period under scrutiny, which of course has to do more with the general attitude of the era-hence the very limited number of originals pertaining to the category-than to the actual dictatorial regimes' restrictive posture.

Intriguingly, while in Hungary publishers were, for the most part, informed by readers about the assumed homosexual orientation of an author, along with any explicit homosexual references in the 24 translations under scrutiny, in Portugal, with the exception of Howard Fast's Spartacus, which was authorized after cuts in 1961, the authorities were obviously unaware of the homosexual "threat" of these translations, and basically did not interfere in their circulation. Paradoxically, it seems, as Baer also notes, due to the invisibility of homosexuality, particularly under dictatorial regimes, such as in Soviet Russia, along with the ignorance of the wider public about 
homosexual lifestyle and behavior, several literary works bypassed the censors' attention (Baer 2010: 25-26).

The almost complete absence of homosexual-themed translations from English in 1950s Hungary can be attributed more to the harsh Stalinist years-when, in fact, all "imperialist" Western literary products were considered as posing a potential threat to the Socialist reader-than to the otherwise deeply homophobic attitude of the Hungarian totalitarian regime

Table 10.1 Homosexual-themed literary translations from English published in Hungary and Portugal between 1949 and 1974

\begin{tabular}{|c|c|c|}
\hline $\begin{array}{l}\text { Published only in } \\
\text { Hungary }\end{array}$ & $\begin{array}{l}\text { Published in both } \\
\text { countries }\end{array}$ & $\begin{array}{l}\text { Published only in } \\
\text { Portugal }\end{array}$ \\
\hline $\begin{array}{l}\text { Mary Renault: The King } \\
\text { Must Die (1961), The } \\
\text { Mask of Apollo (1970) } \\
\text { Sherwood Anderson: } \\
\text { Winesburg, Obio (1962) } \\
\text { W. H. Auden: The Shield } \\
\text { of Achilles (1968) } \\
\text { Jane Bowles: Two Serious } \\
\text { Ladies (1969) } \\
\text { William Styron: The } \\
\text { Confessions of Nat } \\
\text { Turner (1969), (1974) } \\
\text { Lawrence Durrell: Clea } \\
\text { (1970), Justine (1970) } \\
\text { Christopher Isherwood: } \\
\text { Goodbye to Berlin } \\
\text { (1972) } \\
\text { Carson McCullers: Clock } \\
\text { without Hands (1972) } \\
\text { Tennessee Williams: Cat } \\
\text { on a Hot Tin Roof } \\
\text { (1964) } \\
\text { Evelyn Waugh: Brideshead } \\
\text { Revisited (1948), (1973) } \\
\text { Gertrude Stein: The } \\
\text { Autobiography of Alice } \\
\text { B. Toklas(1974) } \\
\text { Mary McCarthy: The } \\
\text { Group } \\
\text { (1974) }\end{array}$ & $\begin{array}{l}\text { Dashiell Hammett: The } \\
\text { Maltese Falcon (1950 } \\
\text { in Portugal; } 1967 \text { in } \\
\text { Hungary) } \\
\text { Raymond Chandler: } \\
\text { The Big Sleep (1951 } \\
\text { in Portugal; } 1967 \text { in } \\
\text { Hungary) } \\
\text { Howard Fast: Spartacus } \\
\text { (1953 in Hungary; } 1961 \\
\text { in Portugal) } \\
\text { Truman Capote: Other } \\
\text { Voices, Other Rooms } \\
\text { (1956 in Portugal; } 1964 \\
\text { in Hungary) } \\
\text { Norman Mailer: The } \\
\text { Naked and the Dead } \\
\text { (1958 in Portugal; } 1967 \\
\text { in Hungary) } \\
\text { Lawrence Durrell: } \\
\text { Balthazar (1961 in } \\
\text { Portugal; 1970 in } \\
\text { Hungary) } \\
\text { Herman Melville: Moby } \\
\text { Dick (1961, 1962, } 1968 \\
\text { in Portugal; 1963, } 1969 \\
\text { in Hungary) } \\
\text { Woolf, Virginia: Orlando } \\
\text { (1962 in Portugal, } 1966 \\
\text { in Hungary) } \\
\text { Tennessee Williams: } \\
\text { Suddenly, Last Summer } \\
\text { (1964 in Hungary; } 1964 \\
\text { in Portugal) } \\
\text { Allen Ginsberg: Howl } \\
\text { (1966 in Hungary, } 1973 \\
\text { in Portugal) }\end{array}$ & $\begin{array}{l}\text { Oscar Wilde: The Picture } \\
\text { of Dorian Gray (1958) } \\
\text { Angus Wilson: Hemlock } \\
\text { and After (1961) } \\
\text { Calder Willingham: End } \\
\text { as a Man (1961) } \\
\text { William Goyen: The } \\
\text { House of Breath (1962) } \\
\text { John Dos Passos: The } \\
\text { 42nd Parallel (1963) } \\
\text { John Dos Passos: 1919 } \\
\text { (1967) } \\
\text { John Dos Passos: The Big } \\
\text { Money (1967) } \\
\text { Mitford Nancy: Love in a } \\
\text { Cold Climate (1964) } \\
\text { Iris Murdoch: The Bell } \\
\text { (1965) } \\
\text { Tennessee Williams: The } \\
\text { Knightly Quest (1970) }\end{array}$ \\
\hline
\end{tabular}


(Gombár 2009: 30). During the Rákosi regime, male homosexuality was vigorously suppressed and even subject to imprisonment. During the political consolidation of the 1960s, and especially after the 1970s, a closeted homosexual lifestyle was already tolerated, which is also reflected in the growing number of homosexual-themed translations published in the country. Nevertheless, the near absence of female same-sex representations in both countries clearly indicates the marginalized position of women as well as the social invisibility of lesbians within both the dominant culture and homosexual subcultures (cf. Takács 2015)

As regards the writers' political views, it might not come as a surprise that almost all the authors of gay and lesbian literature published in Hungary were leftist sympathizers or belonged to left-wing circles at one stage of their career, such as W. H. Auden, Jane Bowles, or Mary Renault. Surprisingly, Truman Capote and Tennessee Williams enjoyed a certain political protection in both countries, which might be ascribed to their world-renowned reputation as writers (Gombár 2011: 122). A distinction should be made, however, between the apparent indulgence shown by the two administrations. The Portuguese conservative valorization of masterpieces of acknowledged literary merit is basically rooted in the Salazar regime's inherently authoritarian nature, while the Communist approach mainly lies in the idealistic conviction of the didactic potential attributed to time-honored literary works. ${ }^{11}$

\section{What the Files Say}

Although it is occasionally quite difficult to determine how far the nonpublication of certain books depended on self-censorship practiced by the Hungarian publisher or on the reviewer's negative opinion and conservative taste, but one thing is evident from the reports. Besides giving their opinion on whether to publish the work in question or not, reviewers were instructed by the publisher to call attention to any detail that would impede its publication due to its political, sexual, or other sensitive nature. Another thing is also clear from the reports; in Hungary, unlike in Portugal, homosexuality as a theme was not to be censored. At the same time, graphic descriptions of sexual acts either pertaining to heterosexual or same-sex love were banned, including William S. Burroughs' The Wild Boys, The Ticket that Exploded, John Rechy's Numbers, or John Cleland's Fanny Hill (see Table 10.2).

Remarkably, the majority of the reviewers justify their negative decision by shifting the entire responsibility to the reading public's homophobic attitude in Hungary, but, in fact, it is often the reviewers themselves who entertain an adverse opinion. A unique counterexample is Miklós Vajda's reader's report on Tennessee Williams's novel Moise and the World of Reason:

In view of the lamentably conservative attitude of the Hungarian reading public and critical audience, especially, toward sexuality, let alone, 
homosexuality in literary representations, the publication of the novel is out of the question. [. . .] it should (and will) be published in every grown-up country. But we-unfortunately-are still not a grown-up country.

(Reader's Report October 30, 1975, my translation) $)^{12}$

Another standard practice of the Socialist publishing industry was the "delaying" technique. Publishers often put questionable works aside for a few years to see whether the author or the work in question would stand the test of time and receive critical acclaim or not. In the meantime, publishers could also bide their time and wait for a politically more favorable atmosphere when the book could be published (Révész 1997: 346-350). James Baldwin's Giovanni's Room, Hubert Selby Jr's Last Exit to Brooklyn, and Christopher Isherwood's Goodbye to Berlin, for instance, had to wait decades before they were published in Hungary (see Table 10.2).

Gore Vidal's case, however, plainly reveals the harmful effect of this delaying technique. As five otherwise non-homosexual-themed novels by Vidal had already been published in Hungary, the publisher turned again in the late 1980s to this tried-and-tested author, but now with the intention of publishing the scandalous novels Myra Breckinridge and Two Sisters. The reviewers unanimously pointed out that the novels are considered outdated in the 1980s.

From the 1980s on, however, when the AIDS epidemic had reached Hungary, the Európa made conscious and serious efforts to open up to a gay and lesbian reading audience. The number of reports on queer authors, such as Lisa Alther, David Leavitt, or Hubert Selby Jr, doubled by 1989. In 1989 the reviewer of the novel Maurice by E. M. Forster, à propos of the author's dedication: "To a Happier Year," regrets the fact that no similar work had until then been available to Hungarian readers, although a gay movement had already been launched in Hungary. Indeed, in 1988, Hungary became

Table 10.2 Homosexual-themed literary translations from English censored in Hungary and Portugal

\begin{tabular}{ll}
\hline $\begin{array}{l}\text { Censored in Hungary on grounds of } \\
\text { homosexuality }\end{array}$ & $\begin{array}{l}\text { Censored in Portugal on grounds of } \\
\text { homosexuality }\end{array}$ \\
\hline Banned: & Banned: \\
William S. Burroughs: The Wild Boys, & John Updike: Couples \\
The Ticket that Exploded & Carson McCullers: Clock without \\
John Rechy: Numbers & Hands \\
John Cleland: Fanny Hill & $\begin{array}{c}\text { Pamela Moore: Chocolates for } \\
\text { Breakfast }\end{array}$ \\
Delayed: & John Cleland: Fanny Hill \\
James Baldwin: Giovanni's Room & \\
Hubert Selby Jr: Last Exit to Brooklyn & Bowdlerized: \\
Christopher Isherwood: Goodbye to & Howard Fast: Spartacus \\
Berlin & \\
Gore Vidal's novels & \\
\hline
\end{tabular}




\section{Zsófia Gombár}

the first East European Nation to permit a homosexual rights association Homeros-Lambda.

In contrast to Hungary, where the invisible "self-censors" were mostly intellectuals such as literary scholars, critics, translators, writers, and eventually literary editors and publishers, in Portugal, the vast majority of the censorship officials were military personnel. Books were normally sent to the Secção de Livros [Book Censorship Section], which was funded as early as 1934 (Gomes 2006: 115). Although the name of the censorship offices along with the administratively superior ministry or department may have varied throughout the years, the locations of the censorship organs remained almost the same during their existence. The three principal censorship boards were located in Lisbon (Southern Zone), Oporto (Northern Zone), and Coimbra (Central Zone). ${ }^{13}$

Based on the censorship reports, it seems that literary works banned on homosexual grounds in Portugal are no more numerous than those banned in Hungary (see Table 10.2). Moreover, aside from the Portuguese translation of Howard Fast's Spartacus, which was purged of all the allegedly homosexual scenes at the behest of the censors, none of these novels was censored due only to their homosexual references; they were censored principally for their immoral content. Pamela Moore's Chocolates for Breakfast, for example, was criticized for portraying a suicide, something that could not be mentioned in Salazar's Portugal (R7606/65).

It is also noteworthy that the Portuguese censors in their comments made a clear distinction between-as they call it-homossexualidade and homossexualismo. The term homossexualidade was consistently used in the censorship reports if the reviewed work was of a scientific or medical nature. In this case, circulation of the book was limited to clinicians and other medical practitioners. Homossexualismo was in general applied to popularizing and apologist literature, which was of course proscribed. ${ }^{14}$

\section{Conclusion}

Even though further studies are needed before an overall conclusion is reached, it can be said that based only on literary translations from English, both regimes showed an ambivalent attitude toward homosexuality. The small number of the works clearly suggests that the free circulation of homosexual-themed literature was restricted in both countries. Nevertheless, the publication of certain works, for example, James Baldwin's Giovanni's Room in 1980 in Hungary or Angus Wilson's Hemlock and After in 1961 in Portugal suggests a finite level of tolerance.

The initial research hypothesis is confirmed not only by the fact that, unlike Portugal, portrayals of homosexuality alone were not censored in Kádár-regime Hungary but also by the fact that in Hungary the publication of translations of queer literary works was, for the most part, a conscious and deliberate choice on the part of the publishers and the cultural 
administration. In contrast, books on homosexual themes were allowed to circulate in Salazar's Portugal as a consequence of the fallacies and inconsistencies inherent in the system that controlled publications.

\section{Notes}

1 The research conducted for this chapter has been undertaken as part of my postdoctoral fellowship (SFRH/BPD/92486/2013) funded by the Portuguese Foundation of Science and Technology (FCT).

2 Recent archival evidence suggests that the decriminalization process was initiated by a petition filed by an unnamed individual—supposedly a homosexual man-which should be regarded a most exceptional case in the Eastern Bloc. Moreover, the amendment seems to have been decisively influenced by the decision of a medical (in this case a psychiatric) committee (Takács and Tóth 2016: 207-223).

3 A limitation clause was introduced, which specified that "perversion against nature conducted in a scandalous manner" should be publishable by up to three years of imprisonment. Moreover, the age of consent for homosexuals was raised to 20 years, and reduced to 18 in 1978, while the age of consent for heterosexual acts was 14 since 1961 . The unequal ages of consent along with the clause on scandalous behavior provided Hungarian authorities with excellent opportunities to keep assumed homosexual citizens under strict control (Takács 2015: 169-170).

4 It should be mentioned that $22.4 \%$ of the 10,011 Portuguese censorship reports on books issued between 1934 and 1974 are still missing, which hinders research to a significant degree (Seruya 2010: 131).

5 The predecessor of the Európa Publishing House was established in 1946 under the name of Új Magyar Könyvkiadó [New Hungarian Publishing House], which was changed to Európa after the 1956 Revolution in 1957. The publisher is mainly specialized in foreign literature.

6 A discrimination law based on sexual orientation was incorporated into the Portuguese Constitution in 2010, and in the same year Portugal became the eighth in the world to recognize same-sex marriage. Same-sex adoption is allowed since 2016. Although Hungary also has a comprehensive equal treatment legislation in force, LGBT people still face discrimination in many areas of life. In 2011, a new Constitution was approved by Viktor Orbán's conservative government that restricted marriage to heterosexual couples and contained no guarantees to protect LGBT people from discrimination.

7 Reed's matrix of interpretation consists of two main axes: the concepts of homosexuality as defined by scholars (normal part of maturation, sexual encounters, separate identity, and performative role) and the relationship of art to homosexuality (explicit description of homoerotic acts or people: made by insiders or outsiders, that is, by heteronormative or non-heteronormative persons, eroticized objects, and products of sexual minorities).

8 For more information on the society, please consult http://en.hatter.hu/. Here I would like to express my gratitude to Sándor Nagy, the founder and director of the archives, for all the tireless help and precious advice. I am also very grateful to Anna Borgos, literary and gender scholar and founding member of the Labrisz Lesbian Association for her suggestions.

9 For more information, see http://porbase.bnportugal.pt/.

10 The project involves a collaboration between two research centers: the Research Centre for Communication and Culture (CECC) and the University of Lisbon Centre for English Studies (CEAUL). The primary objective of the project is to 
gather and process information concerning foreign literary production in Portugal between 1930 and 2000. The database is available for free of charge at www. translatedliteratureportugal.org/.

11 For example, even if Orlando by Virginia Woolf, or novels by André Gide and Robert Pinget were regarded as problematic by the Hungarian authorities, their publications were authorized so that Hungarian readers would be up to date with the main modern Western literary tendencies (Tóth 1992: 346).

12 Ismerve a magyar közvélemény és a kritika siralmas konzervatizmusát a szexualitás_pláne a homoszexualitás_irodalmi ábrázolása terén, a regény magyar kiadása szóba sem kerülhet. [. . .] minden felnőtt országban ki kellene (és ki is fogják) adni. Mi azonban, sajnos nem vagyunk egészen felnőtt ország.

13 For more information, see Seruya (2010), and Špirk (2014).

14 I would like to thank Teresa Seruya for calling my attention to these two terms.

\section{References}

Almeida, São José. 2010. Homossexuais no Estado Novo [Homosexuals in the Estado Novo]. Oporto: Porto Editora.

Baer, Brian James. 2010. "Translating Queer Texts in Soviet Russia.” Translation Studies 4(1): 21-40.

Bart, István. 2000. Világirodalom és könyvkiadás a Kádár-korszakban [Foreign literature and book publishing in the Kádár regime]. Budapest: Scholastica.

Borgos, Anna (ed.). 2011. Eltitkolt évek: Tizenhat leszbikus életút [Secret Years: Sixteen Lesbian Life Journeys]. Budapest: Labris Könyvek.

Borgos, Anna. 2015. "Secret Years: Hungarian Lesbian Herstory, 1950s—2000s." Aspasia 9: 87-112.

Braga, Paulo Drumond. 2011. Filhas de Safo: Uma história de homossexualidade feminina em Portugal [Sappho's Daughters: The History of Female Homosexuality in Portugal]. Lisbon: Texto.

British Books in Hungary: 1945-1978. 1979. Budapest: Hungarian Publishers' and Booksellers' Association.

Csehy, Zoltán. 2014. Szodoma és környéke [Sodom and Environs]. Pozsony: Kalligram.

Gellately, Robert and Nathan Stoltzfus (eds.). 2001. Social Outsiders in Nazi Germany. Princeton, NJ: Princeton University Press.

Gombár, Zsófia. 2009. "The Reception of British Literature Under Dictatorships in Hungary and Portugal." Hungarian Journal of English and American Studies 15(2): 269-284.

Gombár, Zsófia. 2011. "Dictatorial Regimes and English-Language Authors in Hungary and Portugal." In Censorship Across Borders: The Censorship of English Literature in Twentieth-Century Europe, edited by Alberto Lázaro Laufente and Catherine O'Leary, 105-128. Newcastle: Cambridge Scholars Publishing.

Gomes, Joaquim Cardoso. 2006. Os militares e a censura: A censura à Imprensa na Ditadura Militar e Estado Novo (1926-1945) [The Military and Censorship: Press Censorship During the Military Dictatorship and the Estado Novo]. Lisbon: Livros Horizonte.

Hanzli, Péter, B. Gábor Halmai, P. Ildikó Varga, Ágnes Seregély, Judit Gyárfás, and Sándor Nagy (eds.). 2015. Meleg férfiak, hideg diktatúrák [Hot Men, Cold Dictatorships]. Budapest: Civil Müvek Egyesület.

Harvey, Keith. 2000. "Gay Community, Gay Identity and the Translated Text.” TTR 13(1): 137-165. 
"Háttér Support Society for LGBT People in Hungary.” Archive and Library. http:// en.hatter.hu/what-we-do/archive-and-library

Hoffmann, David L. and Annette F. Timm. 2009. "Utopian Biopolitics: Reproductive Policies, Gender Roles, and Sexuality in Nazi Germany and the Soviet Union." In Beyond Totalitarianism: Stalinism and Nazism Compared, edited by Michael Geyer and Sheila Fitzpatrick, 87-129. New York: Cambridge University Press.

"Intercultural Literature in Portugal 1930-2000: A Critical Bibliography.” www. translatedliteratureportugal.org/eng/index.htm

Külföldi szerzők müvei Magyarországon: 1945-1970 [Foreign Authors in Hungary: 1945-1970]. Budapest: Könyvkiadók és Könyvterjesztők Egyesülése, 1971.

Külföldi szerzők müvei Magyarországon: 1971-1975 [Foreign Authors in Hungary: 1971-1975]. Budapest: Könyvkiadók és Könyvterjesztők Egyesülése, 1977.

Linder, Daniel. 2004. "The Censorship of Sex: A Study of Raymond Chandler's the Big Sleep in Franco's Spain.” TTR 17(1): 155-182.

Linder, Daniel. 2014. “Getting Away with Murder: The Maltese Falcon's Specialized Homosexual Slang Gunned Down in Translation." Target 26(3): 337-360.

PORBASE. "The Portuguese Union Catalogue." Available online at http://porbase. bnportugal.pt/

Portugal. Biblioteca Nacional. Boletim de bibliografia portuguesa. 1935-1977. Lisbon: Biblioteca Nacional.

Reader's Reports stored at the Archives of Petőfi Literary Museum in Budapest, Hungary.

Reed, Christopher. 2011. Art and Homosexuality: A History of Ideas. New York: Oxford University Press.

Révész, Sándor. 1997. Aczél és korunk [Aczél and our era]. Budapest: Noran.

Rodrigues, Delfina. 2006. Balthazar de Durrell traduzido em tempos de censura: Contribuição para um estudo do fenómeno tradutológico em Portugal num contexto dictatorial [Durrell's Balthazar Translated in a Censorship Era: Contribution to Translations Studies in Portugal Under Dictatorship]. Chaves: Tartaruga.

Santos, Ana Cristina. 2013. Social Movements and Sexual Citizenship in Southern Europe. Basingstoke, Hampshire: Palgrave, Macmillan.

Santos, Ana Teresa Marques dos. 2008. "Faulkner and the Portuguese Censorship." In Translation and Censorship in Different Times and Landscapes, edited by Teresa Seruya and Maria Lin Moniz, 21-29. Newcastle: Cambridge Scholars Publishing.

Seruya, Teresa. 2010. "Translation in Portugal during the Estado Novo Regime." In Translation Under Fascism, edited by Christopher Rundle and Kate Sturge, 117-144. London: Palgrave Macmillan.

Seruya, Teresa and Maria Lin Moniz. 2008. "Foreign Books in Portugal and the Discourse of Censorship in the 1950s." In Translation and Censorship in Different Times and Landscapes, edited by Teresa Seruya and Maria Lin Moniz, 3-20. Newcastle: Cambridge Scholars Press.

Špirk, Jaroslav. 2014. Censorship, Indirect Translations and Non-Translation: The (Fateful) Adventures of Czech Literature in 20th-Century Portugal. Newcastle upon Tyne: Cambridge Scholars Publishing.

Takács, Judit. 2015. "Disciplining Gender and (Homo)Sexuality in State-Socialist Hungary in the 1970s." European Review of History: Revue européenne d'histoire 22(1): 161-175. 


\section{Zsófia Gombár}

Takács, Judit and Tamás P. Tóth. 2016. “Az 'Idegbizottság' szerepe a homoszexualitás magyarországi dekriminalizációjában” [The Role of the "Neurology Committee" in the 1961 Decriminalization of Homosexuality in Hungary]. Társadalomtudományi Szemle 6(2): 207-223. Available online at http://socio. hu/uploads/files/2016_2/takacs_ptoth.pdf (last accessed November 30, 2016).

Tóth, Gyula. 1992. Irók Pórázon: A Kiadói Föigazgatóság irataiból, 1961-1970 [Writers on the Leash. The Documents of the Publishers' Directorate]. Budapest: MTA Irodalomtudományi Intézet.

West, Donald J. and Richard Green (eds.). 2002. Sociolegal Control of Homosexuality: A Multi-Nation Comparison. New York: Kluwer Academic Publisher. 


\title{
11 On Three Modes of Translating Queer Literary Texts
}

\author{
Marc Démont
}

In this analysis, I characterize and distinguish between three modes of translating queer literary texts. I define their relation to queerness in order to underline the crucial contribution that a queer approach can make to translation studies. Considering the multilayered and prismatic nature of queerness in literary texts and consequently its internal and haunting resistance to unilateral approaches, it is necessary to define the strategies that translators can adopt when faced with queerness's evanescence. Based on specific examples, I suggest that these strategies manifest themselves in three different modes: the misrecognizing translation, the minoritizing translation, and the queering translation. Whereas the misrecognizing translation simply ignores queerness, the minoritizing translation congeals queerness's drifting nature by flattening its connotative power to a unidimensional and superficial game of denotative equivalences. In contrast to these two approaches, I argue that a specific "queering" stance can be developed in which queerness is, on the one hand, made salient thanks to a queer critique of existing translations, and on the other, is respected in its intangibility by developing techniques to preserve, using Kwame Anthony Appiah's expression, the thickness of queer literary texts.

\section{Misrecognizing Translations}

I would like to open this exposition of the three modes with an example taken directly from the traditional queer literary archive. In 1912, Álvaro Armando Vasseur published in Valencia Poemas a translation of poems by Walt Whitman dedicated to love between men. Not surprisingly considering Vasseur's own anxiety regarding his sexuality and masculinity, this translation misrecognizes or fails to recognize homosexual desire, which, in his rendering of the poem, is turned into homosocial desire:

(No es que haya menester de su presencia para acordarme de mis amigos;

En estos últimos tiempos no hago más que pensar en ellos.)

Sin embargo, esta rama constituye para mí un símbolo precioso, me hace pensar en el afecto viril; 
A pesar de todo, y aunque este roble fructifica, allá en la Luisiana, completamente solo en un amplio espacio descubierto,

Proyectando año tras año sus alegres hojas, sin tener junto a él un amigo, un tierno camarada,

Comprendo y reconozco que no podría imitarlo.

(Whitman [Vasseur] 1943: 38)

[I do not need for them to be present in order to remember my friends; As of late, I think only of them.)

Yet this branch constitutes for me a precious symbol, it makes me think of virile affect;

In spite of it all, and although this oak flourishes, over in Louisiana, entirely alone in a large open space,

Projecting year after year its happy leaves, without having near him a friend, a tender companion,

I understand and acknowledge that I could not imitate it.]

It is not needed to remind me as of my own dear friends,

(For I believe lately I think of little else than of them,)

Yet it remains to me a curious token, it makes me think of manly love;

For all that, and though the live-oak glistens there in Louisiana solitary in a wide flat space,

Uttering joyous leaves all its life without a friend a lover near, I know very well I could not.

(Whitman 2007: 150)

The translation of "manly love" by "el afecto viril" and "lover" by "camarada" dilutes the sticky thickness of homosexual affects in the innocence of a watery bromance. Vasseur's misrecognition of Whitman's queer sexuality as well as his switching of gender identifications can be observed throughout his translation. ${ }^{1}$ This misrecognition of the queer sexual dimension is not particularly surprising since other famous queer texts, like Plato's Symposium or Phaedrus have been subject to the normalizing and "straightening" power of translators such as Leonardo Bruni. While this misrecognition is easily corrected by a comparison between the translation and the original text, but it remains of interest as a reminder of the ethical dimension of the task of the translator, linked to the reader by an ethical contract of trust, and as testimony to the systematic attempts to erase queer sexualities and in fine queer subjects.

The next example of misrecognizing translation focuses less on the misrecognition of a "content" within the text than the misrecognition of a context. Focusing on the translation of bear culture in Italian in international and Italian websites, Antonio Gualardia and Michaela Baldo's Bear or "Orso?" Translating Gay Bear Culture into Italian (2010) find that, while the words can find an immediate equivalence ("orso" for bear, "peloso" 
for hairy, "ammiratore" for admirer, etc.), the imaginary behind those words isn't exactly the same. The Italian adjectives associated with bear culture refer to a specific form of masculinity as expressed in la commedia all'italiana (the Italian sexy comedy):

This film genre developed during the late 60's and 70's as a reaction to the previous Italian tradition which was linked with fascist censorship. Those films were never pornographic but played on sexy-comic situations. The plots were always the same; revolving around want-tobe super machos who try to have sex with beautiful young girls discovering their sexuality or with women already sexually mature and frustrated because of boring or absent husbands. The male figures are always explicit in their sexual approach or in displaying their masculinity, which always debouches into chauvinism.

Whereas the bear culture in the United States originally deconstructed "the standards of beauty or in general the gay mainstream image imposed by the media (young, smooth-skinned, gym buffed) which tries to control and label the gay identity as feminized and (or) weak" (2010:23) while trying to define a "new way" of being gay, in Italian culture the translation of the "bear" vocabulary becomes a way of expressing "chauvinism" (2010: 23) and intrahomophobia (2010: 32). As the authors conclude: "Behind the domestication of concepts there is certainly among the Italian bears a desire to pass as heterosexual men" (2010: 35). In this example, the "close" translation unleashes a chain of unanticipated associations in the receiving culture. This stems more from the fallacy of literalness: that it does not bring us "closer" to the original. The literal translation of "bear" as "orso" fails to recognize the incongruence of the cultural contexts in which the terms are understood. By being connected to a whole new set of semantic associations, the potentially subversive content is turned into a conservative strategy to hide a queer sexuality.

\section{Minoritizing Translations}

In 1998, the collection Mille et une nuits published by Fayard, Thierry Martin's new intralingual translation of François Villon's Ballades en jargon [Ballades in jargon] under the title Ballades en argot homosexuel [Ballades in homosexual slang] (Villon 1998). ${ }^{2}$ The mere translation of the title is already problematic and must be contextualized in order to understand the choice of title. The original Ballades en jargon is divided into two parts. The first one, attributed to François Villon (1431-1463), is titled "Le jargon et jobelin dudit Villon" [The Jargon and Jobelin of the so-called Villon] and is composed of six ballades (I-VI) printed in 1489 by Pierre Levet. The second part (VII-XI) is made up of different ballades. One or two ballads in this 
second group are traditionally attributed to Villon, whereas the others are attributed to anonymous authors. The text is therefore made of two layers, making the text's paternity plural and problematic. To add to the difficulty to the difficulty of interpreting the text, it is written in a jargon that shares some words with the jargon des Coquillards, a jargon used by a group of organized thieves in Dijon. However, when Levet decided to print the text, the meaning of the jargon was already lost. For this reason Clement Marot (1496-1544), who undertook to gather and published the complete works of François Villon in 1533, does not include the Ballades because of the difficulty of deciphering and interpreting certain words in the manuscripts: "Touchant le jargon, je le laisse à corriger et exposer aux successeurs de Villon en l'art de la pinse et du croq"(Moland 1893: 4) [regarding the jargon, I leave to the heirs of Villon, experts in the art of pliers and crowbar, the task of correcting and exposing the text]. ${ }^{3}$ Both the presence of jargon des Coquillards in the Ballades and Marot's allusion to the thieves' tools generated a tradition of reading the Ballades as a cryptic text about delinquency and criminality the core meaning of which had probably been lost forever. ${ }^{4}$

However, in 1968, linguist Pierre Guiraud asserted that he had cracked the code of Villon's jargon in Le jargon de Villon ou le gai savoir de la Coquille [Villon's Jargon or the Gay Knowledge of la Coquille]. His analysis was so original and disturbing that Jean-Marcel Paquette in his review of the book for the very authoritative Études littéraires writes in 1969,

If Pierre Giraud weren't known as the erudite author of works Caractères statistiques du vocabulaire, Problèmes et méthodes de la statistique linguistique and most importantly Structures étymologiques du lexique français, we could believe that the present study is but one of numerous attempts undertaken over the last century to make clear Villon's jargonesque language, or, better yet, a somewhat mystifying but amusing farce (1969: 357). ${ }^{5}$

Even if Guiraud limits his study to the first six ballades, that is to say, to "Le jargon et jobelin dudit Villon," one of the strengths of his translation is that he reads the text without changing any words, as opposed to his predecessors who conveniently took for granted that the texts had been altered by various typos. ${ }^{6}$ But the real scandalous and polemical dimension of his interpretation is the key Guiraud offers in the first pages, and that he justifies and illustrates throughout his book. According to him, each ballade is dedicated to a specific type of criminal: les froarts (pick lockers), les rueurs (murderers), les spelicans (con men), les saupiquets (duplicate key makers), les joncheurs (fake law officers), and les gaudissarts (money launderers). But Guiraud's tour de force is that he reads the ballades as an example of trobar clus, or closed form, which was a complex form of poetry used by troubadours of the XII ${ }^{\text {th }}$-XIII ${ }^{\text {th }}$ century. For Guiraud, the text is in fact composed of three different layers describing different situations. The most obvious of 
which is the layer describing the different criminals being arrested and sent to the gallows. The second layer, a bit more obscure, is about card players and gamblers, and exposes their different tricks. Finally, at the core of these ballads lies the third layer, which describes sexual scenes between men. As Guiraud affirms,

The three situations are superimposed; all the words have three meanings and the text has three versions. We have eighteen ballads in the six. [...]. This first version A (theft, torture, gallows) covers the second one (playing, cheating, extortion). Finally, the first one and the second one altogether hide the third (love games) which constitutes the secret meaning of the work.

(Guiraud 1968: 8)

Therefore, if in version A les saupicquez copy the shape of a lock by filling it with lead, being therefore des piqueurs de sceaux [seal stealers], in version $\mathrm{B}$ they are cheaters who pictonnent sus les champs [mark their cards on the back side], and in version $\mathrm{C}$ they are sodomites who piquent les sceaux [steal seals] as in A but here in the sense of "to plug" anuses.

Guiraud's code allows him to offer three translations that are successively and simultaneously mischievous, playful, and "tongue-in-cheek." Despite the fact that he distanced himself somewhat from his own thesis in his following book on Villon, Le Testament de Villon ou le gai savoir de la basoche [Villon's Will or the Gay Knowledge of la Basoche], translators and scholars from Europe and from across the Atlantic stepped into the breach left open by Guiraud. ${ }^{7}$ It is in this context that Thierry Martin's translation of Les ballades en jargon [Ballads in Jargon] into modern French appeared under the title Ballades en Jargon homosexuel in 1998.

In his translator's introduction, Thierry Martin decides to extend the logic of "triple" entendre to all the ballads. He even suggests that the apocryphal ballads might be the work of Colin de Cayeux based simply on the fact that "he was homosexual." Thierry Martin also refines Guiraud's key. For him "the Ballades in Jargon" are variations of a homosexual game relying on two rules: A) it is forbidden to sodomize a man with an erection. B) While he tries to protect himself, the player also atttempts to orally disarm his opponent in order to sodomize him" (6). Finally, even if Martin relies on Guiraud's reading, he inexplicably decides to ignore layer B ("card players"). Even more, while Martin acknowledges the layer A and C, his translation ignores layer A, restricting the text to layer C. It is therefore not surprising that until now, no other publishing house other than Les Milles et une nuits has decided to print this imaginative translation.

Martin's interpretative violence to the original text is probably of greater interest than the accuracy of his translation. ${ }^{8}$ If the text is based on layers of meaning, its literary quality resides in its ambiguity and its capacity to (de)construct its own narrative/meaning. In a sense Villon's text is modern 


\section{Marc Démont}

in its queerness and its ability to disrupt and multiply the associations of the signifying chain. Martin's minoritazing translation, on the contrary, reduces the Ballads' plasticity to a fixed unidimensional text in a way that illustrates the inherent danger in this mode of translation. By reducing the text's queerness to the terms of the contemporary identity politics, the translator suppresses the potential discontinuities, associations, and uncouplings around which the original text, and its own sexual rhetoric, are organized.

In a sense D.A. Miller's “Anal Rope” (1991), about Alfred Hitchcock's 1948 Rope, perfectly illustrates this desire to give a voice, a form, a categorical, and a denotative existence to an ungraspable queerness. In this essay, Miller argues that the critics' ritualized commentaries over Rope's technical prowess are a gimmick distracting viewers from the homosexuality of the characters. The fascination with the technical aspect of the movie, a movie that Hitchcock wanted to shoot in a single, unbroken shot, works literally as a translation, a transference or a displacement of the fascination with homosexuality: "technique acquires all the transgressive fascination of homosexuality, while homosexuality is consigned to the status of a dry technical detail" (Miller 1991: 148). It is in this context that Miller develops an interesting critique of the relation between connotation and homosexuality. Because homosexuality in Rope is only connoted, Miller sees in connotation "the dominant signifying practice of homophobia [. . .] constructing an essentially insubstantial homosexuality." As David Greven rightly argues in his critique of "Anal Rope," Miller's stance is mainly political and must therefore be contextualized:

When D. A. Miller published “Anal Rope," an essay about Alfred Hitchcock's film Rope (1948), in 1990, the AIDS crisis was still raging in the United States, no effective treatment for it was available, homophobia was at its height, and George Bush had taken office, extending his predecessor Ronald Reagan's reign. The intense suspicion of structures of power in Miller's essay and its palpable, though rhetorically contained, anger are in many ways rational, plausible responses to the infuriating national indifference to mass gay suffering, to say nothing of openly derogatory public statements against members of the queer community, that marked the era. Miller's essay has long been famed as an early classic of queer theory for its rhetorical forcefulness and finesse.

(Greven 2012)

For Miller, to talk about homosexuality in the connotative mode is to construct an "essentially insubstantial homosexuality," echoing the fantasy of right-wing politics to annihilate queer voices and bodies. ACT UP's Silence $=$ Death can be translated in Millers words as Connotation $=$ Death . Miller's text testifies to the urgency of making cultural texts speak the language of a specific regime of sexuality, it is aroused by the will to severe the web of connotations in favor of the congealed and explicit world of denotation. 
Minoritizing translations, therefore, could be said to be primarily interested in denotation, that is, in finding strict equivalences between one word and another, even if the text's queerness may suffer in this process. As seen in Ballades en argot homosexual, the whose publishing date of which (1998) corresponds to the fight against French a conservative French president but also to a period of hope since the threat of AIDS had diminished thanks to new medications and a better understanding of the disease, Martin's translation seems to echoes the movement of reappropriation of texts, as the textual equivalence a politics of visibility, even if its queer dimensions (the complex relations between layers for instance) have to be ignored or overlooked. In other words, minoritizing translations often serve the goal of an identity politics at the expense of queerness.

\section{Queer Translations}

I want now to single out another mode of translating queer literary texts, one that can be opposed to the misrecognizing and minoritizing modes. The misrecognizing translation tries to rewrite a text from a certain hegemonic standpoint. Concealing the queerness of a text, this mode of translation aims to suppress the text's disruptive force. On the other hand, minoritizing translations are less interested in suppressing this disruptive force than in assimilating it, transforming it into a fixed explicit form. The queering translation, on the other hand, focuses on acknowledging the disruptive force and recreating it in the target language. These two facets of the queering translation imply two different types of queering practices. The first one, as I will show with Moby Dick, consists in critiquing the work of suppression or assimilation of the previous translation(s) in order to expose the source text's specific manifestation of queerness. The second one seeks to develop techniques to recreate in the target language the queerness of a text.

When French poet Jean Giono undertook the translation of Moby Dick, the Second World War was about to break out and the poet would later write in his book Pour saluer Melville [Tribute to Melville] (1941) that Moby Dick was always by his side in his years as a member of the Resistance. If one can understand that the fraternity of Ishmael and Queequeg might serve as a beacon of a "democratic poetics" (Martin 1986: 68), as opposed to Ahab's paranoid and fascistic obsession with power, it is surprising that a text so saturated with homosocial desire and deep homosexual undertones was chosen to represent male values in a time of war. However, if one looks closely not only at Giono's translation but at the other ones available in French, one can see that this queer dimension has been rendered dull and harmless, when not systematically erased. To expose the work of misrecognition in the French-language translations of Moby Dick, I have decided to focus on one particularly queer chapter: "A Squeeze of a Hand."

In this well-known homoerotic passage, Melville/Ishmael discovers "an abounding, affectionate, friendly, loving feeling” (2002: 323) for his male 
companions and sailors while together they squeeze lumps of sperm. If the reader is aware that this sperm is in fact the spermaceti of the whale, the repetition of the word "sperm" in this orgiastic labor clearly participates in invoking the ghost of a queer sexuality. While the word spermaceti is mentioned once in the first part of the chapter, the word sperm is mentioned eight times. However, in the French translation the word "sperme," which would be the equivalent for "sperm," is nowhere to be found. Sperm is systematically translated as spermaceti. In defense of Giono, this is not the only translation that systematically avoids the word "sperme." In Armel Guerne's 1954 translation, the word "sperme" is carefully in favor of "spermaceti." The word "spermaceti" is equally omnipresent in Henriette Guex-Rolle's 1970 translation, supposedly the most academic and faithful.

Finally, Philippe Jaworski's 2006 translation for the prestigious La Pléiade edition is probably the most interesting one in its half acknowledgment of the text's queer dimension. Jaworski uses the word spermaceti until Melville mentions "the old Paracelsan superstition that sperm is of rare virtue in allaying the heat of anger" (2002: 322) which concentrates, as I will demonstrate later, the text's own immune system against any misrecognizing translation. Forced to acknowledge that Melville is pointing to something beyond the text, using the web of connotations surrounding the word sperm, Jaworski decides to translate: "à cette vieille légende de Paracelse, selon laquelle le sperme de baleine possède la rare vertu d'apaiser l'ardeur de la colère" (Melville [Jaworski] 2006: 457). Whereas Jaworski had previously ignored the word "sperm" in favor of the word "spermaceti," he suddenly becomes overly precise, choosing to translate "sperm" with "sperme de baleine" [whale sperm] in order to circumscribe the threatening web of homoerotic connotations. The old Paracelsian superstition is evidently endowed with the property of soothing homosexual panic since from this point on Jaworski decides to systematically translate "sperm" as "sperme."

This choice of translation appears to be even more paradoxical, however, since in a note of the translator Jaworski argues,

To our knowledge, at least, the word "sperme" is absent from scientific or whale-related literature of the period. The Littré nevertheless includes the word "sperme" as an abbreviation of "spermaceti" to designate the "blanc de baleine." The renowned lexicographer's choice supports our observation (and that of the novel's narrator) of the explicitly erotic nature of the fantasy that emerges during the squeezing of the lumps of spermaceti.

(Melville [Jaworski] 2006: 1259)

First, it is surprising that Jaworski does not find traces of the word "sperm" since it appears in French as early as 1817 in the work of the famous biologist, paleontologist and naturalist Georges Cuvier (1769-1832) in his encyclopedic Le Règne animal distribué d'après son organisation [The Animal Kingdom, Distributed According to Its Organization]. For instance at the 
end of the section entitled "Idée sommaire des fonctions et des organes du corps des animaux, ainsi que des divers degrés de leur complication," [Summary idea of functions and organs of the body of animals, and of the diverse degrees of their complexity] Cuvier states with his great scientific authority: "La liqueur fécondante s'appelle sperme; les glandes qui la séparent du sang, testicules et, quand il faut qu'elle soit introduite dans le corps de la femelle, l'organe qui l'y porte s'appelle verge" (1817: 47) [the fecund liquor is called sperm; the glands that separate it from blood, testicules; and, when it is necessary to introduce it in the body of a female, the organ that carries it there, is called penis]. Needless to add, the modern scientific vocabulary describing sexual organs and activities had already been established when Cuvier penned his definition. Second, if in the second half of the text Jaworski finally chooses to use the word "sperme" after having cautiously specified that Meville was referring to "sperme de baleine," why does he not extend his choice to the first part? And, even more troubling, having acknowledged the "caractère explicitement érotique" of the passage, why limit the translation of sperm to "sperme de baleine?"

Looking back at the other translations, one is compelled to conclude that this line about Paracelsus creates a resistance to any attempt to misrecognize Melville's queer semantic play around the word sperm. Henriette Guex-Rolle adopts such a strategy of misrecognition when she translates the line as "J'en arrivais presque à croire avec Paracelse que cette matière [matter] avait la précieuse vertu de tempérer l'ardeur de la colère" (1989: 429). The same process of avoidance is found in Armel Guerne's translation where "sperm" is translated by "matière étrange" (1981: 599) [strange matter]. Finally, Giono settles the problem with the plain word "spermaceti" (1980: 179). There is a real problem, however, in translating "sperm" by spermaceti. First, the text itself resists this violence. Melville distinguishes clearly in this passage between his use of "sperm" or "spermaceti," saving the latter for the very end of the passage: "I saw long rows of angles in paradise, each with his hands in a jar of spermaceti" (2002: 323). There is, therefore, no objective reason to substitute "sperm" with "spermaceti" since these two words have the same valence as the French "sperme" and "spermaceti." Second, while the word sperma coeti appears in Paracelsus's work, his understanding of the word is very different from the modern word "spermaceti." As mentioned by Melville himself, the origin of the word "spermaceti" is rooted in the belief that the sperm of the whale was actually stored in its head. Translating "sperm" as "spermaceti" is therefore as misleading as translating it as "sperme de baleine" since the latter ignores Melville's voluntary play with at least three levels of meaning. The references to Paracelsus trigger the old primary meaning of spermaceti as sperm, and demonstrate that translating "sperm" by the modern "spermaceti" amounts to orienting the text in a direction that it clearly does not want to take.

Considering the text's homoerotic and orgiastic masturbatory undertones, the French-language translation of the last paragraph of the first part of 
the chapter is also problematic. After this all-male orgy of sperm, Melville/ Ishmael nonetheless concludes with a somewhat surprising statement:

I have perceived that in all cases man must eventually lower, or at least shift, his conceit of attainable felicity; not placing it anywhere in the intellect or the fancy; but in the wife, the heart, the bed, the table, the saddle, the fire-side, the country; now that I have perceived all this, I am ready to squeeze case eternally.

(2002: 323)

The mention of the wife here is problematic after this overtly homoerotic passage, describing sailors enjoying mutual caresses in a "bath" of sperm. However, one must not forget that the terms "husband" and "wife" appear earlier, in the chapters "A Bosom Friend" 10 and "Couterpane," to describe the relationship between the male couple Ishmael/Queequeg. Therefore when the word "wife" appears in "A Squeeze of a Hand," it already has a history in the semantic economy of the text. Not surprisingly, Giono's translation once again ignores the echoes of the word and its implication for understanding both the passage and Ishmael/Queequeg's relation. While Giono translates wife as "femme" in "The Couterpane," he translates it as "compagne" [female companion], attenuating the semantic relation between the two chapters. Jaworski and Henriette Guex-Rolle's renderings of these passages similarly opt for such misrecognizing lexical choices. By using the word "épouse" [spouse (fem.)] to bridge the passages, Armel Guerne is the only translator who, willingly or not, respects the internal semantic relations that Melville draws.

Respecting the queer meaning potential of a text should therefore be a central focus of queering translations, as this practice is instrumental to undoing the strategic erasures or assimilations of misrecognizing or minoritizing translations. In their now classic study Same-sex Love in India (2000), Ruth Vanita and Saleem Kidwai espouse this perspective when they state,

Bowdlerized translations have seriously biased scholars' understanding of several texts, for instance, words referring to beautiful boys in the medieval history Muraqqa, have been translated "lads and lasses." In a recent English translation of the Krittivasa Ramayana, where the text describes the two widows of King Dilipa as living together "in extreme love [sampriti]," the translators renders this as "living together behaving like husband and wife." In the (...) line (...) which states that the sage named their child "Bhagiratha" because he was born of two vulvas (bhaga), the translation simply omits this etymology and states "The sage then blessed them and gave him the name of Bhagiratha."

(Vanita and Kidwai 2000: xix)

Same-sex love in India does not merely carry out a critique of existing translations in order to queer them but confronts the difficult exercise of 
translation in order to offer new texts. Extensive use of the translator's note is possibly the most interesting feature of their approach, one that, in my view, is central of queering translation as it provides a way of counteracting the pervasive effect of both misrecognizing and minoritizing translations. For example, in Laxmi Chandrashekar's translation of H.S. Shivaprakash's Shakespeare Dreamship found in that volume, Chandrashekar translates the Kannada/Sanskrit word samlingrati [one who loves the same sex] by "homosexual." A translator's note, however, immediately interrupts the domesticating process to reintroduce the queerness present in the source text. ${ }^{11}$ Or, in Saleem Kidwai's translation of Hakim Muhammad Yusuf Hasan's Do Shiza, while the translator suggests the word "Hermaphrodites" to translate the Urdu word "khansa," he adds a note to specify that homosexuals and hijras are lumped together in the same category.

The translator's note, therefore, helps to preserve the connotative web of associations in the queer source text.

Boccacio's Il Decamerone offers another example of the possibilities afforded by the use of the translator's note related to the queer figure of the sextons whome Boccacio describes for the first time in G.H. McWilliam's translation as a "gravedigging fraternity [.. .] drawn from the lower orders of society" (1995: 10). As such, they threaten the temporality of the sacred since, despite the presence of the priest that accompanies them, they don't "go to the trouble of pronouncing solemn and lengthy funeral rites, but, with the aid of these so-called sextons, they hastily lowered the body into the nearest empty grave they could find" (1995: 10). But what's more interesting for understanding the relationship between temporality and jouissance in the Decameron is that Pampinea, the eldest of Boccaccio's seven female narrators, echoes Boccacio's description, defining the sextons as "the scum of our city who, having scented our blood, call themselves sextons and go prancing [cavalcare] and bustling all over the place, singing bawdy [disoneste] songs that add insult to our injuries"12 (1995: 15). Despite the fact that G.H. McWilliam offers sometimes lengthy comments in his translation, he remains mute in the face of Pampinea's obvious allusions to the sexton's queer sexuality. As Levenstein points out in her article about sexuality and plague, "Cavalcare' is occasionally an equivocal verb in the Decameron, used as a metaphor for sexual intercourse, and its proximity to the adjective 'disoneste' in this sentence further emphasizes it possible double meaning" (1995: 318). Failing to capture that double meaning limits the queer potential of this classic work. A queer translation has therefore to be in touch with the scholarship surrounding the translated text (here Levenstein) in order to respect and to make salient the ambiguities of the text.

\section{Conclusion}

With this last example in mind, I would like to conclude with Appiah's essay "Thick Translation" (2000) in order to theoretically flesh out my 


\section{8}

understanding of the queering translation. In his essay, Appiah argues that the Gricean theoretical framework does not allow us to fully capture what is at stake in literary translation. For Appiah, if literary practice is made of conventions, it does not necessary offer cues about the ways in which the text must be understood, about what the text is about. This fundamental openness to different readings is in fact what constitutes its literary "property": "It is a feature, simply put, of the written text that we do not have settled and definite ideas about what matters about it. [. . .]. Questions of adequacy of translation thus inherit the indeterminacy of questions about the adequacy of the understanding displayed in the process we know call "reading"-which is to say that process of writing about texts which is engaged in by people who teach them" (Appiah 2000: 816). This pragmatic definition of translation, pragmatic in the sense that its definition is linked to a certain literary practice known as the production of "readings," offers a productive way to define what I mean as queer translation.

A queering mode of translation does its best to translate not only the semantic content or what Appiah defines as its literal content, but to offer a translation that preserves the web of virtual connotative associations and, therefore, the text's ambiguities and potentially disruptive content, in order to open new possibilities of readings. If this mode of translation is connected to Venuti's foreignizing translation in the sense that the queering translation seeks to resist the logic of domination or appropriation, it also goes beyond Venuti's concept since the queering translation remains constantly sensitive to the queerness of the text by voluntarily refusing to offer an "ultimate" translation, by resisting the temptation to close the translation on itself, and by offering commentary that preserves its fundamental ambiguities and highlights its potential interpretative lignes de fuite. Whether in its critical aspect or in its glossing aspect, the queering translation focuses on the choices and strategies that translators make in order to conceal, to congeal, or to leave open a disruptive queer content.

\section{Notes}

1 For further discussion of these questions see Matt Cohen and Rachel Price, Ibid.

2 The collection Mille et une nuits aims at publishing at a very low price, short classical or diverting essays and literary texts such as Arthur Schopenhauer's The Art of Being Right, Étienne de La Boétie's Discourse on Voluntary Servitude or Frédéric Pagès's Descartes and the Cannabis. Thierry Martin is a medievalist, specialist of François Villon and François Rabelais. He has also published Poèmes homosexuels [Homosexual Poems] (2000), Trois études sur la sexualité médiévale [Three Essays on Medieval Sexuality] (2001), and Poésie homosexuelle en Jobelin [Homosexual Poetry in Jobelin] (2007) in the French publishing house Gay Kitsch Camp, specializing in LGBTQ texts.

3 All translations are mine unless otherwise indicated.

4 However some specialists and translators have stubbornly attempted to make sense of this text. See for example Schöne (1888); Marthold (de) (1895); Schwob (1892); Şăineanu (1912); Esnault (1951); Ziwès and Bercy (de) (1960); Lanly (1971). 
5 “Si Pierre Guiraud n'était pas connu pour ce qu'il est, c'est-à-dire pour le très savant auteur des ouvrages sur les Caractères statistiques du vocabulaire (P.U.F. 1953), sur les Problèmes et méthodes de la statistique linguistique (P.U.F. 1960) et surtout sur les Structures étymologiques du lexique français (Larousse 1967), on serait porté à croire que l'étude qui nous est présentée ici constitue simplement l'un d'entre les nombreuses tentatives entreprises depuis un siècle en vue de rendre clair le langage jargonnesque de Villon, ou encore une farce sympathique mais quelque peu mystificatrice."

6 Even the main exegetes of Villon (Champion, Foulet and Thuasne) considered that the text was so corrupted that any project of making sense of the text was a waste of time.

7 Randy Conner exemplifies this appraisal in the dedication of his article to Pierre Guiraud: "The essay is dedicated to the courageous Pierre Guiraud, whose study Le jargon de Villon, ou le gai savoir de la coquille (Paris: Gallimard, 1968), while controversial, remains to date one of the few exploration of premodern French language and culture in terms of homoeroticism."

8 I refer here to Venuti's violence of translation "where translation serves an imperialist appropriation of foreign cultures for domestic agendas" (2010: 68).

9 Isabelle Génin (2008) also noticed major problems with the translation of the gender ambiguities surrounding the sex of Moby-Dick. Jaworski straightens these ambiguities by attributing a masculine gender to the whale where Melville in fact uses indifferently the pronouns it, she or he to refer to the whale.

10 The translation of the last two passages is also very problematic and evinces the translator's homosexual panic. For example, when reading the last sentence: "Thus, then, in our heart's honey-moon, lay I and Queequeg-a cosy, loving pair" (2002: 57) Giono translates: "Et ainsi étions-nous étendus, Queequeg et moi, formant un comfortable et tendre couple dans la lune de miel de notre amitié" (1980: 103). By adding the word "amitié" [friendship], Giono obviously ensures that the text will be interpreted in a non-threatening way.

11 To his translation "Shakespeare: The chap who spread the rumor, that devil's disciple, Marlowe, was himself a homosexual." Chandrashekar adds in a note: "The word used in Kannada is the Sanskrit samlimgrati (one who loves the same sex). Poet and playwright Christopher Marlowe (1564-1593), who was accused of being an atheist and a sodomite, was reported to have remarked that "all they who love not tobacco and boys be fools." He was stabbed to death in a tavern brawl" (Vanita and Kidwai 2000: 344).

12 Italian inclusions mine.

\section{References}

\section{Primary Sources}

Boccacio, Giovanni. 1995. The Decameron. Penguin Books: New York.

Cuvier, Georges. 1817. Le Règne animal distribué d'après son organisation, Vol. I [The Animal Kingdom, Distributed According to Its Organization]. Paris: Deterville.

Gualardia, Antonio and Michela Baldo. 2010. "Bear or "Orso?" Translating Gay Bear Culture into Italian." In Other Words 36: 23-39.

Guiraud, Pierre. 1968. Le Jargon de Villon ou le gai savoir de la Coquille [Villon's Jargon or the Gay Knowledge of la Coquille]. Paris: Gallimard.

Martin, Thierry. 1998. Introduction to Ballades en argot homosexuel. Edited by

François Villon. Paris: Fayard.

Melville, Herman. 1980. Moby Dick. Translated by Jean Giono. Paris: Gallimard. 
Melville, Herman. 1981. Moby Dick. Translated by Armel Guerne. Paris: Presses Pocket.

Melville, Herman. 1989. Moby Dick. Translated by Henriette Guex-Rolle. Paris: Garnier Flammarion.

Melville, Herman. 2002. Moby Dick. New York: W.W. Norton \& Co.

Melville, Herman. 2006. Moby Dick ou le cachalot. Translated by Phillipe Jaworski. Paris: Les Belles Lettres.

Vanita, Ruth and Saleem Kidwai. 2000. Same-Sex Love in India: Readings from Literature and History. New York: St. Martin's.

Villon, François. 1998. Ballades en argot homosexuel [Ballades in Homosexual Slang]. Translated by Thierry Martin. Paris: Fayard.

Whitman, Walt. 1943. Poemas. Translated by Alvaro Armando Vasseur. Buenos Aires: Editorial Schapire.

Whitman, Walt. 2007. Leaves of Grass. University Park, PA: Pennsylvania State University.

\section{Secondary Sources}

Appiah, Kwame Anthony. 2000. “Thick Translation.” In The Translation Studies Reader, edited by Lawrence Venuti, 417-429. London: Routledge.

Cohen, Matt and Rachel Price. 2007. “Introduction: Álvaro Armando Vasseur's Preface to the Sixth Edition of Walt Whitman: Poemas." Walt Whitman Archive. Available online at http://whitmanarchive.org/published/foreign/spanish/vasseur/ preface-intro (last accessed February 7, 2017)

Esnault, Gaston. 1951. "Le Jargon de Villon.” Romania 72: 23-39.

Génin, Isabelle. 2008. "La Baleine blanche a mauvais genre." Palimpsestes 21: 55-74.

Giono, Jean. 1941. Pour saluer Melville [Tribute to Melville]. Paris: Gallimard.

Greven, David. 2012. "Making a Meal of Manhood." Genders 56. Online article accessible by through Full Text Finder (last accessed Februray 8, 2017).

Guirraud, Pierre. 1953. Caratères statistiques du vocabulaire. Paris: P.U.F.

Guiraud, Pierre. 1960. Problèmes et méthodes de la statistique linguistique. Paris: P.U.F.

Guiraud, Pierre. 1967. Structures étymologiques du lexique français. Paris: Larousse.

Lanly, André. 1971. Ballades en jargon. Paris: Champion.

Levenstein, Jessica. 1996. "Out of Bounds: Passion and the Plague in Boccaccio's Decameron." Italica 73(3): 313-335.

Marthold (de), Jules. 1895. Le Jargon de François Villon. Paris: Chamuel Ed.

Martin, Robert K. 1986. Hero, Captain, and Stranger: Male Friendship, Social Critique, and Literary Form in the Sea Novels of Herman Melville. Chapel Hill, NC: University of North Carolina.

Miller, D.A. 1991. “Anal Rope.” In Inside/Out: Lesbian Theories, Gay Theories, edited by Diana Fuss, 145-167. New York: Routledge.

Moland, Louis. 1893. CEuvres complètes de François Villon: Publiée avec une étude sur Villon, des notes, la liste des personnages historiques et la bibliographie. Paris: Garnier Frères.

Paquette, Jean-Marcel. 1969. "Le Jargon de Villon ou le gai savoir de la Coquille," review of Le Jargon de Villon ou le gai savoir de la Coquille, by Pierre Guiraud. Études Littéraires 2(3): 357-360. 
Şăineanu, Lazăr. 1912. Les sources de l'argot ancien. Vol. I \& II. Paris: Honoré et Edouard Champion.

Schöne, Lucien. 1888. Le jargon and jobelin de François Villon suivi du Jargon au théâtre [The Jargon and Jobelin of François Villon Followed by of the Use of Jargon in Theater]. Paris: Alphonse Lemerre Ed.

Schwob, Marcel. 1892. "François Villon d'après des documents nouveaux." Revue des Deux Mondes 112: 375-472.

Venuti, Lawrence. 2010. "Translation as Cultural Politics: Régimes of Domestication in English." In Critical Readings in Translation Studies, edited by Mona Baker, 65-79. New York: Routledge.

Ziwès, Armand and Anne de Bercy. 1960. Le Jargon de Me François Villon. Paris: Waltz et Puget. 


\title{
12 Queering Lexicography Balancing Power Relations in Dictionaries
}

\author{
Eva Nossem
}

\section{Introduction}

In 1755, after nine years of hard work in producing his monumental Dictionary of the English Language, Samuel Johnson described his role as a lexicographer as "a writer of dictionaries; a harmless drudge, that busies himself in tracing the original, and detailing the signification of words" (Johnson 1755: n. p.). In this chapter, I do not consider the lexicographer a "harmless drudge" but rather a powerful producer of authoritative sources of cultural and linguistic knowledge. Similar to the way Foucault sees the author as "a certain functional principle by which, in our culture, one limits, excludes and chooses" (Foucault 1998: 221) and as "the ideological figure by which one marks the manner in which we fear the proliferation of meaning" (Foucault 1998: 222), I refer to the lexicographer not in an essentialist understanding as an individual but as a linguistic and cultural function. As Foucault explains, the author-function "does not refer [. . .] to an actual individual insofar as it simultaneously gives rise to a [. . . ] series of subjective positions" (Foucault 1977: 130-131) and that it "could also reveal the manner in which discourse is articulated on the basis of social relationships" (Foucault 1977: 137).

Therefore, lexicography, like translation, "is never an innocent activity" (Bassnett 2014: 85), and so lexicographers, like translators, "participate in the powerful acts that create knowledge and shape culture" (Tymoczko and Gentzler 2002: xxi). Even though the relationship between lexicography and translation studies seems to be rather obvious, relatively little research has been done on this topic. While many of the studies focus on the use translators make of dictionaries, i.e., of the product, the perspective in this chapter encompasses the lexicographic process itself. Just as Venuti in translation studies shifted the focus away from the product to the user, concentrating on the translator rather than on the translation, I will focus on the lexicographer and their decisions in the production process; the outcome, the dictionary, is only taken into account in order to provide evidence for observations made regarding lexicographical decision making. 
My analysis of the powerful linguistic and cultural function of the lexicographer and of dictionaries as authoritative instruments produced by and producing regimes of cultural and linguistic knowledge/power, developed from a bringing together of queer approaches and lexicography. In what follows, I will focus on power and authority in lexicographical decision making, which influence not only the processes of dictionary making but are also produced by the dictionaries themselves, and in doing so seek to contribute to critical heteronormativity research within the field of theoretical lexicography and to practical dictionary making.

As observed in Nossem (2015: 110), "Queer(ing) Lexicography” sounds like an oxymoron, as the two concepts appear to exclude each other. On the one hand, there is queer with its manifold uses and explanations: queer as "a signifier without a signified" (Cameron and Kulick 2003: 148); or " 'queer' [that] acquires its meaning from its oppositional relation to the norm. Queer is by definition whatever is at odds with the normal, the legitimate, the dominant" (Halperin 1995: 62), and so on. The meaning of "queer" as used in academia and in activist circles is characterized by this anti-normative stance. On the other hand, there is the concept of lexicography, "the professional activity and academic field concerned with DICTIONARIES and other REFERENCE WORKS. It has two basic divisions: lexicographic practice, or DICTIONARY MAKING, and lexicographic theory, or DICTIONARY RESEARCH” (Hartmann 1998: 85). The practice of dictionary making is typically defined by two fundamental activities-namely, categorizing and defining. Lexicography then has at its core those very ideas that the notion of queer tries to avoid or explicitly opposes.

One could argue that these opposed approaches are mutually exclusive. I will show, however, that lexicography's strong reliance on norms and queer's vehement opposition to those norms do not exclude the possibility of a queer lexicographical analysis. I interpret these norms not as dividing lines but as a common ground that allows us to bring these two approaches together. I see norms not as a border that divides or separates, but rather as a border that unites and ensures a common perspective, i.e., norms representing an intersection or a common point of contact.

\section{Norms and Authority in Lexicography}

I understand norms as standards and regulations, habits and best practices, as well as models and ideals. In the context of a queer lexicography, Berlant and Warner's notion of heteronormativity as a rethinking of norms is helpful:

By heteronormativity we mean the institutions, structures of understanding, and practical orientations that make heterosexuality seem not only 
coherent-that is, organized as a sexuality—but also privileged. [. . . It consists less of norms that could be summarized as a body of doctrine than of a sense of rightness produced in contradictory manifestations-often unconscious, immanent to practice or to institutions.

(Berlant and Warner 1998: 550)

Their explanation focuses on the binarism of right and wrong promoted in heteronormative discourses and draws attention to unconsciously introjected norms governing this sense of rightness.

In queering lexicography, I attempt to expose norms as a reflection of and at the same time constitutive of the power structures that play a significant role in the compilation of dictionaries. By queering lexicography, then, we expose the unnaturalness of norms to reveal the dominant discourses of heteronormativity within the final product, the dictionary itself. During the compilation process, the lexicographer comes into contact with a broad range of norms, some imposed from the outside, as heteroregulations, others from within, as autoregulations, set up by the lexicographer themselves. Furthermore, one can distinguish between explicit and implicit norms, i.e., norms that are expressly formulated and those that are only implied. In addition to ensuring a certain structure and regularity, these norms lead to an assumed objectivity, assigned from the outside by the dictionary user, on the one hand, and claimed by the lexicographer themselves, on the other. Furthermore, the dictionary assumes the special role of an expert, a reliable and trustworthy authority, also both assigned from the outside and claimed from within.

As Fontenelle observes, "Dictionaries have existed for hundreds of years and have been compiled to meet very practical needs [. . .]. At the same time, dictionaries can also be seen as cultural artifacts conveying a vision of a community's language" (Fontenelle 2008: 1). Cowie states that already early glossaries, the ancestors of today's dictionaries, "fulfill a vital function in teaching and the transmission of knowledge" (Cowie 2009: 2). This important and authoritative role of teaching and transmitting knowledge is still valid and applicable today and is also acknowledged by Duval: "All lexicographical reference books, such as monolingual dictionaries, bilingual dictionaries, multilingual glossaries or encyclopedias, aim at creating bridges between what users know and what users do not know (Duval 2008: 273)." As these statements show, a dictionary fulfills a special role in creating and transmitting linguistic and cultural knowledge, becoming itself an authoritative cultural product. A dictionary's authority not only derives from the idea of it being a high-quality work with well-structured, accurate information but also from the perception that the dictionary represents an objective source of knowledge.

Dictionaries are generally regarded as valid and highly reliable sources, especially in terms of the linguistic information provided, but also in terms of the cultural and functional/issue-related content. As Atkins and Rundell (2008: 2) explain, "Dictionaries are often perceived as authoritative 
records of how people ought to use language, and they are regularly invoked for guidance on 'correct' usage." The dictionary's role as an authoritative source is based mostly on the assumed expertise of its compilers, i.e., the user's expectation that the provided information is well researched and thus correct.

The typology of the dictionary, as expressed in the title and often outlined in its introduction, can be an indicator of the assumed authority of the work in a given field. Numerous attempts have been made to classify different typologies of dictionaries by distinguishing them according to their function (special or general purpose), the languages (mono- or interlingual), and so on. The dictionaries that aspire to the greatest degree of objectivity and neutrality seem to be general purpose dictionaries. In these cases, the only criterion for the admission of a word to the lemmary appears to be its use (cf. Nossem 2015: 112). In this respect, interlingual, or bilingual dictionaries represent a somewhat special case as they claim, in a certain sense, multiple authorities insofar as they determine the standard in the language $\mathrm{Lx}$, the standard in the language Ly, and put both in relation to each other by establishing equivalences.

Further information regarding the function and content of a dictionary can be found in the introductions, which vary considerably in terms of structure, content and range of information provided. Introductions may refer to both the macro- and the microstructure of the dictionary, and often consist mainly of guidelines for how to use the dictionary. In some cases, the lexicographers offer insight into certain decisions, explaining the structure of an entry and perhaps even some of the criteria that influenced the admission or exclusion of words from the lemmary.

In addition to the dictionary's expert knowledge, another factor that influences the perception of the dictionary is its assumed objectivity. In the 1980 s, the very idea of objectivity was heavily criticized by feminist thinkers. For example, Donna Haraway in Situated Knowledges describes objectivity as a "conquering gaze from nowhere" (Haraway 1988: 582), arguing that objectivity is nothing but an unreachable illusion. Haraway recommends that we step back from all objectivity claims and specify our perspective, because only when acknowledging our own biased view can we assume responsibility for our position. Taking these ideas further, we can argue that under the façade of assumed objectivity lies nothing but a privileged perspective (more or less internalized), or dominant discourse in the Foucauldian sense. Foucault also denies the existence of an absolute truth and argues that certain knowledges exist because they are imposed and constructed by the dominant power structures (cf. Nossem 2015: 114).

Thus objectivity and absolute truth are nothing but illusions promoted by norms, which are often internalized and unconsciously applied, like Berlant and Warner's heteronormative "sense of rightness." These norms and their importance in dictionary making become more evident when examining lexicographical decisions made by the compilers of dictionaries. 


\section{Lexicographical Decisions in Monolingual Dictionary Making}

The first step in dictionary making is the collection of words in an initial corpus, from which the lemmary is then chosen. It is common practice to rely on earlier works. After adding one or more existing dictionaries, the initial corpus is filled with additional sources, such as specialized dictionaries (e.g., of neologisms) or glossaries. Texts that are considered artifacts of high culture, i.e., canonical texts, are then added to the corpus (cf. Nossem 2015: 115-116). Fellner explains the special role of these canonical works as: "Serving as a standard of judgment or authority [. . . canons are powerful instruments of imposing order and structure upon different bodies of knowledge" (Fellner 2008: 224).

Relying on existing dictionaries obviously guarantees a certain continuity and coherence, but the disadvantages are no less obvious. There is an enormous risk of repeating the weak points of prior works and of reproducing the same gaps. Relying on existing works, as a consequence, also means trusting and accepting the decisions and decision making underlying them. And so, not only are the contents of these prior works reproduced and fixed, but so, too, are the values and norms that were linked to their production, which are then passed on to the next generation of dictionaries. If we conceptualize meaning as the result of a continuous series of reproductions and repetitions, we cannot ignore the risk of fossilization that is linked to this aspect of dictionary making. Thus, not only do we create an infinite repetition of the values and norms underlying the older works, but we reproduce and strengthen those values and norms at the risk of excluding new developments. Relying on canonical texts means conferring importance, prestige and thus authority onto certain sources and at the same time depriving other sources of that authority (cf. Nossem 2015: 117-118)

After creating the corpus, the next step is the selection of the lemmary. By admitting and excluding items, or lemmas, the lexicographer for all practical purposes decides which words exist, that is, which words are good enough or important enough to be accepted, and, conversely, which words will be condemned to silence.

In order to avoid inserting all found word forms into the dictionary, the lexicographer usually reduces them to a basic form, the lemma. By determining this form as the standard, it is assigned a neutral value and is thus marked as neutral. At the same time, though, the exact act of marking this form as neutral makes it into a marked form. Furthermore, at the very moment a neutral form is chosen, it is put into a privileged position with regard to other forms, which then become marked as non-standard, or deviant. For example, in the case of verbs, lexicographers tend to choose the infinite form as the basic form and thus as the lemma. In languages with flectional adjectives and nouns, lexicographers usually pick the singular masculine form. (cf. Nossem 2015: 119). At first glance, this decision seems 
obvious, because it is such a common tradition in dictionary making that it is hardly ever questioned. Upon further investigation, however, this decision seems arbitrary, as it simply favors one word form that is currently in use over other forms. This is a typical rule that sometimes is specified (explicit) but other times is not (implicit), because it is thought of as self-evident. The decision to give preference to the masculine form, rather than being arbitrary, however, appears from a queer perspective to be heavily determined from the outside (heteroregulated). It is influenced by and at the same time reinforces the dominant discourse in society, which privileges masculine forms and a male perspective.

All the lexicographer's decisions examined so far refer to the lemma, specifically, which words are accepted to become lemmas and what a lemma as a standard form should look like. In addition to the lemma, a dictionary also consists of additional information, such as pronunciation, origin, and etymology, and grammatical information. A very important piece of information (mostly in monolingual dictionaries) is the definition of the lemma. There are no general rules or norms regarding the content, composition, or structure of the definition, hence a series of diverse ways of defining lemmas can be found, ranging from one-word-definitions, i.e., synonyms, to explanations stretching over several columns and pages.

Kilgarriff observes, "To solve disputes about meaning, a dictionary must be, above all, clear. It must draw a line around a meaning, so that a use can be classified as on one side of the line or the other." (1997: 110). From Kilgariff's observation, Fontenelle deduces,

Lexicographers are therefore under pressure to present sets of discrete, non-overlapping meanings for a word. Yet, when one examines corpus data and actual evidence of usage based upon collections of millions of words of authentic texts, one quickly realizes that these discrete, non-overlapping sets of senses are frequently a myth.

(Fontenelle 2011: 57)

As Fontenelle's comment makes clear, word meanings and the attempt to provide clear-cut definitions represent a major issue in dictionary making. The very moment you give a definition for a lemma, you assume that this lemma has a certain fixed and stable meaning that can be thusly defined. As Derrida underscores with his notions of itérabilité and différance, meanings are neither fixed not stable, nor are their relations to the lemma. Meanings of a word vary over time and place, depending on the user, the context etc. Another problem arises when deciding what information to provide in order to convey a certain meaning and to create an understandable definition. Also in this case, probably for a lack of a universal solution, the lexicographer often relies on earlier works; this again raises the risk of repeating previously fixed meanings and hence strengthening existing norms (cf. Nossem 2015: 120). 


\section{Eva Nossem}

Good examples of all kinds of lexicographical decision making and the various problems surrounding it can be found when examining how words denoting violations of heteronormativity are dealt with. Linguistically, these violations are addressed in the worst case scenario by excluding some of these words entirely from many dictionaries. Even when they are admitted, the entries sometimes contain fallacies, such as obscure, circular, and contradictory definitions, incongruities, or the use of a problematic register in formulating the definition. ${ }^{1}$ This shows the lexicographer's power not only to express their own point of view but also to reinforce and strengthen the dominant discourse by recommending certain words and excluding others from use. Furthermore, the lexicographer has the influential power to assign connotational markers. By assigning a lemma the marker common, for example, it becomes a must for speakers of this language to know this word. If a lemma is marked as vulgar or obscene, it will be excluded from use in many communicative situations. The formulation of examples of usage may also involve borrowing of previously used examples, which runs the risk of reinforcing clichés and stereotypes.

The extent to which a word is silenced or accepted can also be deduced from the quantity and quality of information added to a lemma. It can be considered as an indicator of the level of acceptance of a word and its related ideas and meanings when the lemma comes with an obscure, incomprehensible one-word-definition or when it comes with a clearly formulated definition with non-discriminating usage examples and a series of proposed locutions, compounds, synonyms, antonyms, variants, etc.

\section{Lexicographical Decisions in Interlingual Dictionary Making}

Many of the powerful lexicographical decisions we have discussed for monolingual lexicography also apply to interlingual lexicography. Hartmann defines interlingual dictionaries as "a type of reference work with information on more than one language. The term is used either when the contrast with monolingual dictionary is stressed or when the distinction between bilingual dictionary and multilingual dictionary is considered irrelevant" (Hartmann 2007: 1).

The lexicographer's power to decide on the criteria of admission and rejection of words to the lemmary, the power of giving preference to a determined word form in lemmatization, as well as decisions regarding the determination and fixing of the meanings of a word are the same in the compilation of mono- and interlingual dictionaries. What we have seen for definitions in monolingual dictionaries can analogously be applied for translation equivalents in interlingual dictionaries. Here the lexicographer has the power to fix a specific meaning and to offer an equivalent in another language, thus exercising a multi-faceted power to fix the meaning in the language Lx and in the language Ly. Another aspect of power comes into 
play when lexicographers place source and target words in a relationship to establish equivalences.

In translation studies, equivalence is often explained as a replication in which the same is formulated in different codes and attempts are made to classify the distance of the translation to the original. Accordingly, translation is often viewed as mere rewording or paraphrasing - an idea that Walter Benjamin argued against when he spoke of translation as an "echo" instead of a "copy" and when he described the task of the translator as "aiming at that single spot where the echo is able to give, in its own language, the reverberation of the original work in the alien one" (Benjamin 1996: 258-259). Spurlin puts these "multiple potentialities of translations" in relation to "social, historical, and cultural conditions" and observes how they

[complicate] and [transform] the original text, and [create] new conditions of its reception in the target language, while simultaneously queering the target language and culture by both displacing and broadening its semiotic circuits and intertextual modes of signification.

(Spurlin 2014: 202)

If we then consider that features inevitably get lost, added, or modified in translation (and thus also in finding translation equivalents in interlingual lexicography), the translation itself becomes "a site of supplementarity and difference, that is, a space of indeterminacy that also points to the possibilities of translation as a queer praxis" (Spurlin 2014: 204).

As words from more than one language are selected and placed into a relationship with one other, interlingual lexicography, like translation, participates in the distribution of cultural capital among languages. Casanova "place[s] translation within the universe of international exchanges and [...] [studies] it as a factor in the struggle for legitimacy in the literary and political fields" and analyzes "the role translation plays in consecrating authors and texts, and hence in the distribution and transfer of cultural capital." (Casanova 2010: 285) That distribution of capital, Baker points out, suggests that power struggles are inherent in translation:

Much of the current literature on translation and interpreting approaches cross-cultural encounters that involve an element of linguistic mediation as a space of radical inequality. Translators and interpreters mediating these encounters play a major role in asserting, questioning and sometimes forcefully resisting existing power structures. Viewed from this perspective, translation does not resolve conflict and inequality by enabling dialogue but rather constitutes a space of tension and power struggle in its own right.

(Baker and Pérez González 2011: 44) 
In interlingual lexicography then, the already powerful role of the lexicographer in monolingual lexicography is augmented by assuming the influential role of translator as well.

In the case of interlingual dictionaries, it is also considered good practice to rely on previous work, which has the same ossifying effect as in intralingual dictionaries. Mary Snell-Hornby acknowledges the tradition-boundedness of bilingual dictionaries as a problem in an article entitled "The Bilingual Dictionary: A Victim of its Tradition?"

Maybe that is the reason why this is an area of knowledge not only bound by tradition, but often even paralyzed by unquestioned fixed ideas and prejudices. One such fixed idea is epitomized in that naive question "What's $\mathrm{x}$ in English?," suggesting that a word "is" another word in the foreign language. This is the principle of elementary approximation underlying the vocabulary lists generations of schoolchildren are compelled to learn by heart, and it is unfortunately consolidated in the traditional small size dictionaries such learners buy, use and stick to, perpetuating a practice that has in essence progressed no further than the ancient bilingual word lists on the clay tablets of Old Babylonia.

(Snell-Hornby 1986: 207)

Snell-Hornby criticizes the practice of interlingual lexicography in which words and concepts from different languages and cultures are unified and assimilated, thus neglecting and disregarding their respective particularities and differences:

It does indeed seem that bilingual lexicography has been manoeuvred into a stereotyped pattern of 'translation equivalents,' a principle which [...] lexicographers have followed since time immemorial, but which clashes with the notion that cultures and concepts must be viewed in their own terms, demanding a heuristic method of discovery procedures.

(Snell-Hornby 1986: 216)

This unifying and assimilating approach to different linguistic and cultural systems in interlingual lexicography reflects and reinforces the power imbalance between dominating and dominated languages, just as translations contribute to shaping the relationship between minority and majority groups in society.

For these reasons, Cronin stresses "the urgency of exploring the effects of translation on minority languages" and distinguishes between "translation-asassimilation," i.e. translations that try to erase the minority language, and "translation-as-diversification," i.e. translations that try to preserve the minority language (1998: 148).

The imbalances in power are typically reflected and reinforced in interlingual dictionaries, where often one language dominates over the other, which is typically linked to the purpose of the dictionary. According to the 
user perspective of the dictionary, we can distinguish between active and passive dictionaries, i.e., those "designed to help with encoding tasks, such as the production of a text" (Hartmann 1998: 3), and those designed "to help with decoding tasks, such as the comprehension of a text" (1998: 106). Thus, in interlingual lexicography, the lexicographers decide which words from a language Lx they consider appropriate and important enough to be included in the dictionary and then search for suitable translations of this lemma in the language Ly. In this case, Lx dominates over Ly, as culturally and linguistically specific terms of language Lx are included in the dictionary and then words and phrases from the language Ly are searched for or created and established as equivalents for the Lx term.

Dictionaries designed with the specific purpose of fulfilling both aims are termed bidirectional dictionaries. In such dictionaries, "the translation equivalents can be accessed equally from each of the two languages" (Hartmann 1998: 13), but such dictionaries are rare for, as Hartmann comments: "two-way directionality is difficult to achieve in practice, especially when the languages and cultures in question are very different and the purposes for which the users look up words (reading or writing) diverge" (1998: 13-14) Moreover, even in bidirectional dictionaries there is the risk that $\mathrm{Lx}$ will dominate over Ly, leading to an imbalance between the two parts of the dictionary. This occurs when a term in Lx with no direct equivalent in Ly finds its way into the first part with the language direction Lx to Ly, but as no direct translation equivalent is offered, it cannot be inserted into the second part with the language direction Ly to Lx. In such cases, bidirectional dictionaries, too, reflect and reinforce imbalances in power, as they do not succeed in achieving total reversibility.

So the powerful processes of determining and fixing the meaning of a word are present and identical in both mono- and interlingual dictionary making. The two lexicographical fields, however follow different paths in how they formulate the defined meanings. While monolingual dictionaries offer definitions and synonyms, interlingual dictionaries provide "interlingual synonyms," i.e., translation equivalents. As outlined earlier, in interlingual dictionaries, the lexicographer has the specific task "to provide equivalents for all senses of all headwords, such that each equivalent is identical in meaning to the sense it has been matched with" (Adamska-Sałaciak 2013: 222). In many cases, this rather simple sounding task turns out to be extremely difficult and sometimes impossible as languages and cultures are asymmetrical. As Hartmann comments,

Because of linguistic and cultural anisomorphism, translation equivalents are typically partial, approximative, non-literal and asymmetrical (rather than full, direct, word for-word and bidirectional). Their specification in the BILINGUAL DICTIONARY is therefore fraught with difficulties, and recourse must be had to surrogate EXPLANATORY EQUIVALENTS.

(Hartmann 1998: 51) 


\section{Eva Nossem}

As the perfect translation equivalent hardly ever exists (Bassnett 2014: 33-40), the lexicographer has to find solutions for partial or even zero equivalents, and thus applies different strategies ranging from direct borrowing, new coinage, loan translation and calques to paraphrasing and descriptions in a gloss. Here decisions must be made as to which meaning aspects of the lemma in Lx are to be conveyed and transferred to Ly, and which will be ignored and therefore lost in the transfer. Piotrowski, who confirms that partial equivalence "is said to be the most frequent type of equivalence," draws a link to the decisions made by the lexicographer: "It has to be noted only that the degree of the overlap of semantic features can be manipulated by the lexicographer, who can make the identity of meaning greater or smaller, depending on how many dimensions of meaning he or she will consider relevant" (Piotrowski 1994: 184).

As the processes of meaning determination are identical in mono- and interlingual dictionary making, both suffer from a comparable susceptibility to fallacies or shortcomings, or, interpreted from another perspective, both involve a certain degree of flexibility in lexicographic decisions.

An example for a problematic partial equivalence can be found in the entry for "gay" in the English-German Cambridge Dictionary online: ${ }^{2}$ By putting the English "gay" and the German "schwul" on a level of equivalence, only a part of the meaning potential of the English "gay" is mapped in the German "schwul," as the "schwul" in German is limited to masculine gender and thus only refers to gay men or male homosexuality, while the English "gay" can also include lesbian women and female homosexuality.

A very distorted perspective is shown in the Langenscheid online English-German dictionary. For the English entry "queer," a series of possible translation equivalents are offered. ${ }^{3}$ Most of them focus on older meanings of "queer" in the English language, such as strange, dubious, and ill. Even the very rare meaning of queer as drunk is taken into account. Also "schwul" (male homosexual adj.) is offered as a translation equivalent, thus transferring only a very limited meaning aspect into the German language. Furthermore, connotational information on this specific meaning of "queer" is provided as it is marked as slang. This meaning supposedly derives from the English "queer" used as a slur to refer to homosexual men. The German "schwul," though, today is no longer used exclusively with negative connotations, as the English slur could suggest, but also as a neutral and positive (self-)identifier. The newer meaning potential the English queer has acquired over the last 30 to 40 years as a positive, empowering self-identifier seems to be either ignored or limited to homosexual men, who only represent a small subgroup of people who use "queer" as a self-identifier in English. The English "queer" as an umbrella term for and used LGBT"+ persons as well as the political "queer" as used in activism and in academia are entirely ignored, excluded. "Queer" as part of the German lexicon is not represented, even though especially in the field of activism and academia, "queer" has found entry into the German usage. 
A similar selection of the meaning potential of the English "queer" is offered in the French Larousse online. ${ }^{4}$ Here, too, translation equivalents such as "étrange" (strange), "suspect" (suspicious) and even "fausse" (counterfeit) are put forward. Described as informal and even very informal language, "queer" is translated as "timbré," "cinglé" (in the sense of "crazy") and "homosexual." In the specific latter case, two options are provided: on the one hand, the usage of queer as a slur for homosexual men, translated into French as "pédé" and marked as pejorative, and, on the other, "queer" as a positive self-identifier translated into French as "gay" or "gai," with the additional information "as used by homosexuals—culture, activism, politics."

The example of the English-French dictionary Larousse provides translation equivalents that cover more meaning aspects than the example from the English-German Langenscheid dictionary. Nevertheless, the translation equivalents of the English-French dictionary also show deficits in their meaning potentials and completely ignore "queer" as a loanword in French.

Problems arise when determining what specific meaning is considered worth being admitted into a dictionary, and what other meanings should be excluded. A clear example is when an old, even outdated meaning of an English entry is accepted into the lemmary, while a newer, more current meaning is excluded, as with the entry for "coming out" in the English-French online dictionary Larousse, where the gloss "entrée dans le monde" ['to enter the world or society'] is provided as the only French translation equivalent for the English "coming out," 5 while today's much more common meaning and use would correspond to something like "faire son coming out" (loanword), or "sortir du placard" (calque).

In addition to meaning-related difficulties and fallacies, the process of lemmatization presents difficulties in interlingual lexicography. As outlined earlier, establishing translation equivalents in interlingual lexicography is a task that inevitably produces imbalances between translation and original and, due to its transformative potential regarding both the source and the target languages, represents translation as a queer praxis.

Genderization, in particular, poses challenges to finding or creating translation equivalents between gendered and non-gendered languages, i.e., languages with and without morphologically marked grammatical gender. An example illustrating this problem can again be found in the English-French Larousse, where the English adjective "lesbian" is translated as "lesbien," i.e., the grammatically masculine gendered form. Exactly the same problem, the masculine gendering of the translation equivalent of the grammatically gender-neutral German "lesbisch," can be found in the Langenscheid German-Spanish ("lesbiano") 7 and the Langenscheid German-French ("lesbien"). ${ }^{8}$ The Langenscheid German-Italian online dictionary, in contrast, inserts only the form "lesbica," ${ }^{9}$ which is grammatically marked as female, thus contradicting its general norm to only list the masculine form for gender-variable adjectives. 


\section{Eva Nossem}

The English-German Langenscheid dictionary does not show the problem of genderization in lemmatization, as the translation "lesbisch" is given in the ungendered, unmarked form. ${ }^{10}$ The entry for the English adjective "lesbian," however, presents other problems, listing "erotisch, schwül" (erotic, sultry) as translation equivalents for a specific meaning of "Lesbian," then providing the example of "Lesbian novels," translated as "erotische Romane" (erotic novels). Unfortunately, it does not provide further sources or explanations on this specific meaning of the English "Lesbian."

The frequent impossibility of formulating lemmas in a gender-free way in languages with grammatical gender, or the difficulties in expressing gendered forms in non-gendered languages create a ground for inevitable imbalances between original and translation equivalents. Genderization in lexicography and especially in interlingual lexicography related to the search for translation equivalents is a complex topic with a broad range of issues that need to be taken into account and deserve an in-depth analysis that cannot be provided within the scope of this chapter. Both the examples taken from monolingual as well as those from interlingual dictionaries provide only a glimpse of the kinds of problems that can arise in the compilation of dictionaries. Examining these weaknesses exposes the lexicographical power and the influential role of the lexicographer as the meaning-maker.

\section{Conclusion}

As we have seen, a dictionary is not an objective source of knowledge but rather the product of a series of biased decisions by the lexicographers. Those decisions, however, are not made in a void but are subject to a broad range of external influences, ranging from precise, explicit norms, such as grammar rules, to more general, implicit, and even unconscious socio-cultural norms related to heteronormativity. Both in mono- and interlingual dictionaries, the lexicographers determine meanings, set them in relation, and recommend or exclude words and phrases from use, either by eliminating them from the lemmary or by assigning them connotational markers that discourage their usage in many communicative circumstances. Interlingual dictionaries suffer from the urge to produce translation equivalents. Even though full equivalence is impossible in the majority of cases, lexicographers often tend to suggest "synonymical" translations, even if only partially reflecting the meaning, running the risk that these will be perceived as full equivalents (which they often are by students of the language).

That being said, the lexicographer can still exercise a certain degree of agency. This agency can be found at various levels of dictionary making, thus influencing the final outcome, the dictionary itself. A diachronic analysis, for example, can challenge the naturalness of the dominant discourse by showing how meaning definitions change over time. Because the activity of dictionary making is not innocent, there is a need for greater 
awareness on the part of translators and users in general of the effects of the lexicographer's decision making. The lexicographer is not less a "harmless drudge" but a powerful (re-)producer of linguistic, cultural, and social power structures.

Queer(ing) lexicography contributes to detecting structures of power and of heteronormative discourses in order to make them visible and raise awareness of their existence, a necessary first step in challenging them. The fact that the dictionary represents such a highly influential work with the power to reinforce and strengthen heteronormative discourses, but also to weaken and dismantle them makes this an especially urgent task.

\section{Notes}

1 For examples for fallacies of definition, see Nossem (2015: 121-122).

2 http://dictionary.cambridge.org/dictionary/english-german/gay.

$3 \mathrm{http}: / /$ de.langenscheidt.com/deutsch-englisch/search?term=queer \&q_ cat $=\% 2 \mathrm{~F} \% 2 \mathrm{~F}$.

4 www.larousse.fr/dictionnaires/anglais-francais/queer/605401.

5 www.larousse.fr/dictionnaires/anglais-francais/coming_out/571267.

6 www.larousse.fr/dictionnaires/anglais-francais/lesbian/591948.

7 http://de.langenscheidt.com/deutsch-spanisch/lesbisch?term=lesbisch\&q_ cat $=\% 2$ Fdeutsch-spanisch $\% 2 \mathrm{~F}$.

8 http://de.langenscheidt.com/deutsch-franzoesisch/lesbisch.

9 http://de.langenscheidt.com/deutsch-italienisch/lesbisch.

10 http://de.langenscheidt.com/englisch-deutsch/lesbian.

\section{References}

\section{Primary Sources}

“Cambridge Dictionary English-German: 'Gay." Available online at http://dictionary.cambridge.org/dictionary/english-german/gay (last accessed November 30, 2016).

"Larousse Dictionary English-French: 'coming out." Available online at www. larousse.fr/dictionnaires/anglais-francais/coming_out/571267 (last accessed November 30, 2016).

"Larousse Dictionary English-French: 'lesbian.' ” Available online at www.larousse.fr/ dictionnaires/anglais-francais/lesbian/591948 (last accessed November 30, 2016).

"Larousse Dictionary English-French: 'queer.'” Available online at www.larousse.fr/ dictionnaires/anglais-francais/queer/605401 (last accessed November 30, 2016).

"Langenscheidt Dictionary English-German: 'lesbisch.'" Available online at http:// de.langenscheidt.com/englisch-deutsch/lesbian (last accessed November 30, 2016).

"Langenscheidt Dictionary English-German: 'queer.'” Available online at http:// de.langenscheidt.com/deutsch-englisch/search?term $=$ queer $\& \mathrm{q} \_$cat $=\% 2 \mathrm{~F} \% 2 \mathrm{~F}$ (last accessed November 30, 2016).

"Langenscheidt Dictionary German-French: 'lesbisch.'” Available online at http:// de.langenscheidt.com/deutsch-franzoesisch/lesbisch (last accessed November 30, 2016). 


\section{Eva Nossem}

"Langenscheidt Dictionary German-Italian: 'lesbisch." "Available online at http:// de.langenscheidt.com/deutsch-italienisch/lesbisch (last accessed November 30, 2016).

"Langenscheidt Dictionary German-Spanish: 'lesbisch.' " Available online at http://de. langenscheidt.com/deutsch-spanisch/lesbisch?term=lesbisch\&q_cat $=\% 2$ Fdeutsch-spanisch\%2F (last accessed November 30, 2016).

\section{Secondary Sources}

Adamska-Sałaciak, Arleta. 2013. "Issues in Compiling Bilingual Dictionaries." In The Bloomsbury Companion to Lexicography, edited by Howard Jackson, 213-230. London: Bloomsbury Academic.

Atkins, B.T. Sue and Michael Rundell. 2008. The Oxford Guide to Practical Lexicography. Oxford: Oxford University Press.

Baker, Mona and Luis Pérez-González. 2011. "Translation and Interpreting." In The Routledge Handbook of Applied Linguistics, edited by James Simpson, 39-52. New York: Routledge.

Bassnett, Susan. 2014. Translation Studies, 4th edition. New York: Routledge.

Benjamin, Walter. 1996. Selected Writings Volume I 1913-1926. Edited by Marcus Bullock and Michael W. Jennings. Cambridge, MA and London: The Belknap Press of Harvard University Press.

Berlant, Lauren and Michael Warner. 1998. "Sex in Public." Critical Inquiry 24: 547-560.

Cameron, Deborah and Don Kulick. 2003. Language and Sexuality. Cambridge: Cambridge University Press.

Casanova, Pascale. 2010. "Consecration and Accumulation of Literary Capital: Translation as Unequal Exchange," translated by Siobhan Brownlie. In Critical Readings in Translation Studies, edited by Mona Baker, 285-303. Abingdon and New York: Routledge.

Cowie, Anthony Paul. 2009. Oxford History of English Lexicography. Oxford: Oxford University Press.

Cronin, Michael. 1998. "The Cracked Looking Glass of Servants: Translation and Minority Languages in a Global Age." The Translator 4(2): 145-162.

Duval, Alain. 2008. "Equivalence in Bilingual Dictionaries." In Practical Lexicography: A Reader, edited by Thierry Fontenelle, 273-282. Oxford: Oxford University Press.

Fellner, Astrid. 2008. "Review of a Canon of Our Own? Kanonkritik und Kanonbildung in den Gender Studies [A Canon of Our Own? Canon Criticism and Canon Building in Gender Studies], edited by Marlen Bidwell-Steiner and Karin S. Wozonig." In Aspasia 2008: International Yearbook of Central, Eastern, and Southeastern European Women's and Gender History, edited by Francisca De Haan, Maria Bucur and Krassimira Daskalova, 224-227. Oxford: Berghahn Books.

Fontenelle, Thierry. 2008. "Introduction." In Practical Lexicography: A Reader, edited by Thierry Fontenelle, 1-15. Oxford: Oxford University Press.

Fontenelle, Thierry. 2011. "Lexicography." In The Routledge Handbook of Applied Linguistics, edited by James Simpson, 53-66. New York: Routledge.

Foucault, Michel. 1977. Language, Counter-Memory, Practice: Selected Essays and Interviews. Edited by Donald F. Bouchard. Ithaca: Cornell University Press. 
Foucault, Michel. 1998. Aesthetics, Method, and Epistemology. Edited by James D. Fauban. New York: The New Press.

Halperin, David M. 1995. Saint Foucault: Towards a Gay Hagiography. New York: Oxford University Press.

Haraway, Donna. 1988. "Situated Knowledges: The Science Question in Feminism and the Privilege of Partial Perspective." Feminist Studies 14(3): 575-599.

Hartmann, Reinhard Rudolf Karl. 2007. Interlingual Lexicography. Tübingen: Niemeyer.

Hartmann, Reinhard Rudolf Karl and Gregory James. 1998. Dictionary of Lexicography. London: Routledge.

Johnson, Samuel. 1755. Dictionary of the English Language. London: J. \& P. Knapton.

Kilgariff, Adam. 1997. "I Don't Believe in Word Senses" Computers and the Humanities 31(2): 91-113. Available online at www.jstor.org/stable/30204773; 25/11/2016 (last accessed November 30, 2016).

Nossem, Eva. 2015. "Potere e autorità nei dizionari." gender-sexuality-italy g/s/i 2. Available online at www.gendersexualityitaly.com/potere-e-autorita/ (last accessed November 30, 2016).

Piotrowski, Tadeusz. 1994. "Problems in Bilingual Lexicography." Acta Universitatis Wratislaviensis. 1694 Wydawn, Uniwersytetu Wrocławskiego. Available online at http://citeseerx.ist.psu.edu/viewdoc/download?doi=10.1.1.122.3744\&rep=rep 1\&type $=$ pdf (last accessed November 30, 2016).

Snell-Hornby, Mary. 1986. "The Bilingual Dictionary-Victim of Its Own Tradition?" In The History of Lexicography, edited by R.R.K. Hartmann, 207-218. Amsterdam: Benjamins.

Spurlin, William J. 2014. "The Gender and Queer Politics of Translation: New Approaches." Comparative Literature Studies 51(2): 201-214. Available online at www.jstor.org/stable/10.5325 (last accessed November 30, 2016).

Tymoczko, Maria and Edwin Gentzler (eds). 2002. Translation and Power. Amherst, MA: University of Massachusetts Press. 


\title{
13 Queer Translation as Performative and Affective Un-doing
}

\author{
Translating Butler's Undoing \\ Gender into Italian
}

\author{
Michela Baldo
}

This contribution aims to theorize the interconnections between queer theory and translation by focusing on the discourses surrounding the recent translation into Italian of Judith Butler's Undoing Gender (2004c) by Federico Zappino with the title Fare e disfare il genere (2014) [Doing and Undoing Gender].

Fare e disfare il genere is the retranslation of a previous translation into Italian of the same work by Butler, La disfatta del genere (2006), [Gender's Defeat] whose title suggested a hypothetical "defeat" (disfatta) instead of the concept of renegotiation, of a "doing" (fare) and "undoing" (disfare), which the retranslation aims to foreground. Thinking about gender as undoing offers useful theoretical insights for translation studies, as it brings to the fore the still under-researched concepts of performativity and affect, which play a fundamental role in many translation processes. The insistence on affect and relationality is also found in many reviews of Fare e disfare il genere, often written by activists who participated in the debates taking place in various venues during the book presentations. ${ }^{1}$ The article will explore how these concepts can help to conceptualize "queer" translation and to highlight the productivity of associating the term "queer" with the notion of translation. ${ }^{2}$

\section{Doing and Undoing Gender}

Fare e disfare il genere is not the first retranslation of Butler's work in Italian. In 2013, Zappino retranslated for publisher Mimesis The Psychic Life of Power: Theories in Subjection (1997) as La vita psichica del potere. Teorie del soggetto [The Psychic Life of Power. Theories of the Subject] (Butler 2013a), previously translated for Meltemi in 2005 as La vita psichica del potere. Teorie della soggettivazione e dell'assoggettamento [The Psychic Life of Power. Theories of the Subject and of Subjection]. In that same year, Olivia Guaraldo retranslated for Postmedia books Precarious Life: The Powers of Mourning and Violence (2004a), as Vite precarie. I poteri del lutto e della violenza [Precarious lives. The powers of mourning and violence] (Butler 2013c), previously translated for Meltemi in 2004 with the 
title Vite Precarie. Contro l'uso della violenza in risposta al lutto collettivo [Precarious Lives. Against the Use of Violence as an Answer to Collective Mourning] (Butler 2004d). Finally, again in 2013, Sergia Adamo retranslated for Laterza Gender Trouble: Feminism and the Subversion of Identity (1990), with the title Questione di genere. Il femminismo e la sovversione dell'identità [The Issue of Gender. Feminism and the Subversion of Identity], which was previously translated in 2004 as Scambi di genere. Identità, sesso e desiderio [Gender Swaps. Identity, Sex and Desire] (Butler 2004b), by Roberta Zuppet for publisher Sansoni.

If the translations of Butler's works, which have increased in recent years, show renewed interest in her theories, the retranslations are a curious phenomenon, given the presence of so many of them in such a short time span. A simple reason for this can be found, at least in the case of Fare e disfare il genere, La vita psichica del potere and Vite precarie, in the fact that Meltemi, the publishing house which had published these first translations of Butler, had ceased its activities in 2010 and the publishing houses Mimesis and Postmedia books, after acquiring its inventory, wanted to republish and rebrand some of Meltemi's previous publications. Similarly, in the case of Scambi di genere. Identità, sesso e desiderio (2004b), Laterza wanted to make available again a seminal book by Butler, which had been out of print with publisher Sansoni.

The choice of Butler was dictated by the fact that she had regained popularity in the preceding years judging from the number of translations, a total of four, published between the years 2009 and 2012. If this popularity might have been linked to the fact that she was awarded the prestigious Adorno prize in 2012, it is also partially due, as this chapter will demonstrate, to the increased circulation of queer theory in Italy in the same or preceding years, thanks to various Italian collectives and groups. These are, to name a few, Laboratorio Smaschieramenti (URL) from Bologna, which, since 2007, has been doing critical work on masculinity through the lens of queer theory, and a collection like altera, born in 2010 within the publishing house ETS and directed by Italian queer theorists Marco Pustianaz and Liana Borghi.

Another reason for the retranslations of Butler's works might be ascribed to the intensification of public discourses around the so-called teoria del gender [gender theory] in Italy in the last 10-15 years. "teoria del gender" is a label coined by the Church in the year 2000, and has been used by Catholic and other groups (which I will label in this chapter as anti-gender movements) to delegitimize research done in gender studies, and to oppose the denaturalization of gender and sexuality categories undertaken within them (Garbagnoli 2014), especially in Butler's theorizations, as this research was perceived as seriously threatening the symbolic heteronormative order of society based on hierarchical gender binarism (male versus female).

If Butler's retranslations came about due to the ripe conditions for the circulation of work on queer theory, and from the attempt to make the work of an already popular philosopher available again under a new publisher's name, this re-branding also underscores the need for retelling, expanding, 
and redefining aspects of her theories in view of current public debates. This is the case, for example, with Sergia Adamo's retranslation of Gender Trouble in which the publisher ${ }^{4}$ replaces scambi, or "swaps," "exchanges" in the title with questione, or "issue," "question" to better illustrate the troubling aspect of questioning (the disturbance, the confusion as stated in the translator's preface) (see SIL 2013) given the paradigms of gender and sexuality discussed in Butler's work; this is also the case with Guaraldo's ${ }^{5}$ retranslation of Vite precarie, in which phrases like "to be beside oneself" were retranslated as "essere fuori di sè, essere fuori di se stessi" [to be outside oneself] (Butler 2013c: 49) as opposed to the previous "essere al fianco di se stessi" [to be at the side of oneself] (Butler 2004a: 44-46).

This retelling is not only present in the retranslation of Undoing Gender (as will become evident later in this chapter), but it is also confirmed by the paratextual material accompanying it, such as the afterword written by Zappino. Also La vita psichica del potere. Teorie del soggetto (2013a), mentioned earlier, included additional paratextual material, such as the translation of a dialogue between Butler and Adam Philips, as well as an afterword in the form of a dialogue between Zappino and Lorenzo Bernini. This afterword represented an occasion for the two philosophers to depart from Butler in order to discuss antisocial queer theories, taking as their inspiration Bernini's book Apocalissi Queer [Queer Apocalypses](2013), which came out soon after the publication of the translation. I would like, therefore, to take this need for retelling as my point of departure in discussing Zappino's Fare e disfare il genere (2014).

As stated by Butler, the book revolves around not only what it means "to undo restrictively normative conceptions of sexual and gendered life" but also "the experience of becoming undone" (2004c: 1) - that is, to be "undone by grief, gender, desire, and the Other," as pointed out by some reviewers (Schoch Zavaletta 2005: 152). The movement of undoing, however, presupposes a doing, an activity performed as a sort of "improvisation within a scene of constraint" (Butler 2004c: 1), which Butler had widely discussed in Gender Trouble as part of the broader concept of gender performativity.

In retranslating Undoing Gender, therefore, it seems more appropriate to use two terms like fare e disfare (doing and undoing) to translate "undoing," a choice which was agreed upon by Zappino in consultation with Butler, rather than disfatta [the act of being undone, defeat], chosen in the previous Italian translation. Although hinting at the action of "gender becoming undone" as a transformative moment in time leading to new beginnings, as stated by the translator Olivia Guaraldo ${ }^{6}(2014)$ in the preface to her translation, disfatta also recalls, according to Zappino, ${ }^{7}$ the idea of the defeat and themes associated with it, like death, killing, and ending, rather than the concept of renegotiation and fluidity invoked by the movement between doing and undoing. Because of this ambiguity, Zappino felt the need for a new translation of the title and an undoing and redoing of 
some passages of the previous translation. ${ }^{8}$ Zappino claimed that he revised them by stressing more the concept of doing and undoing present in the title, referring, for example, to the condition of being undone in the experience of falling in love.

In Brescia, Italy, in March 2015, at one of many book presentations, Zappino (2015) said that in Undoing Gender, Butler tries to undo (as she will keep doing on various occasions after that) the "illusions" and misinterpretations that her theories had produced at a discursive level in the years following the publication of her first works, Gender Trouble (1990) and Bodies That Matter (1993).9 Already in 1993, with Bodies That Matter, Butler tried to clarify that gender performativity did not refer to one's choice of performing gender as one's likes, but rather to mimicking or imitating the dominant conventions of gender imposed by the heteropatriarchal system in which one lives. Moreover, she stressed the materiality of the body, which, according to her critics, appeared to have been previously dismissed. However, Butler, who had already emphasized the power of discourse in forming the matter of bodies, sex, sexuality, and gender (therefore pointing to the importance of said materiality), replies in the second half of Undoing Gender to those who had critiqued her theory as apolitical voluntarism, saying that her approach to the subject had surely been political because she had moved in the direction of unsettling socially constructed heteronormative conceptions of gender and sexuality in line with feminist political calls for social transformation..$^{10}$ In this book, Butler is indeed especially interested in looking at the new gender politics that have emerged in recent years, that is, "the combination of movements concerned with transgender, transsexuality, intersex, and their complex relation to feminist and queer theory" (2004c:4).

However, the main aim of Undoing Gender is not to undo previous misinterpretations of Butler's work but rather, as stated earlier, to undo-or to talk about how to undo-restrictive social norms regarding gender and sexuality. Zappino, at the aforementioned book presentation, defines the concept of undoing as being both negative and positive. The negative part refers to the feeling by queer subjects of being "undone" by their non-conforming to dominant gender and sexuality norms, of not being fully recognizable given that "the terms by which they are recognized make their life unliveable" (Butler 2004c: 3). The positive part, however, refers to the possibilities opened up by this undoing. Gender is never something that we do alone. As Butler states, "one is always doing with or for another, even if the other is always imaginary [...] But the terms that make up one's own gender are from the start outside oneself, beyond oneself, in a sociality that has no single author" (2004c: 1). She continues, "One is dependant on the outside to lay claim to what is one's own. The self must be dispossessed in sociality in order to take possession of itself" (2004c: 7).

Since gender is something we do with other people, it follows that it can't be possessed but rather it possesses or dis-possesses us. This condition is 


\section{2}

named by Butler as the condition of the "ec-static subject." Since we are relational subjects, we can't imagine ourselves outside a web of relations. However, these relations decenter us, they bring us outside or even beside ourselves. As stated by Butler, "we are undone by each other. And if we're not, we are missing something" (2004c: 19). Therefore, it is in this undoing, in this loss, that a possibility for transformation is found, a transformation and recreation of new parameters of intelligibility, subjectivity, and thus livability that can exceed the consolidated ones.

Thinking about gender as something we $d o$ and undo together with others provides interesting insights for a discussion of the translation of Butler's Undoing Gender, but also for translation in general—on the one hand, because it makes us think of translation as constant circular movements of "to and fro," and on the other, because it invokes the idea that translation is a dialogic activity. These concepts will be discussed more thoroughly in the subsequent sections.

\section{Translation, Performance, and Performativity}

Since the cultural turn in the 1990s and the more recent sociological turn in the discipline (Angelelli 2012), the last two decades of translation studies have conceptualized translation as a creative activity (Bassnett and Lefevere 1990; Bassnett and Bush 2006) and as a political and transformative one (Tymoczko 2007, 2010; Baker 2006, 2013).

Considering translation as a creative activity connects us to the idea of authorship discussed by Butler in relation to gender, which is constituted in "a sociality that has no single author" (Butler 2004c: 1). The notion of authorship is thus challenged and scattered. This can be easily applied to translation. Translation is no longer seen in traditional terms as a reproductive and derivative activity, a copy (often bad) of an "original" or "authorial" discourse transported from one language to another, but as a creative operation, authorial in its own terms. Drawing again on Butler's seminal work on gender performativity (1990), we can say that translation is a copy of an original that does not exist, and thus originality and authorship become illusions.

This reformulated idea of authorship is linked to the concept of performativity theorized by Butler, who draws on speech acts theory by J.L. Austin and Jacques Derrida's notion of "iterability," and which has been investigated by such scholars of translation studies as Keith Harvey, Luise von Flotow, Douglas Robinson, and Sandra Bermann. Their interest in performativity follows a growing interest in a concept that has been mainly associated with theater translation, to the point that scholars of theater translation, such as Silvia Bigliazzi et al. (2013), refer to a "performative turn" in translation studies. For example, Harvey states that "the notion of performativity seems to have led translation researchers to focus largely on the role played by theatricality and linguistic markers in dialogue that signify gayness" (Harvey 1998: 305). Butler (1990) had indeed paralleled the 
notion of gender performance with "the performance, by different actors, of the same (predictable, conventional, prescribed, rarely radical) script" (von Flotow 2012: 132).

However, performativity exceeds the boundaries of the theatrical field. Robinson (2003), also drawing on Derrida's idea of iterability and Austin's (1962) speech acts theory, sees translation as a series of re-performed acts (spoken or written), which change by virtue of their reiteration in new contexts. Translation can never be a reproduction of past speech acts but is rather a reinvention of them. Both Robinson and Bermann see the performative aspect of translation lying in the fact that, as a speech act, translation does or produces something. For Robinson (2003), translation does something to its audience. Bermann (2014), in the same vein, states that translation is the product of a set of repeated acts in the same way the gendered subject is, given that gender, according to Butler, "is not what one is but rather what one does" (Bermann 2014: 290). However, if performativity is a matter of doing, and we are bound to perform the roles assigned to us by the normative system, "there is also a possibility of resistance and displacement," as "there are gaps, slippages, openings that might be used to question and disrupt this gender-binding repetition" (Bermann 2014: 291). Bermann, drawing on Butler but also on Derrida's notion of iterability, states that the performative has to do with the creation of something new, that is, the notion of creativity mentioned earlier. This is possible since the notion of iterability implies that language is citational, a repetition of something else. This repetition undermines the authors' intentions as it inserts something else into those intentions, a sort of "dehiscence" or "cleft" (Derrida 1985: 18 ) into the subject's intended meaning. If we apply this to translation, we can see both its non-derivative status in relation to an original, which is already a citation of something else, but also its inaugural status in "the making of something new" (Bermann 2014: 289).

Translation is thus performative as it is a doing, but, by virtue of its iterability, it becomes a constant doing and undoing. This back and forth movement is what makes transformation possible, as translation-by infusing target language with otherness-disrupts both the source and the target language. Butler herself talks about this transformative and translational process in Undoing Gender by making specific reference to cultural translation. She states that cultural translation does not mean assimilating into our own foreign and unfamiliar notions (in the specific case categories such as being human, being gendered, and being sexualized) but rather "yielding our most fundamental categories, that is, seeing how and why they break up" (Butler 2004c: 38). And again, cultural translation is not about "translation between two languages that stay enclosed, distinct, unified. But rather, translation will compel each language to change in order to apprehend the other" (Butler 2004c: 38). Translation is, in this sense, a dialogic activity that cannot avoid some sort of fictional or factual relationship with an "other" (be it a source text, a source image, etc.). 
But what exactly do we mean by the other or by otherness? As Bermann states, Butler explains this in the opening chapter of her book Parting Ways: Jewishness and the Critique of Zionism (2012). Here, according to Bermann, translation "acts as a model for political and ethical relationality" (2014: 294), an allegory for the way in which hegemonic cultures can be transformed, undone, by the encounter with otherness. Translation implies an ethical stance, as the encounter with otherness "interrupts our sense of selfhood and expands our capacity to imagine the human" (Bermann 2014: 295). In a talk on translation given by Butler (2016) at California College of the Arts, she argues that translation is not only about realizing the contingency of the language we speak but also the possibility of seeing ourselves faltering in another language. ${ }^{11}$ Translation is thus a transformative activity as it positions itself in a critical relation to power and plays a primary role in processes of social transformation.

\section{Authorship, Performativity, and Affect in Fare e disfare il genere}

In light of what has been discussed in the previous section regarding the scholarly field of translation studies, and given the dyadic relationship between a text and its translation, originality and authorship must be acknowledged within the act of translation itself, and the source text must be acknowledged as to some degree derivative. The traditional view of originality can, therefore, be understood as a fictional idea, generated from the fact that the target text usually follows the source text in time. However, as Benjamin (1996: 254) argues, originality requires translation for its existence, as translation gives the original continued life, "by virtue of the original's translatability." According to Benjamin (1996: 257), "in translation the original rises into a higher and purer linguistic air." The original, in this sense, thus follows rather than precedes translation as it is a concept stemming from translatability. Conferring some of the characteristics of authorship onto translation makes translation a point of departure, and a generative one at that.

Translation creates new authorships as translated books are often presented and performed at events by translators and by whoever else enters those spaces. As Zappino said in an interview, ${ }^{12}$ his translation of Eve Kosofky Sedgwick's Epistemology of the Closet under the title Stanze private. Epistemologia e politica della sessualità (2011), [Private rooms. Epistemology and politics of sexuality], the first translation into Italian of this foundation text of queer theory, invited him to give voice to Sedgwick (and thus impersonate her) at the various presentations of the book in Italy at the time following the publication. ${ }^{13}$

Zappino's presentations of his translation of Sedgwick in 2011 has thus contributed to intensify the debate on queer themes in Italy, along with other events and books, such as the publication in the same year of Queer 
in Italia by Marco Pustianaz, a collection of 25 interviews with Italian queer academics and activists. As a confirmation of this, at the end of 2011, a conference on queer topics took place in Padua, with the title: "Inquietudini Queer" [Queer anxieties]. The call for papers mentions the recent Italian translation of Sedgwick's work as a point of departure for a reflection on eccentricity and what exceeds the norm. Between 2011 and 2013, the "Casa Internazionale delle Donne a Roma" [The International Women's House in Rome] hosted a series of events on queer theory called "Queer it Yourself," organized by the Kespazio collective. The inaugural workshop in December 2011 was dedicated to the discussion of Zappino's translation Stanze private. This is only one example of how translations become entangled in new debates and discussions. Since 2011, interest in queer theory has gained momentum in Italy, as expressed earlier, and this is confirmed by a series of new initiatives dedicated to the topic, not only in LGBTQ spaces, such as the aforementioned collective Smaschiermenti or even the Sommovimento NazioAnale, a network of transfeminist collectives and individuals born in 2012, but also at universities, as shown, for example, by events such as the "Primavera Queer" [Queer Spring] in 2014, a week of discussions and workshops on queer themes at the University of Chieti, ${ }^{14}$ followed by a similar initiative, although shorter, in September 2015 at the University of Padova, entitled "de/Sidera." ${ }^{15}$ A panel organized for the event entitled "Fare e disfare il gender," [Doing and undoing gender] with the participation of Federico Zappino and philosopher Deborah Ardilli, clearly takes inspiration from Zappino's translation of Undoing Gender, with the Italian term "genere" being replaced by the English "gender" in order to discuss via the book the "teoria del gender," thus signaling the foreignness of non-binary/non-heteronormative gender theorizations to Italian culture.

If the presentations of Stanze private might be part of this growing interest in queer theory in Italy, given that Sedgwick is considered one of the most influential queer theorists, then certainly presentations of Fare e disfare il genere have produced similar effects on a larger scale, as they have been more numerous. The book has been presented in various LGBTQ spaces in Italy throughout $2015,{ }^{16}$ and the publicity and the open questions generated at every presentation led to additional presentations. Some of the questions that arose at the book presentations are certainly linked to the debate stirred by the Church and the anti-gender movements against the "teoria del gender." This debate, therefore, was not only involved in preparing the ground for the retranslation of Undoing Gender, as previously argued, but the retranslation, in turn, further intensified the debate. Zappino mentioned in a talk entitled "Sovversione dell'eterosessualità" (2016b $)^{17}$ [Subversion of heterosexuality] the fact that a conservative group, called Giuristi per la vita [Jurists for life], in February 2016 attacked Fare and Disfare il genere at one of their meetings as representing a serious threat to society and to the institution of the family. Moreover, Zappino and Ardilli (2015), in an article written in July 2015 entitled "La volontà di negare" [The will to 
negate], initiated a heated debate among LGBTQ individuals and groups on the type of response that would be most suitable in counteracting the discourses of anti-gender movements. ${ }^{18} \mathrm{~A}$ popular concept circulating through these discourses is "sexual difference." In this regard, an event, which Zappino attended, was organized by the Women's Library in Padova in April 2016, entitled "Fine della differenza sessuale" [The End of Sexual Difference] (Zappino 2016c), which was inspired by one chapter of Fare e disfare il genere and undertook to discuss the productivity of Butler's work for unraveling such a contentious theme.

As a consequence of the discussions generated by the translation and the networks of people (activists, writers, and translators) it created as a result, a collection of essays, written by this network of people and edited by Zappino, came out in September 2016 with the title Il genere tra neoliberismo e neofondamentalismo [Gender between Neoliberalism and Neofundamentalism]. The book, which has been presented already in various LGBTQ spaces in Italy, investigates the links between the concept of neoliberalism and neofundamentalism, the latter understood as those Catholic and non-Catholic conservative views toward gender, bodies, and sexuality, already discussed with reference to the anti-gender movements. A conference based on the topic of the edited collection and entitled Femminismi e liberismo [Feminisms and liberalism], which also saw the participation of Zappino, was held in December 2016 in Florence. Zappino has just completed the translation of one of Butler's latest books, Notes toward a Performative Theory of Assembly (2015), translated as L'Alleanza dei corpi [The coalition of bodies] (2017), which investigates some of the themes included in the edited collection and the aforementioned conference that will be analyzed further next.

This is all a testament to the performative and citational aspects of translation. Translators are social actors, in line with what theorists of the sociological turn in translation studies affirm, and translations have the capacity of producing new social networks and new queer thought, which generate, in turn, new translations, as indicated earlier.

I would define these social networks mostly as "affective networks," to borrow the words of Italian queer theorist Liana Borghi, judging from the number of intense connections, to borrow the words of Zappino, ${ }^{19}$ that Fare $e$ Disfare il genere gave rise to. Borghi has worked on the topic of affect and made it the subject of some of the summer schools she co-organized with Clotilde Barbarulli in Prato in the first decade of the year 2000, drawing on theorists like Eve Sedgwick and Sara Ahmed. For Sedgwick, affect, especially the affect of shame, which she analyzes thoroughly in her Touching Feeling. Affect, Pedagogy, Performativity (2003), ${ }^{20}$ is performative and is specifically related to notions of queer performativity. Moreover, in this book Sedgwick invokes the tactile aspect of affect as something that touches and that can be touched. The performative aspect of affect is also discussed by communication theorists such as Melissa Gregg and Gregory 
Seigworth (2010). According to them, affect is born in the "in-betweenness" of encounters, in the capacity of acting and being acted upon. Affect produces action, and its performativity lies in the fact that it puts the body into motion, into a perpetual becoming, similar to that doing and undoing movement discussed by Butler. Affects put bodies in contact with each other, and in this sense, they can be considered forces that cut across bodies. Among translation studies scholars, Douglas Robinson, Carole Maier, and Elena Basile discussed the affective engagement by translators with their translations. Robinson (1991) suggests a somatic approach to translation, which he further develops in his book Performative Linguistics (2003) mentioned earlier, arguing for the integration of the translator's experience, feelings, and intuitions in the translation process. Maier (2006) drawing from Douglas, when commenting on her translation of Amanda Labarca's "Desvelos en el alba" (1945), explains that the Labarca's work has physically affected her, it has worked its way into her flesh and blood in the same way that other translations had become integral part of her organism.

Basile (2005: 2) discusses the notion of affect when talking about the translator's affective engagement with the source text, stressing concepts such as desire and the role of the unconscious in the translator's labor. Her emphasis is on psychoanalysis, on the question of the acceptance of the otherness of the unconscious and on the driving force of desire and the unconscious, their performative role, we could add, in the production of translations. Sedgwick (2003), too, talks about drives but makes a distinction between drives and affects, detaching the latter from the instrumentality of the former (as drives need to be fulfilled), while Massumi (2002) states that affects should not be conflated with emotions, as we cannot qualify them. This stresses even more the performative aspect of affect, as in this piece I am not interested in qualifying them but in seeing how they are generated, and what they are capable of producing.

I think that affect, which has not yet been systematically theorized in translation studies, is a fundamental element for understanding the peculiarities of activist translation, especially in queer activist movements with their emphasis on the body/embodiment. Theorizing affect can, for example, shed some light on the reasons that push translators to translate with little or no remuneration. It is often because of entering into contact with each other "affectively," of acting together and gravitating toward each other that a translation project or idea takes shape. There are numerous examples of collaborative translations in queer activist spaces in Italy that confirm these assumptions. ${ }^{21}$ Affect thus produces translations at the same exact moment in which it produces movement across bodies and bodies in movement.

Given these premises, translation as an encounter between texts and bodies becomes a space of doing and undoing, that is to say a performative space, which exposes those who occupy it to constant decomposition and recomposition. Affect is thus a driving force, a performative and queering 
force, that enables the encounter with alterity, as Bermann (2014) and Basile (2005) suggest, affecting the way in which translations are produced and the effects they produce.

\section{Translation as a Precarious Space}

In this section, which takes its inspiration from the title of the afterword to the translation of Undoing Gender by Zappino, I will elaborate a bit more on alterity through the notion of precariousness, which is strictly linked to the aforementioned notions of affect and corporeality.

A retranslation of Butler such as Fare e disfare il genere is motivated by the target culture's need to retell a story in order to tackle current debates centered around the concept of gender, as seen in the previous section. These needs are propulsive forces (Massumi 2002; Gregg and Seigworth 2010) that generate, and are generated from, the encounter between activist translators and theorists, between target culture needs and ideas borrowed from the source culture. It is this friction between attachment and unattachment that makes translation possible, as the following section will make clear.

The Italian retranslation not only situates itself within the debate on "teoria del gender" but also produces other debates and writings on the notion of neoliberalism. It reveals and realizes the potentiality of Butler's work (which is not overtly expressed in the source text), as it anchors the discussion more toward the theme of neoliberal austerity and precariousness/precarity, shown by the title of the collection of essays Il genere tra neoliberismo e neofondamentalismo [Gender between Neoliberalism and Neofundamentalism] (Zappino 2016a), which as a project took its inspiration from Fare e Disfare il Genere. Olivia Fiorilli in her review of Zappino's translation says that Undoing Gender, "if conveniently betrayed, is able to speak not only to queer and transfeminist movements, but also to all social movements that fight the exploitative politics of neoliberalism" (Fiorilli 2014). ${ }^{22}$ This betrayal is the aim of Zappino's afterword. The concept of precariousness, which is mainly delineated in Precarious Life: The Powers of Mourning and Violence, is connected in Undoing Gender (2004c) to the previously expressed idea, of our inherent exposure to others, of our intrinsic vulnerability and interdependence on others.

Our life is thus a precarious life, since it is exposed to the violence, will, and arbitrariness of others. As Zappino says, "gender, by being constantly done and undone by language, relationships, norms, is the place of a permanent crisis and precariousness" (2014: 355). Economic crisis, and existential and material precarity, are therefore emphasized by the translator, as these are the major concerns that queer activist groups (but not only) are preoccupied with in Italy at present. The point made by Zappino in his afterword, and analyzed by Fiorilli and others in the many reviews of Fare e Disfare il genere available online, ${ }^{23}$ is that precariousness is not a neutral concept but is exploited by neoliberal discourse. Such discourse aims at neutralizing the 
concept of precarity by pretending it is egalitarian. According to Zappino, it is through the negation of our intrinsic interdependence on each other that "precariousness can be manipulated in different ways in the processes of production and naturalization of economic and social inequalities" (2014: 358)..$^{24}$

Why is this the case? Fiorilli (2014) states that Butler's reflection on the limits of the autonomy of the subject represents a fundamental attack against the neoliberal rationality that is based on the ontology of the sovereignity of the subject. For Butler, instead, as clarified already earlier, the subject does not even possess itself, let alone gender or sexuality. Moreover, Fiorilli (2014) links the exploitation of precariousness to the concepts of intelligibility and recognizability, discussed by Butler in Undoing Gender with reference specifically to the lives of queer, trans, and intersex people. In regulating the intelligibility and recognizability of the subjects, gender, and sexuality norms also regulate their different inclusion within the human, by promoting or negating the conditions for livability. Given that recognizability in our neoliberal economy comes mainly through labor (Fiorilli 2014), it becomes clear how the promise of recognizability given by labor based on our subjective characteristics (recognition of one's values and skills) becomes the site for the worst exploitative moves as it makes us agents actively and eagerly involved in this process.

This insistence on economic precarity and crisis, with its links to labor exploitation in Italy, constitutes a departure from Butler's text, a way of undoing its theories and transforming them, creating the conditions for the reconsideration of welfare and social justice in Italy. This is evident from the themes of the edited collection Il genere tra neoliberismo e neofondamentalismo, and of the forthcoming translation of Butler's last book, mentioned earlier. ${ }^{25}$ This is not the only betrayal. The presentations of Fare e disfare il genere often served as an occasion to discuss and undo the neofundamentalist assumptions underlying the so-called "teoria del gender". Although seemingly opposing concepts, neofundamentalism and neoliberalism are very much linked, according to Zappino (2016a: 11), by the fact that both make reference to the concept of nature in order to either naturalize differences (neoliberalism) or establish a hierarchy among them by appealing to the "naturality of sexual categories" (neofundamentalism).

I would like now to link the considerations made earlier about labor precariousness/precarity to translation as labor starting from the term used earlier-betrayal. We know that betrayal has been associated through the years with translation, most famously in the French phrase "les belles infidèles." The phrase presupposes that, if a translation is beautiful, it must be unfaithful. This metaphor recalls the genderization and sexualization of translation in heteronormative and patriarchal terms: translation is a feminine activity potentially either faithful or unfaithful with regard to a hypothetical husband/patriarch (i.e., the source text or the "original"). As stated by feminist translation theorist Lori Chamberlain (1988), this confirms 
translation's status as a secondary activity with regard to the source text (to which male characteristics of prestige and authority were attributed). The neoliberal feminization of labor, a concept discussed by Cristina Morini (2015), can be easily associated with translation labor-often misrecognized, invisible, precarious, badly paid, or volunteer-but that requires high levels of flexibility in order to meet on-the-spot requests and tight deadlines, a flexibility which is more and more considered to be a natural expression of femininity (and for this reason, tends to increase the exploitation of labor).

Fiorilli (2014) states that avoiding the trap of such recognizability is possible only if collective spaces and communities are created that make possible a material and symbolic existence challenging the norms that assign recognition and value in an unequal and discriminatory way. The translation of Zappino's Undoing Gender and all that preceded and followed it in terms of events and discussions generated in LGBTQ venues around Italy, has shown that translation is a collective matter (even more so when it is collaborative although this was not the case discussed here), and that it does not stop once the actual text is translated but continues through the voices of all the individuals that participate in the discourses opened up by the text. It shows that translation can be a propulsive force that can contribute to the creation of affective networks, which in turn produce new discourses and translations.

Theorizing translation as a precarious space of interdependence and of performative and affective undoings, especially for queer activist translators, for whom gender and sexuality are already precarious places, should also make us reflect on how to reassign symbolic and material value to such important labor.

\section{Conclusion}

This chapter has shown that the translation of Undoing Gender into Italian is an interesting case for theorizing the queering potential of translation. The chapter has drawn a comparison between undoing gender and undoing translation, focusing on the queer performative aspect of this undoing. Translations are constantly undone because of their relationship with otherness, with something outside themselves, and this undoing is affective and productive. Affectivity enters the scenario through the awareness of our capacity to be affected and put into motion by others, while productivity is revealed in the way in which translations are the outcome of networks of affect, which in their turn produce other networks. Finally, Butler's text, in order to effectively reach the Italian audience, needed to be undone. This undoing is evident in the discourses produced by the translation, centered both on the debates surrounding conservative and neofundamentalist ideas of gender and sexuality (promoted by the Church and by anti-gender movements), and mostly on the idea of precariousness and precarity, linked to the notion of neoliberalism. The notion of existential 
and material precariousness, based on Butler's notion of vulnerability, has steered Italian debates toward a consideration of welfare and social justice in the actual political climate of austerity with its damaging effects on people's lives. Like the body, translation is a vulnerable and precarious place, but it is through an awareness of this precariousness that resistance and social transformation is possible, including a transformation in the status of translation as labor.

\section{Notes}

1 See Fiorilli 2014, Lamberti and Balzano 2014, and Simone 2014.

2 A short article in Italian on this theme was published by the author of this chapter for magazine Doppiozero (Baldo 2015).

3 As affirmed by Garbagnoli (2014), "Teoria del gender" has been coined as a term at the beginning of the year 2000 by the "Pontificio Consiglio per la famiglia" (a department of the Catholic Church) with the aim of labelling, distorting and deligitimizing research produced in the field of gender studies. The Church, and many other right wing laic groups in Italy who have embraced the same ideas and are defined as the anti-gender group, claim that gender studies, or the so-called ideologia or teoria del gender pose a threat to the natural family. They oppose all those theories that challenge the naturalization of sexuality norms and the claims by feminist and LGBTQ movements.

4 Translator Sergia Adamo, in an email correspondence of January 24, 2017, told the author of this chapter that the title Questione di genere was chosen by the publisher and not be her.

5 Guaraldo discussed this with the author of this article in an email correspondence in January 2017.

6 Guaraldo told the author of this article, in a mail correspondence in January 2017, that the choice of "disfatta" for the translation was a sort of challenge, which, unfortunately, caused a lot of controversy within LGBTQ groups in Italy.

7 Zappino discussed this with the author of this article in a skype interview with him in September 2014.

8 See endnote 7.

9 For the video of the presentation see CTV Telestreet 2015.

10 On this point, see the review by Schulz 2005 and Gray 2005.

11 In 2015-2016, the California College of the Arts hosted a series of events including a lecture by Judith Butler on February 25 with the goal of questioning the notion of gender in translation. For the programme of the event, see California College of the Arts 2016; for Butler's speech see Butler 2016.

12 The interview was conducted via Skype by the author of this paper in September 2014.

13 The book was presented in June 2011 at the Sicilia Queer Festival in Palermo, at the LGBTQ Centre Maurice in Turin in October 2011, at the LGBTQ centre Ireos in Florence in November 2011, and at the LGBTQ space Cassero in Bologna in December 2011, to name a few (not counting those that took place in the following years, like a presentation that was given within a series of seminars which were called "Qui Quo Queer" organized in Bologna in March 2015).

14 For more information on the event see Chieti Today 2014.

15 The Latin term de-sidera which names the event means "far from the stars." The term desire (from the Latin desiderium) derives from this noun and implies that 
desire is a longing for something which is impossible to reach (as stars are). For more information on the event, see Bioslab 2015.

16 The book was presented at various LGBTQ venues, in cities like Bologna, Milan, Rome, Padua, Florence, Turin, Brescia and others. For the presentation in Milan see Ambrosia 2015 and for the one in Bologna see Libreria delle Donne Bologna 2015.

17 The talk was given in March 2016 in Genua in the last of a series of seminars entitled: "A proposito di gender" [With reference to Gender] organised in collaboration with the journal About Gender. The talk was published in the same year in the magazine "Effimera."

18 Due to the lack of space, the debate surrounding this theme can't be examined in depth in this chapter.

19 I refer to email correspondence of 6 May 2015 between the author of this paper, Zappino and various individuals and groups participating in the presentations of Fare e Disfare il genere.

20 Although she focuses on shame towards the end of the book, she analyses also affects such as joy, interest, and excitement.

21 For example, the queer transfeminist collective Serbilla Serpente, Lafra, Elena Zucchini, Feminoska, and Valentine Braconcini have translated the works of post-porn performer and activist Diana Torres and queer transfeminist Itziar Ziga into Italian.

22 The translation was done by the author of this chapter.

23 On this point, see Simone 2014.

24 The English translation is by the author of this chapter.

25 The new translation project further confirms the performativity of translation discussed in this article.

\section{References}

Ahmed, Sara. 2004. “Affective Economies.” Social Text 79 (2): 117-139.

Ambrosia. 2015. "Presentazione di Fare e Disfare il Genere di Judith Butler.” Available online at https://ambrosia.noblogs.org/post/2015/02/21/presentazione-difare-e-disfare-il-genere-7marzo-piano-terra-h-1930/ (last accessed January 23, 2017).

Angelelli, Claudia V. (ed.). 2012. "The Sociological Turn in Translation and Interpreting Studies." Translation and Interpreting Studies 7(2): 125-128.

Austin, John Langshaw. 1962. How to Do Things with Words, 2nd edition. Cambridge, MA: Harvard University Press.

Baker, Mona. 2006. Translation and Conflict: A Narrative Account. London and New York: Routledge.

Baker, Mona. 2013. "Translation as an Alternative Space for Political Action." Social Movement Studies 12(1): 23-47.

Baldo, Michela. 2015. "Undoing gender. Il disfarsi e rifarsi della traduzione." Available online at www.doppiozero.com/materiali/teorie/undoing-gender-e-ildisfarsi-e-ri-farsi-della-traduzione (last accessed January 27, 2017).

Basile, Elena. 2005. "Responding to the Enigmatic Address of the Other: A Psychoanalitic Approach to the Translator's Labour." New Voices in Translation Studies 1: $12-30$.

Bassnett, Susan and Peter Bush (eds.). 2006. The Translator as Writer. London and New York: Continuum.

Bassnett, Susan and André Lefevere (eds.). 1990. Translation, History and Culture. London: Pinter. 
Benjamin, Walter. 1996. “The Task of the Translator.” In Walter Benjamin: Selected Writings. Volume 1. 1913-1926, edited by Marcus Bullock and Michael W. Jennings, 253-263. Cambridge, MA and London: Harvard University Press.

Bermann, Sandra. 2014. "Performing Translation." In A Companion to Translation Studies, edited by Sandra Bermann and Catherine Porter, 285-297. Hoboken, NJ: Wiley-Blackwell.

Bernini, Lorenzo. 2013. Apocalissi Queer: Elementi di teoria antisociale. Pisa: ETS. Bigliazzi, Silvia, Peter Kofler and Paola Ambrosi. 2013. "Introduction." In Theatre Translation in Performance, edited by Silvia Bigliazzi, Peter Kofler and Paola Ambrosi, 1-26. New York and London: Routledge.

Bioslab. 2015. “de/Sidera. Festival Queer. 23-25 Settembre, Padova.” Available online at www.fuxiablock.org/desidera-festival-queer-232425-settembre-padova/ (last accessed August 1, 2016).

Butler, Judith. 1990. Gender Trouble: Feminism and the Subversion of Identity. New York: Routledge.

Butler, Judith. 1993. Bodies That Matter: On the Discursive Limits of "Sex". New York: Routledge.

Butler, Judith. 1997. The Psychic Life of Power: Theories in Subjection. Stanford, CA: Stanford University Press.

Butler, Judith. 2004a. Precarious Life: The Powers of Mourning and Violence. London and New York: Verso.

Butler, Judith. 2004b. Scambi di genere: Identità, sesso e desiderio. Translated by Roberta Zuppet. Milano: Sansoni.

Butler, Judith. 2004c. Undoing Gender. New York and London: Routledge.

Butler, Judith. 2004d. Vite precarie: Contro l'uso della violenza in risposta al lutto collettivo. Edited by Olivia Guaraldo, translated by Annarita Taronna, Laura Fantone, Fiorenzo Iuliano, Caterina Dominijanni, Fabio De Leonardis and Laura Sarnelli. Roma: Meltemi.

Butler, Judith. 2005. La vita psichica del potere: Teorie della soggettivazione e dell'assoggettamento. Translated by Elena Bonini and Carlotta Scaramuzzi. Roma: Meltemi.

Butler, Judith. 2006. La Disfatta del genere. Translated by Olivia Guaraldo. Roma: Meltemi.

Butler, Judith. 2012. Partying Ways: Jewishness and the Critique of Zionism. New York: Columbia University Press.

Butler, Judith. 2013a. La vita psichica del potere: Teorie del soggetto. Translated by Federico Zappino. Torino: Mimesis.

Butler, Judith. 2013b. Questioni di genere: ll femminismo e la sovversione dell'identità. Translated by Sergia Adamo. Roma: Laterza.

Butler, Judith. 2013c. Vite precarie: I poteri del lutto e della violenza. Translated by Olivia Guaraldo. Milano: Postmedia books.

Butler, Judith. 2014. Fare e disfare il genere. Translated by Federico Zappino. Torino: Mimesis.

Butler, Judith. 2015. Notes Toward a Performative Theory of Assembly. Cambridge, MA: Harvard University Press.

Butler, Judith. 2016. "Judith Butler Lecture: Gender in Translation." Available online at www.facebook.com/events/543796032463509 (last accessed January 23, 2017). 


\section{Michela Baldo}

Butler, Judith. 2017. L'Alleanza dei corpi. Translated by Federico Zappino. Milano: Nottetempo.

California College of the Arts. “Gender in Translation.” 2016. Available online at http:// criticaltheory.berkeley.edu/events/event/gender-in-translation/ (last accessed July 30, 2016).

Chamberlain, Lori. 1988. "Gender and the Metaphorics of Translation." Signs 13(3): 454-472.

Chieti Today. 2014. "Primavera Queer dal 5 al 9 maggio alla D’Annunzio.” Available online at www.chietitoday.it/eventi/primavera-queer-2147269.html (last accessed January 23, 2017).

CTV Telestreet. 2015. "Fare e disfare il genere, di Judith Butler." Available online at www.ctv.bs.it/2015/03/31/fare-e-disfare-il-genere-di-judith-butler/ (last accessed January 22, 2017).

Derrida, Jacques. 1985. "Des Tours de Babels.” Translated by Joseph Graham. In Difference in Translation, edited by Joseph Graham, 165-207. Ithaca, NY and London: Cornell University Press.

Fiorilli, Olivia. 2014. "Butler ai tempi dell'economia della promessa (di riconoscimento)." Available online at http://commonware.org/index.php/gallery/534-butlereconomia-promessa (last accessed August 1, 2016).

Garbagnoli, Sara. 2014. "L'invenzione della teoria del gender." About Gender 3(6): 250-263.

Gray, Erin. 2005. "Undoing Gender.” Available online at http://uppingtheanti.org/ journal/article/01-undoing-gender/ (last accessed July 30, 2016).

Gregg, Melissa and Gregory J. Seigworth (eds.). 2010. The Affect Theory Reader. Durham, NC and London: Duke University Press.

Guaraldo, Olivia. 2014. "La disfatta del Gender e la questione dell'umano.” In Fare e disfare il genere, edited by Judith Butler, translated by Federico Zappino, 9-27. Milano: Mimesis.

Harvey, Keith. 1998. "Translating Camp Talk: Gay Identities and Cultural Transfer." The Translator 4(2): 295-320.

Labarca, Amanda. 1945. Desvelos en el alba. Lima: Cruz del Sur.

Laboratorio Smaschieramenti. Available online at https://smaschieramenti.noblogs. org (last accessed January 10, 2017).

Lamberti, Raffaella e Angela Balzano. 2014. "Fare e difare i generi e le generazioni." Avaliable online at www.lavoroculturale.org/fare-e-disfare/ (last accessed January 23, 2017).

Libreria delle Donne Bologna. 2015. "Fare e disfare il genere, oggi.” Available online at https://ibreriadonnebo.wordpress.com/2015/03/16/fare-e-disfare-il-genere-oggi/ (last accessed January 23, 2017).

Maier, Carol. 2006. "Translating as a Body: Meditations on Mediation. Excerpts 1994-2004." In The Translator as Writer, edited by Susan Bassnett and Peter Bush, 137-148. London and New York: Continuum.

Massumi, Brian. 2002. Parables for the Virtual: Movement, Affect, Sensation (Post-Contemporary Interventions). Durham, NC: Duke University Press.

Morini, Cristina. 2015. "Se freelance è donna. Doppiozero." Available online at www. doppiozero.com/materiali/lavoro-freelance/se-freelance-e-donna (last accessed July 30, 2016).

Pustianaz, Marco (ed.). 2011. Queer in Italia: Differenze in movimento. Pisa: ETS.

"Queer it yourself" 2011-2013. Available online at https://m.facebook.com/pg/ kespazio/events/?ref=page_internal\&mt_nav=1 
Robinson, Douglas. 1991. The Translator's Turn. Baltimore, MD and London: John Hopkins University Press.

Robinson, Douglas. 2003. Performative Linguistics: Speaking and Translating as Doing Things with Words. New York and London: Routledge.

Schoch Zavaletta, Atticus. 2005. "Undoing Gender: Review." The Comparatist 29(1): 152-153.

Schulz, Dirk. 2005. "Review: Judith Butler. Undoing Gender." Available online at www.genderforum.org/fileadmin/archiv/genderforum/illuminating/review_schulz. html (last accessed July 30, 2016).

Sedgwick, Kosofsky Eve. 1990. Epistemology of the Closet. Berkeley, Los Angeles: University of California Press.

Sedgwick, Kosofsky Eve. 2003. Touching Feeling: Affect, Pedagogy, Performativity. Durham, NC: Duke University Press.

Sedgwick, Kosofsky Eve. 2011. Stanze Private. Translated by Federico Zappino. Roma: Carrocci.

SIL. 2013. "Esposti alla precarietà." Available online at www.rachelemuzio.it/SILPROGETTO/articolo-5/ (last accessed January 10, 2017).

Simone, Anna. 2014. "Fare e Disfare il Genere." Available online at www.alfabeta2. it/2014/12/15/disfare-genere-2/ (last accessed January 23, 2017).

Sommovimento NazioAnale. Available online at https://sommovimentonazioanale. noblogs.org (last accessed August 1, 2016).

Tymoczko, Maria. 2007. Enlarging Translation: Empowering Translators. Manchester: St. Jerome Publishing.

Tymoczko, Maria (ed.). 2010. Translation, Resistance, Activism. Amherst, MA: University of Massachusetts Press.

Von Flotow, Luise. 2012. "Translating Women: From Recent Histories and ReTranslations to "Queerying" Translation, and Metramorphosis." Quaderns: Revista de Traducció 19: 127-139.

Zappino, Federico. 2012. "Dalle stanze private agli spazi comuni. Riflessioni intorno a Eve Kosofsky Sedgwick." Available online at www.lavoroculturale.org/dallestanze-private-agli-spazi-comuni-riflessioni-intorno-a-eve-kosofsky-sedgwick/ (last accessed July 30, 2016).

Zappino, Federico. 2014. "Il genere, luogo precario. Note a margine." In Fare e disfare il genere, edited by Judith Butler, translated by Federico Zappino, 355-367. Milano: Mimesis.

Zappino, Federico. 2015. "Fare e difare il genere, di Judith Butler." Available online at www.ctv.bs.it/2015/03/31/fare-e-disfare-il-genere-di-judith-butler/ (last accessed July 30, 2016).

Zappino, Federico (ed.). 2016a. Il genere tra neoliberismo e neofondamentalismo. Verona: Ombre corte.

Zappino, Federico. 2016b. "Sovversione dell'eterosessualità." Available online at http://effimera.org/sovversione-delleterosessualita-federico-zappino/ (last accessed January 10, 2017).

Zappino, Federico. 2016c. "Fine della differenza sessuale." Available online at http://effimera.org/fine-della-differenza-sessuale-federico-zappino/ (last accessed January 4, 2017).

Zappino, Federico and Deborah Ardilli. 2015. "La volontà di negare. La teoria del gender e il panico eterosessuale." Available online at www.lavoroculturale.org/ la-volonta-di-negare/ (last accessed January 4, 2017). 


\title{
14 Years Yet Yesterday \\ Translating Art, Activism, and AIDS across the Visual and the Verbal
}

\author{
Mark Addison Smith
}

\section{Introduction: Semantic Shift and Queering Language}

The word AIDS, purely on a semiotic level and isolated from meaning, consists of four letterforms that are arranged in a non-alphabetic order, contain straight, slanted, and curved strokes, and cluster together in a compact foursome to generate a sign. The sign in question is comprised of a signifier-in this case, the capital letterforms A, I, D, and S-and that which is signified: an isolated patient or a larger community, a local crisis or a global pandemic, a death sentence or a treatable illness, a moment of activism or a history of uncertainty, yesterday or years from now. But, extracted from a context tethered to social force and time, the word itself is harmless: a 1980 Webster's Dictionary defines the lowercase version as a tool providing help or assistance.

In his 1916 text, Course in General Linguistics, Ferdinand de Saussure reminds us of the arbitrariness of language that allows for seemingly disparate connections between a sequencing of letterforms and phonetic sounds that crystallize into a signified concept: "As [language] is a product of both the social force and time, no one can change anything in it, and on the other hand, the arbitrariness of its signs theoretically entails the freedom of establishing just any relationship between phonetic substance and ideas" (Saussure 2011: 76). A word's meaning is initially bound by the historical context in which it originates but, ultimately, subject to interpretation based upon an individual's evolving relationship to that which is being signified. Philosopher Simon Glendinning clarifies that, "while signifiers are always arbitrary relative to signifieds, they can be motivated relative to other signifiers" (Glendinning 1999: 522). Thus, semantic shift allows diachronic linguistic perspective to skew in relation to time and social context, often to positive or negative consequence.

As an artist working with language and typography, I draw inspiration from semantic shift—or, more plainly, the accumulating baggage—ascribed to language across a historical timeframe and, specifically, through a charged lens of gender, sexuality, and queer activism. For example, in the early fourteenth century, the word gay meant beautiful; by mid-fourteenth century it shifted to showy or finely dressed (Wilton 2009). Gay had become the 
new standard for lighthearted at the end of the fourteenth century (Wilton 2009). Over time, lighthearted became loose, then pleasure-seeking, illicit, and ultimately hedonistic, and, by the mid-twentieth century, gay simply meant homosexual (Wilton 2009). In his speech The Tragedy of Today's Gays, Larry Kramer connected gay with tragedy by targeting gay culpability against the AIDS crisis. A question behind my studio practice emerges: Can an isolated word or phrase, stripped from its source material, still maintain the authority and presence of the mind, voice, history, and context-the intent-which is driving the source material? It is this emerging provocation, coupled with the challenge of translating Kramer's verbal-based, linear speech into a visual-based, nonlinear abecedary, which fueled my Years Yet Yesterday drawing series and provided dueling interpretations of its AIDS crisis-themed source material.

Years Yet Yesterday is a 2014 abecedary of 24 drawings, rooted in queer activism and completed to mark the ten-year anniversary of playwright and activist Larry Kramer's 2004 speech, The Tragedy of Today's Gays. Here, language from Kramer's unequivocal speech becomes translated into nuanced eye charts to explore a decade of queer representation and power (mis)alignments amid the escalating AIDS pandemic. Each panel of the abecedary is dedicated to a letter in the alphabet, and drawn using three words-rewritten hundreds of times to push agendas of immediacy and urgency-that appear in Kramer's source speech. The three words within each drawn panel can be translated in any order to invite viewers to reflect upon a decade-long sliver of the 30+ ongoing years of the AIDS crisis while simultaneously questioning the past and the future of activism amid the power of language. By reassigning Kramer's speech into a set of drawings, in which the visual dimension cannot be divorced from the verbal speech, my Years Yet Yesterday series blurs translation boundaries to become a simultaneous intralingual and intersemiotic translation of The Tragedy of Today's Gays: both share the same thoughts; however, the linear, clear-cut order of verbal speech has now become a cacophony of voices through a nonlinear, visual-art medium.

Carla Freccero, in Queer/Early/Modern, defines queer as a series of dueling binaries that posits "both an identitarian position and a refusal of such" (Freccero 2006: 14). Within my Years Yet Yesterday series, Roman Jakobson's categorical modes of translation-intralingual (a rewording via the same language), ${ }^{1}$ interlingual (a shifting of language), and intersemiotic (a reinterpretation of semiotic code)—suddenly become queer, or elusively intertwined, when mapped against the nonconformist rules of a visual-art system. Generally speaking, text-based art both identifies with the rules of verbal language-oftentimes, incorporating common language and syntax-and refutes against them with emphasis placed on emotional and historical connections, that change from person to person, within a nonlinear framework. My art-based translation further defines queer by implementing a fluidity of modes; therefore, overcoming the illusive disjunction between the visual and the verbal. 


\section{Agitprop Art Defines the AIDS Crisis}

The AIDS pandemic first emerged as a bifurcated crisis born in visual and verbal text. Michel Foucault's analysis of late-seventeenth-century sexual discourse remains prescient when mapped against the chaos, speculation, and scrutiny that occurred within an early eighties community struggling to make sense of an America unraveling under the momentum of the AIDS crisis. Amid our natural inclination to speculate about sexuality, we also need to scientifically analyze and categorize in order to assign meaning and, ultimately, decode and understand. We have a need to talk about sex, and AIDS - a disease commonly acquired through unprotected sexual activity—falls under this discussion. Foucault argues,

Toward the beginning of the eighteenth century, there emerged a political, economic, and technical incitement to talk about sex. And not so much in the form of a general theory of sexuality as in the form of analysis, stocktaking, classification, and speculation, of quantitative or casual studies.

(Foucault 1990: 23-24)

Speech is a primary example of linear, speculative, and categorical public discourse used to target and connect audiences in AIDS activism. On November 7, 2004, five days following the reelection of President George W. Bush, Larry Kramer delivered his incendiary speech, The Tragedy of Today's Gays, to a packed audience at New York City's Cooper Union Hall. He declared, "We have lost the war against AIDS" (Kramer 2005b: 44). As a solution, Kramer urged the gay community to unite in safety, action, and speech: "We must have an honest discussion amongst ourselves about what's harming us and what's helping us as a people" (Kramer 2005b: 82). Now, over ten years later, his words simultaneously resonate and sting while fueling ongoing, unending, and nuanced-grayscale—conversations about AIDS-crisis culpability and containment.

Early discussions surrounding the AIDS crisis were not so grayscale, often pitting the healthy against the sick and the heterosexual against the homosexual. Lawrence K. Altman's July 3, 1981 New York Times article, the first to reference a "rare cancer" (Altman 1981: par 1) afflicting 41 homosexual men, opened the floodgate for this divide: the article concludes with the Centers for Disease Control and Prevention's Dr. James Curran promising "no apparent danger to nonhomosexuals from contagion" given that "no cases have been reported to date outside the homosexual community or in women" (Altman 1981: par 15). Almost one year later, gay context was removed from the disease's original name, GRID (Gay Related Immune Deficiency) and the term AIDS (Acquired Immune Deficiency Syndrome) was developed in effort to remain sexually neutral and less targeting. ${ }^{2}$

Contemporary linguist William Leap provides a reminder that "the language of AIDS is a recent construction for speakers of English ... [it] is not 
a unified or uniform construction" (Leap 1996: 40) but, rather, an embodiment of semantic shift measuring strides against cultural stigmas or supporting medical research. AIDS, as we recognize it today, represents a global, sexual, and political health crisis in which 35 million have died, ${ }^{3}$ with sufferers oftentimes feeling marginalized from a lack of humanitarian support, medical research, political recognition, or social compassion.

Visual art provides an outlet for reversing marginalization by rattling a community and reverberating voices across a multitude of communication modes. Compared to the linearity of speech, in which a listener receives information via an ordered and temporal word structuring from another speaker, visual art possesses a communicative nonlinearity in which the viewer ultimately controls the disbursement of information. Avram Finkelstein, founding member of ACT UP, the AIDS Coalition to Unleash Power, and co-creator of their ubiquitous SILENCE =DEATH campaign (1987), speaks about the shift within ownership and order that marks visual-based art as a nonlinear experience:

An image may be authored and so, at least at that point, arguably owned. But once it reaches the public sphere, if it manages to tap into the zeitgeist, it may have its moment. It's the audience that drives the moment, not the author. For this cultural nanosecond, the public sphere is actually an exercise in collectivity. And the moment is an independent thing, free in its entirety, and uncontrollable.

(Baumann 2013: par 22)

For Nelson Santos, Executive Director of New York City-based Visual AIDS (visualaids.org), agitprop artworks infusing text and visual stylization with political urgency are as old as Foucault's need to talk and our need to protest. In an email interview with the author on 13 June 2016, Santos declared: "Text has long been used to call out a direct message'Make Love, Not War,' 'I AM A MAN,' 'My Body, My Rights' . . . these catchy phrases help pass on the message quickly, basically going viral before the internet." Within AIDS activism, text-based visual art becomes its own categorical language system by both adopting a shared word bank with native spoken language but refusing to adopt a system of logical syntactical arrangement for information deployment. It speaks to a specific community about a specific cause, yet refuses to be contained to a singular form or systematic set of rules. Like queer, the mapping of visual art within AIDS activism remains both specific and elusive.

The AIDS crisis, born out of sensationalistic journal articles, indecipherable medical terms, polarizing anagrams, and aggressive protest signs, becomes a logical impetus for text-based art. Santos agrees,

So much complex scientific and political language was being used at the time to explain and define the AIDS pandemic that artists were drawn to breaking down language to concise messages ... Men Use Condoms 
or Beat It (Gran Fury 1988) next to an erect penis, or He Kills Me (Moffett 1987) next to a picture of Reagan laughing, in acknowledgment to the lack of governmental response.

Within agitprop art, lines of communication extend beyond the clear-cut divides of intralingual, interlingual, and intersemiotic definitions by intertwining verbal language with visual principles and elements of design. ${ }^{4}$

Fuck Positive Women is the duplicitous sentiment at the heart of Jessica Whitbread's and Allyson Mitchell's 2011 PosterVIRUS campaign for AIDS Action Now, a Toronto-based organization founded in 1988 to challenge misconceptions and empower those living with AIDS (Whitbread and Mitchell 2011). The poster features an arresting yet unfinished, domestic-style needlepoint revealing the title words to reinforce issues of penetration, risk, and repair within an often overlooked, marginalized community of women suffering from AIDS. Harnessing an intralingual duality of language order and semiotic decoding, Fuck Positive Women becomes more nuanced depending on the viewer's reading order, definition choice, and interior tone of voice.

In the 1990 Chicago public art exhibition Art Against AIDS/On the Road, language-based artist Kay Rosen starts with the acronym for AIDS and, in a reverse discourse play-on-words, lists positive-word synonyms for aid (assist, help, support, among others) across 50 bus tailgate posters (Rosen 1990). Hoping to challenge audience misconceptions and rally communities together, Rosen's word list also incorporates interlingual translation and alliteration by intermixing sound-alike English, Spanish, and French words like support, soccoro, and secours, respectively, alongside asisst, ally, and ayuda.

Gran Fury's SILENCE=DEATH harnessed the power of two words, one equal sign, and a upward pointing pink triangle to initially rally against conservative author William F. Buckley's staggering proposition that all HIV-positive people get forearm and buttocks tattoos to protect others (Buckley 1986: par 15). With a chilling brevity of language and an intersemiotic recoding dating back to Nazi Germany, ${ }^{5}$ it laid the groundwork, 17 years earlier, for the band together-or-die message behind Larry Kramer's 2004 speech, The Tragedy of Today's Gays. Today, it remains a graphic standard for text-based AIDS activism.

Foucault's framework for discourse, including analysis, stocktaking, classification, and speculation, is at the center of my Years Yet Yesterday abecedary; but, I was organically fueled by an art-and-activism need to break down Larry Kramer's language into concise messaging for larger community understanding. In executing the drawing series, I analyzed Kramer's source speech, classified it into an ordered set of alphabetized words, translated these words into a set of text-driven, phrase-based drawings, and used these drawings to invite audience speculation through the decoding of geometric form, grayscale readability, and three-word provocations that targeted the past, present, and future of the AIDS crisis. The drawings organically emerged as if I were generating my own set of protest signs. 


\section{Translating a Duality Between Voices and Seeing}

By pitting an unraveling gay community against an unraveling political sphere, Larry Kramer challenges his audience, using matter-of-fact speech and dueling binaries outlined in The Tragedy of Today's Gays, to consider the AIDS crisis in a blurry, bifurcated context. In terms of clarity, Kramer first blames the escalating AIDS crisis on the gay community's inability to listen. He states,

From the very first moment we were told in 1981 that the suspected cause might be a virus, gay men have refused to accept our responsibility for choosing not to listen, and, starting in 1984, when we were told it was definitely was a virus, this behavior turned murderous.

(Kramer 2005b: 54-55)

The tragedy according to Kramer is simple: gay men are not acknowledging and protecting their history, but, instead, are perpetuating their own demise by willingly and continuously consenting to drug abuse and unprotected sex. Kramer declares,

I wish we could understand and take some responsibility for the fact that for some thirty years those fucking without condoms have been murdering each other with great facility and that down deep inside of us we knew what we were doing.

(Kramer 2005b: 55)

Kramer, second, attacks a right-wing totalitarian-the overpowering cabal he references throughout his speech-that has gained privatized control over industry, politics, healthcare, and media, and has subverted power over a diminishing gay culture and community. Kramer states, "HIV allows them to sell us as sick. And that kills off our usefulness, both in our own minds-their thinking we are sick—and in the eyes of the world-everyone thinking we are sick" (Kramer 2005b: 65). In a textual metaphor for marginalized voices, a total of 72 words were selected for my Years Yet Yesterday abecedary from over 9,000 words spoken by Larry Kramer. In a visual metaphor for marginalized illness, each drawing within the Years Yet Yesterday series evokes a bacteria-clad petri dish containing hundreds of words encircling themselves against the negative space of the rectangular paper.

Both Kramer's speech and the ongoing AIDS pandemic share a bifurcated push and pull in terms of tragedies and triumphs; thus, a forward and reverse syntactical duality was necessary for marking phrases that I ultimately translated into drawings. In preparation for each individual drawing, I first scanned the speech multiple times for words within a given letter category (all J-words, for example). Once I had taken inventory of all words, I rearranged them into three-word phrases. Of particular interest to me were provocations that had deeper resonance within the AIDS pandemic while sharing a kindred spirit, both in terms of overarching themes and tone, with Kramer's speech. 


\section{Mark Addison Smith}

An abundance or limitation within the categorization of same-letter words became a driving constraint. The complete Years Yet Yesterday abecedary consists of 24 works on paper-just shy of 26, given that Kramer didn't speak any words beginning with an X or a Z-with each drawing dedicated to a letter from the alphabet and limited to three words sharing that same letter. Some letters were easier to categorize than others: words beginning with W, C, and R were frequently spoken and shared a wealth of reconfiguration possibilities (I ultimately used Wrong Way Washington, Civil Courage Contaminated, and Research Requires Response, respectively), while words beginning with the letter $\mathrm{J}$, in contrast, were hardly used-twenty words, only, in the entire talk. Here I ended up using July as the central, driving word to reference the 3 July 1981 New York Times article which reported the initial 41 cases of HIV-infected gay men-the rare cancer, as the Times called it (Figure 14.1).

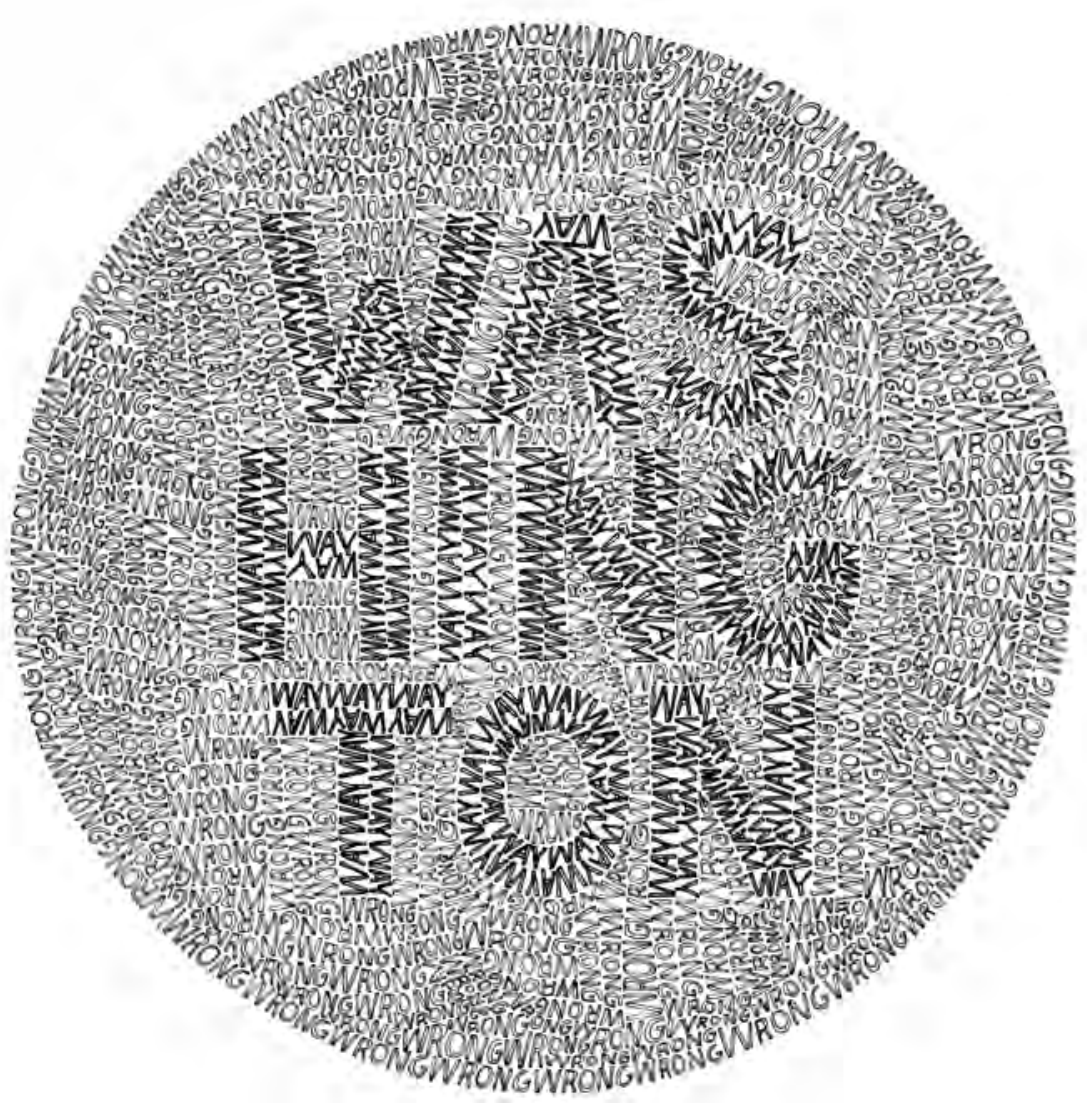

Figure 14.1 W-Wrong Way Washington, India ink pen on paper using language from Larry Kramer's 2004 speech The Tragedy of Today's Gays, $22 \times 15$ inches, from a 2014 abecedary of 24 drawings. 
Gay men, bisexual men, and men who have sex with other men, regardless of race or ethnicity, remain the population most impacted by HIV (CDC 2015: par 2). Men, born with an X and Y chromosome, are much more likely to develop visual impairment, given that the mutated genes responsible for inherited color blindness are limited to the X chromosome (NEI 2015: par 6). Women have the support of a second X chromosome to lessen their chances. An unexpected correlation between Kramer's primarily male demographic and the circular translation for each Years Yet Yesterday drawing provides an underlying commentary connecting disease, marginalization, and gay men.

To visually depict a duality between voices and seeing, my intention for each drawing was to emulate classic, text-based colorblind charts with a twist on substituting exactitude of color combinations for messier shades of dueling grays. It is a misnomer to assume that those with color blindness cannot see color; they can, however they cannot perceive the differences of certain couples of complementary colors (Sarcone 2014: par 1). Within The Tragedy of Today's Gays, Larry Kramer is using his spoken words to challenge us to see. As artistic translator within my Years Yet Yesterday abecedary, I want the audience to perceive binary difference between coupled phrases and coupled shades of gray in order to discern dueling questions-but no visible answers-regarding the past decade of the AIDS crisis.

\section{Jakobson's Verbal-Translation Modes as Visual-Art Tools}

The literal circularity within each drawing's colorblind chart formation is conceptually deepened through the definition of intralingual translation, which has direct roots in circumlocution, a translation mode that encircles specific meaning with a syntactical shifting of word order and tangential questions rather than singular, linear answers (Jakobson 1959: 233). In what Roman Jakobson refers to as intralingual translation, or rewording as applied here, the Years Yet Yesterday series partially functions by communicating antithetical statements about the past decade of the AIDS crisis depending on the reading order within each drawing's three words.

For example, within the $\mathrm{M}$ drawing, $M-$ Miraculous Meds Maybe can also be syntactically rearranged as Maybe Meds Miraculous. The first translation, Miraculous Meds Maybe, places emphasis and responsibility upon the health care industry granting or denying access to a patient's medical needs. Daraprim, a pill used to combat the reoccurrence of Toxoplasma gondii parasitic infections in HIV patients, went from being affordable and readily available to $5000 \%$ above market price in 2015 after US distribution rights were acquired by Turing Pharmaceuticals (Long 2015). The second translation, Maybe Meds Miraculous, places emphasis upon the medicine itself as a divine pill to eradicate symptoms. Pre-exposure prophylaxis drugs such as Truvada, which prevent the HIV virus from latching onto the body, provide hope for a new generation seeking armor against HIV infection, but, further studies and time will reveal possible long-term side effects, escalating cost and availability, and patient commitment for daily medication (Park 2012) (Figure 14.2, Figure 14.3). 


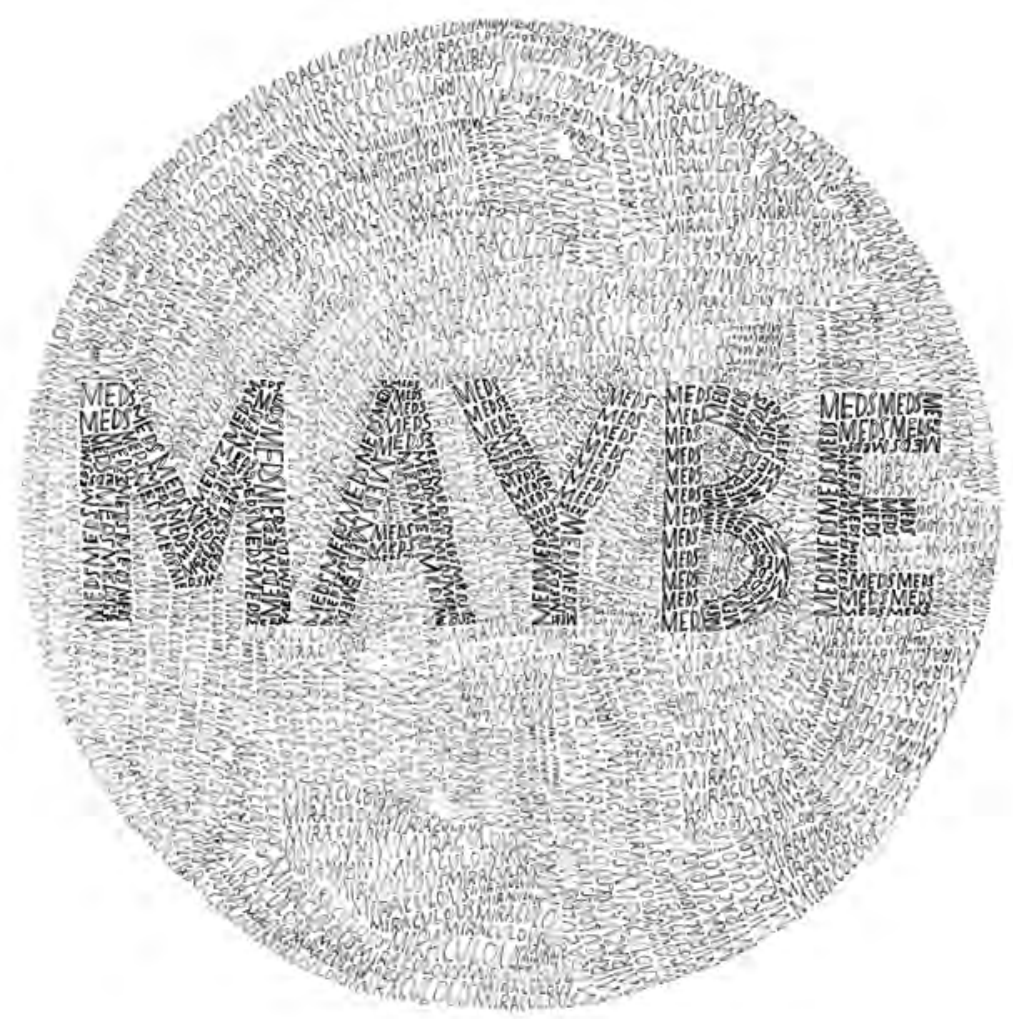

Figure 14.2 M-Miraculous Meds Maybe, India ink pen on paper using language from Larry Kramer's 2004 speech The Tragedy of Today's Gays, $22 \times 15$ inches, from a 2014 abecedary of 24 drawings.

C-Civil Courage Contaminated, restructured as Contaminated Courage Civil, represents the simultaneous healing and destruction at the heart-center of The Tragedy of Today's Gays, as Kramer struggles to maintain empathy toward his audience while acknowledging their role in contributing to the spread of HIV/AIDS as "the worst disaster in recorded human history" (Kramer 2005b: 41-42). Kramer holds the gay community as superior, one in which gay people are "better than other people ... smarter and more talented and more aware ... more tuned in to what's happening, tuned into the moment ... better friends" (Kramer 2005b: 35-36). In referencing the spread of AIDS, however, he interrogates the uplifted crowd, matter-offactly: "Have you ever wondered how many men you killed?" (Kramer 2005b: 55-56). Kramer's controversial accusation had not been voiced until this speech and remains unquestionably charged; however, the intention behind my three-word translation is to bring to light an individual's slippery role in contaminating or protecting their larger community (Figure 14.4). 


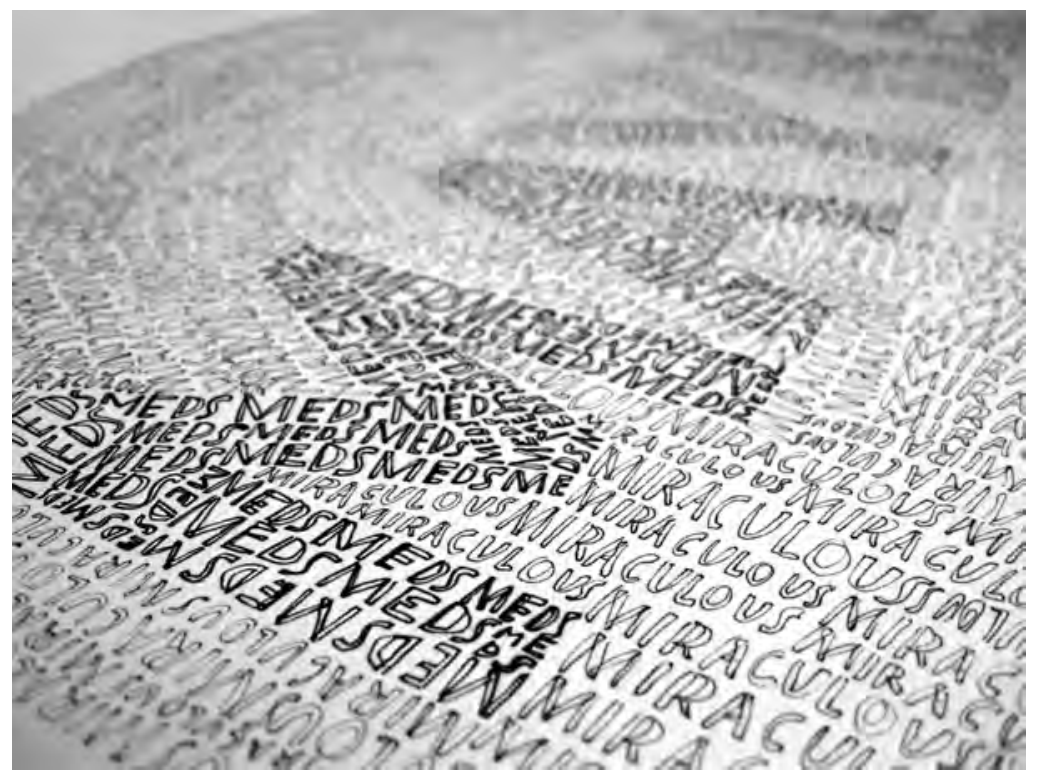

Figure 14.3 A detail from M-Miraculous Meds Maybe highlights the three levels of language (background, middle ground, and larger foreground) contained within each drawing. The three words can be read back-tofront or front-to-back in order to incite dialogue about the ongoing AIDS pandemic.

With D-Denial Days Disappearing, Kramer challenges the crowd to acknowledge the past generations that have died from AIDS, to use this reminder as a catalyst for queer community building, and to not lose community momentum through myopic apathy. Tragically, Today's Gays have lost the 1981 death-drive motivation that urged so many, like Kramer, to organize and voice in a quest for AIDS-crisis reform. In the early '80s, Kramer witnessed the decay and death of his community and co-founded the Gay Men's Health Crisis (GMHC) - which first held meetings in Kramer's apartment and subsequently implemented the world's first AIDS hotline-in retaliation against AIDS-related death (Specter 2002). In 1987, he founded the AIDS Coalition to Unleash Power (ACT UP) as a furious political action uniting those living with HIV/AIDS (Specter 2002). Tragically, in a reverse-translation of Disappearing Days Denial, Kramer admits in a C-SPAN interview that Today's Gays "have moved on ... [AIDS reform is] not an issue they care about. If they're healthy, they're fine. They moved on. If they're infected, they still moved on" (Kramer 2005a). My three-word translation challenges the queer community to remain alert and visible despite the past and present forces-be it a global pandemic or a targeting outsider or faction-that try to eradicate. Hauntingly, these three words reverberate in the aftermath of the Pulse nightclub shooting that took place on 12 June 2016 in Orlando, Florida (Figure 14.5). 


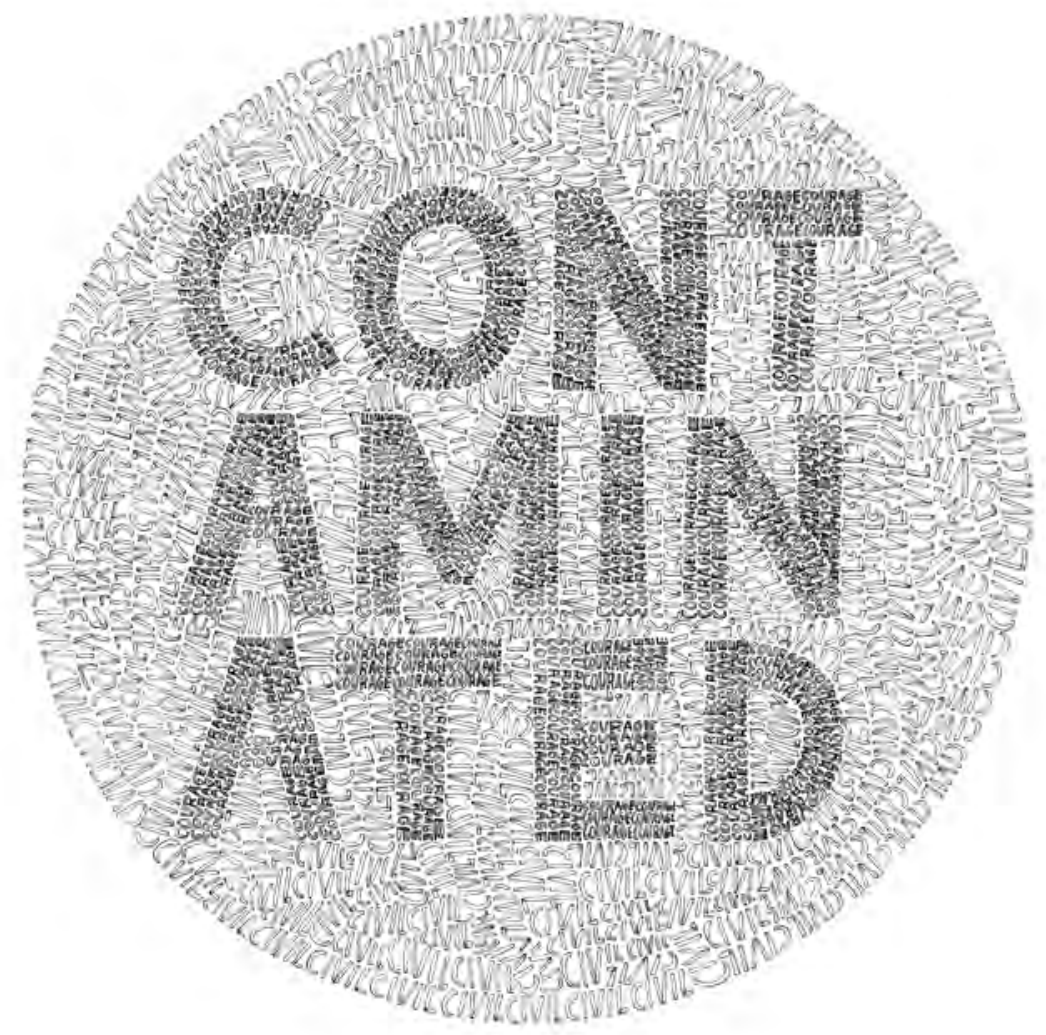

Figure 14.4 C-Civil Courage Contaminated, India ink pen on paper using language from Larry Kramer's 2004 speech The Tragedy of Today's Gays, $22 \times 15$ inches, from a 2014 abecedary of 24 drawings.

Y-Years Yet Yesterday, restructured as Yesterday Yet Years, speaks to the urgency of time depicted within this series: a decade of reflection or the passage of a day-and life-in the blink-of-an-eye. Sharing the title for the complete abecedary of 24 time-based drawings, Years Yet Yesterday provides a not-sosubtle reminder that the AIDS crisis is far from over (Figure 14.6).

While the viewer can parse apart the intralingual and intersemiotic translation modes depicted within the series, clear-cut distinctions between Jakobson's lenses ultimately do not matter within the Years Yet Yesterday drawing translations. Given that the verbal language is also translated as visual language, what surfaces from the drawings, ultimately, is a blurred-or queer-intralingual and intersemiotic hybrid. The visual dynamics-including 


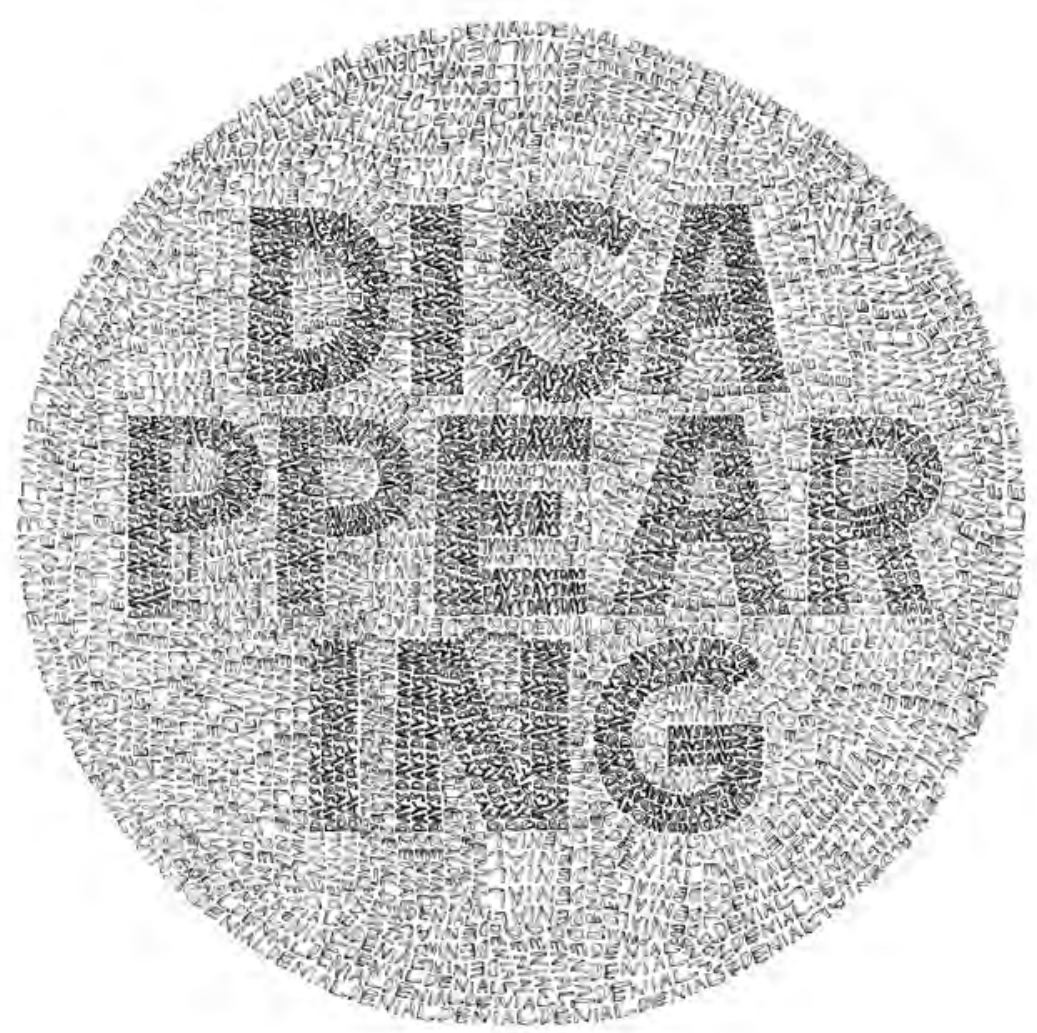

Figure 14.5 D-Denial Days Disappearing, India ink pen on paper using language from Larry Kramer's 2004 speech The Tragedy of Today's Gays, $22 \times 15$ inches, from a 2014 abecedary of 24 drawings.

each drawing's circular form, typographic hierarchies, the organically irregular handwriting, and the discrepancies within stroke weight, line quality, and ink saturation-become tone and message-based typographic storytelling to accompany language decoding.

For example, from a hierarchy standpoint, a larger, driving word is prioritized in each drawing's foreground while smaller background and middle ground words subtly change linguistic meaning to generate differing political and personal conversations depending on which word is read first.

And, across the entire abecedary, the level of ink saturation within the reproduced words convey a struggle for AIDS awareness and the fight against adversity; some words are drawn in deliberate grayscale to remain quietly hidden in plain sight, while other words pack a louder visual punch. 


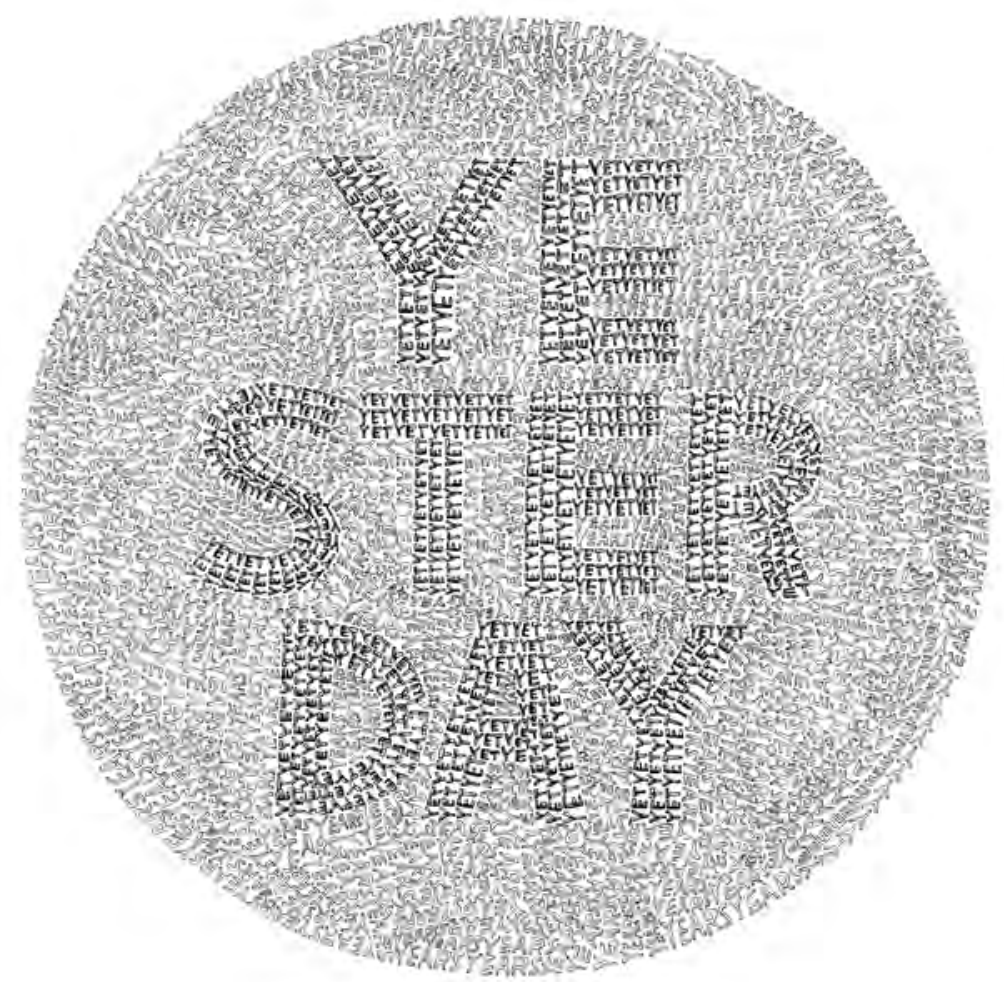

Figure 14.6 Y-Years Yet Yesterday, India ink pen on paper using language from Larry Kramer's 2004 speech The Tragedy of Today's Gays, $22 \times 15$ inches, from a 2014 abecedary of 24 drawings.

Within H-Horror Highest Hope, the saturated black-against-black words are borderline-indistinguishable from one another; Hope barely wins as the drawing's central word. The dark and darker words of E-Expected Elected Emergencies speak to the 2004 reelection of George W. Bush, a bleak moment considered by many members of the LGBTQ community as a second term of nonsupport. Cyclically and just over a decade later, these three prescient words, reshuffled as Emergencies Elected Expected, reflect United States tensions of inclusivity surrounding the 2016 presidential election. O-Obliterates Ourselves Obviously and Q-Questioning Queer Question further reinforce linguistic and conceptual indecipherability with Obviously and Question, barely readable, ironically disappearing into a medium-gray background (Figure 14.7, Figure 14.8, Figure 14.9). 


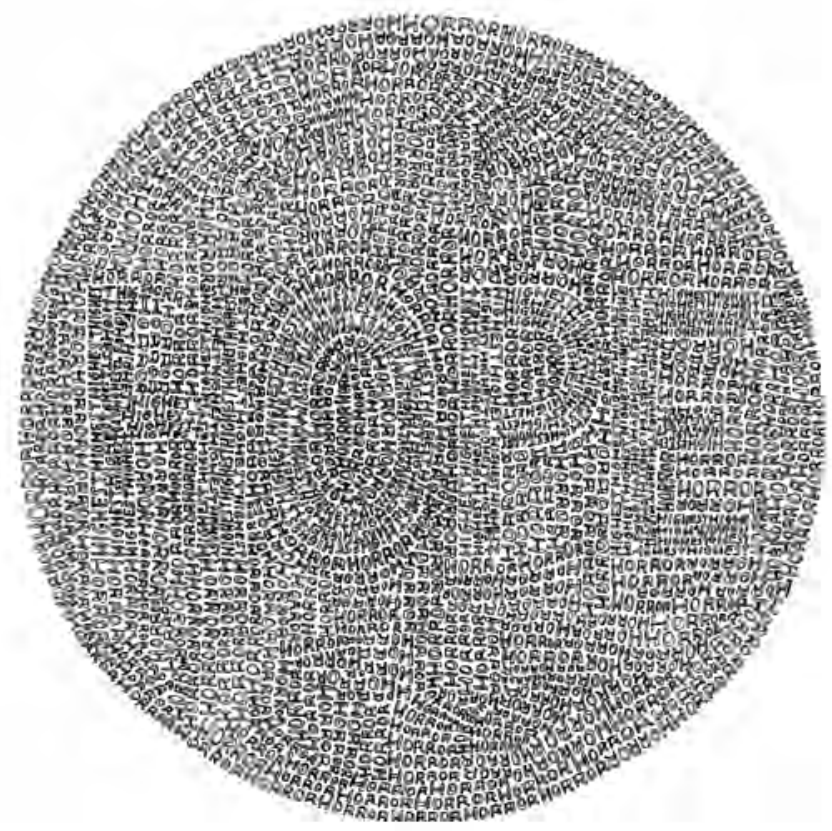

Figure 14.7 H-Horror Highest Hope, India ink pen on paper using language fromLarryKramer's2004speechTheTragedyof Today's Gays, $22 \times 15$ inches, from a 2014 abecedary of 24 drawings.

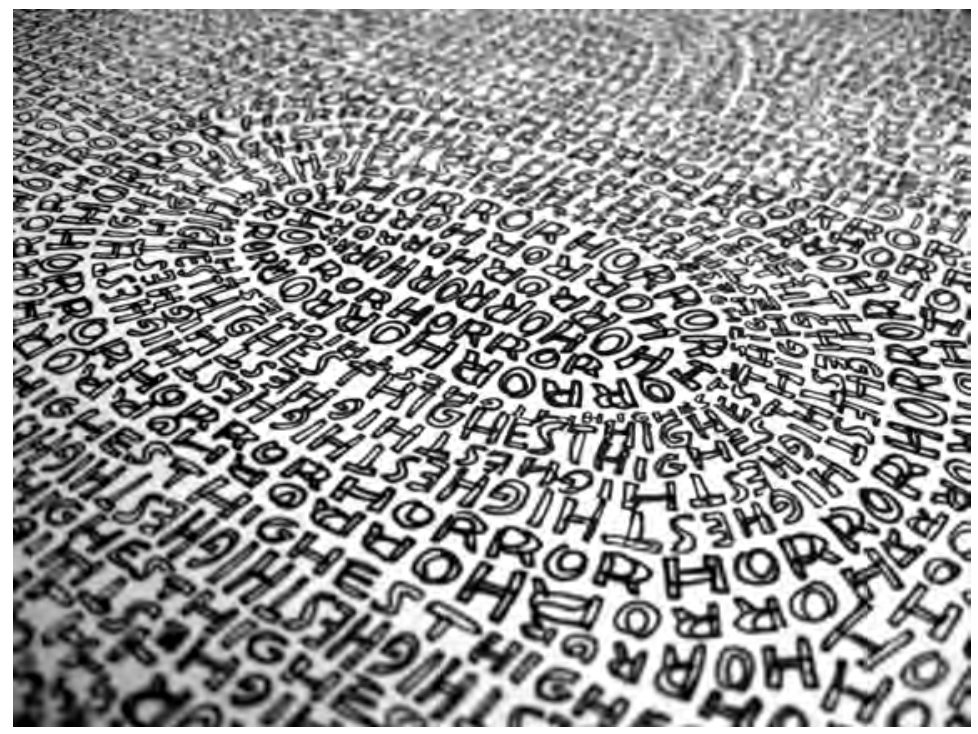

Figure 14.8 Within H-Horror Highest Hope, the black-against-black words are almost indistinguishable from one another. Hope barely emerges as the centralized word provocation. 


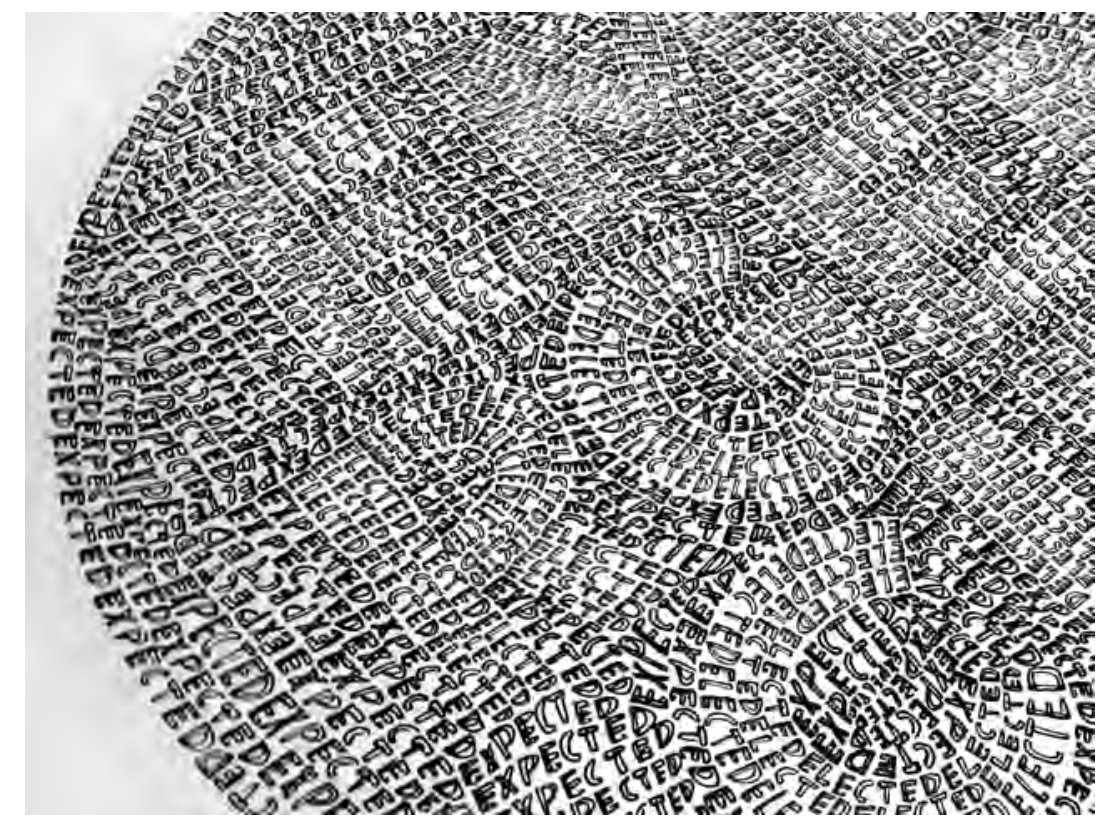

Figure 14.9 E-Expected Elected Emergencies (detail), India ink pen on paper using language from Larry Kramer's 2004 speech The Tragedy of Today's Gays, $22 \times 15$ inches, from a 2014 abecedary of 24 drawings.

Saussure asserts that linguistic meaning is rooted in arbitrary connections between the signifier and that which is signified. Saussure might argue that my 72 chosen words become arbitrary only in the manner in which the viewer chooses to connect them. Viewers may choose to syntactically arrange each individual drawing's three words in any order to derive dueling meaning. Or, viewers may extract words from multiple drawings in an effort to draw associations across the entire series. So, M-Miraculous Meds Maybe, A-Asshole Axis America, B-Blind Before Better, Q-Questioning Queer Question, G-Goddamned Grace Gobbledygook, and F-Fucking Fucked Future could expand to Maybe America Better Question Gobbledygook Future when the larger, central words are reordered beyond the confines of each individual drawing. ${ }^{6}$ Within this nonlinear reading, arbitrariness is not only invited, but becomes a necessary rule for understanding the deeper layers of subtext hidden within my drawing series and Kramer's source speech (Figure 14.10).

\section{Conclusion: Audience Reception and Perception}

At the core of Larry Kramer's speech is a wakeup call for community engagement and AIDS activism. No two words better embody this call-toaction than $I$ and $y o u$, the two words most frequently spoken by Kramer in The Tragedy of Today's Gays. ${ }^{7}$ Kramer-a queer activist known for his 


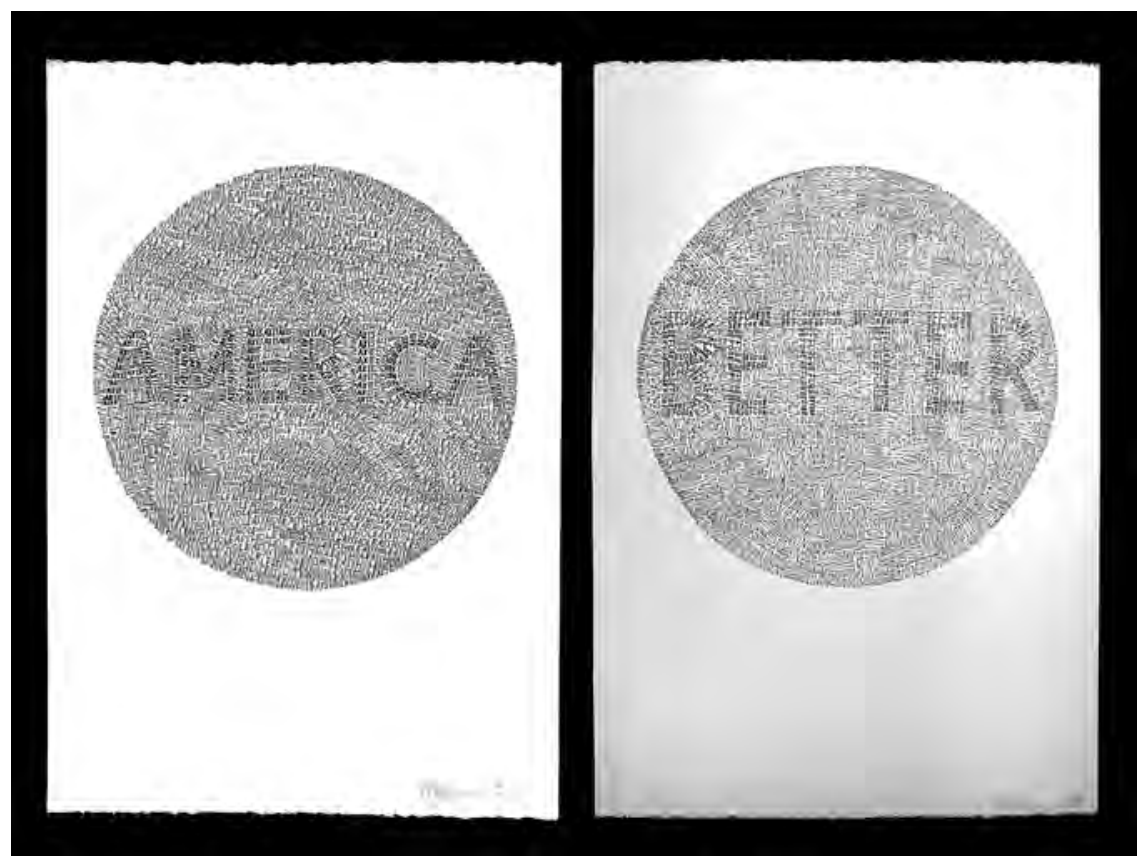

Figure 14.10 Deepening the translation, viewers may extract words across multiple drawings in order to further complicate the conversation surrounding the ongoing AIDS pandemic. Here, A-Asshole Axis America and $\mathrm{B}-$ Blind Before Better implicate on a national scale with America Better as the driving source of interrogation.

cantankerous and vivacious patterns of speech-forms a speech community with his listeners, captivating the LGBTQ community with a cacophony of aggressive language, name calling, inner-community blaming, and, ultimately, truth telling and respectable, powerhouse leadership. The audience and their leader become a collective consciousness, but Kramer (the dominantly spoken $I$ ) is in control.

In turn, each drawing becomes a multimodal translation of this controlled verbal behavior in which Kramer is, literally and figuratively, dying to be heard and won't stop talking until change happens. The process of writing and rewriting a single word hundreds of times across a sequence of round drawings is the visual manifestation of circumlocution-both literally with visual form and figuratively with interchangeable messaging. The result is a visual tactic to overwhelm the viewer with information until they absorb the questions that Kramer and I are posing. At the cross-section of artistic intent and intersemiotic translation, I imagined each handwritten word substituting for an individual person and each drawing accumulating into a unified crowd in mass support of gay rights (Kramer's you, which, like communication, cannot become activated without the driving force of an $I$ ). 


\section{Mark Addison Smith}

The act of listening to a verbal speech, considered a bilateral flow of communication, becomes a unilateral experience through the exchange of discourse between two or more people. I view my collective set of 24 Years Yet Yesterday drawings as a testimony to and extension of Kramer's tireless advocacy: his hope, coupled with my translation, that more voices-in addition to his-will call out, reverberate beyond the linearity of his speech, and incite nonlinear activism within the gay community. As such, my ultimate intent for the Years Yet Yesterday abecedary is to harness the language of visual arts—one that transcends syntactical linguistic arrangement and relies upon intralingual and intersemiotic translation modes in order to spark an open-forum discourse between the individual viewer and a larger community regarding our role within the AIDS pandemic-yesterday, today, and tomorrow.

\section{Notes}

1 In referencing my Years Yet Yesterday drawing series, I'm allowing Jakobson's intralingual definition to also accommodate a shifting of word order, given that my visual-based translations share a common language with Kramer's source speech.

2 Evatt (2006: 2296) reports that the term AIDS was coined on July 27, 1982 in Washington D.C., where members of the Centers for Disease Control and Prevention (CDC) met with representatives from the National Institutes of Health (NIH) and the Food and Drug Administration (FDA) to discuss the possibility of HIV transmission via a blood-born, non-homosexually specific, agent.

3 UNAIDS (2016) reports that 78 million people worldwide have contractedHIV since the pandemic's onset, while approximately 37 million people globally were living with HIV in late 2015.

4 The principles and elements of design are visual-based tools used to create and analyze an artwork. The quantifying elements include shape, direction, size, texture, color, and value. The qualifying principles include balance, gradation, repetition, contrast, harmony, dominance, and unity.

5 The downward pointing pink triangle, used to identify homosexual male prisoners, was one of many concentration camp badges mandated by Nazi Germany.

6 Extracted from the hanging order for my November 20-January 6, 2016 Years Yet Yesterday solo exhibition at the Center on Halsted Gallery in Chicago.

7 In keeping with a deliberately analog-driven practice for developing my Years Yet Yesterday drawing series (handwriting, pen, paper), all word-tallying was done with pencil in hand against my paperback copy of The Tragedy of Today's Gays, oftentimes while riding the New York City subway. I counted 207 instances of $I$ and 196 instances of you for a sweeping majority, but my exact count is admittedly rough. Also of interest: we appears roughly 178 times, gay or gays appears 57 times, AIDS appears 14 times, and faggots - a word commonly associated with Kramer as it's the title of his 1978 fiction book-appears twice.

\section{References}

Altman, Lawrence K.1981. "Rare Cancer Seen in 41 Homosexuals.” The New York Times, July 3. Available online at nytimes.com/1981/07/03/us/rare-cancer-seen-in41-homosexuals.html (last accessed February 6, 2017). 
Baumann, Jason.2013. "The Silence=Death Poster (guest post by Avram Finkelstein).” New York Public LibraryLGBT@NYPL, November 22. Available online at nypl.org/blog/2013/11/22/silence-equals-death-poster (last accessed February 12,2017$)$.

Buckley, Jr., William F.1986. "Crucial Steps in Combating the Aids Epidemic; Identify All the Carriers.” The New York Times, March 18. Available online at nytimes.com/ books/00/07/16/specials/buckley-aids.html?_r=1 (last accessed February 6, 2017).

Centers for Disease Control and Prevention (CDC). 2015. "HIV in the United States: At a Glance." Centers for Disease Control and Prevention. Available online at cdc. gov/hiv/statistics/overview/ataglance.html (last accessed February 6, 2017).

Evatt, BL. 2006. "The Tragic History of AIDS in the Hemophilia Population, 1982-1984." Journal of Thrombosis and Haemostasis 4(11): 295-301.

Foucault, Michel. (1978) 1990. The History of Sexuality: An Introduction, Volume 1. New York: Vintage Books, Random House, Inc.

Freccero, Carla. 2006. Queer/Early/Modern. Durham, NC: Duke University Press.

Glendinning, Simon. 1999. The Edinburgh Encyclopedia of Continental Philosophy. London: Routledge.

Gran Fury Collective. 1988. “Men Use Condoms or Beat It: Crack-and-Peel Sticker.” International Center of Photography (ICP). Available online at icp.org/browse/ archive/objects/men-use-condoms-or-beat-it (last accessed February 12, 2017).

Jakobson, Roman. 1959. “On Linguistic Aspects of Translation.” In On Translation, edited by Reuben A. Brower, 232-239. Cambridge, MA: Harvard University Press.

Kramer, Larry (interview with Michael Specter). 2005a. "C-SPAN2 BookTV," September 29. Available online at www.c-span.org/video/?189402-1/tragedy-todaysgays (last accessed February 12, 2017).

Kramer, Larry. 2005b. The Tragedy of Today's Gays. New York: Penguin Group.

Leap, William. 1996. Word's Out: Gay Men's English. Minneapolis, MN: University of Minnesota Press.

Long, Heather. 2015. "Drug that Skyrocketed 5,000\% Hasn't Come Down in Price." CNN Money, October 9. Available online at money.cnn.com/2015/10/09/ investing/drug-ceo-daraprim-price/ (last accessed February 6, 2017).

Moffett, Donald. 1987. "He Kills Me: Offset Lithograph.” The Museum of Modern Art, New York. Available online at moma.org/collection/works/4809?locale=en (last accessed February 12, 2017).

National Eye Institute (NEI). 2015. "Facts About Color Blindness." National Institute of Health. Available online at nei.nih.gov/health/color_blindness/facts_about (last accessed February 6, 2017).

Park, Alice. 2012. "Truvada: 5 Things to Know About the First Drug to Prevent HIV." Time, July 17. Available online at healthland.time.com/2012/07/17/ truvada-5-things-to-know-about-the-first-drug-to-prevent-hiv/ (last accessed February 6, 2017).

Rosen, Kay. 1990. "AIDS (for Art Against AIDS/On the Road, Chicago): 50 Bus Tailgate Posters.” Available online at kayrosen.com/work.html (last accessed February 12,2017$)$.

Santos, Nelson (email interview with Mark Addison Smith). June 13, 2016.

Sarcone, Gianni A. 2014. "Color Blindness or Color Vision Deficiency." Archimedes Laboratory Project. Available online at archimedes-lab.org/colorblindnesstest. html (last accessed February 6, 2017). 


\section{Mark Addison Smith}

Saussure, Ferninand de. (1916) 2011. Course in General Linguistics. New York: Columbia University Press.

Specter, Michael. 2002. "Public Nuisance.” The New Yorker, May 13: 63-64.

UNAIDS, The Joint United Nations Programme on HIV and AIDS. 2016. "Fact Sheet November 2016." UNAIDS. Available online at unaids.org/en/resources/ fact-sheet (last accessed February 12, 2017).

Whitbread, Jessica and Mitchell, Allyson. 2011. "AIDS Action Now: Fuck Positive Women.” Plastic cross-stitch for PosterVIRUS. Available online at nomorepotlucks. org/site/fuck-positive-women/ (last accessed February 12, 2017).

Wilton, Dave. 2009. “Gay.” Wordorigins.org, February 2. Available online at wordorigins.org/index.php/site/comments/gay/ (last accessed February 12, 2017). 


\section{List of Contributors}

Brian James Baer is professor of Russian and translation studies at Kent State University, where he is a member of the Institute for Applied Linguistics. His research interests include translation pedagogy, translation and censorship, and translation and gender/sexuality. He is the author of Other Russias: Homosexuality and the Crisis of Post-Soviet Identity (Palgave MacMillan, 2009), selected as a Choice Outstanding Academic Title by the American Library Association in 2011, and Translation and the Making of Modern Russian Literature (Bloomsbury 2016). He is the founding editor of the journal Translation and Interpreting Studies and the general editor of the Kent State Scholarly Monograph Series in Translation Studies. He is the co-editor of Volume XII of the ATA Monograph Series, Beyond the Ivory Tower: Re-Thinking Translation Pedagogy (John Benjamins, 2003), and Russian Writers on Translation. An Anthology (St. Jerome, 2013), as well as the editor of Contexts, Subtexts, Pretexts: Literary Translation in Eastern Europe and Russia (John Benjamins, 2011).

Michela Baldo is a lecturer in translation studies at the University of Leicester. She completed a PhD in translation studies (2009) at the University of Manchester and was subsequently employed as a teaching fellow in translation studies at the University of Birmingham, as researcher on subtitling at the Università per stranieri di Siena (Italy), and had a visiting fellowship at the CCWW of the University of London, where she investigated the reception through translation of Italian-American women writers in Italy. At present, she is researching the role of translation in queer activist movements in Italy.

Elena Basile works as an adjunct faculty at the University of Toronto and at York University. She has written on translation, multilingualism, and Canadian poetics and has translated into Italian Nicole Brossard's novel Le désert mauve (2011). She collaborates regularly with artists and academics in Italy, Canada, and France, focusing her research and poetry on the politics of feminist queer migrant poetics. 
Serena Bassi is Leverhulme Early Career fellow at the University of Cardiff, United Kingdom. Her research interests include translation and sexuality, cultural exchange between the United States and Italy, and the history of gay social movements. She published the article "Tick as Appropriate a) Gay b) Queer c) None of the Above: Translation and Sexual Politics in Lawrence Venuti's A Hundred Strokes of the Brush before Bed," which appeared in Comparative Literature Studies.

Leo Tak-Hung Chan is professor of translation and head of the Department of Translation at Lingnan University, Hong Kong. His articles have appeared in Harvard Journal of Asiatic Studies, Translation Studies in the New Millennium, Perspectives, Comparative Literature Studies, TTR, the Translator, Babel, META, Across Languages and Cultures, Quaderns: Revista de Traduccio, Journal of Oriental Studies, Linguistica Antverpiensia and Asian Folklore Studies. His major scholarly publications include One into Many: Translation and the Dissemination of Classical Chinese Literature (2003); Twentieth-Century Chinese Translation Theory: Modes, Issues and Debates (2004), and Readers, Reading and Reception of Translated Prose Fiction in Chinese: Novel Encounters (2010). Professor Chan is president of the Hong Kong Translation Society and chief editor of Translation Quarterly.

Marc Démont is currently a $\mathrm{PhD}$ candidate in the program of Comparative Literature at University of South Carolina. His research focuses on developing a Deleuzian reading of the antisocial turn in queer theory. He has published various articles on American pop culture and queer theory, and his translation of Lee Edelman's No Future is currently in press. His next translation project is the translation of the BDSM novels and the short stories of John Preston into French.

Clorinda Donato is the George L. Graziadio chair of Italian studies at California State University, Long Beach, and professor of French and Italian. She is an eighteenth-century specialist who works on the history of encyclopedias and their translations, and on gender studies. She has published over 70 articles on these topics. Her co-edited volume, Jesuit Accounts of the Colonial Americas-Textualities, Intellectual Disputes, Intercultural Transfers, was published in 2014 by University of Toronto Press. The volume Enlightenment Spain and the Encyclopédie méthodique appeared in 2015 in the series Oxford Studies in the Enlightenment.

Zsófia Gombár is a postdoctoral fellow at the University of Lisbon Centre for English Studies. She completed her doctoral thesis The Reception of British Literature under Dictatorships in Hungary and Portugal at the University of Aveiro in 2012. Her current research interests include literature in English, censorship studies, translation history, and literature education. She is also the initiator and director of a Hungarian research project on literary censorship housed at the Savaria University Centre. 
Klaus Kaindl is associate professor of translation studies at the University of Vienna. He is a founding member of the European Society of Translation Studies. His research interests include translation of multimodal texts (opera, comics, and popular music), fictional representations of translators and interpreters, and translation pedagogy. Together with Franz Pöchhacker, he is general editor of the book series Translatioswissenschaft (Gunter Narr Verlag). His recent books include Berufsziel: Übersetzen und Dolmetschen (2016), co-edited with Mira Kadric, and Transfiction: Research into the Realities of Translation Tiction (2014), co-edited with Karlheinz Spitzl.

Eva Nossem is a graduate translator for German, English, and Italian (Saarland University, Germany), and lecturer in English linguistics. Her PhD dissertation in Italian linguistics was titled "Un dizionario Queer-il lessico italiano della non-eteronormatività." Her research interests include Italian and English linguistics, gender and queer studies, and translation studies.

José Santaemilia is associate professor of English language and linguistics at the Universitat de València, as well as a legal and literary translator. His main research interests include gender/sex and language, sexual language, and translation. He has edited Género, lenguaje y traducción (2003), Gender, Sex and Translation: The Manipulation of Identities (2005), and Woman and Translation: Geographies, Voices and Identities (MONTI, 2011), co-edited with Luise von Flotow.

Evren Savci is an assistant professor of women and gender studies at San Francisco State University. Her research interests include gender, sexualities, queer, feminist, and social theory; globalization and transnationality; cultural sociology; and epistemology. Her upcoming publication Language and Social Knowledge is slated for release in 2017 in the journal Ethnography, although the online version is currently available.

Mark Addison Smith is assistant professor in the Art Department at The City College of New York. His visual-based research explores the crossover between linguistics, queer identity, and narrative construction within instances of overheard dialogue and reconstructed typography. His artwork is included within the permanent collections of the Kinsey Institute, Getty Research Institute, MoMA Franklin Furnace, Tate Library, National Library at the V\&A, Watson Library at The Met, and the Leslie-Lohman Museum of Gay and Lesbian Art in New York City, among others. Recent publications include the book chapter "The Queer Writing on the Bathroom Wall," published in Diversity and Design: Understanding Hidden Consequences (2015). For more on Mark's artwork, visit his website at MarkAddisonSmith.com.

James St. André is associate professor in the Department of Translation at the Chinese University of Hong Kong, where he teaches courses on the 


\section{List of Contributors}

history, theory, and practice of translation between Chinese and English. Research interests include the history of Chinese-English translation, metaphors of translation, translation theory, and queer theory. $\mathrm{He}$ has published articles in various journals, including META, TTR, the Translator, Translation and Interpreting Studies, the Journal of Pragmatics, and Target. Book projects include Thinking through Translation with Metaphors (2010) and with Peng Hsiao-yen China and Its Others: Knowledge Transfer through Translation, 1829-2010; his book Performing China, which develops the queer metaphor of translation as cross-identity performance, is due out from Hawai'i University Press in 2017. His latest project, "Conceptualizing China through Translation" examines how certain key concepts used to understand Chinese culture and society have developed interlingually between English and Chinese from the eighteenth through the twenty-first century.

Sergey Tyulenev is the director of the MA program in translation studies at Durham University, United Kingdom. He publishes widely on the sociology of translation and Russian translation history. His recent publications include Translation and Society (2014), Translation and the Westernization of Eighteenth-Century Russia (2012), and Applying Lubmann to Translation Studies (2011). 


\section{Index}

Abad, Mercedes 14

abecedary 207, 210, 212, 214, 216

activism 2, 4, 7, 49, 52, 173, 182-3, 206-7, 215

activists 11, 79, 188, 195-6

Adamska-Sałaciak, Arleta 181

aestheticization 16

aesthetics 119, 127

agency 15, 38-9, 42, 46, 64-5, 69, 86, 184

AIDS 163, 208-10, 213

AIDS activism 208-10, 215

AIDS crisis 2, 43, 151, 162, 207-14, 216

Allan, Keith 16

Allison, Anne 96

Almeida, São José 145-6

Altman, Dennis 38, 45, 47

Altman, Lawrence K. 208

Amico, Stephen 112

androgyny 99, 102-5

Angelelli, Claudia 192

anglonormativity 4

appropriation 42, 53-4, 125, 168, 180

Apukhtin, Aleksei 123

Arcan, Nelly 14

Asimakoulas, Dimitris 18

Atsuji, Yamamoto 98

Austin, John Langshaw 192-3

Baer, Brian James 16, 18, 20, 44, 46, $60,112,118,123,148-9$

Bailey, Joanne 136

Baker, Mona 61-2, 74, 179, 192

Baldo, Michela 158

Basile, Elena 197-8

Bassi, Serena 59, 73

Bassnett, Susan 172, 182, 192

Bauer, Heike 1-2, 4, 18
Baumann, Jason 209

belles infidèles 18, 27, 86-7, 93, 199

Benderson, Bruce 14

Benjamin, Walter 179, 194

Benvenuti, Carla 65

Berlant, Lauren 27-8, 31, 33, 173-5

Bermann, Sandra 192-4, 198

Bersani, Leo 27

Bershtein, Evgenii 47

Bhabha, Homi 133

Bianchi, Giovanni 130-41

Bigliazzi, Silvia 192

Billiani, Francesca 16

Binnie, Jon 38-41, 46-7

bisexual 11, 21, 58, 213

bisexuality 117

Borghi, Liana 189, 196

Borgos, Anna 145-6

Boulanger, Pier-Pascale 14, 18

Brower, Reuben 97

Brulotte, Gaëtan 13-14

Bruni, Leonardo 158

Bucholtz, Mary 17

Burridge, Kate 16

Burroughs, William 53, 150-1

Burton, William M. 19

Bush, Peter 192

Butler, Judith 13, 133, 188-94, 196-201

Cameron, Deborah 17, 173

Campbell, Jill 136

Cant, Bob 39

Casanova, Erynne de 41-2

Casanova, Pascale 45, 179

Catullus 8, 13

censorship 12-13, 16-18, 20, 42-3, 121, 145-6, 148, 152, 159

Chakrabarty, Dipesh 41, 53, 75 
Chamberlain, Lori 12, 18, 199

Charon, Rita 136

chauvinism 159

Chernyshova-Mel'nik, Natalia 116, 119, 122, 126

Chiaro, Delia 16

Chin, Teroko 100

Cho, Heekyoung 41

Chuillenanáin, Eiléan Ní 16

Cleland, John 13, 130-41, 151

closet 46-7, 113-15, 126, 145, 194

closetedness 113, 115-16, 119

Çolak, Saliha 77

Conant, Martha Pike 87

cosmopolitanism 46

Crawford, Katherine 136

Cruz-Malavé, Arnaldo 40

Csehy, Zoltán 147

Currah, Paisley 3

Defer, Daniel' 51-2

Defert, Michel 51-2

Derrida, Jacques 177, 192-3

Despentes, Virginie 14

dialectics $115,120-1$

dictionaries 43, 172-8, 180-1, 183-5

drag 86, 89-94, 106

Duggan, Lisa 64

Dutta, Aniruddha 61

Edelman, Lee 27-8, 113-14, 120, 125,127

Engelstein, Laura 112

Enikeeva, Dilia 44

Epstein, B.J. 1

equivalence $34,58,60,62-3,68-9$, $86,157-8,163,175,179$,

182,184

erotic literature 13-14

Espin, Oliva 39

ethnography $41,73-81$

Etxebarria, Lucía 14

Fassin, Eric 45

femininity 18,200

feminization 102, 200

Ferguson, Roderick 64

figuration 100

Findlen, Paula 132, 135

Fiorilli, Olivia 198-200

Flotow, Luise von 11-12, 15, 19-20, 192-3

Folkenflik, Robert 135

Fontenelle, Thierry 174, 177 foreignness 133, 195

Foucault, Michel 13, 51, 74, 97, 172, $175,208-10$

framing 74, 78, 85

Fry, Stephen 48-9, 59

fuck 17, 21, 26-31, 34, 211

fuckable 26, 28-30

Gachev, Georgii 43

Garbagnoli, Sara 189

gay $40,42,44,46-7,49-53,58,60$, $69,100,104,146,150-1,182-3$, 206-8, 210-15

gay identity 44, 51, 114, 147, 159

gay subculture $49,51-2$

Geertz, Clifford 72

gei 42-4, 47

Gellately, Robert 145

gender binaries 33, 74, 106

gender identities 58, 60, 72, 76, 100, 106, 158

genderization 183-4, 199

gender performativity 190-2

gender reassignment 102

Getiss, Mark 50

Gilles, Deleuze 52

Gillette, Robert 1

Giono, Jean 163-6

Godayol, Pilar 20

Godwin, Nipper 14

Gombár, Zsófia 16, 146, 150

Gómez-Galisteo, M. Carmen 108

Gramling, David 1-2, 60-1

Grandes, Almudena 14-15

graphesis 114-15, 125-6

Gregg, Melissa 196, 198

Greivz, Rupert 50

Greven, David 162

Grishin, Dmitrii 120

Guaraldo, Olivia 188, 190

Guiraud, Pierre 160-1

Hall, Kira 17

Hall, Stuart 53

Halperin, David M. 97, 109, 173

Hanzli, Péter 145-6

Haraway, Donna 74, 175

Hartmann, Reinhard 173, 178, 181

Harvey, Keith 17-18, 147, 192

Hayes, Jarrod 44

Hays, Sharon 72

Healey, Dan 112, 117

heteronormativity $17,64,173-5,178$, 184-5, 189, 191, 195, 199 
heterosexuality $17,50,105,114,117$, 131, 173, 195

Hill Collins, Patricia 74

HIV 211-12

Hoffmann, David L. 145

Holmes, James 8

homoeographesis 124

homographesis $114-16,120-1,123-7$

homonormativity 64,68

homophobia 15, 44-5, 49, 61, 67, 72,162

homosexuality $1,38,42-6,49-50,52$, 77, 79, 100, 113-14, 117, 120-1, 127, 144-53, 162;minoritarian model of $18,43,45-6,50,54$

homosexual rights $49,76-8$

Hutcheon, Linda 108

identity categories $17,60,64$

identity formation 11, 17, 102

identity politics $69,162-3$

internationalization 58-9, 68-9

intrahomophobia 159

"It Gets Better" project 58-65, 68-9

Iwabuchi, Koichi 108

Jaén, María 14

Jagose, Annmarie 2-3, 13, 15, 18-19

Kalin, Tom 50

Kaplan, Hilal 77

Karakuş, Abdullah 77

Karlinsky, Simon 112

Katz, Jonathan Ned 117

Keenaghan, Eric 17

Keilson-Lauritz, Marita 8

Kespazio collective 195

Kidwai, Saleem 166-7

Kinloch, David 18

Klein, Melanie 31

Klimkiewicz, Aurelia 14

Koliadina, Elena 42

Koller, Veronika 19

Kon, Igor 127, 129

Korkut, Nil 108

Korsh, Fedor 122

Kramer, Larry 207-8, 210-15

Kulick, Don 17, 173

Kulpa, Robert 42

kvir 42, 47-8

Lacayo, Aarón 19

Lanser, Susan 140

Larkosh, Christopher 1, 8, 18-19, 21
Laurentis, Teresa de 141

Leap, William 17, 209

Lefevere, André 192

Leftah, Mohamed 14

Leizer, Ioni 53

lesbian 2-3, 11, 13, 17, 39-40, 44-5, $58,66,76,135,137-8,140-1$, 146-8, 150-1, 183-4

Levet, Pierre 159-60

Levi, Antonia 104

lexicography $172-3,184-5$

LGBT rights $73,75-80$

Livia, Anna 12, 17

localization 59-63, 68-9

Louar, Nadia 14

McEwan, Ian 14

McLelland, Mark 104, 106

McLeod, Ken 106

Maier, Carol 197

Manalansan IV, Martin 40, 60, 64

manga 96

Marco, Marcella de 16

Marot, Clement 160

Marryat, Frederick 84-93

Martin, Thierry 159, 161-3

Martin de León, Celia 86

masculinity 18, 117, 119, 157, 159, 189

Massardier-Kenney, Françoise 20

Massumi, Brian 197-8

Matonina, Ella 122

Melville, Herman 163-6

Merkle, Denise 16

metaphorics 12, 18, 120

Millet, Catherine 14

mimesis 1

minoritarian model 2, 42, 44, 49-50, 53

minority languages 180

Mira, Alberto 17

Mitchell, Allyson 210

Mitsuteru, Yokoyama 101

Möbius, Paul Julius 11

Moffett, Donald 209

Mohanty, Chandra 80

Moland, Louis 160

Mole, Richard 40

Moncrieff, Scott 120-1

Moniz, Maria Lin 16, 144

Morini, Cristina 200

Moss, Kevin 112

Moss, Tamara 41-2

Motschenbacher, Heiko 17

movement, anti-gender 189 , 195-6, 200 
Naiman, Eric 112

Nathanaël 26-9, 31, 33-4

neofundamentalism 196, 198-9

neoliberalism $64,73,81,196,198-200$

Nin, Anaïs 14

norms 74, 173-7, 183, 198, 200

Nossem, Eva 173, 175-7

Notte, Tom 51

objectification 120

Ogi, Fusami 107

O’Hagan, Minako 58-9

Olohan, Maeve 58

otherness 1, 193-4, 197, 200

pacha $84-6,88-9,91-4$

Pailler, Georges 14

Paracelsus 164-5

parody $86,96-7,100,102,106-9$

Pérez González, Luis 179

performativity 114, 136, 188, 192-4, 196-7

Pezzali, Max 66

Phillips, John 13-14, 27, 96

pisteographesis $121,124-6$

poetry 46, 113, 115-19, 121-2, 127

Post, Chad W. 46

postcolonialism 28, 38, 133

Power, Natsu 103

pseudo-translations 84-7

Puri, Jyoti 45

Pustianaz, Marco 189, 195

Pym, Anthony 59, 61, 68

queer activism 60, 200, 206-7, 215

queer agency 40, 138

queer diaspora 39

queer lexicography 173,185

queerness $26,28,34,67,97,131,135$, $157,162-3,167-8$

queer sexualities $8,17,40,112$, 159,164

queer studies 4, 17-18, 60-1, 63-4, 68,81

queer theory $1-3,7,13,79,81,97$, 102, 109, 113-14, 141, 162, 189, 191, 194-5

Rao, Sathya 14, 19, 32

reception 47, 104, 107, 109, 132, 137, 144, 179, 215

Redford, Bruce 134

Reed, Christopher 147-8 religion $16,78-9,144$

resistance 17, 19, 38-9, 54, 106-7, 163

Reve, Gerard 48

Révész, Sándor 151

Richardson, Diane 109

Riemer, Andrew 97

rights 38, 41-2, 44, 77-8, 209

Ríos-Font, Wadda 14

Robinson, Douglas 192-3, 197

Rojek, Robert 41

Romanov, Konstantin (K.R.) 112-13, $115-17,119,122,125-6$

Sahlins, Marshall 72

Said, Edward 74

St. André, James 85, 87, 94, 97, 106

Santaemilia, José 14, 21

Santos, Ana Cristina 145, 148, 209

Santos, Nelson 209

Sappho 13, 130, 134, 140

Saussure, Ferdinand de 206, 215

Schluter, Daniel P. 42

Schoch Zavaletta, Atticus 190

Sedaris, David 48

Sedgwick, Eve 2, 113-15, 127, 194-7

Seigworth, Gregory J. 197-8

self-censorship 12-13, 16, 20, 146, $148,150,152$

self-determination 38,134

self-expression 115,127

self-knowledge 60-1

self-sufficiency 28

Seruya, Teresa 16, 144-5

sexuality 1-4, 8, 11-21, 27, 39, 42, 45-6, 50-2, 60-2, 112-15, 133,

140, 190-1, 199-200, 208

sexualization 17, 19-20, 199

sexual orientation $8,49,51,58,60,72$, 76,148

Shalom, Celia 17

Shamoon, Deborah 104

Sharlot, Eris 63-5, 68

silence 113-21, 162, 176, 209

Snell-Hornby, Mary 180

Soto, Sonia 14-15

Sozaev, Valerii 47

Spiegel, Maura 136

Spurlin, William J. 1, 13, 20, 179

Stephens, Natalie 26, 34; see also

Nathanaël

Stoltzfus, Nathan 145

Stryker, Susan 3, 64

Styron, William 148 
subalternity 38

subtitling $16,59,62$

Takács, Judit 150

Timm, Annette F. 145

transgender identity 64-5

transgendering 96, 99-102, 105, 107

transgenderism 96

translation: intersemiotic 207, 210, 214-16; radical 97, 100, 107-9

Tymoczko, Maria 67, 172, 192

Tyulenev, Sergey 112

undoing 188, 190-3, 199-200

unqueering 131

Vajda, Miklós 150

Valdeón, Roberto 18

Vandebosch, Bart 51

Vanita, Ruth 166
Vega, Miguel Ángel 16

Venuti, Laurence 69, 133, 168,172

Villon, François 159-61

Vize, Zenke 49

Voverait, Klaus 48

Walpole, Horace 134

Warner, Michael 39, 173-4

Welker, James 102

Wells, Peter 39

Whitman, Whit 157-8

Williams, Tennessee 150

Yomoda, Inuhiko 101

Zappino, Federico 188, 190-1, 194-6, 198-200

Zhu, Hongbo 96-7, 108

Zhurden, Erik 51 